\title{
O TRABALHO DE ENFERMAGEM NA REDE BÁSICA DE SAÚDE DE JUIZ DE FORA:
}

Condições favoráveis e desfavoráveis

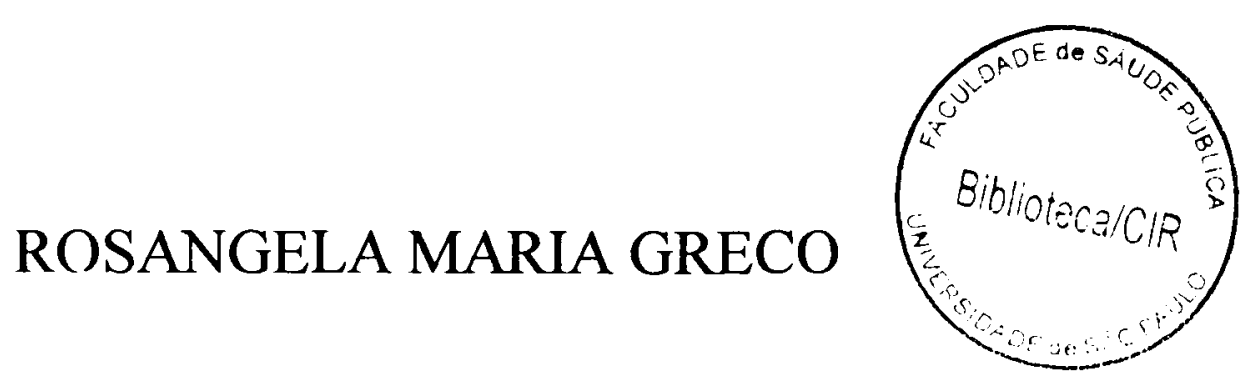

Tese de Doutorado apresentada ao Departamento de Saúde Ambiental da Faculdade de Saúde Pública da Universidade de São Paulo para obtenção do Grau de Doutor

Área de Concentração: Saúde Ocupacional

ORIENTADOR: PROF. DR. JORGE DA ROCHA GOMES

São Paulo

2001 
Autorizo, exclusivamente para fins acadêmicos e científicos, a reprodução total ou parcial desta tese, por processos fotocopiados.

Assinatura:

Data: 


\section{MEUS AGRADECIMENTOS}

A realização deste trabalho só foi possível graças à colaboração de muitas pessoas. Por este motivo, manifesto minha gratidão a todas elas e de forma particular:

à Vilma Machado de Queiroz, pela amizade e por ter-me guiado nos caminhos da pesquisa científica;

ao Prof. Jorge da Rocha Gomes, pela presença na minha vida há mais de 10 anos, como orientador do mestrado e agora do doutorado;

às Professoras Maria Josefina (Susy) Leuba Salum e Maria Rita Bertolozzi, pelas contribuições importantíssimas para a elaboração da redação final do trabalho;

às amigas Simone Cristina de Oliveira e Luciana Aparecida de Paula por terem cuidado da minha casa e das minhas filhas, e pelo apoio incondicional;

às colegas da Disciplina Administração em Enfermagem Ana Paula Riberto Lopes, Amaline Réche Marcondes Gusman, Bernadete Marinho Bara De Martim Gama e Maria das Graças Fonseca, pela amizade e pelo estímulo;

à Neusa e à Rita as quais, através do trabalho na Revista de APS, me mostraram o lado prazeroso do trabalho;

aos trabalhadores de enfermagem das UBS de Juiz de Fora sem os quais este trabalho não poderia ter sido realizado;

ao meu marido Nelson e às minha filhas Anna Maria e Júlia, com o meu pedido de desculpas por lhes ter roubado tanto tempo de convivência;

às minhas mães Assunta Anna e Maria Aparecida e ao meu pai Mauro, pelo colo sempre disponível e pelo exemplo;

dificeis;

às minhas cunhadas Lusmar e Namir, pelo apoio e auxilio nas horas

aos meus irmãos e irmãs de sangue e de coração e a todos que me apoiaram e contribuíram de modo direto e indireto para a realização desse estudo. 


\section{RESUMO}

GRECO, R. M. O trabalho de enfermagem na Rede Básica de Saúde de Juiz de Fora: condições favoráveis e desfavoráveis. Juiz de Fora, 2001. p. [Tese de Doutorado - Faculdade de Saúde Pública da USP].

Objetivo. Uma vez que o processo saúde-doença é determinado socialmente, ou seja, de que formas de trabalhar e de viver geram potenciais de beneficios e de riscos que se expressam no coletivo e nos indivíduos, realizou-se este estudo com o objetivo de descrever e analisar as condições de trabalho dos trabalhadores de enfermagem de Unidades Básicas de Saúde de Juiz de Fora. Para tal, identificaram-se as condições favoráveis e desfavoráveis do trabalho e sua repercussão na vida e no processo saúdedoença desses trabalhadores. Método. A pesquisa, de caráter exploratório, foi realizada por meio de um formulário com questões fechadas e do mapeamento de riscos, através de enquetes coletivas com os trabalhadores, em que foram descritas as condições favoráveis, desfavoráveis e propostas de solução para as situações/problemas levantadas, tendo-se elaborado em seguida a classificação das cargas de trabalho. Resultados. Os trabalhadores das Unidades Básicas estudadas são, em sua maioria, mulheres, casadas, com 2 ou mais filhos, com uma jornada de trabalho de $\mathbf{8}$ horas que consideram insuficiente para a realização das tarefas. Existe uma diferença salarial entre auxiliares e enfermeiros a qual corresponde, na maioria das vezes, ao dobro, ocorrendo o mesmo em relação à renda familiar e "per capita". Possuem casa própria, com mais de cinco cômodos, moram em Juiz de Fora há mais de 4 anos dividindo a moradia com cerca de 4 a 6 pessoas. Em relação ao lazer, recorrem à televisão, lêem, fazem passeios/viagens e freqüentam cinema e teatro. Não participam de grupos ou associações. Consideram o trabalho perigoso e insalubre, já sofreram acidentes com material perfuro-cortante, e apresentam problemas de saúde como hipertensão, referindo-se à presença de cargas fisicas, químicas, biológicas, fisiológicas, mecânicas e psíquicas, com predominância das últimas. Como condição favorável, ou geradora de beneficio no trabalho, citaram a existência de estrutura fisica adequada e bela, de aspecto agradável, a existência de equipamentos, materiais e mobiliários necessários e a funcionalidade da Unidade. Conclusões. A análise mostra que as cargas e as condições desfavoráveis, contrapondo-se às favoráveis, se repetem na maioria das vezes, por exemplo, na inadequação da planta física, na falta de manutenção de equipamentos e instrumentos, na falta de mobiliário adequado, na falta de recursos humanos, no desvio de função, na falta de materiais e medicamentos. A relação com o usuário é, as vezes, conflituosa, o que é expresso através de queixas como tumulto, aglomeração, ruído, insatisfação do usuário pela demora no atendimento, ou pela falta de atendimento, ansiedade e estresse, na recepção das UBSs. Gerando propostas como salas de espera separadas por área de atendimento, externas ao posto, distribuição de senhas, maior orientação e informação aos usuários. Apesar das condições desfavoráveis estarem mais presentes do que as favoráveis. Pode-se dizer que os trabalhadores de enfermagem das Unidades Básicas de Saúde de Juiz de Fora estão sujeitos a condições de trabalho que tanto os expõem a cargas, que ao longo do tempo podem levar a um desgaste das capacidades vitais destes trabalhadores, como estão sujeitos a condições benéficas que podem potencializar essas capacidades. 


\section{ABSTRACT}

GRECO R. M. The nursing work in the Juiz de Fora Basic Health System: favorable and unfavorable conditions. Juiz de Fora; 2001. p [ Doctorate Thesis - Public Health College of The University of São Paulo (USP)].

AIM. This study aims to describe and analyze the working conditions of the nursing workers in the Health Basic Units in Juiz de Fora city (a kind of Health Care Centers in Brazil), identifying the favorable and unfavorable working conditions and their effect in the life and in the health-illness process of these workers since this process is socially determined. That is, the lifestyles and ways of working generate benefits and risks in potential that have effect in the individual and in the collective. METHOD. This exploratory research was performed using a form with closed questions, the mapping of risks and through collective surveys with the workers. This way the favorable and unfavorable conditions were described and proposals for solving the situations/problems aroused. After this, the workloads classification was elaborated. RESULTS. Most of the studied Basic Units workers are married women with two or more children, having an 8 hour working day that they consider not enough to the accomplishment of the tasks. There is a salary difference between the assistants and the nurses that in the most of the time is twice as much. The same occurs in relation to the familiar and per capita incomes. The workers are home owners, their houses have more than five rooms, and they have been living in Juiz de Fora for more than four years sharing their houses with 4 to 6 people. Regarding to leisure time, they watch television, read, go out/travel and go to the cinema and to the theater. They do not take part in groups or associations. They consider their work dangerous and unhealthy, they have already had accidents with perforating-cutting material and they show health problems such as hypertension, which are related to the presence of loads: physical, chemical, biological, physiological, mechanical, and psychical, with the predominance of the last ones. As a favorable condition or a benefit generator condition to the work they mentioned the adequate physical structure and its nice appearance, the existence of equipment, material and furniture and the functionality of the Unit. CONCLUSIONS. The analysis shows that the loads and the unfavorable conditions, opposing to the favorable ones, are repeated most of the time, for example, in the inadequacy of the physical plant, in the lack of equipment and instruments maintenance, in the lack of appropriate furniture, in the lack of humans resources, in the deviation of function, in the lack of materials and medicines. The relationship with the user is conflicting sometimes. This is expressed through complaints about the tumult, agglomeration, noise, user's dissatisfaction for the delay or the lack of medical assistance, anxiety and stress observed in the reception of the Health Basic Units. In the worker's opinion proposals such as waiting rooms outside to the Units separated according to the specialized area, distribution of numbered tickets, better orientation and information given to the users could solve the problems above mentioned. Although the unfavorable conditions are more present than the favorable ones, we can say the nursing workers from the Health Basic Units of Juiz de Fora are under working conditions that expose them as much to loads, that along the time can lead to a consuming of their vital capacities, as to beneficial conditions that can improve these capacities. 


\section{LISTA DE QUADROS}

Quadro 1 - Distribuição das Consultas Ambulatoriais por Tipo, Parâmetro da 15 Organização Mundial de Saúde (OMS) e Situação em Juiz de Fora, 1996.

Quadro 2 - Distribuição dos trabalhadores de enfermagem segundo UBS e 27 participação nos encontros.

Quadro 3 - Descrição do número de famílias e breve histórico das UBSs de 30 Juiz de Fora. Juiz de Fora, 1999.

Quadro 4 - Descrição da força de trabalho em saúde por UBS, Juiz de Fora, 31 1999.

Quadro 5 - Ações realizadas nas UBSs. Juiz de Fora, 1999.

Quadro 6 - Descrição das condições desfavoráveis e das cargas de trabalho 53 das Unidades Básicas de Saúde. Juiz de Fora, 1999. 


\section{LISTA DE TABELAS}

Tabela 1 - Distribuição da força de trabalho em enfermagem por UBS. Juiz 35 de Fora, 1999

Tabela 2 - Distribuição da força de trabalho em Enfermagem nas UBS, 36 segundo faixa etária. Juiz de Fora, 1999.

Tabela 3 - Distribuição da força de trabalho em Enfermagem nas UBSs, 37 segundo estado civil. Juiz de Fora, 1999.

Tabela 4 - Distribuição da força de trabalho em enfermagem nas UBS, 37 segundo número de filhos. Juiz de Fora, 1999.

Tabela 5 - Distribuição da força de trabalho em enfermagem nas UBSs, 37 segundo tempo de formação. Juiz de Fora, 1999.

Tabela 6 - Distribuição da força de trabalho em enfermagem nas UBSs, 39 segundo renda familiar. Juiz de Fora, 1999.

Tabela 7 - Distribuição da força de trabalho em enfermagem nas UBSs, 39 segundo faixa salarial. Juiz de Fora, 1999.

Tabela 8 - Distribuição da força de trabalho em enfermagem das UBSs, 40 segundo destinação do salário para a familia. Juiz de Fora, 1999.

Tabela 9 - Distribuição da força de trabalho em enfermagem nas UBSs; 41 segundo . $^{\circ}$ de horas diárias trabalhadas. Juiz de Fora, 1999.

Tabela 10 - Distribuição da força de trabalho em enfermagem nas UBSs, 41 segundo tempo de moradia no Município. Juiz de Fora, 1999.

Tabela 11 - Distribuição da força de trabalho em enfermagem nas UBSs, 42 segundo propriedade da moradia, Juiz de Fora, 1999.

Tabela 12 - Distribuição da força de trabalho em enfermagem nas UBSs, 42 segundo número de cômodos do domicílio. Juiz de Fora, 1999.

Tabela 13 - Distribuição da força de trabalho em enfermagem das UBSs, 42 segundo número habitantes no mesmo domicílio. Juiz de Fora, 1999.

Tabela 14 - Distribuição da força de trabalho em enfermagem nas UBSs, 43 segundo participação em atividades de recreação. Juiz de Fora, 1999.

Tabela 15 - Distribuição da força de trabalho em enfermagem nas UBSs, 44 segundo participação em grupo/associações. Juiz de Fora, 1999. 
Tabela 16 - Distribuição dos Enfermeiros das UBSs, segundo atividades relacionadas ao Processo de Trabalho de Assistência. Juiz de Fora, 1999.

Tabela 17 - Distribuição dos Auxiliares de Enfermagem das UBSs, segundo 48 atividades relacionadas ao Processo de Trabalho de Assistência. Juiz de Fora, 1999.

Tabela 18 - Distribuição dos enfermeiros das UBSs, segundo atividades relacionadas com o Processo de Trabalho de Gerenciamento da Assistência. Juiz de Fora, 1999.

Tabela 19 - Distribuição dos Enfermeiros das UBSs, segundo atividades 50 relacionadas com o Processo de Trabalho de Gerenciamento Burocrático da Unidade. Juiz de Fora, 1999.

Tabela 20 - Distribuição dos Enfermeiros das UBSs de Juiz de Fora segundo atividades relacionadas com o Processo de Trabalho de Ensino. Juiz de Fora, 1999.

Tabela 21 - Distribuição dos Enfermeiros das UBSs de Juiz de Fora segundo atividades relacionadas com 0 processo de trabalho de investigação. Juiz de Fora, 1999.

Tabela 22 - Distribuição dos Enfermeiros e Auxiliares das UBSs de Juiz de 58 Fora segundo percepção das cargas fisiológicas à qual estão submetidos. Juiz de Fora, 1999.

Tabela 23 - Distribuição dos Enfermeiros das UBSs de Juiz de Fora, segundo 61 opinião sobre o grau de satisfação no trabalho. Juiz de Fora, 1999.

Tabela 24 Distribuição dos Auxiliares de Enfermagem das UBS, segundo 62 opinião sobre o grau de satisfação no trabalho. Juiz de Fora, 1999.

Tabela 25 Distribuição dos Enfermeiros e Auxiliares de Enfermagem das 63 UBS, segundo motivo pelo qual consideram o trabalho perigoso. Juiz de Fora, 1999.

Tabela 26 Distribuição dos Enfermeiros e Auxiliares de Enfermagem das 63 UBS, segundo motivo pelo qual considera o trabalho insalubre. Juiz de Fora, 1999.

Tabela 27 Distribuição dos Enfermeiros e Auxiliares de Enfermagem das 64 UBS, segundo tipo de acidente de trabalho referido. Juiz de Fora, 1999. 


\section{INDICE}

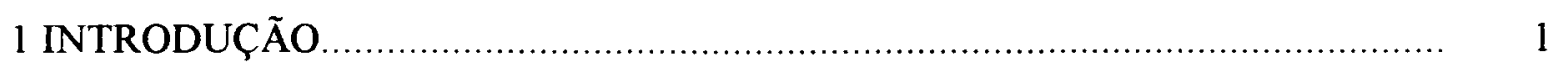

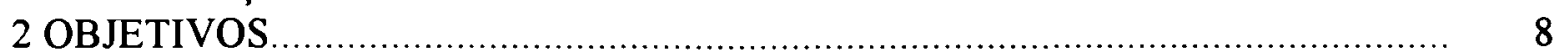

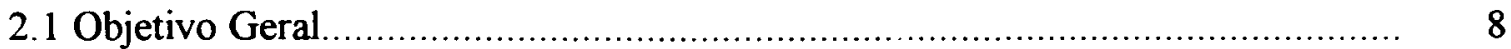

2.2 Objetivo Específico...................................................................................... 8

3 CONTEXTUALIZANDO O CENÁRIO .......................................................... 10

3.1 A cidade de Juiz de Fora ....................................................................... 11

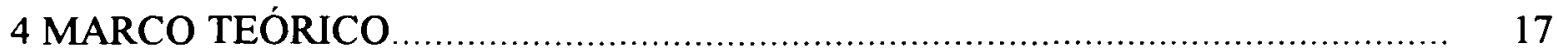

4.1 A relação trabalho-saúde ............................................................................. 18

4.2 Características gerais do trabalho em saúde e em enfermagem nas rede básica..... 20

5 O DESENHO METODOLÓGICO................................................................ 23

6 ANÁLISE E DISCUSSÃO DOS DADOS ............................................................. 29

6.1 Caracteristicas gerais das Unidade Básicas de Saúde (UBSs) ........................... $\quad 30$

6.2 Características gerais dos trabalhadores de enfermagem.................................. $\quad 34$

6.3 Reprodução social dos trabalhadores de enfermagem nas UBSs - dados gerais... 38

6.4 Atividades realizadas no trabalho de enfermagem nas UBSs.............................. 45

6.4.1 O processo de trabalho de assistência à saúde....................................... 46

6.4.2 O processo de trabalho de gerenciamento, ensino e pesquisa..................... 49

6.5 As condições favoráveis e desfavoráveis no trabalho realizado pelos trabalhadores de enfermagem nas UBSs.................................................... 52

$6.6 \mathrm{O}$ trabalho como fonte de desgaste e fortalecimento ......................................... 60

7 CONCLUSÕES.

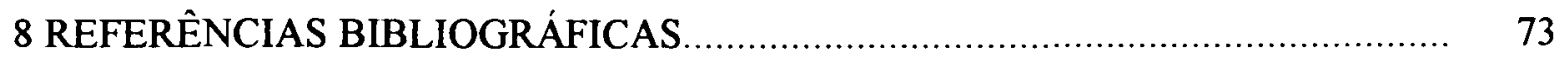

9 ANEXOS de Juiz de Fora ......................................................................... 82

Anexo 2 - Condições de trabalho e de vida dos auxiliares de enfermagem da rede básica de saúde de Juiz de Fora......................................................... 90

Anexo 3 - Termo de Consentimento ................................................................. 97

Anexo 4 - Esquema Gráficos das UBSs........................................................ 99

Anexo 5 - Quadros sinópticos das enquetes coletivas........................................... 123 
1 INTRODUÇÃO 
Ao estudarmos as condições de trabalho dos trabalhadores de enfermagem da Rede Básica de Saúde de Juiz de Fora, fizemo-lo a partir da concepção de que o trabalho é uma categoria social com múltiplas determinações e um processo que se organiza de maneira diferenciada de acordo com o modo de organização da sociedade. É um espaço ao mesmo tempo de dominação e submissão do trabalhador ao capital e de resistência e construção de um 'fazer histórico' dos trabalhadores que buscam o controle das condições e dos ambientes de trabalhn objetivando torná-los mais “saudáveis” (LAURELL, 1993; MENDES; DIAS, 1999).

Na nossa sociedade, que está organizada sobre o modo capitalista de produção, o trabalho é ao mesmo tempo valor de uso e valor de troca: é mágico porque é duplo, carrega em si a maldição da mercadoria, a fantasmagoria do dinheiro: de um lado aparece como valor de uso, realizador de produtos capazes de atender necessidades humanas, de outro, como valor de troca, pago por salário, criador de mercadoria, e ele mesmo é uma mercadoria no mercado" ( CODO et al. 1998 p.97).

Nos dias de hoje, fala-se em um mundo do trabalho que nos países capitalistas se caracteriza pela diminuição da classe operária industrial tradicional e na ampliação do assalariamento do setor de serviços, expansão do trabalho feminino no mundo operário, expansão do trabalho parcial, temporário, precário, subcontratado, terceirizado, com um aumento do desemprego estrutural o que, nos dizeres de ANTUNES (1995, p.42), é um múltiplo e contraditório processo de "heterogeneização, fragmentação e complexificação da classe trabalhadora" .

Nesse contexto, autores como OFFE (1991), GORZ (1982) e HABERMAS, (1987) entre outros, defendem que o trabalho deixou de ser categoria central, pois se estaria vivendo uma crise da sociedade do trabalho, onde este, como elemento estruturante da relação social dos homens com a natureza, estaria deixando de existir.

Estaríamos evoluindo para uma sociedade sem trabalho?

Autores como ANTUNES (1995 e 1999) e BERNARDES (1993), dizem que não. Afirmam que nossa sociedade é uma sociedade do trabalho e que, portanto, deve-se reafirmar a centralidade da categoria trabalho, partindo para uma análise onde o trabalho, como categoria multidimensional, seja a base de sustentação humana, que tem como formas mais elevadas a arte, a ética, a filosofia, a ciência, entre outras.

Em "Os sentidos do trabalho", ANTUNES (1999) afirma que o enfrentamento, tanto na teoria como na prática, da subordinação estrutural e hierárquica do trabalho ao capital, só é possível a partir da reafirmação da centralidade do trabalho, "pois uma coisa é ter a necessidade imperiosa de reduzir a dimensão variável do capital e a conseqüente necessidade de expandir sua parte constante. Outra muito diversa, é imaginar que, eliminando o trabalho vivo, o capital 
possa continuar se reproduzindo. Não seria possível produzir capital e também não se poderia integralizar o ciclo reprodutivo por meio do consumo, uma vez que é uma ahstração imaginar consumo sem assalariados. A articulação entre trabalho vivo e trabalho morto é condição para que o sistema produtivo do capital se mantenha. A tese da eliminação do trabalho abstrato, considerado dispêndio de energia física e intelectual para a produção de mercadoria, não encontra respaldo teórico e empírico para a sua sustentação nos paises capitalistas avançados, como os EUA, o Japão, a Alemanha, e muito menos nos países do chamado Terceiro Mundo."

É com esta concepção de trabalho como categoria central que desenvolvemos este estudo pois, para nós, o trabalho influi na vida e na morte dos seres humanos, é o eixo em torno do qual se organiza a vida, porque é através da inserção do homem no trabalho que ele se reproduz socialmente - reprodução social entendida como produção e consumo (FACCHINI, 1994 a).

Nessa concepção, o trabalho passa a ser detentor de uma dupla possibilidade,podendo vir a ser uma fonte de realização, satisfação, prazer e estruturação da identidade dos sujeitos, mas também podendo ser nocivo e patogênico, levando ao adoecimento e até a morte (SELIGMANH-SILVA, 1994).

Em sua relação com o processo saúde-doença, o trabalho pode ser útil, criador de valores de uso, sendo um estímulo no desenvolvimento das capacidades fisica e mental, sendo um produtor de saúde. Em contrapartida, o trabalho excessivo, que não possibilita a recuperação do desgaste com descanso e lazer, debilita o organismo, a mente, podendo gerar doença (GARCIA, 1989).

Existe então uma relação entre o trabalho e a saúde dos trabalhadores que não é algo recente e, no decorrer da evolução histórica das sociedades, as formas de apreender e lidar com essa relação foram se modificando.

Nas últimas décadas, autores como LAURELL; NORIEGA (1989) e BREILH, GRANDA, (1989), têm contribuído para uma nova compreensão da categoria trabalho e de sua relação com a saúde.

Da concepção de Saúde Ocupacional, que considera o trabalho somente quanto às suas condições materiais, como um problema ambiental, colocando o trabalhador em contato com agentes químicos, fisicos, biológicos e psicológicos que podem levar à ocorrência de acidentes ou doenças, um fenômeno biológico e individual, caminha-se para uma concepção de Saúde do Trabalhador que consiste em um esforço de compreensão de como e por que ocorre o adoecer e o morrer dos trabalhadores. Isto rompe e superan a concepção de que existe apenas um vínculo causal entre a doença e um agente específico, ou um grupo de fatores de risco presentes no ambiente de trabalho, através do estudo dos processos de trabalho, de forma articulada com o conjunto de valores, crenças, idéias e as representações sociais, bem como a possibilidade de consumo de bens e serviços, (GARCIA, 1989; MENDES; DIAS, 1999). 
Na saúde, segundo ALMEIDA et al. (1996, p.146), a centralidade do trabalho está colocada no lidar diário com o paradoxo - vida e morte - "onde o ato produzido é consumido no momento da produção e é desenvolvido por um conjunto de agentes que apresentam alto grau de autonomia, mas que atuam num processo de trabalho coletivo, marcado pela intensa divisão técnica e social e que tem como uma das características a cooperação. Para seu desenvolvimento, na sociedade contemporânea, há, de forma acelerada, a incorporação tecnológica de processos, procedimentos e novos agentes cada vez mais sofisticados, os quais vão se agregando, ao mesmo tempo em que se mantêm os anteriores".

O processo de produção em saúde é composto por vários trabalhos dentre eles o de enfermagem, tendo como cenário, hospitais, ambulatórios, empresas, escolas creches, clínicas, domicílios e unidades básicas de saúde.

Nas últimas décadas, a enfermagem tem sido palco de uma crescente produção de conhecimentos mais crítica e transformadora, que buscaram desnudar a forma de organização do trabalho na enfermagem, entendendo-o como uma prática social resultante de determinantes econômicos, políticos e ideológicos (MELO, 1986).

Esses estudos evidenciaram a crise da enfermagem brasileira, expressa pela divisão técnica e social do trabalho de enfermagem, a condição de assalariamento, as relações de trabalho conflitivas, competitivas e alienantes, a divisão sexual do trabalho e o dilema da prática profissional (ALMEIDA; ROCHA, 1989; MELO, 1986; NAKAMAE, 1987).

Essas análises possibilitaram "uma compreensão da enfermagem não como profissão autônoma e isolada das outras profissões, principalmente as da saúde, mas como uma prática inserida na sociedade brasileira e como tal historicamente estruturada, estabelecendo relações sociais com todos os outros tipos de trabalho e guardando sua especificidade dentro de uma autonomia relativa" levando a uma "visão mais concreta desta prática, dando um passo à frente nos estudos que idealizavam a profissão, impedindo que sua essência e contradições fossem vislumbradas" (ALMEIDA et al., 1989).

Em relação aos estudos que se têm debruçado sobre a saúde do trabalhador de enfermagem, segundo SILVA (1996 p. 1) "apesar de ter havido um incremento de publicações sobre a saúde e trabalho de enfermagem na última década, estas não foram suficientes para caracterizar quanti-qualitativamente os problemas específicos que emergem da relação trabalho-saúde".

Na bibliografia consultada, a maior parte dos estudos são positivistas, tomando como base a concepção multifatorial do processo saúde-doença, sendo que para a análise dos riscos e das condições do trabalho se utilizam da concepção de saúde ocupacional e se referem a instituições hospitalares. 
Dentre os estudos que abordam o conjunto de trabalhadores de instituições hospitalares destacamos os de: FRANCO (1981), WAKAMATSU, et al. (1986), PITTA (1990) do Brasil e BASURTE; PEREZ, (1997) da Espanha.

FRANCO (1981) estudou a ocorrência de morbidade, segundo a queixa e relação com o trabalho, dos trabalhadores de um hospital universitário do interior de São Paulo. Os problemas de saúde citados foram: doenças infectocontagiosas, lombalgia, doença alérgica, fadiga, acidentes de trabalho, dores nas costas, dores articulares, enxaqueca, doenças do aparelho reprodutor, cardiopatia hipertensiva e hiperemese gravidica. Como determinantes para esses problemas foram citados agentes fisicos, químicos, biológicos, psicológicos a sobrecarga de serviço, salários insuficientes, condições de trabalho insatisfatórias e mecanismos formais e informais de controle dos funcionários utilizados pelo hospital, estes últimos definidos pelo autor "como uma forma peculiar de exploração do trabalho".

A partir de uma revisão bibliográfica, WAKAMATSU (1986 p.52), apresenta e analisa os agentes biológicos, químicos e fisicos a que estão expostos os trabalhadores de hospitais e apresenta os critérios legais para se avaliar a insalubridade em diversas áreas, concluindo que, "apesar da importância, principalmente dos riscos biológicos, muito pouco tem sido publicado no Brasil a respeito deste assunto"

Através de uma abordagem psicossocial, PITTA (1990) fez um estudo sobre as relações entre o processo de trabalho e o sofrimento psíquico dos trabalhadores de um hospital geral do município de São Paulo. Sua análise partiu da detecção de sintomas psicoemocionais, buscando o estabelecimento de medidas de associação entre o sofrimento psíquico e o ambiente de trabalho, a divisão de tarefas, o tempo de exposição, o ritmo e o controle do trabalho, as pressões, a repetitividade/monotonia e os duplos ou múltiplos vínculos. $\mathrm{O}$ fato de não encontrar significação estatística entre o trabalho hospitalar na sua natureza e o sofrimento psíquico dos seus trabalhadores fez com que a autora refletisse se o lidar com a dor, sofrimento e morte seriam os elementos determinantes para a produção de sintomas psíquicos, levando-a a considerar que os arranjos ou desarranjos psíquicos individuais se expressam enquanto uma manifestação coletiva.

Na Espanha, BASURTE, PEREZ (1997) realizaram um estudo descritivo sobre os hábitos e as doenças mais freqüentes entre os trabalhadores do Hospital Clínico Universitário de Zaragoza, tendo sido encontradas as seguintes patologias: dores articulares, varizes, dismenorréia, cefaléias, problemas digestivos, rinofaringites e infecções urinárias. Os autores concluem enfatizando a necessidade de que sejam realizados exames periódicos de saúde com os trabalhadores e que estes sejam estimulados a participar dos mesmos para que se consiga uma maior prevenção dos fatores de risco presentes.

Estes trabalhos demonstram que, muitas vezes, as condições nas quais o trabalho em saúde é realizado podem em maior ou menor proporção causar o desgaste do trabalhador. 
Entre os estudos que se preocupam especificamente com as condições de trabalho e o processo saúde-doença dos trabalhadores de enfermagem estão: SOARES; PEIXOTO (1987), SILVA, (1996), LIMA JUNIOR, (1998) do Brasil e MONTOLIU, et al. (1997) da Espanha. Sendo que dentre estes, destacamos ainda, o de SILVA (1996) e o de LIMA JUNIOR (1998) que se preocuparam com a organização do trabalho e as condições de trabalho de trabalhadores de enfermagem de instituições hospitalares, tendo como base o trabalho desenvolvido por LAURELL; NORIEGA (1989), e, portanto, colocando no centro das análises o caráter social du processo saúde-doença e a necessidade da compreensão deste na sua articulação com o processo de produção.

SOARES; PEIXOTO (1987, p.151) fazem um estudo descritivo sobre os graus de riscos a que estão expostos os trabalhadores de enfermagem de um hospital geral da cidade do Rio de Janeiro, concluindo que "o pessoal que exerce atividades no setor hospitalar está sujeito a inúmeros riscos".

MONTOLIU et al. (1997), realizaram um estudo comparativo sobre as condições de trabalho de 10 hospitais do sistema nacional de saúde da Espanha, com o objetivo de fazer um diagnóstico das condições de trabalho do pessoal de enfermagem. Como metodologia foi utilizado o Mapa de Riscos. Em todos os hospitais existe uma importante carga psiquica, seguida da física e biológica. Tendo sido apontados como pontos fortes o bom relacionamento pessoal, o trabalho em equipe e a estabilidade.

Em um estudo realizado no Hospital Universitário da Universidade de São Paulo, SILVA (1996) evidenciou as particularidades da relação de determinação trabalho-saúde expressas nos trabalhadores de enfermagem, no desenvolvimento do trabalho. Através da análise dos elementos do processo de trabalho realizado na instituição, foi possível evidenciar que os trabalhadores estão expostos a todas as cargas de trabalho em diferentes intensidades e com freqüente simultaneidade, caracterizando a gênese do desgaste do trabalho de enfermagem nesse hospital. Como perfil de morbidade sobressaíram os ferimentos perfuro-corto-contusos e os problemas ósteo-músculo-articulares.

A partir da concepção da psicopatologia do trabalho, LIMA JUNIOR (1998 p. 379) buscou desvendar o processo de desgaste/prazer vivenciado pelos trabalhadores de enfermagem do Hospital Universitário de Juiz de Fora. Assim como no trabalho de SILVA (1996), foi evidenciada a exposição do trabalhador de enfermagem a todos os tipos de cargas, caracterizando condições insatisfatórias de trabalho. Entretanto os trabalhadores, através de estratégias de sobrevivência diária, procuram transformar o trabalho penoso, apesar de o prazer no trabalho se constituir em apenas uma expectativa uma vez que imperam os "incidentes críticos da vida organizacional, os sacrificios, as tensões, as injustiças e os sofrimentos que só poderão ser superados quando as relações acontecerem em uma base de parceria, de aprendizagem e criação conjunta, resgatando o sentido moral do trabalho, a 
competência, a dignidade, as aspirações e independência profissionais, bem como o ser humano subjetivo e complexo que dinamiza o mundo organizacional".

Os estudos de FRANCO (1981), PITTA (1990), SILVA (1996) e LIMA JUNIOR (1998) buscaram ir alem da relação de causa e efeito entre o trabalho e o processo saúde-doença dos trabalhadores, através de abordagens psicossociais ou materialistas históricas e dialéticas, voltados entretanto apenas para o trabalho hospitalar.

Entretanto, conforme já mencionamos, o trabalho em saúde e na enfermagem não possui como cenário apenas as instituições hospitalares, ele se dá também em unidades básicas de saúde.

As Unidades Básicas de Saúde, no Brasil, surgiram em 1891, no Estado de São Paulo, com a denominação de Serviços Sanitários, sendo que nessa época estavam voltados para o saneamento do meio, fiscalização profissional e combate às doenças transmissíveis (MASCARENHAS, 1973).

Com a implantação do modelo "Médico-Sanitário" e a incorporação da proposta de educação sanitária, estes serviços passaram a ser denominados de Centros de Saúde e Postos de Assistência Médico-Sanitária, estando voltados para a atenção à saúde da população matriculada, realização de exames periódicos, atendimento de higiene materna e da criança, junto com as ações campanhistas e de polícia sanitária ( ROCHA, 1987; VILLA, et al. 1997).

De estruturas simples os Centros e Postos Médicos foram se complexificando, para dar conta das propostas políticas de expansão de cobertura. Ocorre então uma quebra da polarização do trabalho que estava centrado nas figuras do médico, atendente e visitador, e assim são introduzidos novos profissionais no processo de trabalho, dentre eles o enfermeiro (VILLA, et al. 1997).

A rede básica de saúde nos dias de hoje se caracteriza por aglutinar um contingente expressivo de trabalhadores. Entretanto, na bibliografia pesquisada, não encontramos estudos voltados para o trabalho que é realizado em UBS e que fizessem uma análise sobre as repercussões deste trabalho no processo saúde-doença e na vida destes trabalhadores

Assim por acreditarmos que os trabalhadores de enfermagem de UBS estão submetidos a condições de trabalho que são especificas, decidimos realizar este estudo que teve como finalidade descrever as particularidades da relação trabalhosaúde, no desenvolvimento do trabalho da enfermagem na rede básica de saúde de Juiz de Fora. 
2 OBJETIVOS 


\subsection{Objetivo Geral}

- descrever e analisar as condições de trabalho dos trabalhadores de enfermagem de Unidades Básicas de Saúde de Juiz de Fora, identificando as condições favoráveis e desfavoráveis do trabalho e sua repercussão na vida e no processo saúde-doença desses trabalhadores

\subsection{Objetivos Específicos}

- descrever e analisar as condições de trabalho e de vida de trabalhadores da rede básica de saúde de Juiz de Fora;

- analisar as inter-relações entre as condições de trabalho e de vida e os processos de desgaste e fortalecimento. 
3 CONTEXTUALIZANDO O CENÁRIO 
Este trabalho foi desenvolvido em 11 Unidades Básicas (UBSs) localizadas na região urbana da Cidade de Juiz de Fora.

Antes de estarmos contextualizando a política de saúde do município, consideramos importante estar relatando alguns aspectos que dizem respeito a características históricas e ao desenvolvimento da cidade de modo a introduzir o tema.

\subsection{A cidade de Juiz de Fora ${ }^{1}$}

Juiz de Fora é uma cidade cosmopolita e localiza-se a sudeste do Estado de Minas Gerais, na Zona da Mata Mineira, entre as serras da Mantiqueira e do Mar. Ocupa uma área de $1.424 \mathrm{Km} 2$, e apresenta uma população de 424.479 habitantes.

A cidade começou no final do século XVIII e início do século XIX, quando Garcia Rodrigues Paes, filho do bandeirante Fernão Dias Paes, abriu um caminho ligando a Corte ao centro da Região das Minas - o "Caminho Novo", concluido em 1704 por Domingos Rodrigues da Fonseca.

Ao longo desse caminho, que acompanhava as margens do Rio Paraíba do Sul, surgiu o povoado agrícola de Santo Antônio do Morro da Boiada do Paraíbuna, mais conhecido como arraial de Santo Antônio do Paraíbuna, que foi posteriormente denominado Santo Antônio do Paraíbuna do Juiz de Fora, pois na região residia Bustamante e Sá, aposentado da carreira jurídica no cargo de Juiz de Fora.

O cargo jurídico de Juiz de Fora, segundo BOTTI (1994) "foi trazido para as colônias americanas pelos colonizadores portugueses e espanhóis. A tradição ibérica assimilou essa função jurídica dos mouros, invasores da Península Ibérica, durante a Idade Média Ocidental. Os árabes, por sua vez, tomaram esse cargo jurídico das antigas Alexandrias. Nas Alexandrias, Alexandre, O Grande, da Macedônia, instituiu essa função para que o juiz das Alexandrias, morando fora da comunidade urbana, pudesse julgar com isenção de pessoa".

Nas imediações da fazenda de Bustamante existiam algumas pequenos comércios e quando os moradores dos povoados vizinhos iam às compras diziam estar indo ao Juiz de Fora, passando a ser esse o nome popular dado à vila que foi elevada à categoria de Município em 31/05/1850. Foi contudo em 1865, que, oficialmente o Município de Santo Antônio do Paraíbuna passou a ser chamado de Juiz de Fora por sugestão do Barão de São Marcelino à Assembleia Provincial

\footnotetext{
1 Os dados apresentados foram extraidos do livro "Companhia mineira de eletricidade" de BOTTI (1994). dos Anuários Estatísticos de Juiz de Fora dos anos de 1995 e 1997 da Universidade Federal de Juiz de Fora e do Plano Municipal de Saúde da Secretaria Municipal de Saúde de Juiz de Fora de 1997.
} 
Inicialmente, o desenvolvimento econômico da região esteve ligado ao plantio do café e à pecuária, sendo que, mesmo com a crise cafeeira, a cidade continuou crescendo graças à construção da Estrada União e Indústria por Mariano Procópio. Com a implantação da Estrada de Ferro D. Pedro II e a construção da primeira Usina Hidrelétrica da América Latina, surgiram pequenas e médias indústrias na região que vêm sustentando o desenvolvimento econômico até os dias de hoje.

Com a industrialização, a cidade adquiriu características que fizeram Rui Barbosa chamá-la de Manchester Mineira por compará-la com a cidade inglesa.

Juiz de Fora é uma cidade que vem crescendo economicamente, sendo que um dos fatores desse crescimento é o fácil acesso a Belo Horizonte (de onde dista $260,5 \mathrm{Km})$, a São Paulo $(486,3 \mathrm{Km})$ e ao Rio de Janeiro $(179,8 \mathrm{Km})$.

Com uma população predominantemente jovem, $52,36 \%$ na faixa etária entre 0 a 29 anos e, em sua maioria, residente na área urbana $(98,76 \%)$, apresenta uma economia onde a atividade comercial e a de serviços são predominantes, seguidas pelas industriais e, por último, por atividades do setor primário.

Do total de estabelecimentos existentes em Juiz de Fora, a indústria participa com $16,2 \%$ ( $7 \%$ de indústria têxtil e de vestuário, $2 \%$ de indústria da construção civil, $1,7 \%$ da indústria de produtos alimentares, $1 \%$ de indústria metalúrgica e $4,6 \%$ de outras), o comércio com $39,4 \%$ e o segmento de serviços com $44,3 \%$. A abertura de novas fábricas, como a Montadora Mercedez-Benz, veio reforçar o setor industrial e dinamizar a economia da cidade que é também o principal centro comercial da Zona da Mata.

Em relação às redes de ensino de $1^{\circ}$ e $2^{\circ}$ graus, Juiz de Fora conta com 137 escolas municipais com 35.895 alunos, 50 estaduais com 48.674 alunos, 2 federais com 2.339 alunos, 117 particulares com 29.214 alunos e uma militar com 534 alunos. Para o ensino de $3^{\circ}$ grau existem 5 instituições, dentre elas a Universidade Federal de Juiz de Fora, que oferece o curso de Enfermagem com 30 vagas.

O Curso de Enfermagem da Universidade Federal de Juiz de Fora foi criado em 1978, como um Departamento da Faculdade de Medicina, absorvendo o corpo docente e discente da Fundação Hermantina Beraldo, tradicional escola de enfermagem na região.

A Faculdade de Enfermagem de Juiz de Fora é uma referência para toda a região da Zona da Mata Mineira e assim o corpo discente da Faculdade é em sua maioria proveniente de cidades vizinhas.

Juiz de Fora é também um centro de cultura e lazer, contando com 13 entidades culturais, 15 corais, 6 orquestras, 5 bandas, 5 grupos de divulgação 
folclórica, 6 teatros, 7 cinemas, 13 grupos teatrais, 15 galerias de arte, 6 bibliotecas e 9 museus.

Em relação à condição de saneamento básico, a grande maioria das residências $(97,04 \%)$ contam com canalização interna da água, 94,66\% delas abastecidas plea rede pública; $91,65 \%$ das instalações sanitárias são ligadas à rede de esgotos e $90,79 \%$ dos domicilios fazem uso da coleta de lixo domiciliar que é realizada a cada dois dias. Esses dados constituem um demonstrativo das boas condições de saneamento do Município. Quando comparados com os indicadores do Estado de Minas Gerais em que apenas 78,81\% das residências apresentam canalização interna de água, $86,24 \%$ delas abastecidas pela rede, $63,92 \%$ dos domicílios possuem instalação sanitária ligada à rede e $56,76 \%$ fazem uso da coleta de lixo.

Juiz de Fora, no entanto, não está livre do crescimento desordenado e o preço pago por esse desenvolvimento são as agressões ao meio ambiente, sujeitando o municipio a degradações e diversas formas de poluição como, por exemplo, a descarga doméstica de entulhos e de lixo em terrenos vazios, encostas e cursos d'água, o destino final do lixo industrial, junto aos resíduos domiciliares, não levando em conta o volume e a periculosidade específica, a descarga de esgoto em córregos sem tratamento, a existência de precárias fossas sépticas e o vazamento de tanques de postos de gasolina, com a contaminação do lençol freático.

Os indicadores de saúde mostram uma população com uma expectativa de vida ao nascer de 67 anos (sendo de 65 anos para os homens e de 73 anos para as mulheres), uma taxa de natalidade de 19/1000 hab., taxa de mortalidade geral de $6,96 / 1000$ hab., estando em queda a taxa de mortalidade infantil, 23,15/1000 hab., no ano de 1997, conforme o comportamento nacional.

A principal causa de mortalidade geral são as doenças do aparelho circulatório $(37,51 \%)$ seguidas das doenças do apareiho respiratório $(13,36 \%)$ e dos neoplasmas $(13,18 \%)$.

Dados do Instituto de Saúde do Trabalhador mostram que ocorreram 1.321 acidentes de trabalho notificados em Juiz de Fora, no ano de 1997, sendo que dentre eles, a maioria $(85,62 \%)$ recebeu tratamento ambulatorial. $\mathrm{Na}$ distribuição dos acidentes de trabalho por faixa etária, $18,09 \%$ ocorreram na faixa etária de 40 a 50 anos, $19,15 \%$ na faixa de 34 a 40 anos e $13,47 \%$ na de 30 a 34 anos.

A cidade possui 27 hospitais, 48 Unidades Básicas de Saúde, aproximadamente 1 médico para 410 habitantes e 1 leito hospitalar para 120 habitantes. A distribuição médico por habitante, está abaixo da recomendação da Organização Mundial de Saúde (OMS) que preconiza que o ideal é que haja 1 médico por 200 habitantes. 
Em relação à utilização pela população dos equipamentos de saúde, $0,8 \%$ da população vêm recebendo atendimento, sendo que a OMS preconiza que seja atendida $0,6 \%$ da população, isto da perspectiva da população de modo geral sem estratificação por possibilidade de acesso aos bens de produção e consumo.

Os Serviços de Saúde de Juiz de Fora, segundo dados da Secretaria Municipal de Saúde, estão distribuídos por 12 Regiões Sanitárias que contam com 35 Unidades Básicas de Saúde (UBS) na zona urbana e 14 UBSs na zona rural, para a atenção básica. $\mathrm{Na}$ atenção secundária conta-se com 5 Institutos (da Criança, da Mulher, Saúde Mental, Clínicas Especializadas e Saúde do Trabalhador), 2 unidades regionais e um Pronto Socorro Municipal. Já na atenção terciária, conta-se com 19 hospitais conveniados com o SUS/JF (13 gerais e 06 psiquiátricos), dos quais 2 são públicos (Hospital Universitário - Federal e Hospital Dr. João Penido - Estadual) e 17 privados com ou sem fins lucrativos .

Em 1992, a partir de um convênio de descentralização administrativa, firmado entre a Secretaria Municipal de Saúde de Juiz de Fora e a Secretaria de Estado da Saúde de Minas Gerais, o município passou a assumir toda a rede assistencial até então sob a gestão do Estado; a partir de 1995, o município passou para gestão semiplena.

Com o objetivo de desenvolver um modelo de assistência primária tendo como base a territorialização a um custo compatível com a disponibilidade de recursos do município, e visando ao desenvolvimento de ações de promoção e proteção à saúde, identificação e prevenção de fatores de risco, bem como o tratamento precoce das doenças dos indivíduos e das famílias, em dezembro de 1996, foi instituído em Juiz de Fora o Programa de Saúde da Família, implantado em 20 Unidades Básicas de Saúde (JUIZ DE FORA, 1996).

No que diz respeito à força de trabalho em enfermagem, segundo dados do Conselho Regional de Enfermagem de Minas Gerais (COREN - MG) de 30/09/98, a cidade de Juiz de Fora possuía 489 enfermeiros (24\%), 668 técnicos de enfermagem (32\%) e 922 auxiliares de enfermagem (44\%), não sendo contabilizados os agentes de saúde. Os serviços de saúde do SUS de Juiz de Fora contam com 93 enfermeiros, 34 no nível primário, 49 no secundário, 9 no nível central e 1 cedido.

Em Juiz de Fora a política de saúde, sob a égide da política nacional, passou a ser de responsabilidade da Prefeitura a partir de 1992, através de um convênio de descentralização administrativa entre a Secretaria Municipal de Saúde de Juiz de Fora e a Secretaria de Estado da Saúde de Minas Gerais.

Segundo diagnóstico de 1997, há uma distorção na organização da assistência à saúde no município, estando o modelo centrado na atenção individual, curativa, com ênfase na especialização e na dependência de um aparato tecnológico para apoio do diagnóstico. O sistema apresenta uma baixa cobertura da atenção básica, e um alto percentual de consultas de urgência (vide quadro 1). 
Quadro 1: Distribuição das Consultas Ambulatoriais por Tipo, Parâmetro da Organização Mundial de Saúde (OMS) e Situação em Juiz de Fora, 1996.

\begin{tabular}{|l|c|c|}
\hline \multicolumn{1}{|c|}{ Tipo de consultas } & $\begin{array}{c}\text { Parâmetro OMS/\% do } \\
\text { total de consultas }\end{array}$ & $\begin{array}{c}\text { Situação de Juiz de Fora/ } \\
\%\end{array}$ \\
\hline Básicas & 70 & 28,6 \\
\hline Especializadas & 15 & 46,8 \\
\hline Urgência/Emergência & 15 & 24,6 \\
\hline Total & 100 & 100 \\
\hline
\end{tabular}

Adaptado do Plano Municipal de Saúde (JUIZ DE FORA, 1997).

Além disso, o modelo assistencial predominante em Juiz de Fora caracteriza-se por uma atenção programática baseada na livre demanda sem planejamento local das ações de saúde; as Unidades Básicas não vêm conseguindo interferir no perfil de morbi-mortalidade, apesar de possuirem um diagnóstico local; dificuldade de acesso aos serviços, pois a atenção é restrita a um número determinado de usuários; carência de recursos humanos; dificuldades de organização e funcionamento das UBSs devido ao um gerenciamento centralizado - o que já vem sendo contornado, de certa forma, com a implantação da gerência local ; precariedade do sistema de referência e contra-refêrencia; atuação restrita da vigilância epidemiológica e sanitária pela sua centralização excessiva, além de falta de insumos da rede de apoio diagnóstico e terapêutico.

$\mathrm{Na}$ tentativa de reverter esse modelo assistencial, em consonância com a proposta política do Ministério da Saúde, em 1995, foi implantado em Juiz de Fora o Programa de Saúde da Família (PSF), com equipes constituídas por um profissional médico, um enfermeiro, um assistente social e dois auxiliares de enfermagem para prestarem assistência a 800 familias.

Segundo o Ministério da Saúde, o PSF tem como objetivo geral “ Contribuir para a reorientação do modelo assistencial a partir da atenção básica, em conformidade com os princípios do Sistema Único de Saúde, imprimindo uma nova dinâmica de atuação nas unidades básicas de saúde, com definição de responsabilidades entre os serviços de saúde e a população" (BRASIL, 1997 p. 10). Além disso, em Juiz de Fora, nas UBSs onde está implantado o PSF, espera-se que sejam alcançados também os seguintes objetivos: "interferir positivamente, no perfil de morbimortalidade de cada território; nortear a hierarquização e a regionalização do sistema de saúde; facilitar a implantação efetiva da referência e da contra-referência" (FARAH, 1999 p. 75)

Apesar de o PSF ainda não estar implantado em todas as UBS de Juiz de Fora, tem sofrido seguidas avaliações com a finalidade de que sejam feitos ajustes.

Na primeira avaliação do Plano Municipal de Saúde de 1997 constatou-se que "apesar do pouco tempo, avaliamos que algumas unidades não estão trabalhando de acordo com os objetivos traçados, o que vem destoando da proposta do Ministério da Saúde e da Secretaria de Saúde de Juiz de Fora Nas 
unidades onde foi implantado tem-se criado uma demanda reprimida e o trabalho de toda a equipe esta sendo comprometido. Essa distorção teve como principal causa a não criação de instrumentos de acompanhamento, controle e avaliação das ações desenvolvidas neste programa, e também pela falta de uma equipe de supervisão, assessoramento clínico e gerencial e desajuste quantitativo de recursos humanos proporcionalmente à população adscrita" (JUIZ DE FORA, 1997 p. 59).

Em março de 1998, foi realizada outra avaliação nas 19 Unidades que desenvolvem o PSF, concluindo-se que nem todas vêm trabalhando de acordo com as propostas e diretrizes do programa, sendo que a maioria (11) receberam uma avaliação regular, apenas uma teve avaliação ótima, seis avaliação boa e dois avaliação péssima. Segundo FARAH (1999 p.78), "dentre os problemas detectados encontravam-se: falta de infra-estrutura fisica e material; falta de recursos humanos qualificados para atuarem no Programa, em proporção adequada ao número de habitantes por território; não pagamento do adicional de desempenho para os enfermeiros, assistentes sociais e auxiliares de enfermagem, o que gerou a saída de vários profissionais capacitados para outros setores da Secretaria; e a falta de articulação do nível central com o local (as UBSs). Foram citados ainda como dificultadores: mudança de gestores do sistema; centralização das ações de gerenciamento, planejamento e programação; sistema de informação precário com falta de retorno das informações epidemiológicas às UBS.

Com o objetivo de superar o modelo tradicional e solucionar as dificuldades citadas, o Plano Municipal lançou a proposta de revisão do sistema através da incorporação do projeto de Cidade Saudável, com a reprogramação das UBS's através do fortalecimento dos Sistemas Locais de Saúde, da participação dos Conselhos Locais e Regionais de Saúde e a utilização do planejamento estratégico situacional como aporte metodológico para o diagnóstico sócio-epidemiológico e o enfrentamento dos problemas de saúde detectados.

Entretanto, segundo FARAH (1999 p. 86), essa proposta ainda está no discurso, devido a falta de conhecimento da maioria dos profissionais de saúde sobre as propostas contidas no Plano Municipal de Saúde, apesar de este ter sido elaborado com a representação de usuários, trabalhadores e profissionais de saúde; deficiência de recursos humanos em quantidade e com capacitação para atuar na promoção e reabilitação da saúde; falta de recursos materiais, medicamentos e equipamentos; insuficiência da rede de apoio diagnóstico; inexistência de um sistema de referência e contra-referência e "pela própria situação em que se encontra a saúde no Brasil". 
4 MARCO TEÓRICO 


\subsection{A relação trabalho-saúde}

Um marco teórico-filosófico desse estudo é o de que o processo saúde-doença é determinado socialmente, ou seja, de que formas de trabalhar e de viver geram potenciais de beneficios e de riscos que se expressam no coletivo e nos indivíduos que o compõem através da "saúde e sobrevivência e do adoecimento e morte "(GRANDA; BREILH 1989 p: 37).

Essa compreensão toma corpo, no final da década de 60 e início dos anos 70, com o movimento da Medicina Social, nas palavras de BREILH (1995), uma expressão renovada da Saúde Pública, buscando a superação do empirismo e da medicalização desta.

A Medicina Social problematiza e concebe a saúde-doença não apenas como um processo biopsíquico, mas como um processo social, cujo nexo biosíquico é "a expressão concreta da corporeidade humana do processo histórico em um momento determinado" (LAURELL; NORIEGA 1989, p.100)

Como uma decorrência desse movimento surge a Saúde Coletiva que, segundo BREILH (1995), "se fundamenta em uma base conceitual diferente, posto que não reduz à compreensão dos comportamentos das doenças a relações formais (unicausais ou multifatoriais) que restringem a análise às relações empíricas. Propõe também, e complementarmente, uma superação dos métodos funcionalistas e fenomenológicos nos quais se sustenta o trabalho tradicional e rompe com o estreito marco médico e Estatal, reclamando o caráter protagonico da própria população e de outras organizações que não são serviços curativos de saúde...(p.89)".

Segundo LAURELL; NORIEGA (1989), estudar o processo saúdedoença da coletividade como uma expressão de processos sociais, significa analisar os fenômenos de saúde e doença no contexto econômico, político e ideológico da sociedade e não apenas como fenômeno biológico que ocorre no âmbito individual.

Para COHN; MARSIGLIA (1993), reinvindicar o caráter social do processo saúde-doença significa negar que o desgaste do homem seja devido apenas a processos naturais, como o envelhecimento e as doenças que ignora as especificidades históricas e sociais.

O perfil de saúde e o de doença devem ser considerados como dois pólos de uma mesma unidade, cuja expressão é a luta entre os "efeitos saudáveis e potenciadores dos valores de uso a que tem acesso uma classe durante sua reprodução social e os efeitos nocivos dos contravalores que atingem seus membros enquanto se desenvolve esta reprodução social com seus processos interrelacionados de trabalho e consumo, e suas relações de distribuição e intercâmbio" (GRANDA; BREILH 1989, p. 184). 
O trabalho deve ser considerado como uma categoria social e não apenas decorrente de risco ambiental e o processo saúde-doença do trabalhador como expressão do processo de exploração capitalista (LAURELL; NORIEGA, 1989).

Assim, segundo LAURELL; NORIEGA (1989), para se estudar a relação trabalho-saúde, uma categoria analítica fundamental é o processo de produção, pois "na sociedade capitalista, o processo de produção organiza toda a vida social e porque é, simultaneamente, o processo de valorização do capital e modos específicos de trabalhar - processo de trabalho. Esta categoria permite, então, estudar sob uma realidade concreta a lógica de acumulação (processo de valorização) e seu meio - o processo de trabalho - como um modo específico de trabalhardesgastar-se e como enfrentamento de classe em termos de estratégias de exploração e de resistência, que, por sua vez, determinam padrões específicos de reprodução" (p.36).

Assim sendo, o modo capitalista de produção se caracteriza por dois elementos inseparáveis, o processo de valorização do capital ou seja de produção de mais-valia e por modos específicos de trabalhar ou processos de trabalho. $\mathrm{O}$ processo de valorização e o processo de trabalho estão intimamente relacionados, uma vez que o primeiro ocorre através do segundo pois o processo de trabalho é a materialização do processo de valorização (LAURELL; NORIEGA, 1989).

O processo de trabalho pode ser entendido como um processo entre o homem e a natureza, onde o homem por sua atividade transforma um objeto determinado, esteja este em estado natural ou já trabalhado, em um produto determinado, e ao modificar dessa forma a natureza ele transforma a si mesmo. Os elementos que constituem o processo de trabalho são: o objeto, os meios e ou instrumentos e a finalidade do trabalho (MARX, 1988).

Ao considerarmos que o modo de produção de uma sociedade determina o modo de vida e as formas de organização dessa sociedade, consideramos também que um determinado modo de produção implica um processo de reprodução, pois a produção não ocorre na ausência de consumo, e o consumo depende da produção (VICTORA, et al 1990).

Assim há que se compreender o processo saúde-doença também a partir da reprodução social, que segundo GRANDA; BREILH (1989, p. 52) "constituem a explicação científica daquelas categorias imprecisas que a epidemiologia tradicional utiliza: as 'condições de vida' ou 'fatores ambientais, culturais e socio-econômicos' dos grupos".

As cargas de trabalho são outra categoria, proposta por LAURELL; NORIEGA (1989) para a análise da relação trabalho-saúde. O conceito de carga se contrapõe ao conceito de risco da medicina do trabalho que considera estes como agentes nocivos isolados entre si e da dinâmica do processo de trabalho, e ao conceito de "fatores de risco" do modelo epidemiológico que preconiza a presença simultânea de vários deles para produzir a doença 
Conceitualmente as cargas de trabalho podem ser definidas como "exigências ou demandas psicobiológicas do processo de trabalho, gerando ao longo do tempo as particularidades do desgaste do trabalhador. Em outras palavras, as cargas são mediações entre o porcesso de trabalho e o desgaste psicobiológico" (FACHINI, 1994 p.180). Segundo LAURELL; NORIEGA (1989 p.110), o conceito de cargas " possibilita uma análise do processo de trabalho que extrai e sintetiza os elementos que determinam de modo importante o nexo biopsíquico da coletividade operária e confere a esta um modo histórico específico de andar a vida".

A identificação das cargas de trabalho permitem que se estude o impacto do objeto, dos meios e instrumentos, e da organização e divisão do trabalho, sobre a saúde do trabalhador, $\mathrm{e}$ "como estes elementos consomem a força de trabalho, ou desgastam as capacidades vitais do trabalhador" (FACCHINI, 1994 p. 180).

As cargas de trabalho, operacionalmente, podem ser agrupadas, segundo sua natureza ou característica básica, em cargas que têm uma materialidade externa e que se modificam na interação com o corpo, como as fisicas, biológicas, químicas e mecânicas e aquela que adquirem materialidade no próprio corpo humano e se expressam internamente através dele, como as fisiológicas e psíquicas (LAURELL; NORIEGA 1989; FACHINI, 1994).

\subsection{Características gerais do trabalho em saúde e de enfermagem na rede básica}

O trabalho em saúde, se caracteriza por ser um processo de produção coletivo, parte do modo de produção capitalista da nossa sociedade, e que se insere no setor terciário da economia nacional, especificamente na prestação de serviços.

O processo de produção em saúde tem especificidades, sendo elas: o lidar cotidiano com paradoxos, como a vida e a morte, a dor e o prazer, tendo como foco do trabalho o monitoramento e o acompanhamento dos perfis de saúde-doença e de reprodução de grupos sociais, sendo um processo histórico; seu produto não é uma mercadoria que simplesmente se troca no mercado, mas é fruto das relações que se estabelecem entre os homens em sociedade; o desenvolvimento do trabalho não ocorre de modo isolado, ele é conseqüência da articulação e das relações estabelecidas no trabalho de vários agentes (ALMEIDA et al., 1997; QUEIROZ; SALUM, 1996)

A Enfermagem e as profissões de saúde de modo geral são tratadas como se fossem "desvinculadas do mundo do trabalho que obedece às leis sociais de necessidades, de carecimento, e esta desvinculação as coloca acima e além do mundo do trabalho, exaltando suas qualidades de 'verdade', de 'ciência', 'dedicação', de 'bem', 'sacerdócio' e de 'autonomia'”(ALMEIDA; ROCHA, 1997). 
No entanto, se consideramos a Enfermagem como uma prática técnica, ou seja, que possui um conjunto de instrumentos técnicos e científicos dos quais se utiliza para sua atuação e também como uma prática social, que não se faz isoladamente, que sofre as marcas do modo como a sociedade se estrutura e se organiza e, portanto, que deve ser tomada como parte do contexto no qual está inserida, contexto esse que é sócio-político-econômico e que possui uma história, devemos, então, considerá-la parte do processo de produção em saúde (SILVA, 1989).

Segundo QUEIROZ; SALUM (1996 p. 204), “a enfermagem, ao compor parcela do trabalho coletivo de saúde e seus integrantes parcela do trabalhador coletivo de saúde, não tem um processo próprio de trabalho, tampouco um objeto que lhe é específico. Como as outras prática sociais, ela tem responsabilidade de desenvolver sua especificidade nos processo de trabalho (assistência, gerenciamento, investigação e ensino) do processo de produção, processos de trabalho estes aos quais as demais práticas sociais também se conectam com suas especificidades".

Assim, a enfermagem pode ser definida como uma ação, ou uma atividade que é realizada predominantemente por mulheres que através dela reproduzem a sua própria existência. Para atuar no objeto do processo de produção em saúde, naquilo que lhe é específico, faz uso dos conhecimentos de outras ciências e de uma síntese produzida por ela mesma tendo em vista, como produto final, o atendimento das necessidades sociais, ou seja, a promoção da saúde, prevenção de doenças, recuperação do indivíduo e o controle da saúde da população (ALMEIDA; ROCHA, 1997 p. 18)

Ainda em relação ao caráter social e histórico do trabalho de enfermagem, ALMEIDA; ROCHA (1997 p.18) colocam que:

"as necessidades ou os carecimentos humanos não são de um homem só, pois este vive, sofre, trabalha junto com outros homens, e assim também não são naturais, portanto, carecimentos sociais que, tomados como finalidades, presidem o processo do trabalho e produzem a satisfação destes carecimentos". Assim, a geração e a satisfação das necessidades através do trabalho, é um processo social e histórico, pois é através dele que se dá a produção e reprodução do homem social. "Os agentes do trabalho de enfermagem, assim como aqueles portadores de necessidades de saúde, se relacionam com outros homens, através de seus produtos, na divisão social do trabalho. Não é portanto um processo natural, bom ou mau, é necessariamente social e histórico"

O trabalho de enfermagem se operacionaliza através da participação em diferentes processos de trabalho: o de assistência à saúde - cuidar; o de gerenciamento dessa assistência - administrar; o de investigação científica produção de saber e o de ensino - qualificação da força de trabalho em saúde (CASTELLANOS, et al. 1989; QUEIROZ; SALUM, 1996). 
A especificidade do trabalho da enfermagem está na sua forma de intervenção no objeto, ou seja, nos meios e instrumentos que utiliza para transformar o objeto em direção à finalidade. Historicamente esses meios e instrumentos têm sido: observação, levantamento de dados, planejamento, evolução, avaliação, sistemas de assistência, procedimentos técnicos, procedimentos de comunicação e de interação, a própria força de trabalho, os equipamentos e materiais, os modelos e métodos de administração, entre outros (CASTELLANOS, et al. 1989; ALMEIDA; ROCHA, 1997).

Segundo QUEIROZ; SALUM (1996 p. 55), a enfermagem, tendo por base o modelo assistencial, os princípios e diretrizes do SUS, e em articulação com as outras práticas, delineia um plano de intervenção que se operacionaliza no acompanhamento sistemático e horizontal dos processos saúde-doença dos corpos social e individual.

Em nosso país, o trabalho em saúde está organizado em dois modelos principais: o modelo do controle da doença na sociedade - o modelo epidemiológico/coletivo - e o modelo de recuperação da força de trabalho - o modelo individual/clínico, sendo importante ressaltar que estes dois modelos não são excludentes, eles são dimensões de mesma realidade que é a saúde (GONÇALVES, 1994).

A enfermagem como uma parcela do trabalho em saúde está presente na produção de serviços de saúde em nivel individual que se operacionaliza predominantemente na assistência hospitalar, assim como no nível coletivo predominante na rede básica de atenção à saúde.

Para a atuação no modelo epidemiológico/coletivo, segundo ALMEIDA et al (1997 p. 62), "o trabalho de enfermagem tem se diversificado, indo desde o 'cuidar' de enfermagem, seja do indivíduo, família e grupos da comunidade, passando pelas ações educativas, administrativas, até a participação no planejamento em saúde". 
5 O DESENHO METODOLÓGICO 
Tendo por base as concepções assinaladas anteriormente para o estudo das condições de trabalho dos trabalhadores de enfermagem de UBSs de Juiz de Fora, foram pesquisadas as condições favoráveis e desfavoráveis do trabalho e sua repercussão na vida e no processo saúde doença desses trabalhadores.

$\mathrm{Na}$ área de saúde do trabalhador, para a investigação da relação entre a Saúde e o Trabalho, segundo RIGOTTO (1994), podem ser utilizados alguns instrumentos, tais como: a entrevista com o trabalhador, a enquete coletiva e o estudo dos locais de trabalho. Estes instrumentos já têm sido utilizados por vários autores, dentre eles citamos FACCHINI, (1986), LAURELL; NORIEGA (1989), POSSAS (1989) e PITTA (1990).

Neste trabalho, a descrição e análise das condições de trabalho dos trabalhadores de enfermagem foi realizada através de dois instrumentos: o Mapa de Risco das unidades estudadas elaborado a partir de enquêtes coletivas e a aplicação de formulários com questões estruturadas para serem aplicados no local de trabalho.

O Mapa de Riscos foi originalmente utilizado pelo Modelo Operário Italiano, como uma estratégia para se descreverem as condições ambientais dos locais de trabalho mesmo sem se ter acesso a estes espaços. Consiste na representação gráfica do processo de trabalho com os riscos e danos decorrentes (ODONNE, 1986).

Segundo FACCHINI (1994), o Modelo Operário, quando comparado com os métodos tradicionais de abordagem da Saúde do Trabalhador, inova pela sua operacionalização e pelos seus quatro princípios básicos : valorização da experiência ou subjetividade operária, não delegação da produção dos conhecimentos pelos trabalhadores, levantamento das informações por grupos homogêneos de trabalhadores e validação consensual das informações, que consiste no registro de dados que todos do grupo reconhecem como corretos ou válidos.

$\mathrm{Na}$ enfermagem, o Mapa de Riscos foi utilizado no estudo realizado por SILVA (1996) sobre o desgaste do trabalhador de enfermagem no Hospital Universitário da Universidade de São Paulo, que elaborou seu estudo baseando-se na proposta de LAURELL; NORIEGA (1989).

Neste estudo, o Mapa de Riscos foi utilizado com o objetivo de estudar o ambiente de trabalho, as condições desfavoráveis ou cargas advindas da relação entre o trabalhador e o objeto, os meios e instrumentos e a organização do trabalho. Assim como as condições favoráveis, seguindo-se os passos do trabalho elaborado por PICCOLO (1998), sobre condições perigosas e favoráveis do trabalho em obras do metrô, que mesclou aspectos do modelo proposto por LAURELL; NORIEGA (1989) e do modelo proposto por BETTANCOURT (1995), "buscando superar os limites da aplicação usual do mapa de riscos", expandindo-o para Mapa de Beneficios e Riscos, incluindo assim a identificação das condições desfavoráveis e favoráveis ao trabalho. 
Para se elaborar o Mapa de Riscos utilizou-se a enquete coletiva, que consiste na aplicação dos princípios do modelo operário italiano, já apresentados, ou seja, em uma técnica na qual as informações são levantadas segundo grupos homogêneos de trabalhadores, valorizando-se a experiência ou subjetividade dos trabalhadores, registrando-se os dados reconhecidos como corretos ou válidos (validação consensual) pelos participantes (LAURELL et al., 1990).

Grupos homogêneos de trabalhadores são definidos como grupos de trabalhadores que compartilham determinadas condições de trabalho e que guardam "vínculos orgânicos" entre si (LAURELL et al. 1990).

Para a realização do estudo foram escolhidas 11 Unidades Básicas de Saúde com as quais a Faculdade de Enfermagem vem desenvolvendo atividades de ensino, por acreditar-se na possibilidade de contribuição para o fortalecimento da integração entre a escola e o serviço.

Os formulários utilizados na coleta de dados (anexos 1 e 2) foram elaborados de modo a contemplar informações sobre a forma como se processa o trabalho, a vida cotidiana e o processo saúde-doença dos trabalhadores de enfermagem, diferenciando-se enfermeiros de auxiliares de enfermagem.

Para que pudéssemos descrever as atividades de enfermagem que vêm sendo desenvolvidas, nas UBS estudadas, por enfermeiros e auxiliares, utilizamos como recurso a relação de atividades composta pelo conjunto de ações determinadas pela lei do exercício profissional (BRASIL, 1986) e proposta no programa de saúde da familia, decompondo-as em atividades de assistência à saúde, de gerenciamento da assistência, de ensino e de investigação.

A construção das questões foi baseada também no questionário sobre condições de saúde dos médicos internos do projeto: "Determinantes Epidemiológicos en el Trabajo Hospitalario" de BREILH(1995) e no instrumento utilizado por PITTA (1990) em seu trabalho "Hospital dor e morte como oficio"

Para trabalharmos a reprodução social dos trabalhadores de enfermagem das UBS optamos por utilizar as dimensões: renda, uso do espaço e agregação social, baseado no trabalho da FUNDAÇÃO SEADE (1992), no estudo de POSSAS (1989), especificamente no que diz respeito a condições de vida e no estudo de QUEIROZ; SALUM (s/d).

Para dar inicio à coleta de dados, junto à responsável pela Coordenação de Estágio da Faculdade de Enfermagem de Juiz de Fora, foram levantadas as Unidades Básicas de Saúde com as quais a Faculdade vêm desenvolvendo atividades de estágio ou de prática de ensino ${ }^{2}$, tendo sido referidas as

\footnotetext{
2 A Faculdade de Enfermagem de Juiz de Fora faz uma diferenciação entre prática e estágio curricular. No ensino com prática existe a supervisão direta do professor. ou seja, estc deve
} 
seguintes Unidades: Retiro, Jardim Esperança, Jardim da Lua, São Benedito, Nossa Senhora das Graças, São Judas Tadeu, Santa Cruz, Santa Cecília, Santa Efigênia, Furtado de Menezes e Vila Olavo Costa.

A partir de um contato prévio com o responsável pela coordenação das Unidades Básicas de Saúde, foi solicitada a permissão para se realizar a pesquisa. Em reunião com os gerentes das Unidades, o projeto de pesquisa foi apresentado com ênfase nos objetivos e finalidade do estudo tendo sido assumido pela pesquisadora o compromisso de socializar os resultados da pesquisa e, pelo coordenador, o de garantir um espaço para a apresentação dos resultados. Os entrevistados foram convidados a participar do estudo através do consentimento esclarecido, conforme recomendação da Comissão de Ética (anexo 2).

Através de contato telefônico foi agendada uma primeira visita às Unidades onde foram levantados dados para a caracterização do serviço e para a elaboração do desenho gráfico da área fisica (anexo 3).

Com o esquema gráfico da área fisica e a descrição da unidade, foi agendado um segundo encontro (também através de contato telefônico, com cada UBS), que contasse, dessa vez, com a participação de toda a equipe de enfermagem para que se pudesse confeccionar o mapa de riscos e beneficios.

Os encontros foram agendados em dias e horários escolhidos pela enfermeira responsável pela equipe considerando a disponibilidade de todos ficarem afastados do trabalho por cerca de uma hora. Na maioria das unidades foram escolhidos dias nos quais não haveriam atendimento por já estarem reservados para reuniões da Unidade. Naquelas em que isso não foi possível, os horários para os encontros eram os de menor movimento, contando com a colaboração de Assistentes Sociais e outros profissionais.

Inicialmente solicitou-se ao grupo que confirmasse se o esquema gráfico da área física refletia a realidade, e se os dados levantados, de caracterização da unidade, estavam corretos.

Em seguida, foi feita apresentação formal ao grupo dos elementos do processo de trabalho utilizando-se para isso um exercício de correlação proposto por SALUM et al (1996) que toma como referência o processo de produção de uma padaria.

Contando com a participação de todos, fez-se a descrição dos elementos do processo de trabalho em enfermagem, destacando o significado do objeto, dos meios e instrumentos e da organização, relacionando esses elementos com as condições favoráveis e com as condições desfavoráveis, exemplificadas pelas cargas fisicas, químicas, biológicas, mecânicas, fisiológicas e psíquicas .

permanecer no campo de prática com o aluno; no estágio curricular a supervisão é indireta sem a necessidade da permanência do docente no campo com o aluno. 
Tendo-se feito essa descrição do processo de produção de modo genérico e, especificamente, dos elementos do processo de trabalho em enfermagem, passava-se à construção do Mapa de Beneficios e de Riscos caminhando-se no esquema gráfico da área física onde eram apontadas pelo grupo as condições favoráveis e as condições desfavoráveis vividas em cada ambiente. Além disso, para cada condição desfavorável solicitava-se que o grupo apontasse uma proposta de solução.

Esta forma de construção possibilitou às equipes uma visão dc processo de trabalho e de sua relação com o processo saúde-doença, fazendo com que, ao repensar todo o processo, o grupo visualizasse o conjunto de propostas para a transformação das condições desfavoráveis, conforme recomenda SILVA (1996).

Os dados levantados nas enquetes coletivas quando da construção dos Mapas foram anotados pela pesquisadora que procedeu à sua sistematização e elaboração de um quadro sinóptico que foi entregue ao grupo em um terceiro encontro para validaçào (anexo 4). Neste terceiro encontro foram aplicados individualmente os formulários.

Nem todos os trabalhadores das unidades participaram da construção do Mapa e destes, nem todos responderam às perguntas do formulário, conforme mostra o quadro 2. O fato explica-se porque entre o segundo e o terceiro encontros ocorreram algumas mudanças na equipe, tais como troca de enfermeiros, contratação de enfermeiros e auxiliares, licença-saúde, férias, ou recusa em responder as questões (de dois auxiliares).

Quadro 2: Distribuição dos trabalhadores de enfermagem segundo UBS e participação nos encontros.

\begin{tabular}{|c|c|c|c|c|c|c|}
\hline \multirow{2}{*}{$\begin{array}{c}\text { Unidades Básicas de } \\
\text { Saúde } \\
\end{array}$} & \multicolumn{2}{|c|}{$\begin{array}{l}N .^{\circ} \text { de trab. da } \\
\text { equipe de enf. }\end{array}$} & \multicolumn{2}{|c|}{$\begin{array}{l}\text { N. de trab. no } \\
2^{\circ} \text { encontro }\end{array}$} & \multicolumn{2}{|c|}{$\begin{array}{l}\text { N. }{ }^{0} \text { de trab. no } \\
3^{\circ} \text { encontro }\end{array}$} \\
\hline & Enf. & Aux. & Enf. & Aux. & Enf. & Aux. \\
\hline FURTADO DE MENEZES & 1 & 3 & 1 & 3 & 1 & 2 \\
\hline JARDIM DA LUA & 1 & 2 & 1 & 1 & 1 & 1 \\
\hline JARDIM ESPERANÇA & 1 & 2 & 1 & 2 & 1 & 2 \\
\hline $\begin{array}{l}\text { NOSSA SENHORA DAS } \\
\text { GRAÇAS }\end{array}$ & 1 & 4 & 1 & 3 & 1 & 2 \\
\hline OLAVO COSTA & 1 & 2 & 1 & 2 & 1 & 3 \\
\hline RETIRO & 1 & 2 & 1 & 2 & 2 & 1 \\
\hline SANTA CECÍLIA & 1 & 1 & 1 & 1 & 1 & 2 \\
\hline SANTA CRUZ & 1 & 2 & 1 & 1 & 1 & 2 \\
\hline SANTA EFIGENIA & 1 & 2 & 1 & 1 & 3 & 1 \\
\hline SÃO BENEDITO & 1 & 2 & 1 & 2 & 1 & 2 \\
\hline SÃO JUDAS & 1 & 2 & 1 & 1 & 1 & 2 \\
\hline
\end{tabular}


A partir da descrição das condições desfavoráveis foi elaborada a classificação das cargas de trabalho, pela pesquisadora, tendo como referência LAURELL; NORIEGA (1989), FACCHINI (1994) e os elementos do processo de trabalho em enfermagem descritos por QUEIROZ; SALUM (1996). 
6 ANÁLISE E DISCUSSÃO DOS DADOS 


\subsection{Características gerais das Unidades Básicas de Saúde (UBSs)}

As Unidades Básicas de Saúde estudadas passaram e vêm passando por mudanças em sua estrutura e em seu funcionamento decorrentes algumas vezes de avaliações internas, em outras do contexto e das políticas de saúde. Para que se possa conhecer como estão estruturadas e organizadas as UBSs algumas características básicas estão descritas no quadro 3 .

Quadro 3: Descrição do número de familias e breve histórico das UBSs de Juiz de Fora. Juiz de Fora, 1999.

\begin{tabular}{|c|c|c|}
\hline UBS estudada & $\begin{array}{l}\text { Pop. Em } \\
\text { familias }\end{array}$ & Breve histórico \\
\hline $\begin{array}{c}\text { FURTADO DE } \\
\text { MENEZES }\end{array}$ & 1083 & $\begin{array}{l}\text { Construída na década de } 60 \text {, funcionou como } \\
\text { policlínica até agosto de } 1995 \text {, quando foi implantado } \\
\text { o PSF }\end{array}$ \\
\hline $\begin{array}{l}\text { JARDIM DA } \\
\text { LUA }\end{array}$ & 1000 & $\begin{array}{l}\text { Construída com verba do PSF há } 3 \text { anos, devido a um } \\
\text { movimento da comunidade. }\end{array}$ \\
\hline $\begin{array}{c}\text { JARDIM } \\
\text { ESPERANÇA }\end{array}$ & 700 & $\begin{array}{l}\text { Inaugurada em } 11 / 09 / 82 \text { devido a um movimento da } \\
\text { comunidade. O prédio atual era um Centro } \\
\text { Comunitário que foi reformado para ser uma UBS }\end{array}$ \\
\hline $\begin{array}{l}\text { NOSSA } \\
\text { SENHORA DAS } \\
\text { GRAÇAS }\end{array}$ & 5000 & $\begin{array}{l}\text { Construída em } 1988 \text { para ser uma policlínica, nunca } \\
\text { tendo funcionado como tal, não possui o PSF } \\
\text { implantado. }\end{array}$ \\
\hline OLAVO COSTA & 1363 & $\begin{array}{l}\text { Existe há mais de } 5 \text { anos, e era um centro } \\
\text { comunitário, tendo sido reformada há } 3 \text { anos. }\end{array}$ \\
\hline RETIRO & 1133 & $\begin{array}{l}\text { A Unidade foi construída com verba do Banco } \\
\text { Interamericano de Desenvolvimento (BIRD) tendo } \\
\text { sido inaugurada em } 12 / 11 / 82 \text {. Foi reformada e } \\
\text { reinaugurada em } 1 / 12 / 98\end{array}$ \\
\hline $\begin{array}{l}\text { SANTA } \\
\text { CECÍLIA }\end{array}$ & 1666 & $\begin{array}{l}\text { Existe desde } 1982 \text {, há } 2 \text { anos foi reformada, não } \\
\text { possui o PSF. }\end{array}$ \\
\hline SANTA CRUZ & 2500 & $\begin{array}{l}\text { Funcionava em um antigo centro espírita. Em } 1992 \text { foi } \\
\text { construído o prédio atual, que foi reformado há um } \\
\text { ano }\end{array}$ \\
\hline $\begin{array}{c}\text { SANTA } \\
\text { EFIGENIA }\end{array}$ & 1833 & $\begin{array}{l}\text { Existe há } 12 \text { anos. Funcionava em um antigo centro } \\
\text { social que foi reformado para ser uma UBS. O prédio } \\
\text { atual já foi reformado por } 3 \text { vezes. }\end{array}$ \\
\hline SÃO BENEDITO & 2500 & $\begin{array}{l}\text { O prédio atual foi construído há dois anos com verbas } \\
\text { do PSF }\end{array}$ \\
\hline SÃO JUDAS & 1333 & $\begin{array}{l}\text { Existe desde 1983. Foi reformada por reivindicação da } \\
\text { comunidade }\end{array}$ \\
\hline
\end{tabular}


A maioria das Unidades foram construídas a partir da década de 80 , os prédios das UBS São Benedito, Jardim da Lua e Santa Cruz são os mais recentes, tendo sido construídos para funcionarem como unidades de saúde com verba do PSF. Já as unidades Jardim Esperança, Olavo Costa e Santa Efigênia eram centros comunitários que foram reformados. Furtado de Menezes e Nossa Senhora das Graças foram construídas para funcionarem como policlínicas e as unidades Retiro, Santa Cecília, São Judas também já sofreram modificações tanto na estrutura fisica, como em seu funcionamento. De modo geral, todas as unidades, mesmo as mais recentes, sofreram alterações na estrutura fisica ou sofreram reformas, muitas até mais de uma vez, na tentativa de se recuperar e ou adequar o espaço fisico com as propostas de trabalho.

Quadro 4: Descrição da força de trabalho em saúde por UBS, Juiz de Fora, 1999.

\begin{tabular}{|l|c|c|c|c|c|c|}
\hline \multicolumn{1}{|c|}{ UBSs estudadas } & \multicolumn{6}{c|}{ Recursos Humanos * } \\
\hline FURTADO DE MENEZES & Med. & Enf. & Aux. E & A. Soc. & Dent. & V. \\
\hline JARDIM DA LUA & 2 & 1 & 3 & 1 & 2 & 1 \\
\hline JARDIM ESPERANÇA & 2 & 1 & 2 & 1 & 2 & 1 \\
\hline N. S. DAS GRAÇAS & 12 & 1 & 4 & 1 & 2 & 1 \\
\hline OLAVO COSTA & 3 & 1 & 2 & 1 & - & 1 \\
\hline RETIRO & 2 & 1 & 2 & 1 & 1 & 1 \\
\hline SANTA CECÍLIA & 5 & 1 & 1 & 1 & - & 1 \\
\hline SANTA CRUZ & 3 & 1 & 2 & 1 & 2 & 1 \\
\hline SANTA EFIGENIA & 5 & 1 & 2 & 1 & - & 1 \\
\hline SÃO BENEDITO & 3 & 1 & 2 & 1 & 1 & 1 \\
\hline SÃO JUDAS & 1 & 1 & 2 & 1 & & 1 \\
\hline
\end{tabular}

Dados obtidos no primeiro encontro com as unidades básicas sujeito a alterações;

Med. $=$ médico, Enf. $=$ enfermeiro, Aux.E $=$ auxiliar de enfermagem, $\mathrm{AS}=$ assistente social, Dent. $=$ dentista: $V=$ videofonista (que realiza marcação de consultas por telefone com niveis secundários de atenção à saúde)

Em relação ao número de familias atendidas as Unidades com maior área de abrangência são: Nossa Senhora das Graças, Santa Cruz e São Benedito. 
Todas as Unidades possuem na composição da equipe de trabalho Enfermeiros, Auxiliares de Enfermagem, Médicos, Assistentes Sociais e Videofonistas, em 06 unidades existe também o Dentista e o Serviço de Limpeza é terceirizado.

Entre as UBS estudadas, o Programa de Saúde da Família ainda não foi implantado na UBS Nossa Senhora das Graças e na UBS Santa Cecília. Em relação ao funcionamento apenas a UBS Nossa Senhora das Graças funciona em três períodos, de segunda a sexta-feira das 7 às $21 \mathrm{~h}$ (sem intervalo para almoço), e as demais unidades funcionam de segunda a sexta-feira das 7 às 11 e das 13 às $17 \mathrm{~h}$ (com intervalo para almoço). Nas unidades Jardim da Lua, Olavo Costa, Santa Cecília, Santa Efigênia e São Judas não há atendimento odontológico por não existirem espaço fisico e equipamentos necessários.

Todas as unidades são territorializadas, ou seja, possuem uma área e população delimitadas de atendimento, sendo que cada Unidade mantém uma especificidade que é determinada pelas necessidades da comunidade e pela forma particular dos profissionais organizarem os seus trabalhos.

Assim como no trabalho de ALMEIDA et al. (1997), foi possivel identificar no trabalho das UBSs um bloco de ações: recepção da clientela; consulta médica; grupos, desdobrando-se em outras atividades como coleta de exames laboratoriais, curativos, aplicação de tratamentos, imunização, visitas domiciliares e encaminhamentos a serviços de nível secundário.

Verificou-se ainda que, em todas as unidades, são realizadas: consultas médicas, com diferenças em relação ao número de consultas e a distribuição segundo demanda espontânea, urgências e rotina; grupos educativos, existindo também diferenças em relação aos tipos de grupo e temas abordados e ações de imunização, procedimentos de enfermagem e coleta de exames (Quadro 5).

Entretanto, de modo geral, as ações estão mais voltadas para o atendimento à criança e à mulher, uma vez que em todas as UBS é realizado o atendimento de puericultura e grupos para atenção ao desnutrido. Em relação à saúde da mulher, a ênfase vem sendo dada aos direitos reprodutivos, pré-natal e exame preventivo do câncer de colo de útero e de mama sendo que apenas 2 unidades possuem grupos de climatério. Como atuações diferenciadas, surgem os grupos de adolescentes (presente em apenas 01 UBS), de controle de peso (em 03 UBS) e de diabetes (em 04 UBS). 
Quadro 5: Ações realizadas nas UBS. Juiz de Fora, 1999.

\begin{tabular}{|c|c|}
\hline UBS & Açōes \\
\hline $\begin{array}{l}\text { FURTADO } \\
\text { DE } \\
\text { MENEZES }\end{array}$ & $\begin{array}{l}\text { São realizadas } 16 \text { consultas por período (8 para demanda espontânea, } 4 \\
\text { agendadas e } 4 \text { urgências); atendimentos de puericultura, pré-natal e } \\
\text { exame preventivo do câncer de colo de útero e mama; grupos de controle } \\
\text { de hipertensão, de peso, direitos reprodutivos, atenção ao desnutrido e } \\
\text { reuniões educativas com a pastoral e conselho de saúde; a Unidade } \\
\text { oferece ainda realização de curativos, imunização, coleta de exames, } \\
\text { aplicação de medicamentos, verificação de PA e nebulização }\end{array}$ \\
\hline $\begin{array}{l}\text { JARDIM } \\
\text { DA LUA }\end{array}$ & $\begin{array}{l}\text { São realizadas } 14 \text { consultas por período (6 agendadas, } 6 \text { para demanda } \\
\text { espontânea, e } 2 \text { para urgências); atendimento para prevenção do câncer } \\
\text { de colo de útero e de mama; pré-natal e puericultura; grupos de: atenção } \\
\text { ao desnutrido, adolescentes e direitos reprodutivos e são realizadas ações } \\
\text { de curativos, imunização, coleta de exames, aplicação de medicamentos, } \\
\text { verificação de PA e nebulização }\end{array}$ \\
\hline $\begin{array}{l}\text { RDIM } \\
\text { PERANÇA }\end{array}$ & $\begin{array}{l}\text { São realizadas } 16 \text { consultas por período; atendimentos de puericultura; } \\
\text { grupos de: atenção ao desnutrido, controle da hipertensão, direitos } \\
\text { reprodutivos e climatério e são realizadas ações de curativos, imunização, } \\
\text { coleta de exames, aplicação de medicamentos, verificação de PA, } \\
\text { nebulização e eletrocardiograma. Os dentistas desenvolvem um programa } \\
\text { de prevenção de cáries }\end{array}$ \\
\hline $\begin{array}{l}\text { NOSSA } \\
\text { SENHORA } \\
\text { DAS } \\
\text { GRAÇAS }\end{array}$ & $\begin{array}{l}\text { Existe um atendimento da demanda espontânea realizada pelos médicos } \\
\text { clínicos, os ginecologistas e pediatras atendem } 16 \text { consultas por período } \\
\text { ( } 2 \text { para urgências), são realizados atendimentos de Pré-natal, puericultura } \\
\text { e prevenção do câncer de colo de útero e de mama, grupos de Direitos } \\
\text { reprodutivos e de atenção ao desnutrido e são realizadas ações de } \\
\text { imunização, curativo, coleta de exames, aplicação de medicamentos, } \\
\text { verificação de PA e nebulização }\end{array}$ \\
\hline $\begin{array}{l}\text { OLAVO } \\
\text { COSTA }\end{array}$ & $\begin{array}{l}\text { São realizadas } 13 \text { consultas por período para o atendimento da demanda } \\
\text { espontânea; atendimento de pré-natal, puericultura, exame preventivo do } \\
\text { câncer de colo de útero e de mama; grupos de: direitos reprodutivos, } \\
\text { atenção ao desnutrido, controle de hipertensão, diabetes e são realizadas } \\
\text { ações de imunização, curativo, coleta de exames, aplicação de } \\
\text { medicamentos, verificação de PA e nebulização }\end{array}$ \\
\hline RETIRO & $\begin{array}{l}\text { São realizadas } 16 \text { consultas por período; atendimentos de puericultura, } \\
\text { pré-natal prevenção do câncer de colo de útero e de mama; existem os } \\
\text { grupos de: controle de hipertensão, direitos reprodutivos, gestantes, } \\
\text { atenção ao desnutrido e são realizadas ações de imunização, curativo, } \\
\text { coleta de exames, aplicação de medicamentos, verificação de PA e } \\
\text { nebulização }\end{array}$ \\
\hline $\begin{array}{l}\text { SANTA } \\
\text { CECÍLIA }\end{array}$ & $\begin{array}{l}\text { São realizadas } 16 \text { consultas por período (14 para demanda espontânea e } \\
2 \text { urgências); atendimentos de puericultura; grupos de: atenção aos } \\
\text { desnutridos, direitos reprodutivos e climatério e são realizadas ações de } \\
\text { imunização, curativo, coleta de exames, aplicação de medicamentos, } \\
\text { verificação de PA e nebulização }\end{array}$ \\
\hline
\end{tabular}




\begin{tabular}{|c|c|}
\hline $\begin{array}{l}\text { SAI } \\
\text { CRL }\end{array}$ & $\begin{array}{l}\text { São realizadas } 16 \text { consultas por período ( } 14 \text { para demanda espontânea e } 2 \\
\text { urgências); atendimentos puericultura, exame preventivo do câncer de } \\
\text { colo de útero e de mama; grupos de: atenção ao desnutrido, direitos } \\
\text { reprodutivos, controle de hipertensão e diabetes e são realizadas ações de } \\
\text { imunização, curativo, coleta de exames, aplicação de medicamentos, } \\
\text { verificação de PA e nebulização }\end{array}$ \\
\hline NIA & $\begin{array}{l}\text { São realizadas } 15 \text { consultas por período; atendimentos de puericultura, } \\
\text { prevenção do câncer de colo de útero e de mama; grupos de: atenção ao } \\
\text { desnutrido, direitos reprodutivos, controle de hipertensão, diabetes } € \\
\text { obesidade; e são realizadas as ações de imunização, curativos, coleta de } \\
\text { exames, aplicação de medicamentos, verificação de PA e nebulização }\end{array}$ \\
\hline $\begin{array}{l}\text { SÃO } \\
\text { BENEDITO }\end{array}$ & $\begin{array}{l}\text { São realizadas } 15 \text { consultas por período; visitas domiciliares com } \\
\text { agendamento prévio; atendimento de puericultura, pré-natal e exame } \\
\text { preventivo do câncer de colo de útero e de mama; grupos de: atenção aos } \\
\text { desnutridos, controle de hipertensão e diabetes, direitos reprodutivos e } \\
\text { são realizadas ações de imunização, curativos, coleta de material para } \\
\text { exames, aplicação de medicamentos, verificação de PA e nebulização }\end{array}$ \\
\hline $\begin{array}{l}\text { SÃO } \\
\text { JUDAS }\end{array}$ & $\begin{array}{l}\text { São realizadas } 16 \text { consultas por período ( } 12 \text { de demanda espontânea e } 4 \\
\text { urgências); visitas domiciliares; atendimento de puericultura, pré-natal e } \\
\text { prevenção do câncer de colo de útero e de mama; grupo de: controle de } \\
\text { hipertensão, de peso e atenção ao desnutrido e são realizadas ações de } \\
\text { imunização, curativos, coleta de material para exames, aplicação de } \\
\text { medicamentos, verificação de PA e nebulização }\end{array}$ \\
\hline
\end{tabular}

\subsection{Características Gerais dos trabalhadores de Enfermagem}

Conforme já dissemos anteriormente, nesta pesquisa foram estudadas 11 UBS com as quais a Faculdade de Enfermagem de Juiz de Fora possuía algum tipo de convênio, seja para o desenvolvimento de prática ou de estágio curricular

O número e a distribuição dos trabalhadores de enfermagem nestas unidades não foi o mesmo durante todo o processo de desenvolvimento da pesquisa, tendo se modificado no decorrer da mesma, devido a contratação de enfermeiros e auxiliares em algumas delas.

Entre o $1^{\circ}$ e o $3^{\circ}$ encontros foram contratados mais enfermeiros para as unidades Retiro e Santa Efigênia e mais auxiliares para as unidades Olavo Costa e Santa Cecilia.

No entanto, é importante ressaltar que mesmo com a contratação de profissionais da área, na maioria das unidades, uma das queixas da enfermagem, é a de falta de pessoal, o que pode ser visualizado, quando comparamos o número de auxiliares e de enfermeiros existentes com o número de auxiliares e enfermeiros que deveriam existir segundo a população em número de famílias atendida pela Unidade conforme preconiza o Programa de Saúde da Família (tabela 1). 
A predominância feminina torna a enfermagem sujeita a estereótipos comuns da vivência feminina na sociedade, assumindo-se atitudes de obediência, submissão e ausência de uma atitude questionadora (FONSECA, 1995; JONAS, 1995, PADILHA, et al., 1997).

Além disso faz com que se incorporem as dificuldades das mulheres trabalhadoras do Brasil, ou seja, desvalorização do trabalho, desigualdade salarial, segregação ocupacional, dupla jornada e discriminação (JONAS, 1995).

Para PADILHA (1995, p.255), "a prática da enfermagem não pode ser analisada de forma desvinculada da história de vida de cada enfermeiro(a). A menina que cresce submetida a um processo educacional diferencial entre homem e mulher, tendo interiorizado os papéis passivos que lhe impuseram, dificilmente deixará de repeti-los com comportamentos estereotipados na vida profissional representados por obediência, pouca politização, etc. Não queremos de forma alguma radicalizar essa idéia mas tampouco nos alienarmos a ela".

Quanto à faixa etária, os trabalhadores de enfermagem de modo geral são em sua maioria jovens, na faixa etária de 31 a 40 anos. No entanto, ao analisarmos as categorias separadamente, existem diferenças em relação a distribuição etária dos enfermeiros e dos auxiliares. Os enfermeiros se caracterizam por serem mais jovens, estando em sua totalidade na faixa de 20 a 40 anos (100\%). Os auxiliares, apesar de também estarem em sua maioria distribuídos na faixa etária de 20 a 40 anos (60\%), também se encontram na faixa de 41 a 60 anos (40\%), sendo que a faixa de 41 a 50 representa o segundo contingente etário mais expressivo (25\%), conforme mostra a tabela 2 .

Tabela 2: Distribuição da força de trabalho em Enfermagem nas UBS, segundo faixa etária. Juiz de Fora, 1999.

\begin{tabular}{|c|c|c|c|c|}
\hline FAIXA ETÁRIA & \multicolumn{2}{|c|}{$\mathrm{N}^{\circ}$ de enfermeiros $/ \%$} & \multicolumn{2}{|c|}{$\mathrm{N}^{\circ}$ de auxiliares $/ \%$} \\
\hline 20 a 30 & 4 & 28,6 & 3 & 15 \\
\hline 31 a 40 & 10 & 71,4 & 9 & 45 \\
\hline 41 a 50 & & & 5 & 25 \\
\hline 51 a 60 & & & 3 & 15 \\
\hline TOTAL & 14 & 100,0 & 20 & 100 \\
\hline
\end{tabular}

No que diz respeito ao estado civil, a maioria dos enfermeiros e $40 \%$ dos auxiliares são casados sendo que $78,6 \%$ dos enfermeiros e $55 \%$ dos auxiliares possuem filhos, o que acarreta frequentemente uma dupla jornada de trabalho vivida pelas mulheres, pois além do trabalho remunerado, é realizado também o trabalho doméstico de cuidado com a casa, os filhos e o companheiro ou marido. 
Tabela 3: Distribuição da força de trabalho em Enfermagem nas UBS, segundo estado civil. Juiz de Fora, 1999.

\begin{tabular}{|c|c|c|c|c|}
\hline Estado civil & \multicolumn{2}{|c|}{$\mathrm{N}^{\circ}$ de enfermeiros/ $\%$} & \multicolumn{2}{|c|}{$\mathrm{N}^{\circ}$ de auxiliares $/ \%$} \\
\hline Solteiro & 3 & 21,4 & 10 & 50 \\
\hline $\begin{array}{c}\text { Casado } \\
\text { Viúvo }\end{array}$ & 8 & 57,2 & 8 & 40 \\
\hline Separado & & & 1 & 5 \\
\hline Divorciado & 1 & 7,2 & 1 & 5 \\
\hline União livre & 1 & 7,2 & & \\
\hline Total & 14 & 100,0 & 20 & 100 \\
\hline
\end{tabular}

Tabela 4: Distribuição da força de trabalho em enfermagem nas UBS, segundo número de filhos. Juiz de Fora, 1999.

\begin{tabular}{|c|c|c|c|c|}
\hline $\mathrm{N}^{\circ}$ de filhos & \multicolumn{2}{|c|}{$\mathrm{N}^{\circ}$ de enfermeiros $/ \%$} & \multicolumn{2}{|c|}{$\mathrm{N}^{\circ}$ de auxiliares/\% } \\
\hline 0 & 3 & 21,4 & 9 & 45 \\
\hline 1 & 2 & 14,3 & 2 & 10 \\
\hline 2 & 3 & 42,9 & 3 & 15 \\
\hline 3 & 3 & 21,4 & 5 & 25 \\
\hline 4 & & & & \\
\hline 5 & & & 1 & 5 \\
\hline Total & 14 & 100 & 20 & 100 \\
\hline
\end{tabular}

Apesar de jovens, os enfermeiros em sua maioria possuem mais de 10 anos de formação, ocorrendo o mesmo entre os auxiliares, sendo que dois deles já estão formados há mais de 30 anos conforme pode ser verificado através da tabela 5 .

Tabela 5: Distribuição da força de trabalho em enfermagem nas UBS, segundo tempo de formação. Juiz de Fora, 1999.

\begin{tabular}{ccccc}
\hline Anos de formado & \multicolumn{2}{c}{$\mathrm{N}^{\circ}$ de enfermeiros $\%$} & \multicolumn{2}{c}{$\mathrm{N}^{\circ}$ de auxiliares $/ \%$} \\
\hline 1 a 5 & 3 & 21,4 & 1 & 5 \\
6 a 10 & 3 & 21,4 & 7 & 35 \\
11 a 15 & 7 & 50,0 & 3 & 15 \\
16 a 20 & 1 & 7,2 & 4 & 20 \\
21 a 25 & & - & 3 & 15 \\
26 a 30 & & & 2 & 10 \\
Total & 14 & 100,0 & 20 & 100 \\
\hline
\end{tabular}


Apesar do tempo de formação, mais da metade $(57,2 \%)$ dos enfermeiros não freqüentaram cursos de especialização. Entre os que se especializaram, a maioria o fez em Saúde da Família (28,6\%), programa instituído no Município de Juiz de Fora há apenas 4 anos (JUIZ DE FORA, 1996).

Os motivos apontados para a falta de especialização foram: falta de oportunidade $(16,7 \%)$; não quer fazer $(33,3 \%)$ e não atuava como enfermeiro $(16,7 \%)$ sendo que $33,3 \%$ não responderam.

O fato de a maioria dos enfermeiros possuírem mais de 10 anos de formação, aliado à falta de especialização, pode estar dificultando a atuação desse profissional, gerando ansiedade.

Isso ocorre uma vez que a proposta de modelo assistencial do SUS preconiza ações de atenção à saúde coletiva, privilegiando a promoção e prevenção. No entanto, muitos desses profissionais podem ter sido formados com currículos baseados no modelo biomédico, ou seja que privilegiavam as ações individuais e curativas, de complementariedade ao ato médico, com um ensino fragmentado e dicotomizado em relação a teoria $X$ prática e ao saber $X$ fazer, aliando-se a esse fato a ausência de educação continuada nos serviços, o mesmo ocorrendo em relação aos auxiliares de enfermagem, uma vez que a formação desses trabalhadores também é pautada no modelo biomédico (ALMEIDA; ROCHA, 1989; SALUM et al., 1996; FARAH, 1999).

\subsection{Reprodução Social dos Trabalhadores de Enfermagem nas UBS - dados gerais}

Para descrevermos a reprodução social dos trabalhadores de enfermagem das UBS optamos por trabalhar com as seguintes dimensões: renda, uso do espaço e agregação social.

Em relação a renda os dados foram obtidos perguntando-se através da aplicação do formulário qual a renda mensal da família, faixa total de bruto do último mês, e destinação do salário para o orçamento familiar.

A renda, o salário de um trabalhador, tem um papel relevante na reprodução da força de trabalho, pois teoricamente ele deveria ser o suficiente para que o trabalhador consiga manter-se vivo e deste modo continue vendendo sua força de trabalho (CATANI, 1984).

Ao analisarmos os dados obtidos em relação a renda familiar, existe uma diferença significativa entre enfermeiros e auxiliares. Para a maioria dos enfermeiros a renda familiar esta acima de 11 salários mínimos, enquanto que para a maioria dos auxiliares a renda familiar é de no máximo 11 salários mínimos. 
Tabela 6: Distribuição da força de trabalho em enfermagem nas UBS, segundo renda familiar. Juiz de Fora, 1999.

\begin{tabular}{lcccc}
\hline Renda familiar salários mínimos & $\mathrm{N}^{\circ}$ de enfermeiros /\% & $\mathrm{N}^{\circ}$ de auxiliares $/ \%$ \\
\hline Menos de 4 & 2 & 14,3 & 10 & 50 \\
$4-7,3$ & & & 3 & 15 \\
$7,3 \mathrm{I}-11$ & 3 & 21,4 & \multicolumn{2}{c}{10} \\
$11 \mathrm{I}-14,7$ & 4 & 28,6 & 2 & 10 \\
$14,7 \mathrm{I}-18,4$ & 5 & 35,7 & \multicolumn{2}{c}{100} \\
Mais de 18,4 & 14 & 100 & 20 & 100 \\
Total & & &
\end{tabular}

Verifica-se ainda que, enquanto $35,7 \%$ dos enfermeiros possuem uma renda familiar de mais de 18,4 salários mínimos, apenas $10 \%$ dos auxiliares possuem uma renda familiar de mais de 14,7 salários mínimos, podendo chegar até no máximo a 18,4 salários.

No que diz respeito à renda bruta, 7,2\% dos enfermeiros ganham até 18,4 salários mínimos, $35,7 \%$ - 7,3 salários mínimos e $57,2 \%$ - 11 salários mínimos. Em relação aos auxiliares, $80 \%$ ganham até 3,7 salários mínimos e $20 \%$ até 7,3 salários mínimos.

Tabela 7 : Distribuição da força de trabalho em enfermagem nas UBS, segundo faixa salarial. Juiz de Fora, 1999.

\begin{tabular}{|c|c|c|c|c|}
\hline Faixa salarial em salários mínimos & \multicolumn{2}{|c|}{$N^{\circ}$ de enfermeiros $/ \%$} & \multicolumn{2}{|c|}{$\mathrm{N}^{\circ}$ de auxiliares $/ \%$} \\
\hline Menos de 4 & & - & 16 & 80 \\
\hline $4-7,3$ & 5 & 35,7 & 4 & 20 \\
\hline $7,3 \mathrm{I}-11$ & 8 & 57,2 & & \\
\hline $11 \mathrm{I}-14,7$ & & - & & \\
\hline $14,7 \mathrm{I}-18,4$ & 1 & 7,2 & & - \\
\hline Total & 14 & 100,0 & 20 & 00 \\
\hline
\end{tabular}

A participação do salário de cada trabalhador na composição da renda familiar é semelhante pois a maioria dos enfermeiros $(78,6 \%)$ e a maioria dos auxiliares $(75 \%)$ contribuem com mais de $50 \%$ do salário para a renda familiar, sendo que apenas $21,4 \%$ dos enfermeiros e $20 \%$ dos auxiliares contribuem com menos da metade do salário, e apenas $5 \%$ dos auxiliares não contribui com a renda familiar. 
Tabela 8 : Distribuição da força de trabalho em enfermagem das UBS, segundo destinação do salário para a família. Juiz de Fora, 1999.

\begin{tabular}{lcccc}
\hline Destinação do salário & \multicolumn{2}{c}{$\mathrm{N}^{\circ}$ de enfermeiros $\%$} & \multicolumn{2}{c}{$\mathrm{N}^{\circ}$ de auxiliares $/ \%$} \\
\hline Total & 5 & 35,7 & 7 & 35 \\
$<50 \%$ & 3 & 21,4 & 4 & 20 \\
$50 \%$ & 3 & 21,4 & 2 & 10 \\
$>50 \%$ & 3 & 21,4 & 6 & 30 \\
Nada & \multicolumn{2}{c}{-} & 1 & 5 \\
Total & 20 & 100 & 20 & 100 \\
\hline
\end{tabular}

A análise das tabelas mostra que o salário bruto dos enfermeiros é, na maioria das vezes, o dobro do salário dos auxiliares assim como a renda familiar.

Se considerarmos que as famílias dos enfermeiros e dos auxiliares são constituidas em sua maioria por no máximo 6 pessoas, podemos concluir que a renda per capita das familias dos enfermeiros é de 3 salários mínimos enquanto para os auxiliares é de 1,2 salários mínimos, aproximadamente.

A diferenciação salarial é um elemento importante na divisão social do trabalho de enfermagem, pois segundo MELO (1986) "a origem de classe diferente, aliada à diferenciação de salários e ao papel desempenhado pela enfermeira, como gerenciador, quase sempre autoritário, dos interesses das instituições ou dos patrões para quem trabalha, é a explicação para a permanente disputa e conflito entre enfermeiras e categorias auxiliares. Esta questão vem sempre sendo identificada como problemas de ordem pessoal e não como conflito entre classes sociais diferentes, que defendem interesses distintos".

Ainda a este respeito FONSECA (1995) afirma que "a ocupação das categorias funcionais de enfermagem encontra-se na relação direta da inserção de classe dos seus agentes sociais. Assim, enquanto atendentes, auxiliares e técnicos de enfermagem pertencem ao proletariado, a enfermeira advém de classes superiores, geralmente da burguesia e suas frações".

Quanto ao beneficio oferecido pelo trabalho, apenas foi relatado o recebimento de vale transporte, sendo que entre os auxiliares $80 \%$ referiu-se a receber esse beneficio e entre o enfermeiros $64,3 \%$.

Em relação ao número de horas trabalhadas, não existem diferenças significativas uma vez que tanto enfermeiros como auxiliares em sua maioria trabalham 08 horas diárias, apesar disso é importante ressaltar que mais de $20 \%$ tanto de enfermeiros como de auxiliares trabalham mais de 08 horas diárias, o que significa que, para poderem estar complementando a renda familiar, estes trabalhadores possuem um segundo emprego, sendo que 35,7\% dos enfermeiros e $30 \%$ dos auxiliares referiram possuir um segundo trabalho. 
$\mathrm{Na}$ medida em que o trabalhador dedica mais de 08 horas diárias ao processo de produção, ele pouco ou nada se dedica à família, aos amigos, ao lazer, aos movimentos sociais, ao descanso e ao ócio, o que pode estar dificultando a recuperação da força de trabalho, e consequentemente imprimindo um maior desgaste

Tabela 9 : Distribuição da força de trabalho em enfermagem nas UBS; segundo $n^{0}$ de horas diárias trabalhadas. Juiz de Fora, 1999.

\begin{tabular}{|c|c|c|c|c|}
\hline $\mathrm{N}^{\circ}$ de horas diárias & \multicolumn{2}{|c|}{$\mathrm{N}^{\circ}$ de enfermeiros $/ \%$} & \multicolumn{2}{|c|}{$\mathrm{N}^{\circ}$ de auxiliares/ $\%$} \\
\hline Menos de 8 horas & & & 2 & 10 \\
\hline 8 horas & 11 & 78,6 & 13 & 65 \\
\hline Mais de 8 horas & 3 & 21,4 & 5 & 25 \\
\hline Total & 14 & 100 & 20 & 100 \\
\hline
\end{tabular}

Uma vez que a renda apenas não é suficiente para caracterizar a reprodução social dos trabalhadores, pois segundo um estudo da FUNDAÇÃO SEADE (1992) "a renda, inegavelmente, constituí uma boa medida sintética da possibilidade de satisfazer, em uma economia de mercado, os requisitos básicos à sobrevivência. No entanto, ainda que seja um fator limitante do consumo, esta também é influenciada pelos gastos com transporte, pela estabilidade do emprego, pela diversidade e natureza dos bens que integram o patrimônio familiar, etc." , para estudarmos o uso do espaço social, selecionamos também as categorias propriedade da habitação, tempo de moradia em Juiz de Fora, número de cômodos do domicilio (quartos, salas, cozinha, banheiros) e número de pessoas que compartilham da mesma residência.

Em relação ao tempo de moradia, $71,4 \%$ dos enfermeiros e $75 \%$ dos auxiliares residem em Juiz de Fora há mais de 10 anos conforme mostra a tabela 10.

Como já foi discutido anteriormente, Juiz de Fora possui boas condições de saneamento básico, de saúde e de emprego, sendo considerada uma Cidade que apresenta boas condições de vida, o que contribui para a fixação e permanência da população na Cidade (UFJF, 1998; FARAH, 1999).

Tabela 10: Distribuição da força de trabalho em enfermagem nas UBS, segundo tempo de moradia no Município. Juiz de Fora, 1999.

\begin{tabular}{lcrrr}
\hline \multicolumn{1}{c}{$\mathrm{N}^{\circ}$ de anos } & $\mathrm{N}^{\circ}$ de enfermeiros $\%$ & \multicolumn{2}{c}{$\mathrm{N}^{\circ}$ de auxiliares $/ \%$} \\
\hline Menos de um ano & \multicolumn{4}{c}{$\mathrm{l}$} \\
1 a 3 anos & 1 & 7,2 & \multicolumn{1}{c}{5} \\
4 a 6 anos & 1 & 7,2 & 2 & 10 \\
7 a 9 anos & 1 & 7,2 & 2 & 10 \\
Mais de 10 anos & 10 & 71,4 & 15 & 75 \\
Total & $13^{*}$ & 93,0 & 20 & 100 \\
\hline
\end{tabular}

* um dos enfermeiros não mora em Juiz de Fora 
Quanto à propriedade da habitação, 85,7\% dos enfermeiros e 65\% dos auxiliares possuem a residência que habitam, conforme mostra a tabela 11 .

Tabela 11: Distribuição da força de trabalho em enfermagem nas UBS, segundo propriedade da moradia, Juiz de Fora, 1999.

\begin{tabular}{lcccc}
\hline Condição de propriedade & \multicolumn{2}{c}{$\mathrm{N}^{\circ}$ de enfermeiros / \% } & \multicolumn{2}{c}{$\mathrm{N}^{\circ}$ de auxiliares $/ \%$} \\
\hline Própria & 12 & 85,7 & 13 & 65 \\
Alugada & 2 & 14,3 & 7 & 35 \\
Total & 14 & 100 & 20 & 100 \\
\hline
\end{tabular}

Ser proprietário de sua habitação coloca tanto enfermeiros como auxiliares em uma condição social diferenciada em contraposição às familias que necessitam lançar mão de aluguéis, empréstimos e invasões, para resolver seus problemas de moradia.

Consideramos importante ressaltar ainda que, mesmo apresentando, comparativamente com os enfermeiros, um ganho mensal individual e familiar menor, os auxiliares conseguiram adquirir sua casa própria.

Para termos uma idéia da condição de moradia utilizamos como parâmetro, o número total de cômodos das residências (incluindo-se banheiros, cozinhas e salas) e o número de pessoas que habitam as residências como mostram as tabelas 12 e 13 abaixo.

Tabela 12 : Distribuição da força de trabalho em enfermagem nas UBS, segundo número de cômodos do domicílio. Juiz de Fora, 1999.

\begin{tabular}{|c|c|c|c|c|}
\hline $\mathrm{N}^{\circ}$ de cômodos & \multicolumn{2}{|c|}{$\mathrm{N}^{\circ}$ de enfermeiros $/ \%$} & \multicolumn{2}{|c|}{ N. ${ }^{\circ}$ de auxiliares $/ \%$} \\
\hline 1 a 2 & & & & \\
\hline 3 a 4 & & & & \\
\hline 5 a 6 & 5 & 35,7 & 8 & 40 \\
\hline 7 ou mais & 9 & 64,3 & 12 & 60 \\
\hline Total & 14 & 100,0 & 20 & 100 \\
\hline
\end{tabular}

Tabela 13: Distribuição da força de trabalho em enfermagem das UBS, segundo número de habitantes no mesmo domicílio. Juiz de Fora, 1999.

\begin{tabular}{|c|c|c|c|c|}
\hline $\mathrm{N}^{\circ}$ de pessoas & \multicolumn{2}{|c|}{ N. ${ }^{\circ}$ de enfermeiros $/ \%$} & \multicolumn{2}{|c|}{ N. ${ }^{\circ}$ de auxiliares/ \% } \\
\hline Mora sozinho & 2 & 14,3 & 2 & 10 \\
\hline l a 3 & 5 & 35,7 & 9 & 45 \\
\hline 4 a 6 & 7 & 50 & 8 & 40 \\
\hline 7 a 9 & & & & \\
\hline Mais de 10 pessoas & & & 1 & 5 \\
\hline Total & 14 & 100 & 20 & 100 \\
\hline
\end{tabular}


Os dados destas tabelas nos mostram que tanto enfermeiros como auxiliares apresentam uma condição de moradia favorável, residindo em casas amplas com mais de 5 cômodos, sendo que a maioria é ocupada com no máximo 6 pessoas.

Para estudarmos a agregação social, identificamos as atividades de recreação e a participação em grupo/associação conforme as tabelas 14 e 15 abaixo.

Em relação à organização grupal, este indicador juntamente com as outras variáveis, pode sinalizar as condições genéricas de reprodução social da sociedade por traduzirem, na sua sintese, as repercussões que o projeto neoliberal pode desencadear na vida social, através da desagregação das estruturas de representação coletiva (QUEIROZ; SALUM, 1996 )

Tabela 14: Distribuição da força de trabalho em enfermagem nas UBS, segundo participação em atividades de recreação. Juiz de Fora, 1999.

\begin{tabular}{|c|c|c|c|c|}
\hline Atividade & \multicolumn{2}{|c|}{$\mathrm{N}^{\circ}$ de enfermeiros $/ \%$} & \multicolumn{2}{|c|}{ N. ${ }^{\circ}$ de auxiliares $/ \%$} \\
\hline Atividade fisica & 6 & 42,9 & 5 & 25,0 \\
\hline $\begin{array}{l}\text { Atividade cultural (cinema, teatro, } \\
\text { concertos) }\end{array}$ & 10 & 71,4 & 9 & 45,0 \\
\hline Leitura & 11 & 78,6 & 19 & 95,0 \\
\hline Assistir televisão & 11 & 78,6 & 19 & 95,0 \\
\hline Turismo(viagens, passeios) & 11 & 78,6 & 19 & 95,0 \\
\hline Outras & & & $2^{*}$ & 10,0 \\
\hline
\end{tabular}

* cantar em coral

Entre as atividades de lazer, as mais citadas foram: assistir televisão, ler e praticar turismo.

A televisão, segundo GOLDENSTEIN (1991), é o veículo de informação mais utilizado em todas as camadas sociais. Já em relação ao hábito da leitura, é importante ponderar que este é um hábito valorizado socialmente, o que pode levar a um viés nas declarações. Chama ainda atenção a menção às atividades de passeios e viagens, o que talvez se explique pela característica do trabalho de enfermagem, que ainda é restrito ao espaço da unidade básica de saúde e que, conforme referência dos trabalhadores de enfermagem, usualmente é um local pouco iluminado e ventilado, fazendo com que ao sair dele os trabalhadores tenham necessidade de realizar atividades fora dos limites de sua residência.

As atividades fisicas são as menos citadas tanto pelos enfermeiros como pelos auxiliares, o que talvez se explique pelo fato de os trabalhadores serem em sua maioria, mulheres com familias que, nos momentos de lazer necessitam de atividades que permitam a participação de filhos e companheiros, como por exemplo nos passeios e viagens. Outro fator, que pode contribuir para a pequena freqüência dessa atividade, diz respeito ao sentimento de obrigatoriedade das práticas esportivas e de exercícios fisicos para a manutenção da saúde fisica e mental, perdendo assim o caráter de lazer. 
As atividades culturais (cinema, teatro, concertos) estão mais presentes entre os enfermeiros, o que vêm demonstrar uma diferença social entre as duas categorias de trabalhadores.

Em relação à participação em atividades associativas, verificou-se que a maioria dos trabalhadores não participa de nenhum grupo ou associação, o que pode limitar o poder de pressão na luta por melhores condições de vida e de trabalho. Sobre esta questão, a enfermagem historicamente se caracteriza pela "pouca participação nos movimentos de classe e com a classe, sejam eles políticos ou culturais", o que em parte se explica pelo espírito de abnegação, doação, submissão e sujeição da profissão aos demais profissionais, principalmente ao médico (PADILHA, 1995).

Tabela 15: Distribuição da força de trabalho em enfermagem nas UBS, segundo participação em grupo/associações. Juiz de Fora, 1999.

\begin{tabular}{lcccc}
\hline \multicolumn{1}{c}{ Tipo } & $\mathrm{N}^{\circ}$ de enfermeiros/ $\%$ & $\mathrm{~N}^{\circ}$ de auxiliares/\% \\
\hline Relacionado ao trabalho & 2 & 14,2 & 2 & 10 \\
Relacionado a igreja & 3 & 21,4 & 5 & 25 \\
Não participa & 10 & 71,4 & 13 & 65 \\
Total & 14 & 100 & 20 & 100 \\
\hline
\end{tabular}

Pelo fato de ser uma profissão eminentemente de mulheres, conforme já afirmamos anteriormente, a enfermagem na prática profissional assume atitudes de obediência, submissão e ausência de atitude questionadora e científica. Por outro lado a enfermeira domina e submete os demais membros da equipe de enfermagem, assim como os pacientes (PADILHA, et al. 1997).

A este respeito ainda, PADILHA et al. (1997) observam que “o silêncio é uma marca distintiva da enfermeira no imaginário social, que frequentemente é representada pelo gesto que o simboliza com o dedo indicador sobre a boca, solicitando silêncio, em cartazes divulgados há décadas(...). Este pode ser discutido de duas formas: o silêncio pela omissão (submissão) e acato às ordens médicas, como também, o silêncio que domina pelas ações e não pelas palavras. É o poder silencioso, porém decisivo."

Por outro lado a falta de participação em grupos ou associações pode se dar também como uma conseqüência da carga de trabalho diária $(8$ horas diárias para a maioria), conforme já foi mostrado na tabela 15 , e do fato de a maioria dos trabalhadores serem mulheres que possuem a responsabilidade com a casa e a familia. 
Verifica-se que, em relação ao processo de reprodução social, as condições de vida de enfermeiros e auxiliares são diferenciadas em decorrência do desnivel salarial entre as categorias e da falta de acesso às atividades culturais pelos auxiliares. Por outro lado existe uma aproximação quando se analisam as demais atividades de lazer e as condições de habitação.

\subsection{As atividades realizadas no trabalho de enfermagem nas UBS}

O trabalho de enfermagem, conforme já dissemos anteriormente, deve ser compreendido como uma prática que está inserida em um contexto maior, que é o processo de produção capitalista e que é complementar e interdependente do processo de produção na saúde, guardando uma certa especificidade e uma autonomia relativa na relação com as demais profissões, principalmente as da saúde (ALMEIDA, et al. 1989).

Uma vez que a enfermagem compõe parcela do trabalho coletivo de saúde, seu objeto e sua finalidade são os mesmos do processo de produção de serviços de saúde, ou seja o aperfeiçoamento dos perfís epidemiológicos enquanto grupos sociais homogêneos e indivíduos/famílias. Ela desenvolve sua especificidade nos processos de trabalho assistência, gerenciamento, investigação e ensino do processo de produção, que articulam as diferentes práticas profissionais (QUEIROZ; SALUM, 1996).

É um trabalho que se estrutura pautado em uma distribuição de tarefas, procedimentos e responsabilidades por diferentes categorias, com formação escolar diversificada, permeada por determinações econômicas, políticas e ideológicas, que caracterizam uma divisão do trabalho que não é apenas técnica mas também social ALMEIDA; ROCHA, 1989; MELO, 1986).

Em relação à atuação dos enfermeiros de UBSs de Juiz de Fora, FARAH (1999) afirma que estes desenvolvem principalmente atividades de natureza administrativa, sendo que as ações de natureza propedêutica e terapêutica são complementares ao ato médico e de outros profissionais.

A prática profissional do enfermeiro, principalmente a partir da década de 80 , tem sido objeto de discussões e questionamentos a respeito do que é assistência e o que é gerenciamento/administração na enfermagem (SILVA et al., 1993). 
A falta de compreensão sobre a interrelação que existe entre a função assistencial e a função administrativa tem gerado certa polemica nos meios acadèmicos, sendo comum a referencia à função administrativa como uma das causas do afastamento do profissional da assistência ao paciente, ou como sendo restrita, unicamente, à realização de atividades burocráticas (VICENTIM, et al. S/d).

Quando optamos por utilizar a decomposição das atividades em assistência, gerência, ensino e investigação, o fizemos como um recurso, mas compreendemos que a participação do enfermeiro nos processos de trabalho assistencial, gerencial, de ensino e pesquisa se dá de forma articulada compondo o processo de produção em saúde.

Pois segundo VICENTIM (s/d.) "A Administração da Assistência de Enfermagem é uma forma de organização do trabalho do enfermeiro adequado à realidade, não dicotômica, onde o administrar é subsídio para o assistir", ocorrendo o mesmo em relação ao ensino e à pesquisa.

\subsubsection{O processo de trabalho de Assistência à saúde}

Em relação à participação da enfermagem no processo de trabalho de assistência à saúde, QUEIROZ; SALUM (1996, p. 205) afirmam que "os instrumentos de trabalho é que dão a especificidade da enfermagem, dentre eles os saber e a tecnologia de enfermagem construídos sobre o modelo clínico e o modelo epidemiológico, mas revisitados de modo a fundamentar o 'cuidar' do coletivo, dos grupos sociais e dos individuos famílias durante seu processo social e biológico de existência. $\mathrm{O}$ trabalho em si se caracteriza principalmente pela presença constante da enfermagem junto ao objeto, acompanhando (diretamente ou à distância) o objeto mesmo no 'cuidar' das outras práticas de saúde".

Quanto às atividades relacionadas ao processo de trabalho de assistência, conforme mostra a tabela 16, a maioria dos enfermeiros realiza orientações ao indivíduo, familia e comunidade, visando à educação para a saúde; consulta e prescrição de enfermagem, assim como cuidados de enfermagem de maior complexidade técnica, ou outros relacionados à assistência à gestante e puérpera, à criança e ao adolescente, bem como a prevenção e controle sistemático de danos que podem ser causados à clientela durante a assistência de enfermagem, infecção e doenças transmissíveis. 
Tabela 16: Distribuição dos Enfermeiros das UBS, segundo atividades relacionadas ao Processo de Trabalho de Assistência. Juiz de Fora, 1999.

\begin{tabular}{lrr}
\hline \multicolumn{1}{c}{ Atividades } & \multicolumn{2}{c}{$\begin{array}{c}\text { N. }{ }^{\circ} \text { de } \\
\text { enfermeiros/\% }\end{array}$} \\
\hline $\begin{array}{l}\text { Desenvolve orientações ao individuo, familia e comunidade, } \\
\text { visando a educação para a saúde; }\end{array}$ & 13 & 92,8 \\
Consulta de enfermagem & 11 & 78,6 \\
Cuidados de enfermagem de maior complexidade técnica que & 11 & 78,6 \\
exigem conhecimentos de base científica e capacidade de tomar & & \\
decisões imediatas & 11 & 78,6 \\
Assistência de enfermagem à criança & 10 & 71,4 \\
Prescrição de enfermagem & 10 & 71,4 \\
Assistência de enfermagem à mulher, gestante e puérpera & 9 & 64,3 \\
Prevenção e controle sistemático de danos que possam ser & & \\
causados à clientela durante a assistência de enfermagem. & 8 & 57,2 \\
Prevenção e controle sistemático da infeç̧ão e das doenças & & \\
transmissíveis; & 7 & 50,0 \\
Assistência de enfermagem ao adolescente & 6 & 42,9 \\
Assistência de enfermagem ao idoso & 5 & 35,7 \\
Assistência de enfermagem ao trabalhador & 3 & 21,4 \\
Outra atividade (técnicas básicas de enfermagem; supervisão da & 3 & \\
equipe de enfermagem e grupo de controle de peso) & & \\
\hline
\end{tabular}

A assistência ao adolescente é realizada por $50 \%$ dos enfermeiros, ao trabalhador por apenas 35,7 e aos idosos por $42,9 \%$ dos enfermeiros, o que nos leva a concluir que ou estes grupos não constituem prioridade na assistência ou eles estão sendo atendidos em níveis mais centrais e especializados.

No que diz respeito às atividades de assistência, de competência dos auxiliares, a descrição de tarefas e procedimentos realizados pelos auxiliares vem mais uma vez demonstrar a tendência do atendimento da UBS para a atenção à saúde da mulher e da criança, aparecendo também a visita domiciliar e a identificação de familias de risco como um sinal da busca de uma atenção voltada ao coletivo, desvelando uma tentativa de reversão do modelo clínico para o epidemiológico, conforme mostra a tabela 17 . 
Tabela 17: Distribuição dos Auxiliares de Enfermagem das UBS, segundo atividades relacionadas ao Processo de Trabalho de Assistência. Juiz de Fora, 1999.

\begin{tabular}{|c|c|c|}
\hline Atividades & $\mathrm{N}^{\circ} \mathrm{de}$ & iliares \\
\hline Observa e reconhece sinais e sintomas & 19 & 95 \\
\hline $\begin{array}{l}\text { Participa da discussão e organização } \\
\text { do processo de trabalho da unidade de saúde }\end{array}$ & 19 & 95 \\
\hline Faz visitas domiciliares & 18 & 90 \\
\hline Presta cuidados de higiene e conforto ao paciente & 17 & 75 \\
\hline Executa ações de tratamento simples & 15 & 65 \\
\hline Executa procedimentos na área de atenção à criança & 15 & 65 \\
\hline $\begin{array}{l}\text { Executa procedimentos de vigilância sanitária e epidemiológica no } \\
\text { controle } \\
\text { de doenças infecto-contagiosas }\end{array}$ & 15 & 65 \\
\hline Identifica as familias de risco & 12 & 60 \\
\hline Executa procedimentos na área de atenção à mulher & 14 & 60 \\
\hline Executa procedimentos na área de atenção ao idoso & 10 & 50 \\
\hline Descreve sinais e sintomas & 8 & 40 \\
\hline $\begin{array}{l}\text { Executa procedimentos de vigilância sanitária e epidemiológica no } \\
\text { controle de doenças crônico degenerativas }\end{array}$ & 6 & 30 \\
\hline Executa procedimentos na área de atenção ao adolescente & 5 & 25 \\
\hline Executa procedimentos na área de atenção ao trabalhador & 5 & 25 \\
\hline $\begin{array}{l}\text { Executa procedimentos de vigilância sanitária e epidemiológica no } \\
\text { controle da tuberculose }\end{array}$ & 2 & 10 \\
\hline Outra atividade (orienta sinais e sintomas) & 1 & 5 \\
\hline $\begin{array}{l}\text { Executa procedimentos de vigilância sanitária e epidemiológica no } \\
\text { controle da hanseníase }\end{array}$ & & \\
\hline
\end{tabular}

No entanto, tem ficado para o nível mais especializado a atenção para doenças como tuberculose, hanseníase e saúde do trabalhador, em relação por exemplo ao controle da hipertensão arterial como uma doença crônico-degenerativa, uma vez que existem grupos de hipertensos em 7 unidades.

Em relação à participação dos auxiliares nessas atividades, estes parecem que ou não atuam ou não percebem a sua participação nessa ação.

A pequena participação de enfermeiros e auxiliares nas ações de vigilância sanitária e epidemiológica, em Juiz de Fora, é resultado da centralização das informações e da falta de pessoal capacitado nas Unidades para estar trabalhando com a epidemiologia, desenvolvendo-se um trabalho que não é integrado com as UBSs, reforçando o modelo curativo (FARAH, 1999). 


\subsubsection{O processo de trabalho de gerenciamento, de ensino e de pesquisa}

Em relação à participação da enfermagem no processo de trabalho de gerenciamento da produção da assistência à saúde, QUEIROZ; SALUM (1996 p. 205) colocam que ocorre um recorte do objeto e da finalidade do processo de produção em saúde e "assim, o objeto do processo de trabalho de gerenciamento da produção da assistência - no recorte da enfermagem - é a dinâmica de como se processa a assistência de enfermagem na sua aderência e articulação com os perfis epidemiológicos do coletivo (que articula a metodologia de assistência, e a complementariedade da prática de enfermagem com as demais práticas sociais) e a finalidade específica é a de compatibilizar essa dinâmica às necessidades de transformação dos perfis epidemiológicos. Dentre os instrumentos de trabalho, podemos destacar, entre outros, os modelos e os métodos gerenciais, o processo de educação continuada; o trabalho em si se dá sob a orientação do Plano Diretor para a Saúde do Município (SILOS) e pelo plano diretor para a assistência de enfermagem à ele subordinado"

Entre as atividades relacionadas ao gerenciamento da assistência, a maioria dos enfermeiros: mantém atualizado e organizado o registro de enfermagem, realiza planejamento, organização, coordenação, execução e avaliação dos serviços de assistência de enfermagem; participa na formulação do diagnóstico de saúde da população e na elaboração, execução e avaliação dos planos assistenciais de saúde.

A participação na elaboração do diagnóstico de saúde da população, uma conseqüência da orientação do Plano Diretor de Saúde do Município, mais uma vez, pode estar indicando uma tentativa de se estar voltando para a atenção ao coletivo contrapondo-se ao modelo clínico individual ainda predominante nas unidades.

Tabela 18 : Distribuição dos enfermeiros das UBS, segundo atividades relacionadas com o Processo de Trabalho de Gerenciamento da Assistência. Juiz de Fora, 1999.

\begin{tabular}{lcc}
\hline \multicolumn{1}{c}{ Atividades } & \multicolumn{2}{c}{$\mathrm{N}^{\circ}{ }^{\circ}$ de } \\
& enfermeiros $/ \%$ \\
\hline Organiza e mantém atualizado o registro de enfermagem & 14 & 100,0 \\
Planejamento, organização, coordenação, execução e avaliação & 13 & 92,8 \\
dos serviços de assistência de enfermagem; & 10 & 71,4 \\
Participação na formulação do diagnóstico de saúde da população \\
$\begin{array}{l}\text { Participação na elaboração, execução e avaliação dos planos } \\
\text { assistenciais de saúde: }\end{array}$ & 8 & 57,2 \\
\hline
\end{tabular}


Em relação, às atividades de enfermagem relacionadas com o gerenciamento burocrático da Unidade, a maioria dos enfermeiros realiza a organização e direção do serviço de enfermagem e de suas atividades técnicas e auxiliares, conforme mostra a tabela 19.

Tabela 19: Distribuição dos Enfermeiros das UBS, segundo atividades relacionadas com o Processo de Trabalho de Gerenciamento Burocrático da Unidade. Juiz de Fora, 1999.

\begin{tabular}{lccc}
\hline \multicolumn{1}{c}{ Atividades } & \multicolumn{2}{c}{$\begin{array}{c}\mathrm{N}^{\circ} \text { de } \\
\text { enfermeiros/\% }\end{array}$} \\
\hline $\begin{array}{l}\text { Organização e direção do serviço de enfermagem e de suas } \\
\text { atividades técnicas e auxiliares }\end{array}$ & 13 & 92,8 \\
$\begin{array}{l}\text { Participação no planejamento, execução e avaliação dos programas } \\
\text { de saúde em todos os níveis; }\end{array}$ & 5 & 35,7 \\
$\begin{array}{l}\text { Consultoria, auditoria e emissão de parecer sobre matéria de } \\
\text { enfermagem; }\end{array}$ & 2 & 14,3 \\
$\begin{array}{l}\text { Participação em projetos de construção ou reformas de unidades; } \\
\text { Participação no processo de recrutamento e seleção de pessoal de } \\
\text { enfermagem; }\end{array}$ & 2 & 14,3 \\
\begin{tabular}{l} 
Outra (previsão e provisão de materiais) \\
\hline
\end{tabular}
\end{tabular}

A pequena participação dos enfermeiros em atividades de consultoria, auditoria e emissão de pareceres sobre matéria de enfermagem e no planejamento, execução e avaliação dos programas de saúde em todos os níveis são um indicativo da reduzida presença política dos enfermeiros de unidades básicas junto aos órgãos centrais, bem como da imposição de programas e propostas de ação sem que se ouça os trabalhadores envolvidos.

Do mesmo modo o fato de que apenas $14,3 \%$ dos enfermeiros responderam ter participado de projetos de construção e reforma de unidades pode ser um dos elementos explicativos da inadequação dos locais de trabalho relatada pelos trabalhadores, uma vez que quem atua nos locais de trabalho não está sendo ouvido sobre as necessidades para o desenvolvimento do mesmo.

Este fato pode ainda estar contribuindo também, para que, como conseqüência, sejam realizadas reformas sucessivas das edificações.

Quanto ao recrutamento e seleção de pessoal de enfermagem, nenhum enfermeiro referiu ter participação nessa atividade, pois esta atividade é centralizada no setor de Recursos Humanos da Secretaria de Saúde do Município.

Nas atividades relacionadas ao ensino, em relação à participação e/ou colaboração com escolas na formação de pessoal de enfermagem em todos os niveis (uma vez que em todas as unidades escolhidas existe ou o estágio supervisionado ou a 
prática de ensino de graduação em enfermagem), esperava-se que todos os enfermeiros citassem essa atividade. No entanto apenas $64,3 \%$ referiram realizar esta ação, o que pode ser um indicativo da distância existente entre o serviço e a Faculdade de Enfermagem.

Chama a atenção a pequena participação dos enfermeiros no processo de recrutamento, seleção e na definição de programas de atualização e aperfeiçoamento de pessoal de enfermagem. Apesar de essas atividades serem centralizadas no setor de Recursos Humanos da Secretaria de Saúde do Município, os enfermeiros das Unidades deveriam estar sendo chamados a participar desses processos por serem os responsáveis diretos pela equipe de enfermagem nas respectivas UBS.

Tabela 20: Distribuição dos Enfermeiros das UBS de Juiz de Fora, segundo atividades relacionadas com o Processo de Trabalho de Ensino. Juiz de Fora, 1999.

\begin{tabular}{lcc}
\hline \multicolumn{1}{c}{ Atividades } & \multicolumn{2}{c}{$\begin{array}{c}\mathrm{N}^{\circ} \text { de } \\
\text { enfermeiros } / \%\end{array}$} \\
\hline $\begin{array}{l}\text { Participa e/ou colabora com as escolas na formação de pessoal de } \\
\text { enfermagem em todos os niveis }\end{array}$ & 964,3 \\
$\begin{array}{l}\text { Planeja, organiza, executa e avalia o treinamento do pessoal de } \\
\text { enfermagem e de educação continuada em serviço }\end{array}$ & 8 & 57,2 \\
$\begin{array}{l}\text { Define programas de atualização e aperfeiçoamento do pessoal de } \\
\text { enfermagem }\end{array}$ & 2 & 14,3 \\
Não realiza & 1 & 7,2 \\
\hline
\end{tabular}

As atividades relacionadas com a pesquisa de modo geral foram as menos citadas, conforme mostra a tabela abaixo

Tabela 21: Distribuição dos Enfermeiros das UBS de Juiz de Fora segundo atividades relacionadas com o processo de trabalho de investigação. Juiz de Fora, 1999.

\begin{tabular}{lcc}
\hline \multicolumn{1}{c}{ Atividades } & \multicolumn{2}{c}{$\mathrm{N}^{\circ}$ de enfermeiros. } \\
& \multicolumn{3}{c}{$/ \%$} \\
\hline Participa em pesquisa na área da saúde em geral & 3 & 21,4 \\
Realiza pesquisas em assuntos de enfermagem & 1 & 7,2 \\
Outra atividade (pesquisa informal para trabalhar com grupos) & 1 & 7,2 \\
\hline
\end{tabular}

FARAH (1999), ao descrever as ações de enfermagem nas UBSs de Juiz de Fora, verificou que são predominantes as ações administrativas e burocráticas, sendo que as ações assistenciais ficam restritas aos programas verticais determinados pelo Ministério da Saúde. Para o alcance de um modelo de saúde que privilegie as ações preventivas, afirma que "será necessário que se reestruturem essas Unidades com recursos humanos e qualidade e quantidade suficientes". 
Ao levantarmos, junto aos trabalhadores de enfermagem, as atividades por eles desenvolvidas, não o fizemos com o intuito de delimitar as funções e compará-las, mas sim com o objetivo de, ao descrever o que é feito, pensar-se nas condições em que esse trabalho é realizado. Foi por isso que optamos por partir de uma descrição já existente, contida na Lei do Exercício Profissional e no Programa de Saúde da Familia, que serviu de referência para que os trabalhadores pudessem pensar sobre o que fazem no seu quotidiano e, dessa forma, ter mais clareza sobre o objeto, os meios e instrumentos e a finalidade do trabalho realizado.

De modo geral, no processo de trabalho realizado pelos trabalhadores de enfermagem, tanto nas unidades onde ainda não foi implantado o PSF, como nas que foi implantado o Programa, existe uma intenção de se estar prestando uma atenção à saúde coletiva junto a uma atenção clínica individual que ainda é o que predomina. Como dificuldades para o alcance dessa proposta são citadas pelos trabalhadores a falta de recursos humanos, materiais, de treinamento e educação continuada, de integração e comprometimento dos vários profissionais que atuam nas unidades.

\subsection{As condições favoráveis e desfavoráveis no trabalho realizado pelos trabalhadores de enfermagem nas UBS}

Conforme já citado anteriormente para se realizar a descrição das condições favoráveis, desfavoráveis e as propostas de solução das unidades estudadas foram utilizados um formulário e o Mapa de Risco.

O mapeamento de risco foi realizado partindo-se do esquema gráfico da área fisica de cada unidade. Em seguida foi elaborado um quadro esquemático para permitir a visualização das situações relatadas e a classificação das cargas.

Uma primeira análise do quadro nos mostra que, quantitativamente, as cargas psíquicas $(41,7 \%)$ são as que mais aparecem, seguidas das mecânicas $(25 \%)$, das biológicas $(12,0 \%)$, das fisicas $(10,7 \%)$ das fisiológicas $(8,3 \%)$, tendo sido a que menos apareceu a carga química $(2,3 \%)$.

As cargas psiquicas dizem respeito às fontes geradoras de estresse e, assim sendo, segundo FACCHINI (1994), estão relacionadas a todos os elementos do processo de trabalho e com todas as cargas, apesar de estarem mais presente na divisão e organização do trabalho.

Em relação às cargas psíquicas referidas pelos trabalhadores de enfermagem das UBSs, observa-se que estas aparecem tanto na relação com o objeto/finalidade, como com os meios e instrumentos e divisão e organização, estando mais presentes neste último, corroborando a análise feita por FACCHINI (1994).

Em todas as unidades ocorre falta de mobiliário, de materiais e equipamentos e há instalações fisicas que necessitam de manutenção. Em 10 (90,9\%) 
unidades foi referida a presença de ruido, em $09(81,81 \%)$ a existência de instalações inadequadas; em $07(63,63 \%)$ materiais e equipamentos necessitavam de manutenção e falta de instalações fisicas e em $06(54,54 \%)$ ocorre falta de recursos humanos.

A este respeito pode se dizer que a falta de condições materiais, de manutenção de equipamentos e instrumentos bem como a falta de recursos humanos nos serviços públicos são o resultado da proposta neoliberal de privatização das instituições públicas, inclusive as da área da saúde (GERCHAM, 1995), entre outras coisas.

Quadro 6: Descrição das condições desfavoráveis e das cargas de trabalho das Unidades Básicas de Saúde. Juiz de Fora, 1999.

\begin{tabular}{|l|l|}
\hline \multicolumn{1}{|c|}{ Condições desfavoráveis } & Cargas de trabalho \\
\hline $\begin{array}{l}\text { Capacidade de atendimento menor do que a procura gerando } \\
\text { tensão, estresse; }\end{array}$ & Psíquica \\
\hline Insatisfação dos usuários & Psiquica \\
\hline Falta de recursos humanos & Psíquica \\
\hline Sobrecarga de trabalho da equipe & Psíquica \\
\hline Agressividade dos usuários & Psíquica, mecânica \\
\hline Usuários insatisfeitos com o atendimento & Psíquica \\
\hline Falta de conforto para os usuários & Psíquica, \\
\hline $\begin{array}{l}\text { Dificuldade para realizar trabalhos educativos com } \\
\text { comunidade }\end{array}$ & Psíquica \\
\hline Interrupção de atendimento por usuários & Psíquica \\
\hline Concentração de usuários na porta das salas & Psíquica, \\
\hline $\begin{array}{l}\text { Dificuldade na dispensação de medicamentos por falta de cópia } \\
\text { da prescrição médica }\end{array}$ & Psíquica \\
\hline Entrada de animais na Unidade Básica & Mecânica \\
\hline Presença de insetos e roedores & Biológica \\
\hline Impressos e potes de material para exames entregues “sujos" & Biológica \\
\hline Falta de materiais e equipamentos & $\begin{array}{l}\text { Psíquica, mecânica, } \\
\text { biológica, fisiológica }\end{array}$ \\
\hline Materiais e equipamentos inadequados & $\begin{array}{l}\text { Psíquica, mecânica, } \\
\text { biológica, fisiológica }\end{array}$ \\
\hline Materiais e equipamentos que necessitam de manutenção & Psíquica, mecânica \\
\hline Falta de mobiliário & $\begin{array}{l}\text { Psíquica, mecânica, } \\
\text { fisiológica }\end{array}$ \\
\hline Mobiliário que necessita de manutenção mecânica, \\
\hline Mobiliário inadequado & $\begin{array}{l}\text { Psíquica, } \\
\text { fisiológica }\end{array}$ \\
\hline & $\begin{array}{l}\text { Psíquica, mecânica, } \\
\text { fisiológica }\end{array}$ \\
\hline & \\
\hline
\end{tabular}




\begin{tabular}{|l|l|}
\hline $\begin{array}{l}\text { Ruido: pela concentração de pessoas em um mesmo local; } \\
\text { devido ao aparelho de nebulização, devido ao aparelho de } \\
\text { televisão, fevisica } \\
\text { odontológicos ao compressor dos equipamentos }\end{array}$ & \\
\hline Manipulação de material perfuro-cortante & Psíquica, mecânica \\
\hline Falta de transporte suficiente & Psíquica \\
\hline Instalações fisicas que necessitam de manutenção & $\begin{array}{l}\text { Psíquica, mecânica, } \\
\text { biológica }\end{array}$ \\
\hline Instalações fisicas inadequadas & $\begin{array}{l}\text { Psíquica, mecânica, } \\
\text { biológica, fisiológica }\end{array}$ \\
\hline Falta de instalações fisicas & $\begin{array}{l}\text { Psíquica e mecânica, } \\
\text { biológica }\end{array}$ \\
\hline $\begin{array}{l}\text { Falta de limpeza (mesa, cadeiras e chão empoeirados, } \\
\text { banheiros exalam odor desagradável) }\end{array}$ & Biológica, química \\
\hline Iluminação deficiente & fisica \\
\hline Local de trabalho frio & Física \\
\hline Local de trabalho quente & Física, \\
\hline Ventilação insuficiente & Física \\
\hline Umidade & Física \\
\hline Distribuição e localização inadequada das salas e serviços & Mecânica, fisiológica \\
\hline Espaço fisico pequeno & $\begin{array}{l}\text { Psíquica, } \\
\text { fisiológica }\end{array}$ \\
\hline Atividades burocráticas em excesso & Psíquica \\
\hline Falta de organização & Psíquica \\
\hline Acesso dos usuários as salas e serviços fora do atendimento & Psíquica \\
\hline Dificuldade de acesso às salas e serviços dentro da unidade & Mecânica, fisiológica \\
\hline Utilização de salas para mais de uma atividade ou serviço & Psíquica, mecânica \\
\hline Falta de privacidade & Psíquica \\
\hline Desvio de função & Psíquica \\
\hline Descontinuidade do trabalho pela falta de material & Psíquica \\
\hline Decisões tomadas em reuniões não são seguidas & Psiquica \\
\hline Sala projetada para uma atividade sendo utilizada para outra & Psíquica, mecânica \\
\hline & \\
\hline
\end{tabular}

Ainda em relação à carga psiquica, $85,7 \%$ dos enfermeiros se consideram submetidos a tensão emocional; $64,3 \%$ consideram o trabalho repetitivo, mas apenas $28,6 \%$ o consideram monótono. Quanto aos auxiliares, estes se mostram mais insatisfeitos pois $80 \%$ se consideram submetidos a tensão emocional; $90 \%$ consideram o trabalho repetitivo e $45 \%$ consideram-no monótono.

Pode-se dizer que os trabalhadores de enfermagem, acentuadamente os auxiliares, estão submetidos a uma condição que, por não possibilitar a inovação no trabalho, por ser repetitivo e tenso, pode se configurar como potencialmente perigoso para o aparelho psíquico. A falta de possibilidade de livre atividade não permite uma descarga de energia emocional do trabalhador. Segundo DEJOURS (1994), “ o bem-estar, em matéria de carga psíquica, não advém só da ausência de funcionamento, mas, pelo contrário, de um livre funcionamento, articu'ado 
dialeticamente com o conteúdo da tarefa, expresso, por sua vez, na própria tarefa e revigorado por ela".

Além disso, a tensão emocional pode ser considerada uma fonte de estresse, na medida em que as pressões e as exigências do trabalho se configurem em cansaço e esforço excessivo (FIORI, s/d.).

CHAVES; MOURA (1999) realizaram um estudo em um hospital universitário na cidade de Porto Alegre, com o objetivo de estar identificando as fontes geradoras de estresse no trabalho do enfermeiro, obtendo como resultado que o gerenciamento de pessoal é a principal fonte de estresse, apresentando o maior número de correlações significativas com os sintomas de estresse, levando a alterações imunitárias, músculo-articulares e cardiovasculares.

As cargas mecânicas são derivadas da tecnologia empregada bem como das condições de instalação e manutenção do processo de produção. Semelhantemente às cargas psíquicas, estas cargas, ao interagirem com o trabalhador, representam riscos à sua integridade biopsicossocial, sendo que algumas situações citadas como cargas psíquicas configuram-se também como mecânicas.

As cargas mecânicas, assim como as cargas psíquicas, estão mais presentes na relação com a divisão e organização do trabalho e os meios e instrumentos, sendo que todas as situações citadas pelos trabalhadores e consideradas relacionadas a estes elementos do processo de trabalho implicam uma carga ao mesmo tempo psíquica e mecânica, conforme FACCHINI (1994).

Em relação à divisão e organização do trabalho, $08(72,72 \%)$ unidades citaram o espaço físico da UBS como pequeno para o desenvolvimento de todas as atividades bem como a necessidade de utilização de uma sala para mais de uma atividade ou serviço; 07 unidades $(63,63 \%)$ afirmam que a distribuição e localização das salas e serviços é inadequada; $05(45,45 \%)$, que existe acesso dos usuários às salas e serviços fora do período de atendimento, além do fato de que salas que foram projetadas para uma atividade estão tendo que ser utilizadas para outra.

Nas enquetes, os trabalhadores expressaram insatisfação significativa em relação à estrutura fisica das unidades, mesmo nas que já sofreram reformas ou cuja construção é relativamente nova. Segundo eles, os trabalhadores não têm sido ouvidos quando da construção ou realização de reformas e, assim, as estruturas não são adequadas ás necessidades dos processos de trabalho, pois quem projeta nem sempre conhece o trabalho e as necessidades de quem irá trabalhar naquela estrutura.

Os dados levantados no formulário vêm corroborar os dados dos mapas de risco pois $71,4 \%$ dos enfermeiros e $70 \%$ dos auxiliares consideram que no trabalho estão submetidos a instrumentos e ou equipamentos defeituosos, $64,3 \%$ dos enfermeiros e $65 \%$ dos auxiliares utilizam instrumentos e ou equipamentos inadequados e $57,2 \%$ dos enfermeiros e $45 \%$ dos auxiliares trabalham em espaços fisicos deficientes. 
As cargas biológicas ou orgânicas são decorrentes principalmente da relaçâo com o objeto de trabalho e das condições de higiene ambiental, mas também estão relacionadas a quaisquer organismos animais ou vegetais que estejam presentes no ambiente de trabalho (FACCHINI, 1994; LAURELL; NORIEGA, 1989).

Nas UBSs elas apareceram relacionadas também aos meios e instrumentos de trabalho devido à falta ou inadequação de materiais, equipamentos e instalações.

Conforme já foi explicitado anteriormente, as cargas interagem entre si e, assim, algumas das situações descritas, além de caracterizarem cargas biológicas, podem-se caracterizar também como cargas mecânicas, psíquicas, e químicas.

Se, em relação ao número de situações, as cargas biológicas possuem uma menor expressão, por outro lado, qualitativamente, elas são de grande significação, uma vez que implicam um risco de contaminação.

Os trabalhadores de enfermagem percebem que $o$ risco de contaminação está presente no seu dia a dia, pois quando perguntamos sobre a insalubridade e periculosidade do trabalho, apontaram como causa o risco de se infectarem. Além disso, quando questionados sobre o risco de contaminação por microorganismos, todos os auxiliares e enfermeiros referiram estar sujeitos a ele.

Para conviver com a certeza de que se está sujeito ao risco de contrair alguma doença, o trabalhador acaba fazendo uso de mecanismos de defesa e de resistências considerando o risco como inerente ao trabalho, independente da vontade do trabalhador e de abrangência coletiva, uma vez que todos os que estão naquele ambiente estariam sujeitos a ele (DEJOURS, 1988).

Estar quotidianamente convivendo com esta situação gera medo e ansiedade. Assim, segundo DEJOURS (1988), pode surgir daí um certo desprezo, uma inconsciência em relação à situação de risco, o medo é abafado, sufocado por atitudes de negação e desprezo pelo perigo, como uma forma de defesa, de negação de sua existência, pois " A consciência aguda do risco de acidente, mesmo sem maiores envolvimentos emocionais, obrigaria o trabalhador a tomar tantas precauções individuais que ele se tomaria ineficaz do ponto de vista da produtividade".

Em relação às possibilidades de contaminação, uma vez que na bibliografia pesquisada não encontramos nenhum estudo específico com trabalhadores de Unidades Básicas de Saúde, consideramos os mesmos citados para a área hospitalar, ou seja, de se contrair doenças como: tuberculose, hepatite, rubéola, doença meningocócica, escabiose, herpes, AIDS, candidiase além de outras (MAURO, 1988). 
As cargas fisicas são decorrentes da relação entre as condições do ambiente de trabalho e o trabalhador, são uma expressão "das exigências técnicas para a transformação do objeto de trabalho" (FACCHINI, 1994 p. 181; LAURELL NORIEGA, 1989).

Entre as situações geradoras de cargas fisicas, a ventilação insuficiente foi a mais relatada presente em todas as unidades. O ruído apareceu em $10(90,9 \%)$ UBSs e a iluminação insuficiente em $9(81,81 \%)$.

Como construímos o mapa de risco de cada sala das UBSs, os riscos podem dizer respeito somente a uma ou duas salas. Ainda que em graus diferenciados, estas situações foram citadas pelos trabalhadores das Unidades como de risco, pois em algum momento do processo de trabalho elas são percebidas.

Ambientes abafados, escuros e com ruido, além de gerarem desgaste fisico sobre o trabalhador, geram e potencializam desgaste psíquico.

Particularmente no que diz respeito à poluição sonora, seus efeitos nocivos se estendem também a outros órgãos, aparelhos e funções do organismo, podendo causar ou agravar hipertensão, estresse, causar aumento de tensão muscular, incapacidade de concentração e aumento do número de acidentes (AZEVEDO et al, 1993).

Ao responderem o formulário individualmente, $10(71,4 \%)$ enfermeiros e $14(70 \%)$ auxiliares afirmaram que estão submetidos a ruído no trabalho; $01(7,2 \%)$ enfermeiro e nenhum auxiliar referiram-se à radiação e $05(35,7 \%)$ enfermeiros e 03 $(15 \%)$ auxiliares disseram estar sujeitos a vibrações.

Ainda em relação às cargas fisicas, no formulário, individualmente perguntou-se a percepção dos trabalhadores em relação à temperatura, iluminação e ventilação e apesar de na enquete coletiva ter aparecido deficiência em relação a essas condições, individualmente a maioria de enfermeiros e de auxiliares não se referiram a nenhum problema em relação a estas condições. Talvez isso tenha ocorrido pois no geral, aparentemente, as condições fisicas do ambiente de trabalho são suficientes, mas é no particular ao se discutir espaço por espaço que a deficiência fica mais evidente, toma corpo e concretude.

As cargas fisiológicas são decorrentes dos modos de realizar o trabalho (FACCHINI, 1994; LAURELL; NORIEGA, 1989).

Nas UBSs, elas revelam-se na falta de materiais, equipamentos e mobiliários, bem como na necessidade de manutenção de equipamentos, mobiliários e instalações fisicas, presente em todas as unidades. 
O processo de trabalho em enfermagem em UBS não se caracteriza por exigir, na maioria das vezes, um grande esforço fisico, o que é referendado pelos trabalhadores, pois apenas $3(21,4 \%)$ enfermeiros e $3(15 \%)$ auxiliares referiram-se a se considerar sujeitos a trabalho fisico "pesado".

No entanto, a carga fisiológica se evidencia em relação à postura que muitas vezes o trabalhador tem que assumir para desenvolver algumas tarefas, a qual em muitos casos é decorrente de estrutura fisica inadequada, de instrumentos e ou equipamentos inadequados ou defeituosos, o que pode ser evidenciado nas respostas individuais do formulário e que estão expressas na tabela 22 .

Tabela 22: Distribuição dos Enfermeiros e Auxiliares das UBSs de Juiz de Fora segundo percepção das cargas fisiológicas a qual estão submetidos. Juiz de Fora, 1999.

\begin{tabular}{|c|c|c|c|c|}
\hline Cargas fisiológicas & \multicolumn{2}{|c|}{$\mathrm{N}^{\circ}$ de enfermeiros $/ \%$} & \multicolumn{2}{|c|}{ N. ${ }^{\circ}$ de auxiliares $/ \%$} \\
\hline Trabalho físico pesado & 3 & 21,4 & 3 & 15 \\
\hline Postura inadequada & 9 & 64,3 & 11 & 55 \\
\hline Arranjo fisico deficiente & 8 & 57,2 & 9 & 45 \\
\hline $\begin{array}{l}\text { Instrumentos e/ ou equipamentos } \\
\text { defeituosos }\end{array}$ & 10 & 71,4 & 14 & 70 \\
\hline $\begin{array}{l}\text { Instrumentos e/ ou equipamentos } \\
\text { inadequados }\end{array}$ & 9 & 64,3 & 13 & 65 \\
\hline
\end{tabular}

A análise da tabela evidencia também a falta de manutenção dos equipamentos, o que acarreta carga tanto fisiológica como psíquica, tendo sido referida por cerca de $70 \%$ tanto dos enfermeiros e auxiliares.

Na literatura pesquisada encontramos vários estudos sobre aspectos ergonômicos e posturais do trabalho de enfermagem em unidades hospitalares (ALEXANDRE, et al. 1991; BERNARDINA, et al. 1995; ALEXANDRE et al. 1996; ALEXANDRE, 1998 e ZANON; MARZIALE, 2000).

Apesar de estes estudos se referirem ao trabalho em unidades hospitalares e estarem voltados principalmente para a questão das condições ambientais do trabalho, acreditamos que eles podem auxiliar na reflexão sobre a realização de técnicas e atividades que podem significar uma carga fisiológica e são comuns ao desenvolvimento do trabalho de enfermagem, independente do local.

Nesse sentido, ALEXANDRE, et al. (1991) frente a constatação de que "a dor nas costas é uma das queixas mais freqüentes do pessoal de enfermagem", propõe um modelo de curso de orientação sobre aspectos ergonômicos e posturais no trabalho do pessoal de enfermagem.

Para esses autores o trabalhador de enfermagem deve ter conhecimento e conscientização sobre a utilização de posturas de trabalho e as normas adequadas para movimentação e transporte de pacientes, para evitar agressões diárias à coluna 
vertebral. No entanto afirmam como mais importante "despertar uma consciência crítica em relação aos efeitos do ambiente de trabalho sobre a saúde do trabalhador" (ALEXANDRE, et al. 1991, p.64).

BERNARDINA et al. (1995), fazem um estudo sobre as posturas adotada pelos membros da equipe de enfermagem de um hospital de uma cidade do interior de São Paulo, durante a realização de técnicas de colheita de sangue, administração de medicação endovenosa e soroterapia. E concluem que os trabalhadores adotam posturas inadequadas que levam a um maior gasto de energia $\mathrm{e}$ flexões da coluna vertebral desnecessárias, necessitando serem alertados para a utilização de princípios de mecânica corporal.

ALEXANDRE, et al. (1996), através de uma avaliação clínica especifica de trabalhadores de enfermagem de um hospital universitário, realizada por um grupo interdisciplinar, verificaram a ocorrência de algia na coluna vertebral da maioria dos trabalhadores, estando presente principalmente lombalgia e cervicolombalgia.

Em relação às atividades ocupacionais dos trabalhadores de enfermagem que podem causar lesões no sistema músculo-esquelético da coluna vertebral, ALEXANDRE, (1998), menciona o levantamento de peso excessivo, o levantamento e manuseio de cargas de modo incorreto, os levantamentos repetitivos e a manutenção de uma postura por tempo prolongado, referindo-se a ser necessário que se realizem estudos ergonômicos, envolvendo equipamentos, mobiliários, pessoa e tarefas do ambiente hospitalar, para atuar no sentido de minimizar ou eliminar essas condições.

ZANON; MARZIALE (2000), em um estudo sobre a postura corporal dos trabalhadores de enfermagem na movimentação de pacientes acamados, em uma unidade ortopédica de um hospital do interior de São Paulo, identificaram como dificuldades encontradas para a realização do procedimento: espaço pequeno, elevada carga física e falta de pessoal, caracterizando essa atividade como penosa.

As cargas químicas dizem respeito às substâncias químicas presentes no processo de trabalho, conforme citado anteriormente, e foram as que menos apareceram, sendo que, quando presentes, estão relacionadas também com outras cargas (FACCHINI, 1994; LAURELL; NORIEGA, 1989).

Elas estão presentes no processo de trabalho em enfermagem pois manipula-se uma gama de agentes químicos.

UVA; FARIA (2000), citando dados da Organização Mundial de Saúde (OMS), referem-se a que as substâncias quimicas constituem o mais extenso dos grupos de fatores de risco de natureza profissional com cerca de 100.000 substâncias consideradas agente de doença profissional, sendo que destas, de $200 \mathrm{a}$ 300 são mutagênicas e cancerígenas. 
$\mathrm{Na}$ enquete coletiva não foi possível evidenciar de modo significativo a presença dessas cargas, mas isso não significa que os trabalhadores não se percebam expostos a elas, pois nas respostas individuais do formulário elas foram citadas.

Quando questionados se estavam submetidos a poeiras, vapores e gases, todos os enfermeiros e $19(95 \%)$ dos auxiliares afirmaram que sim. Em relação a produtos químicos tóxicos, $08(57,2 \%)$ enfermeiros e $19(50 \%)$ auxiliares referiramse a estar submetidos.

Nas enquetes coletivas, os trabalhadores foram estimulados a expressar não apenas as cargas, mas também, quando existentes, as condições favoráveis presentes no processo de trabalho em enfermagem nas UBSs.

Uma primeira análise quantitativa mostra que em todas as Unidades foram mencionadas condições favoráveis, mas como a enquete foi realizada a partir da análise de cada espaço fisico, houve referências também a espaços que não apresentavam "nada de bom".

Como condições favoráveis foram citados: bom relacionamento com a comunidade, e com a equipe, ventilação e iluminação adequadas, existência de materiais, equipamentos, mobiliário, instalações adequadas, salas assim como espaço físico adequado, bonito/agradável, calmo/tranquilo e organizado, existência de espaço fisico, privacidade e distribuição das salas.

Chamou-nos atenção a referência de alguns trabalhadores em relação à existência de espaço para determinadas ações como sendo uma condição favorável, mesmo estes espaços não possuindo as condições necessárias para o desenvolvimento das atividades, pois segundo eles a simples existência do espaço fisico já podia ser considerado um aspecto positivo.

Em relação às propostas de solução, a maioria está relacionada a um serviço de manutenção mais ágil e atuante, a aquisição de materiais, equipamentos e mobiliários e até a reforma da UBS, mas surgiram propostas também relativas à restruturação da unidade, com mudança de salas e consultórios entre os serviços, passiveis de serem realizadas imediatamente.

\subsection{O trabalho como fonte de desgaste e fortalecimento}

O trabalho, dependendo das condições em que é realizado, pode levar a um desgaste do trabalhador, a perda da capacidade potencial e/ou efetiva do conjunto de processos biopsíquicos, podendo ou não expressar-se sob a forma de doença, ou pode significar o fortalecimento, ou seja, um estímulo para o desenvolvimento das capacidades fisicas e mentais do ser humano, um produtor de saúde (LAURELL; NORIEGA, 1989; GARCIA, 1989).

Segundo LAURELL; NORIEGA (1989, p. 116) “a complexidade do desgaste faz com que haja dificuldades para mostrá-lo diretamente, sobretudo porque 
em sua maior parte é inespecífico e não se expressa com clareza em elementos facilmente observáveis ou mensuráveis". Assim sendo, é dificil de se captar o desgaste a não ser que se faça uso por exemplo de sinais e sintomas, perfil patológico, ou de indicadores do processo.

Nesse sentido, ao apresentarmos e descrevermos a percepção dos trabalhadores de Enfermagem das UBS de Juiz de Fora sobre o trabalho como fonte de desgaste e fortalecimento, fazemo-lo como uma primeira aproximação com o tema

Perguntamos aos enfermeiros como se sentiam no trabalho e a maioria se disse satisfeito em relação ao aproveitamento de suas aptidões, nível de responsabilidade, poder de decisão, perspectivas de carreira, reconhecimento social do cargo ou atividade profissional, possibilidades de contatos e intercâmbio profissional, relacionamento com os colegas e possibilidade de realizar trabalho criativo e inovador. Mas o trabalho aparece como fonte de insatisfação em relação ao salário $(50 \%)$ e ao volume de tarefas administrativas $(64,3 \%)$.

Tabela 23: Distribuição dos Enfermeiros das UBS de Juiz de Fora, segundo opinião sobre o grau de satisfação no trabalho. Juiz de Fora, 1999.

\begin{tabular}{|c|c|c|c|c|c|c|c|c|c|}
\hline \multirow{3}{*}{$\begin{array}{c}\text { Como se sente no trabalho } \\
\text { em relação a: }\end{array}$} & \multicolumn{8}{|c|}{ Grau de satisfação } & \multirow[t]{3}{*}{ Total } \\
\hline & \multicolumn{2}{|c|}{$\begin{array}{l}\text { Muito } \\
\text { satisfeito }\end{array}$} & \multicolumn{2}{|c|}{ Satisfeito } & \multicolumn{2}{|c|}{ Insatisfeito } & \multicolumn{2}{|c|}{$\begin{array}{l}\text { Muito } \\
\text { insatisfeito }\end{array}$} & \\
\hline & $\mathrm{N}$ & $\%$ & $\mathbf{N}$ & $\%$ & $\mathrm{~N}$ & $\%$ & $\mathrm{~N}$ & $\%$ & \\
\hline $\begin{array}{l}\text { Aproveitamento de suas } \\
\text { aptidões }\end{array}$ & 2 & 28,6 & 9 & 64,3 & 3 & 21,4 & & - & 14 \\
\hline $\begin{array}{l}\text { Aplicação prática dos } \\
\text { conhecimentos teóricos } \\
\text { adquiridos }\end{array}$ & 1 & 07,2 & 7 & 50,0 & 6 & 42,9 & & - & 14 \\
\hline Salário & & $\ldots$ & 4 & 28,6 & 7 & 50,0 & 3 & 21,4 & 14 \\
\hline Nivel de responsabilidade & & 07,2 & 8 & 57,2 & 5 & 35,7 & & 一 & 14 \\
\hline Poder de decisão & & - & 9 & 64,3 & 5 & 35,7 & & - & 14 \\
\hline Perspectivas de carreira & & - & 10 & 71,4 & 3 & 21,4 & & - & 14 \\
\hline $\begin{array}{l}\text { Reconhecimento social do } \\
\text { cargo ou atividade } \\
\text { profissional }\end{array}$ & & 一 & 9 & 64,3 & 5 & 35,7 & & 一 & 14 \\
\hline $\begin{array}{l}\text { Possibilidades de contatos e } \\
\text { intercâmbio profissional }\end{array}$ & & - & 10 & 71,4 & 4 & 28,6 & & - & 14 \\
\hline $\begin{array}{l}\text { Volume de tarefas } \\
\text { administrativas }\end{array}$ & 0 & 0,0 & 5 & 35,7 & 9 & 64,3 & & - & 14 \\
\hline $\begin{array}{l}\text { Relacionamento com os } \\
\text { colegas }\end{array}$ & 4 & 28,6 & 10 & 71,4 & & - & & - & 14 \\
\hline $\begin{array}{l}\text { Possibilidade de realizar } \\
\text { trabalho criativo e inovador }\end{array}$ & & - & 8 & 57,2 & 6 & 42,9 & & - & 14 \\
\hline
\end{tabular}


Já para os auxiliares, a maioria se diz satisfeita com o aproveitamento de suas aptidões, com a aplicação prática dos conhecimentos teóricos adquiridos, com as possibilidades de contatos e intercâmbio profissional e relacionamento com os colegas e insatisfeita em relação ao salário, ao poder de decisão, às perspectivas de carreira, ao reconhecimento social do cargo ou atividade profissional, ao volume de tarefas administrativas e possibilidade de realizar trabalho criativo. Em relação ao nivel de responsabilidade, metade (50\%) se diz satisfeita.

Do mesmo modo a relação com os membros da equipe de saúde e entre auxiliares e enfermeiros aparentemente é de sentimentos positivos. A totalidade dos auxiliares se referiu a que, em relação a equipe de enfermagem, o sentimento é de respeito e companheirismo. Em relação à equipe de saúde, $95 \%$ se referiram a sentimento de respeito e $90 \%$ ao de companheirismo. Igualmente a totalidade dos enfermeiros afirmou o sentimento de respeito em relação à equipe de enfermagem e $85,7 \%$ o de companheirismo. Em relação à equipe de saúde, $92,8 \%$ se referiram ao sentimento de respeito e $85,7 \%$ ao de companheirismo.

Tabela 24: Distribuição dos Auxiliares de Enfermagem das UBS, segundo opinião sobre o grau de satisfação no trabalho. Juiz de Fora, 1999.

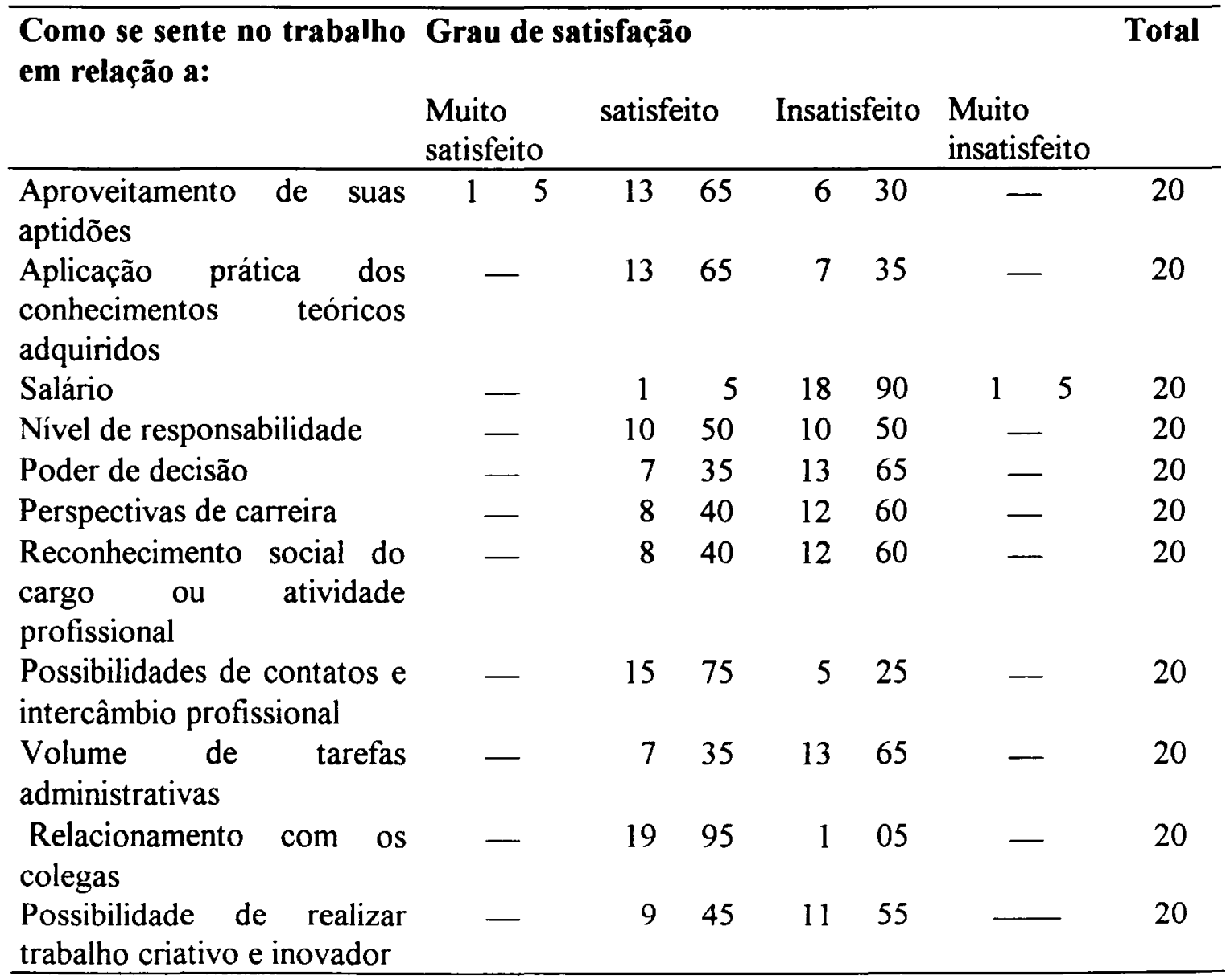


Da análise das respostas percebe-se que a insatisfação é mais presente no trabalho dos auxiliares do que no dos enfermeiros, sendo comum a insatisfação em relação ao salário e ao volume de tarefas administrativas. Quando perguntamos ao trabalhadores como consideravam o tempo para realizar as tarefas, entre os auxiliares $45 \%$ responderam ser insuficiente e $55 \%$, suficiente. Entre os enfermeiros, a maioria $(64,3 \%)$ disseram ser insuficiente e 35,7 , suficiente.

No que diz respeito ao sentimento ao final da jornada de trabalho, a maioria de enfermeiros $(71,4 \%)$ e de auxiliares $(70 \%)$ disseram sentir necessidade de descansar, não apresentando, portanto, disposição para realizar outras atividades, sejam elas de trabalho, lazer ou estudo, o que pode ser um indicador do processo de desgaste do trabalho.

Em relação às condições de trabalho, $10(64,3 \%)$ dos enfermeiros e 17 (75\%) dos auxiliares consideram o trabalho perigoso, sendo que a maioria dos enfermeiros (13-92,8\%) e todos os auxiliares consideram o trabalho insalubre.

Tabela 25: Distribuição dos Enfermeiros e Auxiliares de Enfermagem das UBS, segundo motivo pelo qual consideram o trabalho perigoso. Juiz de Fora, 1999.

\begin{tabular}{lcccc}
\hline \multicolumn{1}{c}{ Motivo } & N. ${ }^{\circ}$ de enfermeiros $/ \%$ & N. ${ }^{\circ}$ de auxiliares $/ \%$ \\
\hline Risco de contaminação & 8 & 80,0 & 13 & 76,4 \\
Risco de agressão & 2 & 20,0 & 3 & 17,7 \\
Risco com equipamentos & 0 & 0,0 & 1 & 5,9 \\
Total & 10 & 100 & 17 & 100 \\
\hline
\end{tabular}

O motivo predominante, referido por enfermeiros e auxiliares, que os faz considerar o trabalho perigoso e insalubre, foi o risco de contaminação.

Tabela 26 : Distribuição dos Enfermeiros e Auxiliares de Enfermagem das UBS, segundo motivo pelo qual considera o trabalho insalubre. Juiz de Fora, 1999.

\begin{tabular}{|c|c|c|c|c|}
\hline Motivo & \multicolumn{2}{|c|}{$\mathrm{N}^{\circ}$ de enfermeiros $/ \%$} & \multicolumn{2}{|c|}{$\mathrm{N}^{\circ}$ de auxiliares $/ \%$} \\
\hline Risco de contaminação & 12 & 75,00 & 18 & 90 \\
\hline Contato com vários riscos & 1 & 6,25 & 1 & 5 \\
\hline Falta de material & 1 & 6,25 & \multicolumn{2}{|c|}{ 一 } \\
\hline Presença de mofo & 1 & 6,25 & \multicolumn{2}{|c|}{ - } \\
\hline Contato com doenças contagiosas & \multicolumn{2}{|c|}{ - } & 1 & 5 \\
\hline Ventilação e iluminação deficiente & 1 & 6,25 & \multicolumn{2}{|c|}{ - } \\
\hline Total & 16 & 100 & 20 & 100 \\
\hline
\end{tabular}

No que diz respeito à ocorrência de acidentes de trabalho, 4 (28,6\%) enfermeiros e $9(45 \%)$ auxiliares referiram-se a ter sofrido algum tipo de acidente, sendo as lesões com material perfuro cortante as mais citadas. 
Vários autores, dentre eles citamos SILVA (1988), SANTOS (1989), FIGUEIREDO, ( 1992), BRANDI et al (1996), BENATTI, (1997), JODRA (1997), GIR et al. (1998), ALEXANDRE; BENATTI (1998), afirmam que dentre os acidentes de trabalho mais freqüentes entre trabalhadores de enfermagem estão as lesões perfuro-cortantes, seguidas de lesões osteoarticulares tais como contusões e torções.

Segundo BRANDI et al (1996), a preocupação em se estar estudando a ocorrência de acidentes de trabalho com trabalhadores de saúde, especificamente no que diz respeito ao acidente com material perfuro-cortante, aumentou com o surgimento da AIDS, devendo-se ressaltar, como sendo também de grande importância nesse tipo de acidente o risco de contaminação pelo virus da hepatite $B$, que apresenta alta capacidade infectante.

- Tabela 27: Distribuição dos Enfermeiros e Auxiliares de Enfermagem das UBS, segundo tipo de acidente de trabalho referido. Juiz de Fora, 1999.

\begin{tabular}{|c|c|c|c|c|}
\hline \multirow{2}{*}{$\begin{array}{c}\text { Tipo } \\
\text { Se picou com agulha contaminada }\end{array}$} & \multicolumn{2}{|c|}{$\mathrm{N}^{\circ}$ de enfermeiros $/ \%$} & \multicolumn{2}{|c|}{ N. de auxiliares $/ \%$} \\
\hline & 4 & $\overline{80}$ & 6 & 66,7 \\
\hline Escorregou e caiu & & & 1 & 11,1 \\
\hline Tropeçou e torceu o tornozelo & & & 1 & 11,1 \\
\hline $\begin{array}{l}\text { Acidente na quebra de ampola de } \\
\text { vacina BCG }\end{array}$ & 1 & 20 & & \\
\hline $\begin{array}{l}\text { Enrolou o dedo na bomba de sangue } \\
\text { (hemodiálise) }\end{array}$ & & & 1 & 11,1 \\
\hline Total & $5^{*}$ & 100 & 9 & 100 \\
\hline
\end{tabular}

- um enfermeiro referiu-se a mais de um tipo

Entre os profissionais da área de saúde, o risco de transmissão do vírus da hepatite $B$, chega a ser de três a cinco vezes maior do que na população em geral (AYUB; LOPES, 1998).

JODRA (1997), ao apresentar dados do registro de Vigilância Epidemiologica da Comunidade de Madrid, na Espanha, mostrou que, em relação a ocorrência de acidentes com material procedente de pacientes HIV, entre os trabalhadores da área de saúde, os de Enfermagem são os que mais se acidentam $(61,8 \%)$, seguidos dos médicos $(20,2 \%)$

Ao relacionar a ocorrência de acidente com material perfuro-cortante com os anos de trabalho na instituição, GIR et al., (1998), demonstraram que a maioria dos acidentes ocorrem entre enfermeiros e auxiliares com mais de 10 anos de formação, o que pode ter como justificativa "educação continuada insuficiente, falta de sensibilização e conscientização pessoal, supervisão continua e sistemática da prática insuficiente, a percepção individual sobre o risco, a desvalorização das ações preventivas e consequentemente a qualidade de vida". 
BENATTI, (1997), em sua pesquisa concluiu existir associação entre a ocorrência de acidentes $\mathrm{e}$ as condições de trabalho entre trabalhadores de enfermagem, citando entre outros como elementos potenciadores do risco de acidente: posturas cansativas adotadas durante o trabalho, falta de tempo para o lazer e consumo de bebidas alcoólicas.

Através da construção teórica da relação entre as condições de trabalho e de vida dos trabalhadores de enfermagem das UBS de Juiz Fora, podemos elaborar uma certa predição em relação ao padrão de desgaste destes trabalhadores.

A exposição do trabalhador de enfermagem ao risco de acidente com material potencialmente contaminado gera medos, angústias, inquietações contribuindo para o processo de desgaste desses trabalhadores (GIR, et al. 1998).

Em relação à ocorrência de doenças entre os enfermeiros, apenas 2 referiram-se a estar apresentando hipertensão arterial e glaucoma; entre os auxiliares 3 mencionaram hipertensão, 1 mencionou tendinite e 1 referiu-se a problema na córnea, totalizando 5 referências.

Para solucionar o problema de saúde, a totalidade dos enfermeiros e a maioria dos auxiliares (80\%) afirmaram ter procurado assistência médica particular e estar fazendo uso de medicação.

Quantitativamente, a análise das doenças relatadas pelos trabalhadores não se mostra expressiva em relação ao desgaste a que os trabalhadores estariam expostos. É necessário assim retornarmos à definição de desgaste que não deve ficar restrita à doença aparente, mas deve considerar também a possibilidade de desenvolvimento de determinada doença tendo em vista a exposição às cargas. Portanto, a existência de um trabalhador hipertenso significa que todos os demais podem estar expostos a cargas de trabalho que podem vir a gerar hipertensão ou outras enfermidades.

Para MENDES; DIAS (1999), os trabalhadores tanto partilham dos "perfis de adoecimento e morte da 'população geral', em função de sua idade, gênero, grupamento social, ou inserção em algum grupo de risco mais específico", como podem "adoecer ou morrer por causas específicas do trabalho, seja pela profissão que exercem, pele emprego que têm, ou pelas condições adversas em que seu trabalho é realizado".

Segundo a Lei n. ${ }^{\circ} 8.213$, de 24 de julho de 1991, art. 20, doença profissional é a "doença produzida ou encadeada pelo exercicio do trabalho peculiar a determinada atividade constante da respectiva relação elaborada pelo Ministério do Trabalho e da Previdência Social", sendo que, no Brasil, a relação de doenças profissionais é composta por uma lista de 27 agentes patogênicos, ou de risco, a que podem estar expostos os trabalhadores (BRASIL, 1992). 
Assim, as doenças profissionais são aquelas em que o trabalho ou suas condições constituem a causa direta desses agravos, ou seja o nexo causal é direto e imediato MENDES; DIAS (1999).

As doenças relacionadas ao trabalho, são aquelas que apresentam um aumento da freqüência de sua ocorrência ou uma precocidade de seu surgimento ou ampliação do espectro de sua etiologia devido a inserção no trabalho como, por exemplo, a hipertensão arterial de motoristas de transportes de passageiros, a asma brônquica, a dermatite de contato alérgica, a perda auditiva induzida pelo ruído entre outras - MENDES; DIAS (1999).

Nesse estudo, os problemas de saúde referidos pelos trabalhadores de enfermagem se caracterizam como doenças relacionadas ao trabalho.

Segundo SILVA (1996), a preocupação com o controle dos efeitos do trabalho na saúde dos trabalhadores de enfermagem surgiu há algumas décadas. Como exemplos citamos o trabalho desenvolvido pela Organização Intrnacional do Trabalho - OIT que, em 1977, em Genebra, em sua Conferência Mundial, reconhecendo a especificidade e a importância do trabalho de enfermagem que, junto às outras categorias de trabalhadores dos serviços de saúde, desempenham um papel relevante na proteção e recuperação da saúde e bem estar da população, adotou a Convenção 149 e a Recomendação 157 que dispuseram sobre as condições de trabalho e vida dos trabalhadores de enfermagem e pelo Conselho Internacional de Enfermeiras - CIE, que, em 1987, na Nova Zelândia, realizou um fórum para tratar da saúde e segurança no trabalho de enfermagem (OIT, 1977; CIE,1987)

Entretanto não encontramos estudos sobre a incidência de doenças entre os trabalhadores de enfermagem de UBS.

Nos estudos realizados em instituições hospitalares, os principais problemas de saúde apontados pelos trabalhadores de enfermagem são relativos a: problemas de coluna, doenças do aparelho genito-urinário, outros problemas ortopédicos e reumatológicos, doenças infecciosas e parasitárias, hipertensão arterial (SOARES; PEIXOTO 1987; SILVA, 1996; LIMA JUNIOR, 1998 e MONTOLIU, et al. 1997).

Outro indicador que pode revelar-nos uma certa predição em relação ao desgaste do trabalhador, é a ocorrência de acidentes de trabalho em que, conforme já foi mostrado anteriormente, entre os enfermeiros e auxiliares de enfermagem, as lesões com material perfuro cortante foram as mais citadas, sendo que nesse caso $100 \%$ dos trabalhadores que manipulam agulhas estão sujeitos a esse tipo de acidente, o que é agravado pela falta no local de trabalho de instrumentos, tais como aparelho para destruir as agulhas, que possam estar minimizando este risco. A existência do risco de acidente, implica carga mecânica e psíquica que levam a um desgaste mental do trabalhador, conforme já foi discutido anteriormente. 
LIMA JUNIOR (1998 p. 121) em seu estudo sobre o processo de desgaste/prazer no trabalho dentro de um hospital universitário, refere-se a que " $\mathrm{Na}$ organização hospitalar, dificilmente existe a preocupação com aspectos relacionados à proteção, à promoção, e à manutenção da saúde de seus funcionários; esta situação é paradoxal, pois ao mesmo tempo que o hospital tem como missão salvar vidas e recuperar a saúde dos individuos enfermos, favorece o adoecer das pessoas que nele trabalham"

Em relação ao trabalho da equipe de enfermagem, este mesmo autor afirma que "neste contexto, os enfermeiros, técnicos e auxiliares de enfermagem expõem a sua saúde e segurança à mercê das condições de trabalho que os colocam diante de riscos ocupacionais diversos favorecendo o aparecimento de acidentes, sofrimentos e doenças" (LIMA JUNIOR, 1998 p. 121).

No caso dos trabalhadores de enfermagem das UBS, pode-se concluir que estão expostos a condições que implicam um desgaste que, se no momento não está sendo expresso através de sinais e sintomas, pode vir a desencadear um desequilíbrio no processo saúde-doença destes trabalhadores. 
7 CONCLUSÕES 
Este estudo teve como objeto as condições de trabalho dos trabalhadores de enfermagem de 11 Unidades Básicas de Saúde de Juiz de Fora, com as quais a Faculdade de Enfermagem da UFJF vem desenvolvendo atividades de ensino.

Através da identificação das condições favoráveis e desfavoráveis presentes no trabalho, segundo a percepção do trabalhador, pode-se sinalizar para a repercussão, dessas condições, na vida e no processo-saúde doença desses trabalhadores.

As UBSs estudadas se caracterizam por serem construções em sua maioria da década de 80 , apresentando estruturas fisicas que vêm dificultando o desenvolvimento das atividades. Apesar de já terem sofrido sucessivas reformas, ainda necessitam que seus espaços sejam reestruturados para se adequarem às propostas de trabalho. Em apenas uma unidade a estrutura fisica se constituiu em condição favorável, contribuindo para o desenvolvimento do trabalho.

A maioria dos trabalhadores são mulheres, casadas e com 2 ou mais filhos, com uma jornada de trabalho diária de cerca de 8 horas, que consideram insuficiente para a realização das tarefas

Assim, esses trabalhadores permanecem $1 / 3$ do seu dia no local de trabalho e relatam a inexistência de um local apropriado para guarda de pertences pessoais.

Quando retornam às suas casas, sentem necessidade de descansar, o que nem sempre é possível devido ao trabalho doméstico com a casa, os filhos e o companheiro ou marido.

A divisão social do trabalho de enfermagem se faz presente entre os trabalhadores estudados, por exemplo quando identificamos que a diferença entre o salário de enfermeiros e auxiliares é de, na maioria das vezes, o dobro, ocorrendo o mesmo em relação à renda familiar e per capita. No que diz respeito à posse da moradia, também existe uma diferença mas esta é menor uma vez que $65 \%$ dos auxiliares e $85,7 \%$ dos enfermeiros possuem casa própria, com mais de cinco cômodos. $\mathrm{O}$ acesso ao lazer também é diferenciado, apesar de em ambas as categorias a televisão, a leitura, viagens e passeios terem sido citados como as principais fonte de lazer sendo que a frequência a cinema, teatro e concertos aparece mais entre os enfermeiros.

Em relação às ações que vêm sendo realizadas, tanto as de competência dos auxiliares como as dos enfermeiros demonstram a predominância do modelo clínico individual nas UBSs; apesar de existirem ações que mostram um movimento na direção de uma atenção mais voltada para o coletivo. 
A assistência à saúde se restringe predominantemente nà atenção de alguns aspectos da saúde da mulher e da criança, sendo que a atenção à saúde do adulto e do trabalhador tem ficado para níveis mais especializados.

Nas Unidades foram mencionadas condições favoráveis, que não estão presentes em todas elas, sendo que muitas das vezes quando ausentes significam um condição desfavorável.

Foram citados: bom relacionamento com a comunidade, e com a equipe; ventilação, iluminação e instalações adequadas, existência de materiais, equipamentos e mobiliários; existência de espaço físico bonito/agradável, calmo/tranquilo e organizado, com distribuição adequada das salas e existência de privacidade.

A simples existência do espaço físico para o desenvolvimento de determinada ação foi encarada como uma condição favorável, mesmo estes espaços estando necessitando de mais recursos, pois as dificuldades em relação à falta de espaço é tão forte e presente que a simples existência deste é considerada positivamente.

As condições desfavoráveis do trabalho fazem com que os trabalhadores estejam submetidos a cargas fisicas, químicas, biológicas, fisiologicas, psíquicas e mecânicas com predominância das últimas.

O trabalho é realizado com desvio de função, com falta de organização, atividades burocráticas em excesso, em espaços físicos deficientes, mal iluminados, ruidosos e pouco ventilados, utilizando-se instrumentos e ou equipamentos defeituosos, inadequados, ou que necessitam de manutenção, com falta de recursos humanos, materiais e de mobiliário, convivendo-se quotidianamente com o risco de contaminação e submetidos a pó e poeira.

O trabalho realizado não é considerado "pesado" em relação ao desenvolvimento de atividade fisica, mas os trabalhadores evidenciam $o$ fato de assumir postura física inadequada em decorrência das condições de trabalho.

A relação com o usuário é, às vezes, conflituosa, o que é expresso através da queixa de tumulto, aglomeração, ruído, insatisfação do usuário pela demora no atendimento, ou pela falta de atendimento, ansiedade e estresse, na recepção das UBS.

O método utilizado de mapeamento de riscos através da enquete coletiva favoreceu a auto-reflexão do trabalhador sobre a sua condição de trabalho, levando-o a elaborar estratégias de enfrentamento das situações/problema mencionadas. 
Assim os trabalhadores apresentaram propostas sobre como solucionar alguns dos problemas levantados, como por exemplo existência de um serviço de manutenção mais ágil e atuante; aquisição de materiais, equipamentos e mobiliários; reforma das UBSs; reestruturação interna das unidades; organização de salas de espera separadas por área de atendimento, externas ao posto; utilização de senhas e maior orientação e informação aos usuários.

Demonstraram também uma descrença na possibilidade de encaminhamento e resolução dos problemas, como no caso de algumas das cargas fisicas como iluminação e ventilação insuficientes, por considerarem a solução muito ampla, com sugestões do tipo: "-- só construindo outro posto".

O trabalho aparece como fonte de satisfação tanto entre enfermeiros como entre auxiliares em aspectos que dizem respeito à possibilidade de relacionamento interpessoal, e como fonte de insatisfação no que diz respeito ao volume de tarefas administrativas e em relação ao salário.

Ele é considerado também perigoso e insalubre, sendo que alguns trabalhadores já sofreram acidentes com material perfuro-cortante, e apresentam problemas de saúde como hipertensão.

As UBSs são espaços onde se pretende tratar e prevenir doenças. Por que então estes não são locais mais saudáveis para os trabalhadores e para a comunidade? Por que não possuem algum tipo de entretenimento para as crianças e adultos, como brinquedos, som ambiente e revistas? Em algumas das unidades construídas com a verba do PSF, o aspecto agradável (paredes limpas e coloridas, balcões novos), mencionado pelos trabalhadores chama a atenção.

É evidente que muitas das condições desfavoráveis e portanto geradoras de cargas poderiam ser evitadas se os trabalhadores fossem ouvidos, por exemplo, em relação à disposição e organização dos espaços dentro da unidade. Ocorre no serviço uma falta de participação dos trabalhadores nas decisões que são tomadas, tanto porque eles não são ouvidos como porque não se fazem ouvir.

Assim como hoje algumas unidades estão sendo construídas, e o trabalho está sendo direcionado em função e para servir ao programa de saúde da familia, no passado algumas unidades também foram construídas para servirem a programas específicos (como as policlínicas). Embora, em seu início, estes espaços tenham funcionado e servido aos interesses para os quais foram criados, o tempo, as mudanças políticas e as necessidades da população mostraram a insuficiência ou a inadequação dessas propostas, restando espaços físicos insalubres, inadequados, de dificil reestruturação que acabam passando por sucessivas reformas, utilizando o dinheiro público, sem nunca se adequarem de fato às necessidades dos trabalhadores $\mathrm{e}$ de atendimento da comunidade. 
Pode-se concluir que as condições desfavoráveis estão mais presentes do que as favoráveis. No entanto, os trabalhadores de enfermagem das UBSs de Juiz de Fora estão sujeitos a condições de trabalho que tanto os expõem a cargas, que ao longo do tempo podem levar a um desgaste das capacidades vitais destes trabalhadores, como estão sujeitos a condições benéficas que, se ampliadas, podem potencializar essas capacidades. 
8 REFERÊNCIAS BIBLIOGRÁFICAS 
ALEXANDRE, N. M. C. Ergonomia e as atividades ocupacionais da equipe de enfermagem. Rev. Esc. Enf. USP, São Paulo, v.32, n. 1, p.84-90. 1998.

ALEXANDRE, N. M. C. et al. Dores nas costas e enfermagem. Rev. Esc. Enf. USP, São Paulo, v.30, n.2, p.267-85. 1996.

ALEXANDRE, N. M. C. et al. Modelo de um curso de orientação sobre determinados aspectos ergonômicos e posturais no trabalho do pessoal de enfermagem. Rev. Bras. De Saúde Ocup., São Paulo, v.19, n74, p.61-65. 1991.

ALEXANDRE, N. M. C.; BENATTI, M. C. C. Acidentes de trabalho afetando a coluna vertebral: um estudo realizado com trabalhadores de enfermagem em um hospital universitário. Rev. Latino-am. Enf. Ribeirão Preto, v.6, n.2, p.65-72. 1998.

ALMEIDA, M. C. P. de et al. A situação da enfermagem nos anos 80. In: Anais $41^{\circ}$ Congresso Brasileiro de Enfermagem. Florianópolis, 1989.

ALMEIDA, M. C. P; ROCHA, S. M. M. (org.) O trabalho de enfermagem. São Paulo, Cortez, 1997.

ALMEIDA, M.C. P. de et al. O Trabalho de Enfermagem e sua articulação com o processo de trabalho em saúde coletiva - rede básica de saúde. In: ALMEIDA, M. C. P de; ROCHA, S. M. M.(org.). O trabalho de enfermagem. São Paulo, Cortez, 1997, p.61-112.

ALMEIDA, M.C. P. de et al. Os determinantes dos modelos assistenciais e a qualificação da força de trabalho em enfermagem. In: $48^{\circ}$ Congresso Brasileiro de Enfermagem. Anais, São Paulo, 1996.

ALMEIDA, M.C. P. de; ROCHA, J.S.Y. O saber da enfermagem e sua dimensão prática. São Paulo, Cortez, 1989.

ANTUNES, R. Adeus ao trabalho: ensaios sobre as metamorfoses e a centralidade do mundo do trabalho. São Paulo, Cortez, 1995.

ANTUNES, R. Os sentidos do trabalho: ensaio sobre a afirmação e a negação do trabalho. São Paulo, Boitempo, 1999.

AQUINO, et al. Mulher, Saúde e trabalho no Brasil: desafios para um novo agir. Cad. Saúde Públ., Rio de Janeiro, v.11, n.2, p.281-290, abr/jun., 1995.

AZEVEDO, A. P. et al. Ruido - um problema de saúde pública (outros agentes físicos). In: BUSCHINELLI, J. T. et al (org.) Isto é trabalho de gente? Vida, doença e trabalho no Brasil. São Paulo, Vozes, cap.21, p. 403-35. 1993. 
BASURTE, D. B.; PEREZ, M. B. Estudio descriptivo de los hábitos y patologias mas frecuentes en una unidad de salud laboral. Rev . Medic. Y Seg. del Trab. Madri. Espanha, n. 173, p.41-46. 1997.

BENATTI, M. C. C. Acidente do trabalho em um Hospital Universitário: um estudo sobre a ocorrência e os fatores de risco entre trabalhadores de enfermagem. São Paulo, 1997. Tese (Doutorado) - Escola de Enfermagem da Universidade de São Paulo.

BERNARDES, R. Trabalho a centralidade de uma categoria analítica. São Paulo em Perspectiva, v. 8 n. 1, p33-41, 1993.

BERNARDINA, L. D. et al. Postura corporal adotada pelos membros da equipe de enfermagem durante procedimentos de colheita de sangue, administração de medicação endovenosa e soroterapia. Rev. Esc. Enf. USP, São Paulo, v.29, n. 3, p.317-30. 1995 .

BETANCOURT, O. La salud y el trabajo: reflexiones teórico-metodológicas, monitoreo epidemiológico, atención básica en salud. Quito, CEAS, 1995.

BOTTI, C. A. H. et al. Companhia mineira de eletricidade. Companhia Energética de Minas Gerais, Centro de Pesquisas Sociais, UFJF. 1994.

BRANDI, S. et al. Ocorrência de acidente de trabalho por material perfuro-cortante entre trabalhadores de enfermagem de um Hospital Universitário da cidade de Campinas. Rev. Esc. Enf. USP, São Paulo, V.32, n.2, p.124-33, ago. 1998.

BRASIL. Consolidação das Leis do Trabalho. São Paulo, Saraiva, 1992.

BRASIL. Constituição da República Federativa do Brasil. Brasília, Imprensa Oficial da União, 1988.

BRASIL. Lei n. ${ }^{\circ} 7.498$, de 25 de junho de 1986. Dispõe sobre a regulamentação do exercício de Enfermagem e dá outras providências. Brasília, Conselho Federal de Enfermagem, 1986.

BRASIL. Ministério da Saúde. Secretaria de Assistência à Saúde. Coordenação de Saúde da Comunidade. Saúde da Família: uma estratégia para a reorientação do modelo assistencial. Brasilia. Ministério da Saúde, 1997.

BREILH, J. Nuevos conceptos y técnicas de investigación: guia pedagógica para un taller de metodología. Quito, CEAS, 1995.

CASTEllaNOS, B. E. P. et al. Os desafios da enfermagem para os anos 90 . In: Anais. Congresso Brasileiro de Enfermagem, 41. Florianópolis, ABEN, 1989. 
CHAVES, E. H. B. ; MOURA, G. M. S. S. O estresse na atividade gerencial do enfermeiro. Rev. Panam. Salud. Publica. V.6, n.6, 1999, p.415-425.

CODO, W. et. al. Indivíduo trabalho e sofrimento: uma abordagem interdisciplinar. Petrópolis, Vozes, 1993.

COHN, A.; MARSIGLIA, R. G. Processo e organização do trabalho. In: FISCHER, F. M.; GOMES, J. da R.; COLACIOPPO, S. Tópicos de Saúde do Trabalhador. São Paulo, HUCITEC, 1989. p.56-74.

COLACIOPPO, S. Higiene Ocupacional: da teoria à prática. In: FISCHER, F. M.; GOMES, J. da R.; COLACIOPPO, S. Tópicos de Saúde do Trabalhador. São Paulo, HUCITEC, 1989. p.73-98.

CONSEJO INTERNACIONAL DE ENFERMERAS (CIE). Salud en el Trabajo: la proteción de los interesses del personal de enfermería. Nueva Zelandia, 1987.

COSTA, A. E. et al. Os pré-juizos e a tradição na enfermagem. Rev. Esc. Enf. USP, v.29, n.3, p.261-66, dez. 1995.

DEJOURS, C. A loucura do trabalho: estudo de psicopatologia do trabalho. São Paulo, Oboré, 1988

DEJOURS, C. et al. Psicodinâmica do trabalho: contribuições da escola Dejouriana à análise da relação prazer, sofrimento e trabalho. São Paulo, Atlas, 1994.

FACCHINI, L. A . Uma contribuição da epidemiologia: o modelo da determinação social aplicado à saúde do trabalhador. In: BUSCHINELLI, J. T. et al (org.) Isto é trabalho de gente? Vida, doença e trabalho no Brasil. São Paulo, Vozes, cap. 11, p. 179-86, 1994.

FACCHINI, L. A. Por que a doença? A inferência causal e os marcos teóricos da análise. In: BUSCHINELLI, J. T. P. ; ROCHA, L. E. ; RIGOTTO, R. M. (Orgs.) Isto é trabalho de gente? Vida, doença e trabalho no Brasil. Petrópolis, Vozes, 1994 a.

FACCHINI, L.A. Processo de trabajo, cambio tecnológico y desgaste obrero el caso del ingenio de azúcar " Adolfo Lopez Mateos". México, 1986. Dissertação (Mestrado) - Universidad Autônoma Metropolitana.

FARAH, B. F. Educação Continuada das Enfermeiras no Sistema Único de Saúde: o caso da rede básica de Juiz de Fora. Rio de Janeiro; 1999. [Dissertação de mestrado - Escola de Enfermagem Anna Nery da Universidade Federal do Rio de Janeiro]. 
FIGUEIREDO, R. M. DE. Opinião dos servidores de um hospital escola a respeito de acidentes com material perfurocortante na cidade de Campinas. Rev. Bras. S. Ocup., São Paulo, v.20, n76, p. 26-33 1992.

FIORI, A. M. Stress ocupacional. Rev. Cipa. S/d. p.40-49.

FONSECA, R. M. G. S. da. Mulher, trabalho e enfermagem: o nexo coesivo. In: $47^{\circ}$ Congresso Brasileiro de Enfermagem. Anais, Goiânia, 1995.

FRANCO, A. R. Estudo preliminar das repercussões do processo de trabalho sobre a saúde dos trabalhadores de um hospital geral. Ribeirão Preto, 1981. Tese (Doutorado) - Faculdade de Medicina de Ribeirão Preto, Universidade de São Paulo.

FUNDAÇÃO SEADE. Pobreza e riqueza: pesquisa de condições de vida na Região Metropolitana de São Paulo: definição e mensuração da pobreza na Região Metropolitana de São Paulo: uma abordagem multissetorial. São Paulo, SEADE, 1992.

GARCIA, J. C. A categoria trabalho na Medicina. In: NUNES, E. D. (org.) Juan César Gárcia: Pensamento social em saúde na América Latina . São Paulo, Cortez, 1989, p. 100-26.

GERSCHAN, S. A democracia inconclusa: um estudo da reforma sanitária brasileira. Fiocruz, Rio de Janeiro, 1995.

GIR, E. et al. A enfermagem frente a acidentes de trabalho com material potencialmente contaminado na era do HIV. Rev. Esc. Enf. USP, São Paulo, v. 32, n.3, p.262-72, out. 1998.

GOLDENSTEIN, G. T. Lazer operário e consumo cultural na São Paulo dos anos oitenta. Rev. Adm. Emp. São Paulo, n.31, v.3 p.13-35, 1991.

GONÇALVES, R. B. M. Tecnologia e organização social das práticas de saúde: características tecnológicas de processo de trabalho na rede estadual de centros de saúde de São Paulo. Hucitec/ABRASCO, São Paulo, 1994.

GORZ, A. Adeus ao proletariado. Rio de Janeiro, Forense, 1982.

GRANDA, E.; BREILH, J. Saúde na sociedade: guia pedagógicn sobre um novo enfoque do método epidemiológico. Rio de Janeiro, ABRASCO/Cortez, 1989.

HABBERMAS, J. A nova instransparência. Novos Estudos Cebrap, São Paulo, n. $18,1987$. 
JODRA, V. M. Registros de accidentes biológicos en trabajadores sanitarios expuestos a contactos con sangre $u$ otros productos procedentes de pacientes. Med. Seg. Trab. Madrid, n. 174, p.43-50, 1997.

JONAS, E. Gênero, mercado de trabalho e conformação profissional - um olhar sobre a mulher trabalhadora de enfermagem. In: $47^{\circ}$ Congresso Brasileiro de Enfermagem. Anais, Goiânia, 1995.

JUIZ DE FORA, PREFEITURA MUNICIPAL. Decreto n. 5773 de 12 de novembro de 1996: Institui o Programa de Saúde da Família no âmbito do Município de Juiz de Fora Juiz de Fora. 1996.

JUIZ DE FORA. Plano Municipal de Saúde, Secretaria Municipal de Saúde, 1997 (mimeo).

LAURELL A C.; NORIEGA M. Processo de produção e saúde: trabalho e desgaste operário. São Paulo, Hucitec, 1989.

LAURELL, A. C. et al. La experiencia obrera como fuente de conocimiento: confrontación de resultados de la encuesta colectiva e individual. Cuadernos Méd. Sociales, n.51. 1990.

LAURELL, A. C. La política social en la crisis: una alternativa para el sector salud. Saúde e Sociedade, n.2, v.2, p.85-99, 1993.

LIMA JUNIOR, J. H. V. L. Trabalhador de Enfermagem: de anjo de branco a profissional. São Paulo, 1998. Tese (Doutorado) - Escola de Administração de Empresas de São Paulo - Fundação Getúlio Vargas.

MANTOVANI, M. de F. et al. A morbidade em trabalhadores de enfermagem hospitalar. (mimeo).

MARX, K. O capital: critica da economia politica. 3.ed. São Paulo. Nova Cultural. 1988. V.1.

MASCARENHAS, R dos S. História da Saúde Pública no Estado de São Paulo. Rev. Saúde Publ. São Paulo, n.7, p.433-46, 1973.

MAURO, M. Y. C. A saúde do trabalhador de enfermagem. Jorn. Bras. Enf. São Paulo, n.87 ano XII, set/out. 1988.

MELO, C. M. M. de. Divisão social do trabalho e enfermagem. São Paulo, Cortez, 1986.

MENDES, R. DIAS, E. C. Saúde dos trabalhadores. In: ROUQUAYROL, M. Z. ALMEIDA FILHO, $\mathrm{N}$ de (org.) Epidemiol00ogia e Saúde. Rio de Janeiro, MEDSI, p. $431-56,1999$. 
MENDES, R.; DIAS, E. C. Da medicina do trabalho à saúde do trabalhador. Rev. Saúde Públ, v.25, n.5, p.341-9. 1991.

MONTOLIU, M. A. et al. Condiciones de trabajo en hospitales. Estudio comparativo en 10 hospitales del sistema nacional de salud. Rev . Medic. Y Seg. del Trab. Madri. Espanha, n. 174, p.17-24. 1997.

NAKAMAE. D. D. Novos Caminhos da Enfermagem. São Paulo, Cortez, 1987.

ODDONE, I. et al. Ambiente de trabalho: a luta dos trabalhadores pela saúde. São Paulo, HUCUTIC, 1986.

OFFE, C. Trabalho e sociedade: problemas estruturais e perspectivas para o futuro da sociedade do trabalho. Rio de Janeiro, Tempo brasileiro, vol 1 e 2, 1991.

ORGANIZACIÓN INTERNACIONAL DEL TRABAJO (OIT). Convenio 149 de la OIT. Convenio sobre el empleo y condiciones de trabajo y de vida del personal de enfermeria . Ginebra, 1977.

ORGANLZACIÓN INTERNACIONAL DEL TRABAJO (OIT). Recomendación 157 de la OIT. Recomendación sobre el empleo y condiciones de trabajo y de vida del personal de enfermeria . Ginebra, 1977.

ORGANIZACIÓN INTERNACIONAL DEL TRABAJO (OIT). Reunión Conjunta sobre condiciones de trabajo y de vida del personal de enfermería. Ginebra, 1973.

PADILHA, M. I. C. de S. A mulher/enfermeira nos âmbitos doméstico-familiar e público - uma abordagem teórica-contextual. Rev. Esc. Enf. USP, v.29, n.3, p.246-60, dez. 1995.

PADILHA, M. I. C. de S. et al. Enfermeira - a construção de um modelo a partir do discurso médico. Rev. Esc. Enf. USP. v.31, n.3, p.437-51, dez, 1997.

PICCOLO, L. A. V. Condições perigosas e favoráveis do trabalho em obras do metrô: expandindo os mapas de risco no estudo da relação trabalho/saúde. São Paulo, 1998. 115p. Dissertação (Mestrado) - Escola de Enfermagem, Universidade de São Paulo

PITTA, A. Hospital dor e morte como oficio. São Paulo, HUCITEC 1990.

POSSAS, C. Epidemiologia e sociedade: heterogeneidade estrutural e saúde no Brasil. São Paulo, HUCITEC, 1989.

QUEIROZ, V. M.; SALUM, M. J. L. Operacionalizando a heterogeneidade do coletivo na releitura da categoria reprodução social. São Paulo, s/d. (mimeo). 
QUEIROZ, V. M.; SALUM, M. J. L. Reconstruindo a intervenção de enfermagem em saúde coletiva face a vigilância à saúde. In: 48 Congresso Brasileiro de Enfermagem. São Paulo, ABEn, 1996.

RIGOTTO, R. M. Investigando a relação entre saúde e trabalho. In: BUSCHINELLI, J. T. P. ; ROCHA, L. E. ; RIGOTTO, R. M. (Orgs.) Isto é trabalho de gente? Vida, doença e trabalho no Brasil. Petrópolis, Vozes, 1994.

ROCHA, S. M. M. Puericultura e enfermagem. São Paulo, Cortez, 1987.

SALUM, M. J. L. et al Necessidades de aperfeiçoamento dos enfermeiros da Secretaria de Estado da Saúde do Estado de São Paulo diante do Sistema Único de Saúde. Saúde Deb., n. 51

SANTOS, W.D.F. et al. Acidentes típicos de trabalho em pessoal de enfermagem. Rev. Bras. Saúde. Ocup., v.17, n.68, p.38-42, 1989.

SELIGMAN SILVA, E. Desgaste mental no trabalho dominado. Rio de Janeiro, Cortez, 1994.

SILVA, E. M. et al. Enfermagem: realidade e perspectiva na assistência e no gerenciamento. Rev. Lat. Am. Enf. Ribeirão Preto, v.1, n.1, p. 59-63, 1993.

SILVA, V. E. F. da Estudo sobre acidentes de trabalho ocorridos com trabalhadores de enfermagem de um hospital de ensino. São Paulo, 1988. 176p. Dissertação (Mestrado) - Escola de Enfermagem, Universidade de São Paulo.

SILVA, V. E. F. da. O desgaste do trabalhador de enfermagem: relação trabalho de enfermagem e saúde do trabalhador. São Paulo, 1996. Tese (Doutorado) Escola de Enfermagem, Universidade de São Paulo.

SOARES, O. ;PEIXOTO, J. C. Graus de riscos a que estão expostos os trabalhadores em instituições hospitalares: modelo de intervenção de enfermagem centrado nos riscos dominantes. Rev. Bras. Enf., Brasilia, v.40, n.2/3, p. 150-156.1987.

UNIVERSIDADE FEDERAL DE JUIZ DE FORA (UFJF). Anuário Estatístico de Juiz de Fora - 1995. Juiz de Fora. Centro de Pesquisas Sociais/UFJF/Prefeitura Municipal. 1996.

UNIVERSIDADE FEDERAL DE JUIZ DE FORA (UFJF). Anuário Estatístico de Juiz de Fora - 1997. Juiz de Fora. Centro de Pesquisas Sociais/UFJF/Prefeitura Municipal. 1998.

UVA, A. de S. ; FARIA, M. Exposição profissional a substâncias químicas: diagnóstico das situações de risco. Rev. Port. de Saúde Públ. Lisboa, Portugal, v. 18, n. 1, p. $5-10,2000$. 
VICENTIM, L. et al. Administração da assistência de enfermagem e a atuação do enfermeiro. $\mathrm{s} / \mathrm{d}$. (mimeo).

VICTORA, C. G. et al. Pobreza e saúde: como medir nível sócio-econômico em estudos epidemiológicos de saúde infantil? In: Congresso Brasileiro de Epidemiologia 10, Campinas, 1990.

WAKAMATSU, C. T. et al. Riscos de insalubridade para o pessoal de hospital. Rev. Bras. S. Ocup., São Paulo, v. 14, n53, 1986.

ZANON, E.; MARZIALE, M. H. P. Avaliação da postura corporal dos trabalhadores de enfermagem na movimentação de pacientes acamados. Rev. Esc. Enf. USP, São Paulo, v.34, n. 1, p.26-36. 2000. 
ANEXO 1 
Formulário . $^{\circ}$

Condiçōes de trabalho e de vida dos ENFERMEIROS da rede básica de saúde de Juiz de Fora

1 - DADOS GERAIS

1.1 - Em que dia/mês/ano você nasceu?

1.2 - Sexo M( ) F( )

1.3 - Qual o seu estado civil?

Solteiro ( )

Casado ( )

Viúvo ( )

Separado ( )

Divorciado ( )

União livre ( )

1.4 - Você tem filhos?

Sim ( ) Quantos?

não ( )

2 - DADOS SOBRE MORADIA

2.1 - Há quanto tempo mora em Juiz de Fora?

Menos de um ano ( )

De 1 a 3 anos ( )

De 4 a 6 anos ( )

De 7 a 9 anos ( )

10 ou mais anos ( )

2.2 - A residência onde você mora é:
própria
alugada
cedida
( )
( )
( )

2.3 - Quantos cômodos tem sua residência?

1 a 2 cômodos

3 a 4 cômodos

5 a 6 cômodos

7 ou mais cômodos

( )
$($ )
$($ )

2.4 - Quantas pessoas moram com você ?

Mora sozinho (a) ( )

De 1 a 3 pessoas ( )

De 4 a 6 pessoas ( )

De 7 a 9 pessoas ( )

10 ou mais pessoas ( ) 


\section{3 - DADOS SOBRE LAZER}

3.1 - Das que eu vou citar, qual ou quais as atividades de recreação você realiza?:

Esporte (atividade fisica)

Vê televisão

Atividades culturais (cinema, teatro, concertos)

Leituras (revistas, jornais, romances)

Turismo (viagens, passeios)

Outras

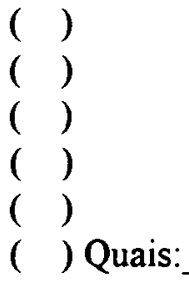

\section{DADOS DE ORGANIZAÇÃO SOCIAL}

4.1 -- Você participa ativamente de algum grupo/associação? (admite mais de uma resposta):

ligado ao trabalho

ligado ao bairro

( )

ligado a igreja

( )

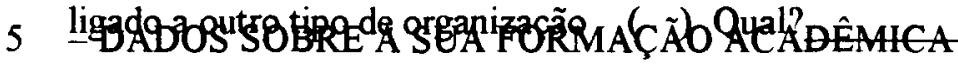

5.1 - Em que ano você se formou?

5.2 - Você tem alguma especialização?

$\operatorname{sim}($ ) Área

não ( ) Por que?

6 - DADOS SOBRE A ORGANIZAÇÃO DO TRABALHO

6.1 - Atualmente você têm quantos empregos:

um emprego

dois empregos

( )

três empregos

( )

( )

mais de três empregos

( )

6.2 - Quantas horas você trabalha por dia?:

menos de 8 horas

8 horas

mais de 8 horas

$($ )
$($ )

6.3 Quais das seguintes atividades relacionadas à prestação da assistência, que eu vou citar, você realiza?

consulta de enfermagem

prescrição de enfermagem

cuidados de enfermagem de maior complexidade técnica que exigem

conhecimentos de base cientifica e capacidade de tomar decisões imediatas ( )

assistência de enfermagem à gestante, e puérpera

assistência de enfermagem à criança

assistência de enfermagem ao adolescente

assistência de enfermagem ao trabalhador

assistência de enfermagem ao idoso

outra atividade

Não realiza

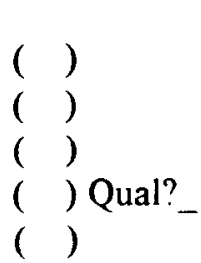


6.4 Quais das seguintes atividades relacionadas com a administração da assistência de enfermagem, que eu vou citar, você realiza?

organização e direção do serviço de enfermagem e de suas atividades técnicas

e auxiliares

planejamento, organização, coordenação, execução e avaliação dos serviços de

assistência de enfermagem;

consultoria, auditoria e emissão de parecer sobre matéria de enfermagem;

participaç̃o na elaboraça execucão e avaliacão dos planos assisteciais de saúde; ( )

participação na formulação do diagnóstico de saúde da população; ( )

participação em projetos de construção ou reformas de unidades;

participação no processo de recrutamento e seleção de pessoal de enfermagem; ( )

participação no planejamento, execução e avaliação dos programas de saúde em

todos os niveis;

prevenção e controle sistemático da infecção e das doenças transmissiveis;

prevenção e controle sistemático de danos que possam ser causados à clientela

durante a assistência de enfermagem.

outra atividade

Qual?

Não realiza

6.5 Quais das seguintes atividades relacionadas com o ensino, que eu vou citar, você realiza?

define programas de atualização e aperfeiçoamento do pessoal de enfermagem;

planeja, organiza, executa e avalia o treinamento do pessoal de enfermagem e

de educação continuada em serviço;

desenvolve orientações ao individuo, familia e comunidade, visando à

educação para a saúde;

participa e/ou colabora com as escolas na formação de pessoal de enfermagem em

todos os niveis.

outra atividade

Qual?

Não realiza

6.6 Quais das seguintes atividades relacionadas com pesquisa, que eu vou citar, você realiza?

Realiza pesquisas em assuntos de enfermagem; participa em pesquisa na área da saúde em geral; organiza e mantém atualizado o registro de enfermagem; outra atividade

Qual?

Não realiza

6.7 Você acha que o tempo para realizar todas as suas tarefas em cada dia de trabalho é:

$\begin{array}{ll}\text { insuficiente } & (\text { ) } \\ \text { suficiente } & (\text { ) } \\ \text { mais do que suficiente } & (\text { ) }\end{array}$


6.8 - No seu trabalho você se sente: muito satisfeito (4); satisfeito (3), insatisfeito (2), muito insatisfeito (1) em relação a:

aproveitamento de suas aptidões

aplicação prática dos conhecimentos teóricos adquiridos

na formação acadêmica

salário

nivel de responsabilidade

poder de decisão

perspectivas de carreira

reconhecimento social do cargo ou atividade profissional

possibilidades de contatos e intercâmbio profissional ( )

volume de tarefas administrativas

relacionamento com os colegas

possibilidade de realizar trabalho criativo e inovador ( )

6.9 - De maneira geral, quando você sai do trabalho no fím da jornada:

sente necessidade de descansar

tem disposição para se divertir

tem disposição para continuar trabalhando na mesma atividade

tem disposição para cuntinuar trabalhando em outra atividade

tem disposição para estudar

\section{7 - DADOS SOBRE O AMBIENTE DE TRABALHO}

7.1 - Para você a temperatura do seu local de trabalho é: agradável desagradável

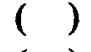

( )

7.2 - A condição de iluminação do seu local de trabalho é: excessiva ( )

suficiente ( )

insuficiente ( )

outra ( ) Qual?

7.3 - A condição de ventilação do seu local de trabalho é: excessiva ( ) suficiente ( ) insuficiente ( ) outra

( ) Qual? 
7.4 - Em seu trabalho você está submetido a :

risco de contaminação por microorganismos

(vírus, bactérias e fungos)

poeiras, vapores, gases

produtos químicos tóxicos

radiações

ruído

vibrações

trabalho fisico pesado

postura inadequada

tensão emocional

monotonia

repetitividade

arranjo fisico deficiente

(falta de espaço, piso escorregadio e outros) ( )

instrumentos e ou equipamentos inadequados

instrumentos e ou equipamentos defeituosos ( )

7.5 - Considera o seu trabalho perigoso?:

$\operatorname{sim}($ ) não ( )

7.6 Se sim, por quê?

7.7 Considera o seu trabalho insalubre?

Sim ( ) não ( )

7.8 Se sim, por quê?

7.9 - Você já sofreu algum acidente de trabalho?

$\operatorname{sim}($ ) não ( )

Tipo

\section{8 - DADOS SOBRE A RELAÇÃO NO TRABALHO}

8.1 - Em relação aos membros da equipe de enfermagem, a relação deles com você é de (admite mais de uma resposta):

$\begin{array}{ll}\text { respeito } & (\text { ) } \\ \text { obediência } & (\text { ) } \\ \text { companheirismo } & (\text { ) } \\ \text { competição } & (\text { ) } \\ \text { rivalidade } & (\text { ) } \\ \text { subalternidade } & (\text { ) } \\ \text { outro } & (\text { Qual? }\end{array}$


8.2 A relação dos demais membros da equipe de saúde com você é de (admite mais de uma resposta):
respeito
obediência
companheirismo
competição
rivalidade
subaltemidade
Outro

$\begin{array}{ll}( & ) \\ ( & ) \\ ( & ) \\ ( & ) \\ ( & ) \\ ( & ) \\ ( & \text { Qual? }\end{array}$

8.3 - Em relação à sua atenção aos pacientes, você se sente:

muito satisfeito

satisfeito

insatisfeito

muito insatisfeito

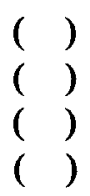

\section{9 - DADOS SOBRE OS BENEFÍCIOS DO TRABALHO}

9.1 - O seu trabalho oferece algum dos beneficios abaixo (admite mais de uma resposta)?

Cesta básica

Vale transporte

Assistência médica

Vale refeição

Creche ou auxilio-creche

Outro

Nenhum

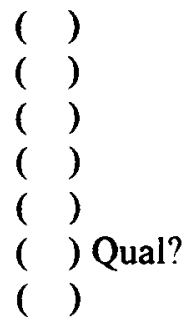

9.2 - Qual a faixa de total bruto você recebeu do último mês em reais?:

menos de 500,00

500,00 a 1000,00

1001,00 a 1500,00

1501,00 a 2000,00

2001,00 a 2500,00

mais de 2500,00

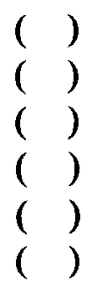

9.3 - Qual a renda mensal da sua familia em reais?

menos de 500,00

500,00 a 1000,00

1001,00 a 1500,00

1501,00 a 2000,00

2001,00 a 2500,00

mais de 2500,00

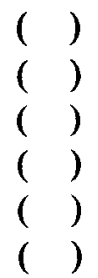


9.4 - Quanto do seu salário você destina para o orçamento familiar?:

todo o salário

menos que a metade( )

metade

mais que a metade

nada

( )

( )

( )

10 - DADOS SOBRE O PROCESSO SAÚDE - DOENÇA

10.1 - Tem algum problema de saúde no momento?

$\operatorname{sim}($ ) não ( )

10.2 - Se sim, qual?

10.3 - Para você seu problema de saúde tem relação com o seu trabalho? $\operatorname{sim}($ não ( )

10.4 - O que você fez ou está fazendo para resolver o seu problema de saúde?

Nada

Procurou o convênio

Procurou médico particular

Procurou pronto socorro

Procurou posto de saúde

( )

( )

( )

Procurou hospital público

Procurou hospital particular

Outro

( )

( )

( )

( )

( ) Qual?

OBRIGADA 
ANEXO 2 
Formulário $\mathrm{n}^{\circ}$

Condições de trabalho e de vida dos AUXILIARES DE ENFERMAGEM :

\section{1- DADOS}

1.1 -Em que dia/mês/ano você nasceu?

$1.2-\operatorname{Sexo} M()$ F ( )

1.3 - Qual o seu Estado civil?

Solteiro

Casado

( )

Viúvo

Separado ( )

Divorciado ( )

União livre ( )

1.4 - Você tem filhos?

Sim ( ) Quantos?

não ( )

\section{2- DADOS SOBRE MORADIA}

2.1- Há quanto tempo mora em Juiz de Fora?

Menos de um ano ( )

De 1 a 3 anos

De 4 a 6 anos

De 7 a 9 anos

ou mais anos

2.2 - A residência onde você mora é:

própria

alugada

cedida

2.3 - Quantos cômodos tem sua residência?

1 a 2 cômodos

3 a 4 cômodos

5 a 6 cômodos

7 ou mais cômodos

$$
\begin{aligned}
& () \\
& () \\
& () \\
& ()
\end{aligned}
$$

2.4 - Quantas pessoas moram com você ?

$\begin{array}{ll}\text { Mora sozinho (a) } & (\text { ) } \\ \text { De } 1 \text { a } 3 \text { pessoas } & (\text { ) } \\ \text { De } 4 \text { a } 6 \text { pessoas } & (\text { ) } \\ \text { De } 7 \text { a } 9 \text { pessoas } & (\text { ) } \\ 10 \text { ou mais pessoas } & (\text { ) }\end{array}$




\section{3 - DADOS SOBRE LAZER}

3.1 - Das que eu vou citar, qual ou quais as atividades de recreação você realiza?:

Esporte (atividade fisica)

Vê televisão

Atividades culturais (cinema, teatro, concertos)

Leituras (revistas, jomais, romances)

Turismo (viagens, passeios)

Outros

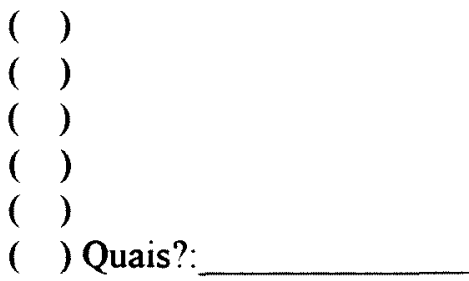

\section{4 - DADOS DE ORGANIZAÇÃO SOCIAL}

4.1 - Você participa ativamente de algum grupo/associação? (admite mais de uma resposta):
ligado ao trabalho
ligado ao bairro
( )
ligado a igreja
( )
( )
ligado a outro tipo de organização ( ) Qual?

\section{5 - DADOS SOBRE A SUA FORMAÇÃO ACADÊMICA}

5.1 - Em que ano você terminou o curso de auxiliar?

\section{6 - DADOS SOBRE A ORGANIZAÇÃo DO TRABALHO}

6.1 - Atualmente você tem quantos empregos:

$\begin{array}{ll}\text { um emprego } & (\text { ) } \\ \text { dois empregos } & (\text { ) } \\ \text { três empregos } & (\text { ) }\end{array}$

6.2 - Quantas horas você trabalha por dia:

menos de 8 horas $\quad($ )

8 horas ( )

mais de 8 horas ( )

6.3-Quais das seguintes atividades você realiza?

Observa e reconhece sinais e sintomas ( )

Descreve sinais e sintomas

Executa ações de tratamento simples

Presta cuidados de higiene e conforto ao paciente ( )

Identifica as familias de risco

Faz visitas domiciliares ( )

Executa procedimentos na área de atenção à criança ( ) 
Executa procedimentos na área de atenção à mulhe

Executa procedimentos na área de atenção

ao adolescente

Executa procedimentos na área de atenção

ao trabalhador

Executa procedimentos na área de atenção ao idoso

Executa procedimentos de vigilância sanitária e

epidemiológica no controle da tuberculose

Executa procedimentos de vigilância sanitária e

epidemiológica no controle da hanseníase

Executa procedimentos de vigilância sanitária e

epidemiológica no controle de

doenças crônico degenerativas

Executa procedimentos de vigilância sanitária e

epidemiológica no controle

de doenças infecto-contagiosas

Participa da discussão e organização

do processo de trabalho da unidade de saúde

outra atividade

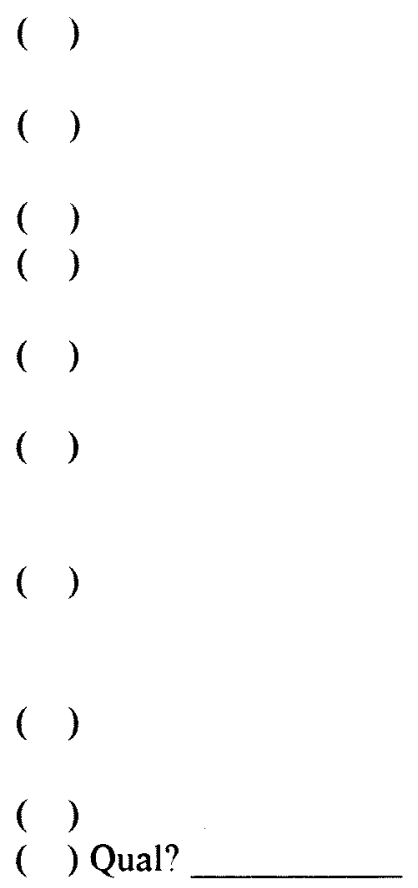

6.4 - Você acha que o tempo para realizar todas as suas tarefas em cada dia de trabalho é:

insuficiente

suficiente

mais do que suficiente

6.5 - No seu trabalho você se sente: muito satisfeito (4); satisfeito (3), insatisfeito (2), muito insatisfeito (1) em relação a

aproveitamento de suas aptidões

aplicação prática dos conhecimentos teóricos adquiridos

no curso de auxiliar

salário

nivel de responsabilidade

poder de decisão

perspectivas de carreira

( )

( )

( )

reconhecimento social do cargo ou atividade profissional - ( )

possibilidades de contatos e intercâmbio profissional ( )

volume de tarefas administrativas

relacionamento com os colegas

possibilidade de realizar trabalho criativo e inovador

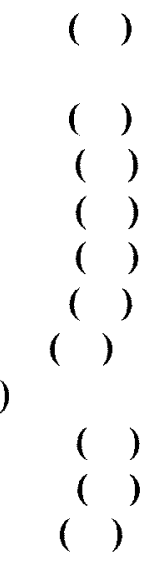

6.6 -Usualmente, ou de maneira geral, quando você sai do trabalho no fim da jornada sente necessidade de descansar tem disposição para se divertir ( )

tem disposição para continuar trabalhando com a mesma atividade tem disposição para continuar trabalhando em outra atividade tem disposição para estudar

( )

( )

( )

( ) 
7- DADOS SOBRE O AMBIENTE DE TRABALHO

7.2 - A temperatura do seu local de trabalho é:

agradável

desagradável

7.3 - A condição de iluminação do seu local de trabalho é:

$\begin{array}{ll}\text { excessiva } & (\text { ) } \\ \text { suficiente } & (\text { ) } \\ \text { insuficiente } & (\text { ) } \\ \text { outra } & (\text { ) Qual? }\end{array}$

7.4 - A condição de ventilação do seu local de trabalho é:

$\begin{array}{ll}\text { excessiva } & (\text { ) } \\ \text { suficiente } & (\text { ) } \\ \text { insuficiente } & (\text { ) } \\ \text { outra } & (\text { ) Qual? }\end{array}$

7.5 - Em seu trabalho você está submetido a :

risco de contaminação por microorganismos

(virus, bactérias e fungos)

poeiras, vapores, gases

produtos químicos tóxicos

radiações

radiaçôs ( )

ruído ( )

vibrações ( )

trabalho físico pesado ( )

postura inadequada ( )

tensão emocional ( )

monotonia ( )

repetitividade ( )

arranjo fisico deficiente

(falta de espaço, piso escorregadio e outros) ( )

instrumentos e ou equipamentos inadequados ( )

instrumentos e ou equipamentos defeituosos ( )

7.6 - Considera o seu trabalho perigoso:

$\operatorname{sim}($ ) não ( )

Se sim, porque?

7.7 - Considera o seu trabalho insalubre?

$\operatorname{sim}($ ) não ( )

Se sim, porque?

7.8 - Você já sofreu algum acidente de trabalho?

$\operatorname{sim}($ ) Tipo

não ( ) 


\section{8 - DADOS SOBRE A RELAÇÃO NO TRABALHO}

8.1 - A relação dos membros da equipe de enfermagem, com você é de (admite mais de uma resposta):

$\begin{array}{ll}\text { respeito } & (\text { ) } \\ \text { obediência } & (\text { ) } \\ \text { companheirismo } & (\text { ) } \\ \text { competição } & (\text { ) } \\ \text { rivalidade } & (\text { ) } \\ \text { subalternidade } & (\text { ) } \\ \text { outro } & (\text { ) Qual? }\end{array}$

8.2 - A relação dos membros da equipe de saúde com você é de (admite mais de uma resposta):

Respeito

Obediência

Companheirismo

competição

rivalidade

subalternidade

Outro

$\begin{array}{ll}( & ) \\ ( & ) \\ ( & ) \\ ( & \\ ( & ) \\ ( & ) \\ ( & \text { Qual? }\end{array}$

8.3 - Em relação à sua atenção aos pacientes, você se sente: muito satisfeito

satisfeito

insatisfeito

( )

muito insatisfeito

$($ ( )

( )

\section{9 - DADOS SOBRE OS BENEFÍCIOS DO TRABALHO}

9.1 - O seu trabalho oferece algum dos beneficios abaixo (admite mais de uma resposta)?

Cesta básica

Vale transporte

Assistência médica

Vale refeição

Creche ou auxílio-creche

Outro

Nenhum

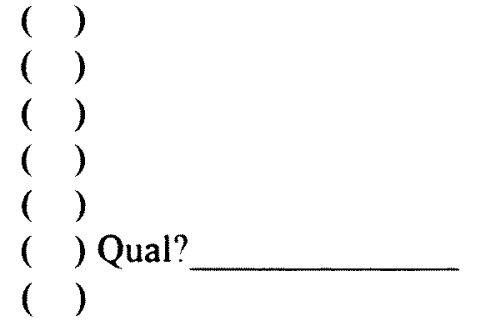

9.2 - Qual a faixa de total bruto você recebeu do último mês em reais: menos de 500,00 500,00 a 1000,00 1001,00 a 1500,00 1501,00 a 2000,00 2001,00 a 2500,00 mais de 2500,00 
9.3 - Qual a renda mensal da sua familia em reais?:

menos de 500,00

500.00 a 1000,00

1001,00 a 1500,00

1501,00 a 2000,00

2001,00 a 2500,00

mais de 2500,00

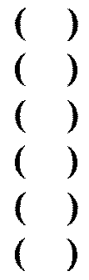

9.4 - Quanto do seu salário você destina para o orçamento familiar?:

todo o salário

menos que a metade

metade

mais que a metade

nada

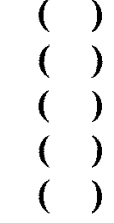

\section{0 - DADOS SOBRE O PROCESSO SAÚDE - DOENÇA}

10.1 - Tem algum problema de saúde no momento?
$\operatorname{sim}()$
não ( )

Se sim, qual?

10.2 - Para você seu problema de saúde tem relação com o seu trabalho? $\operatorname{sim}()$ não ( )

10.3 - O que você fez ou está fazendo para resolver o seu problema de saúde?

Nada

Procurou o convênio

Procurou médico particular

Procurou pronto socorro

Procurou posto de saúde

Procurou hospital público

Procurou hospital particular

Outro

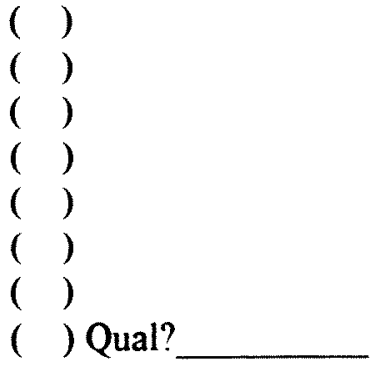

OBRIGADA 


\section{ANEXO 3}




\section{TERMO DE CONSENTIMENTO}

Declaro, de acordo com a Resolução 196/96 do Conselho Nacional de Saúde, que regulamenta pesquisas envolvendo seres humanos, que tomei conhecimento detalhado da pesquisa que está sendo conduzida pela Enfermeira Rosângela Maria Greco e estou formalmente dando meu consentimento livre e esclarecido para ser um dos integrantes do grupo a ser pesquisado.

Declaro, ainda, que estou ciente de todas as eventuais implicações que possam decorrer da pesquisa.

Juiz de Fora, de de 1999. 
ANEXO 4 


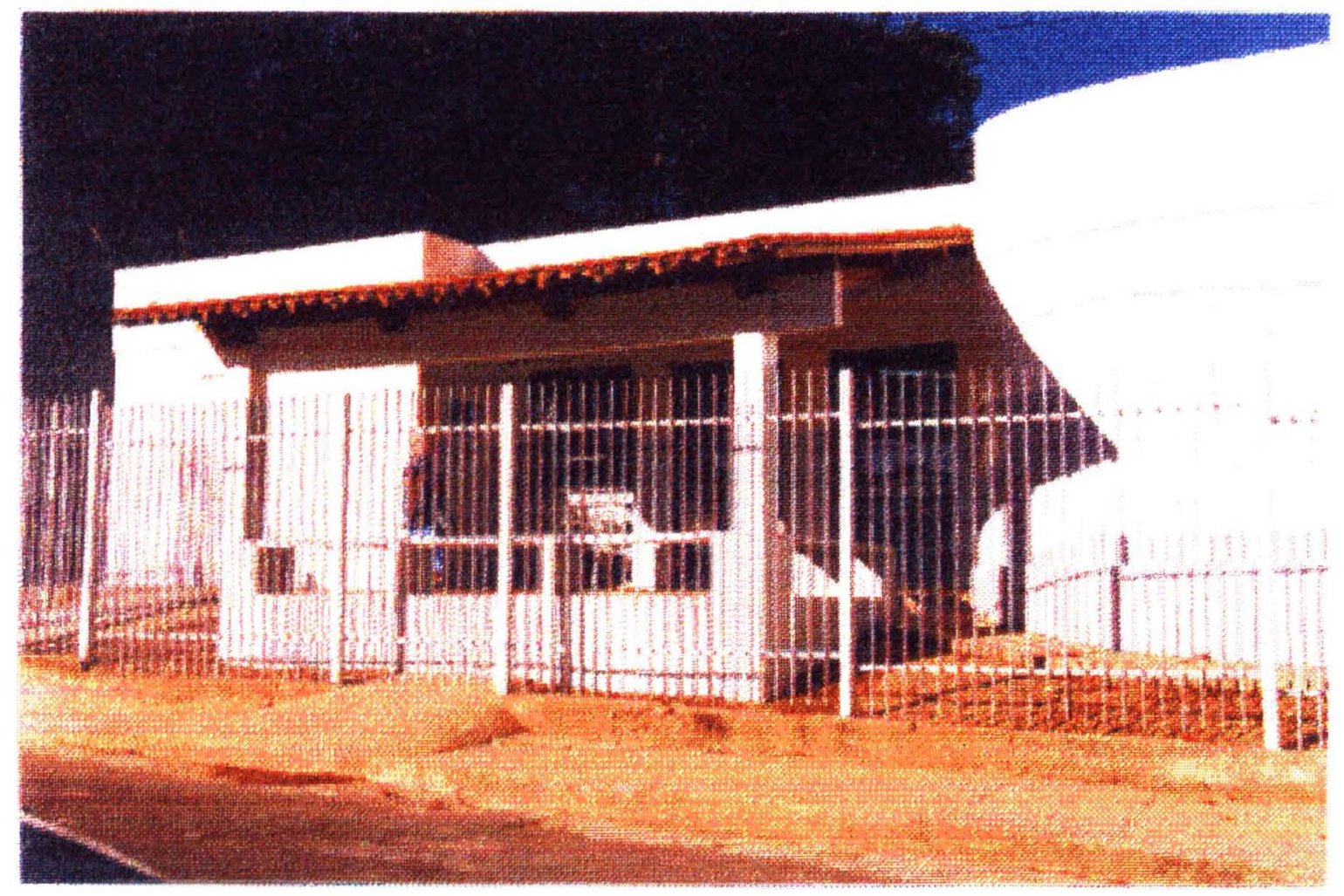

\section{Unidade Básica de Saúde São Benedito}

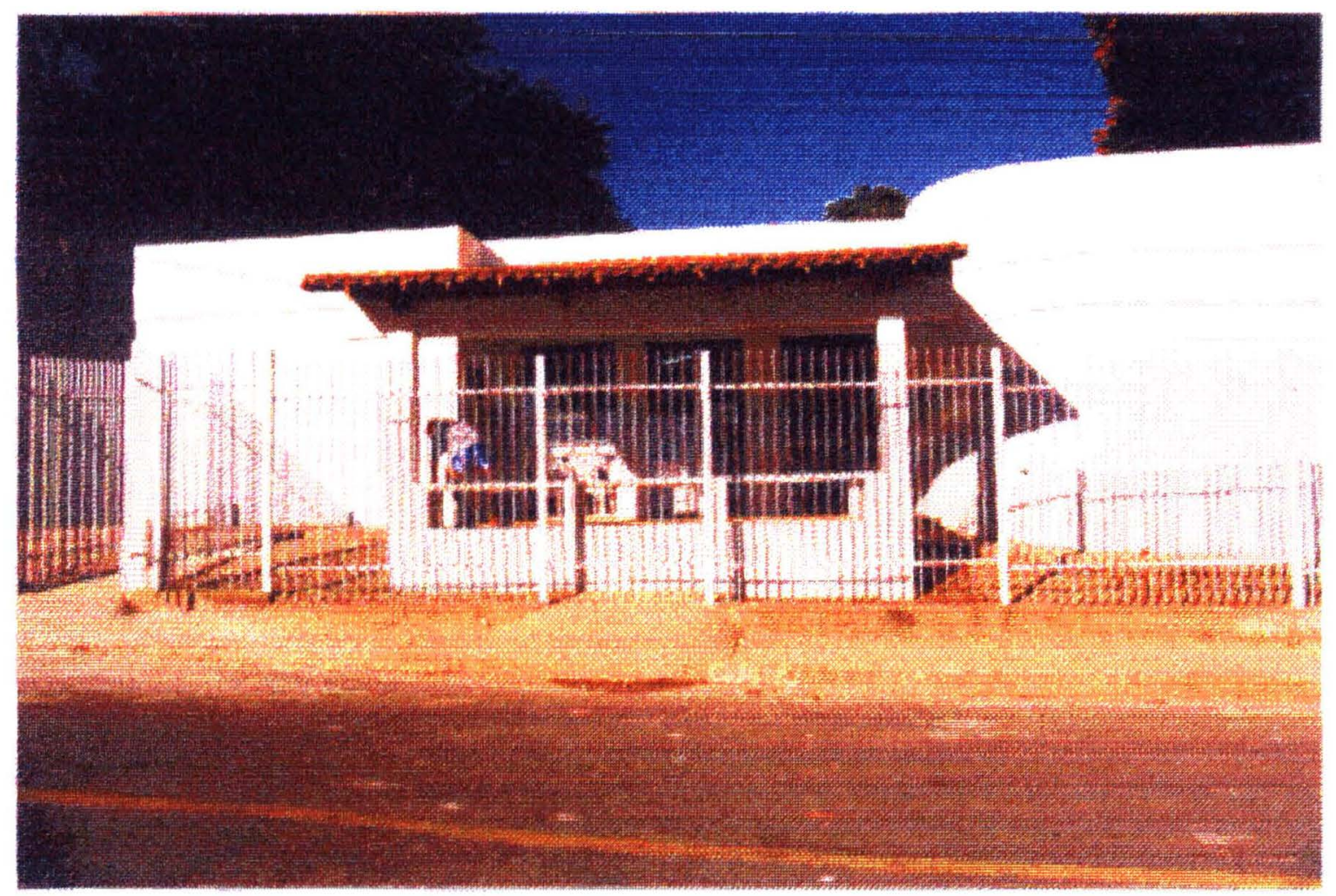




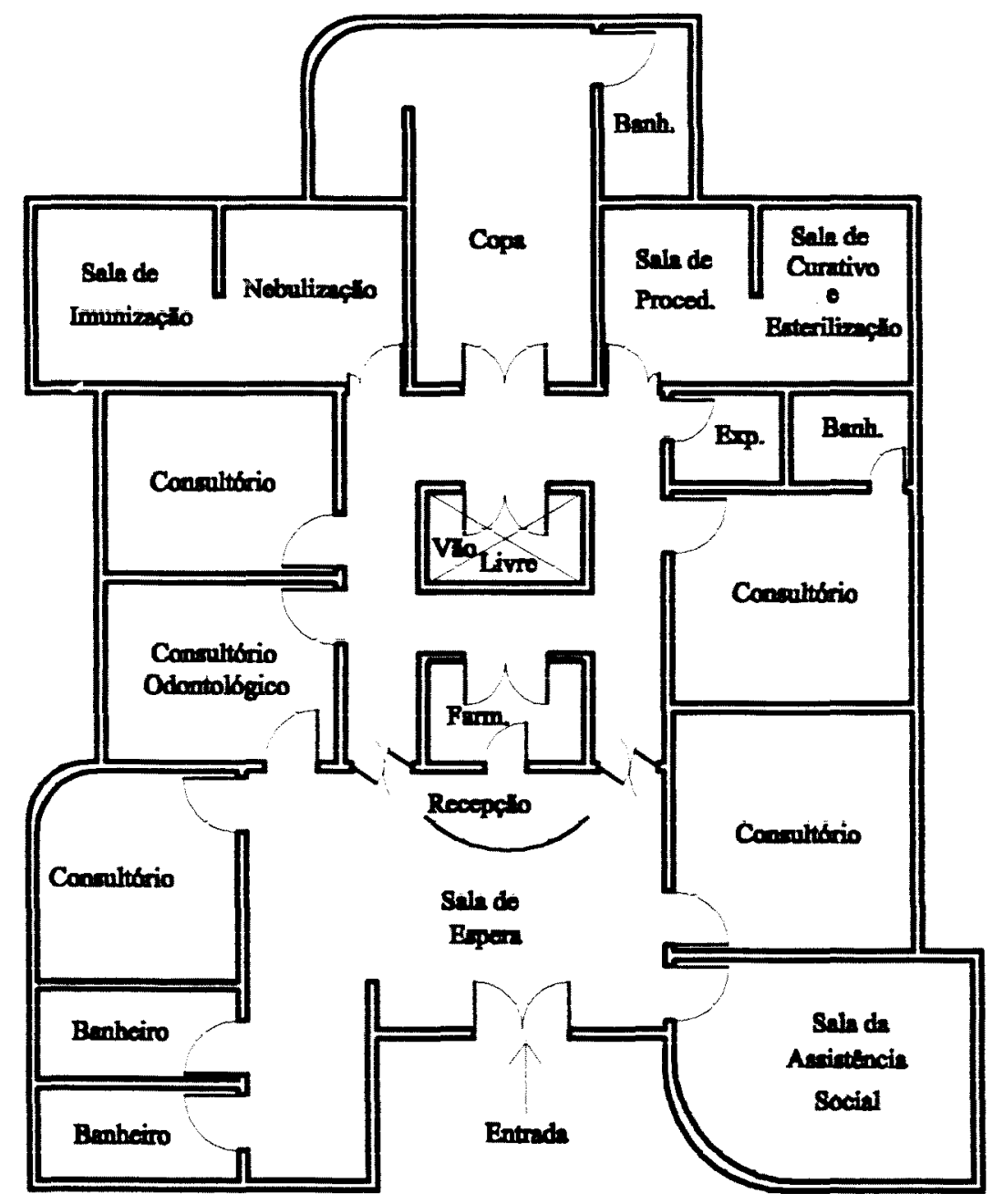

UBS 380 Benstituo 


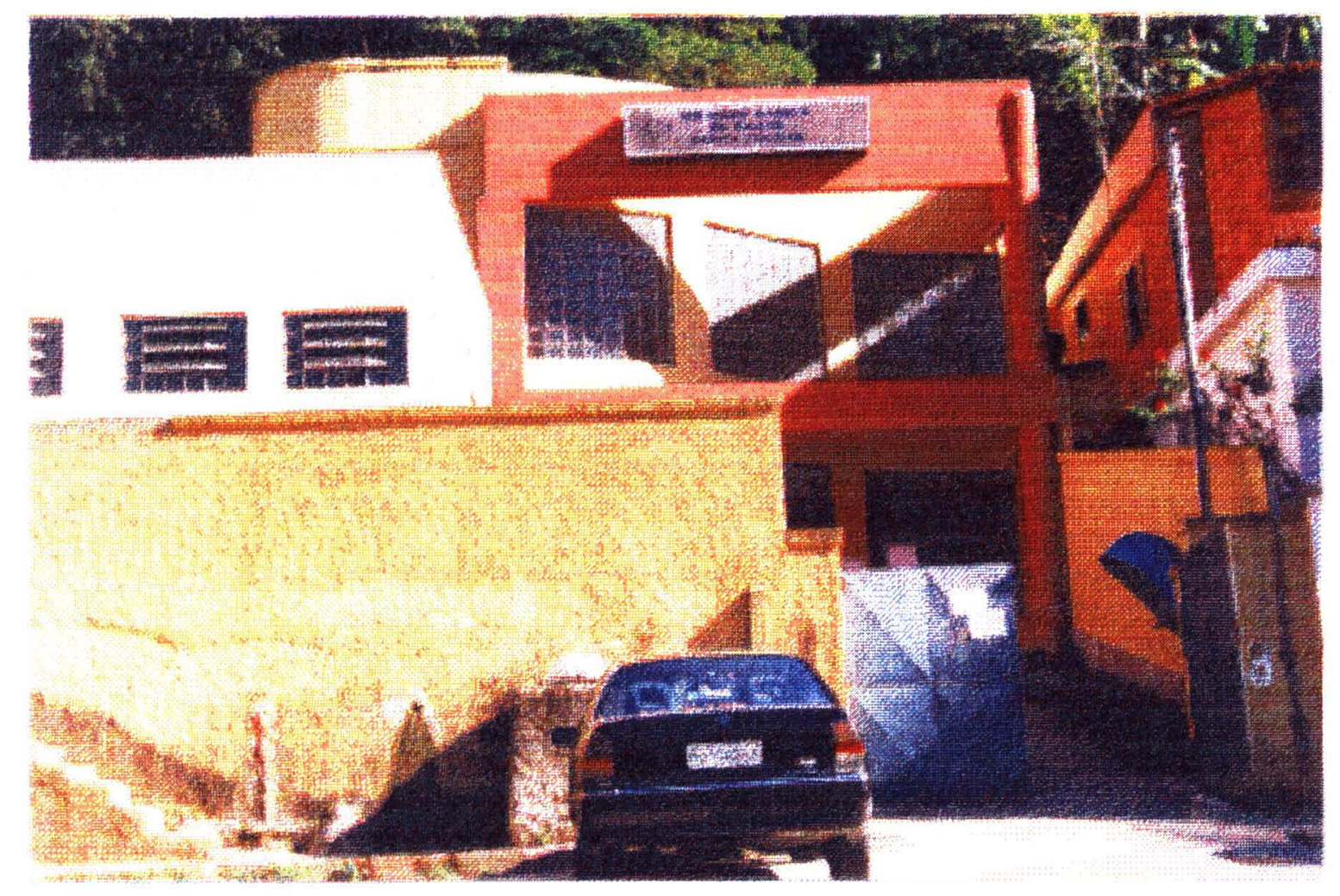

\section{Unidade Básica de Saúde Santa Cecília}

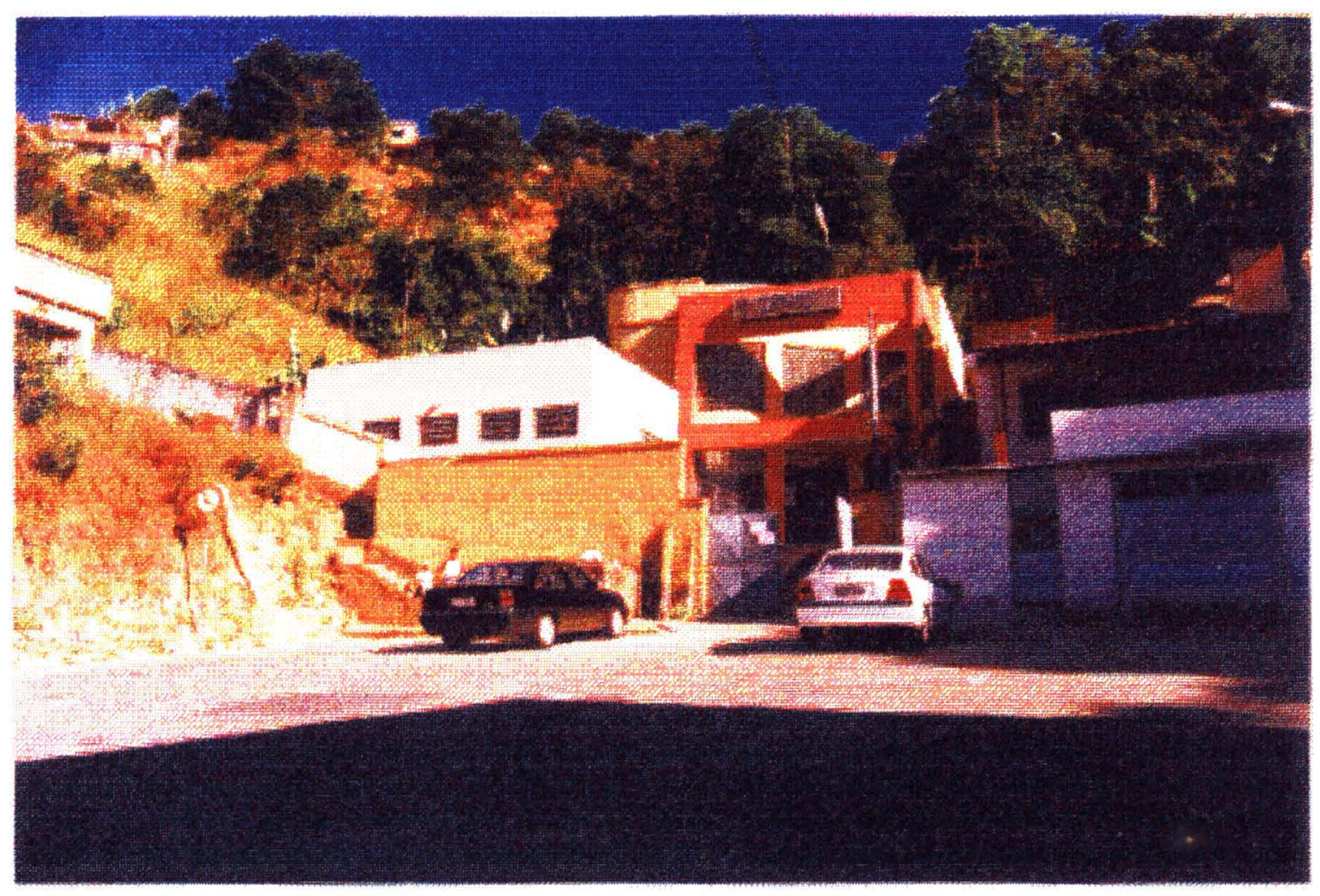




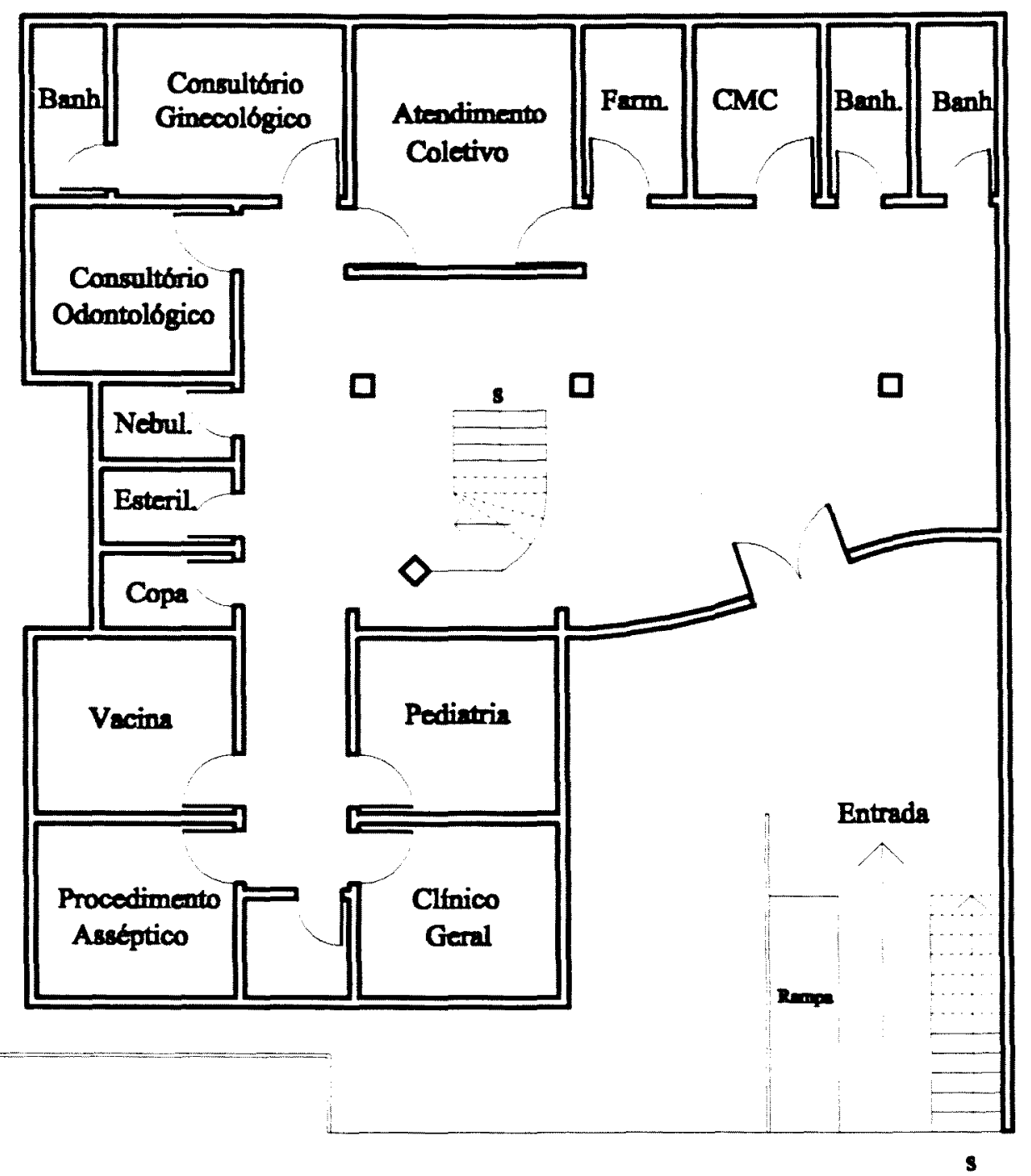

UBS Santa Cocllia

$1^{\circ}$ Piso 


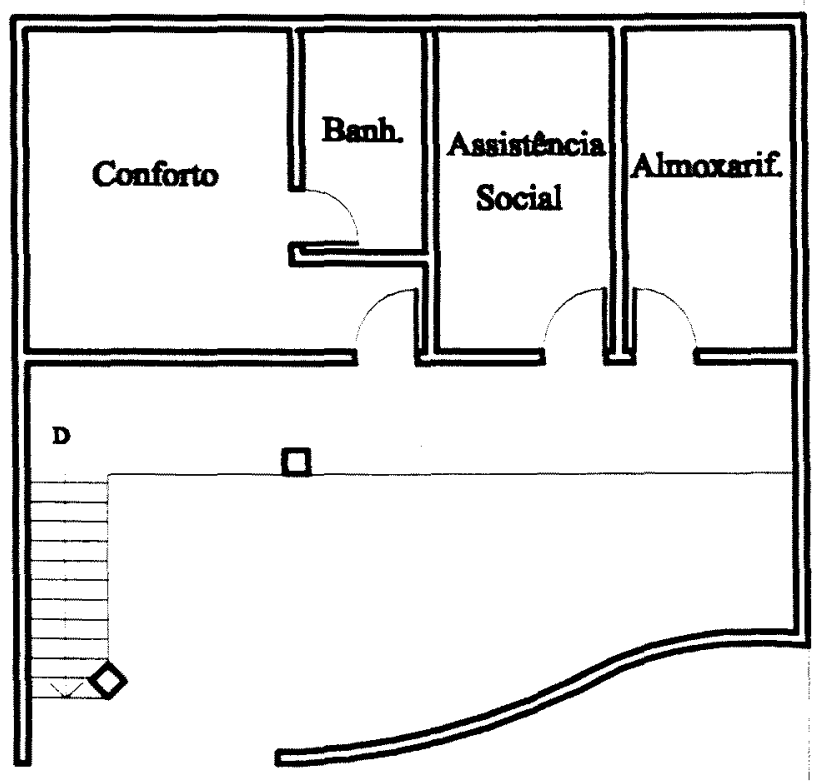

UBS Santa Cecllia

$2^{\circ}$ Piso 

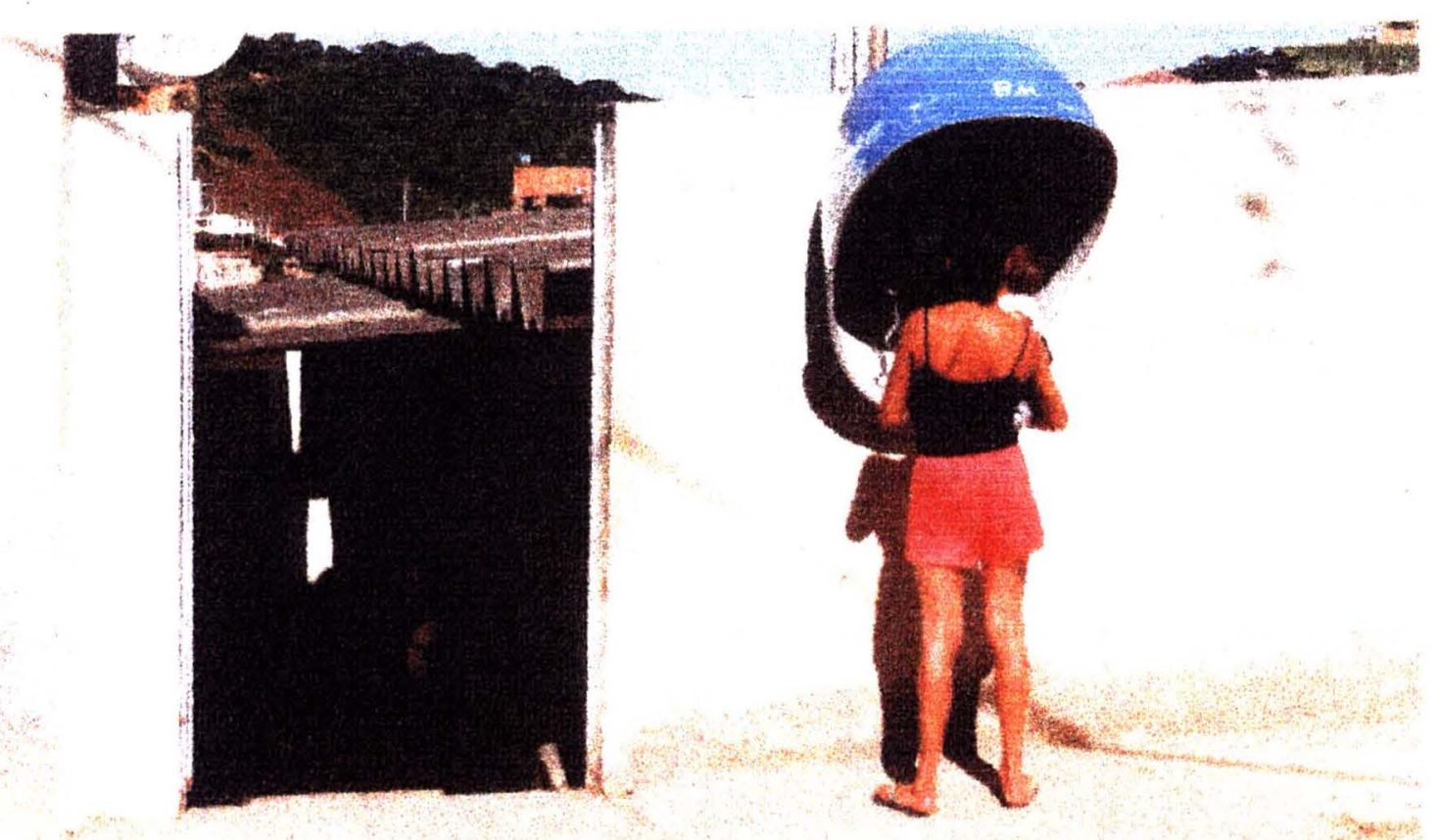

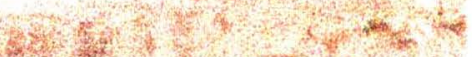

Unidade Básica de Saúde Santa Efigência

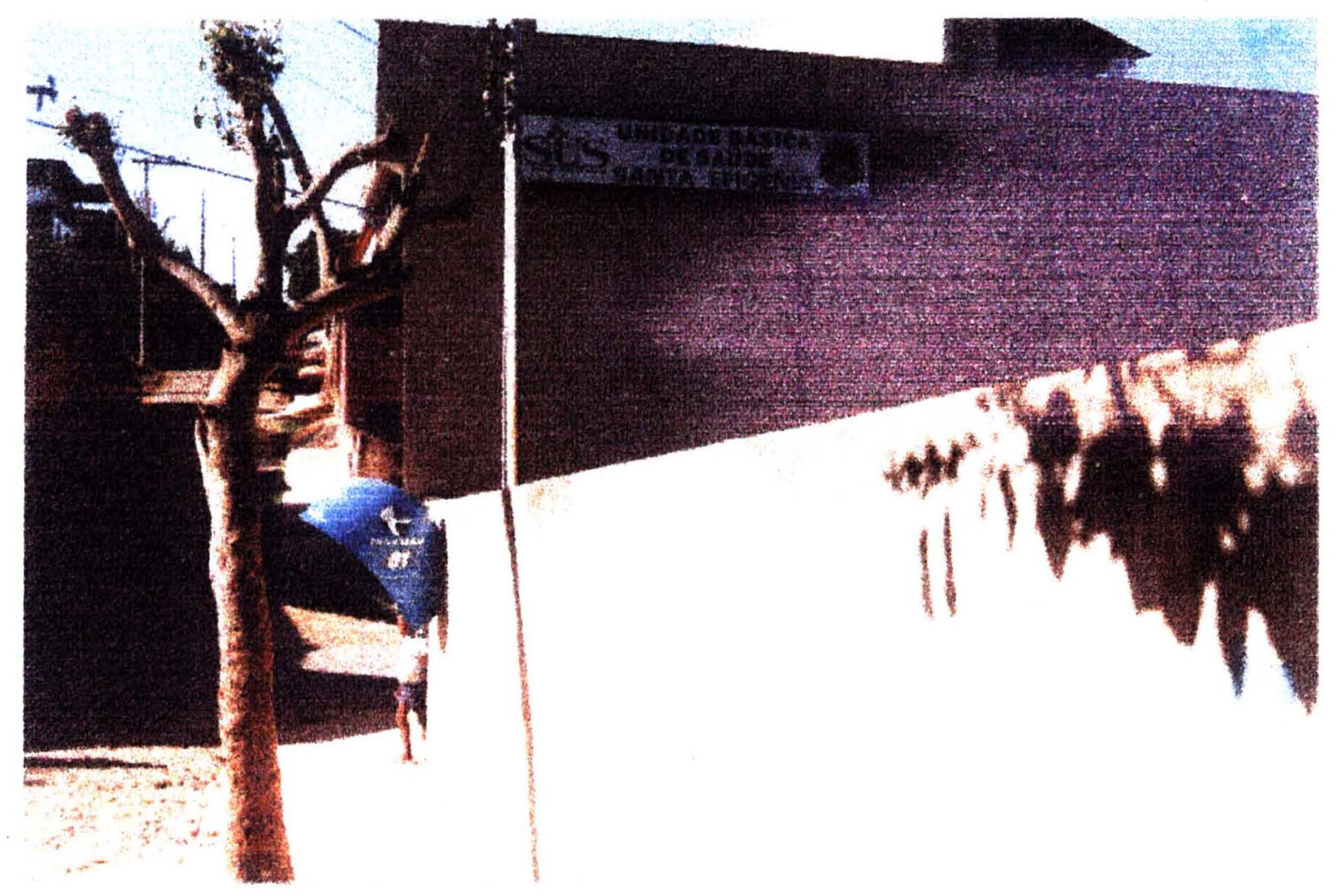




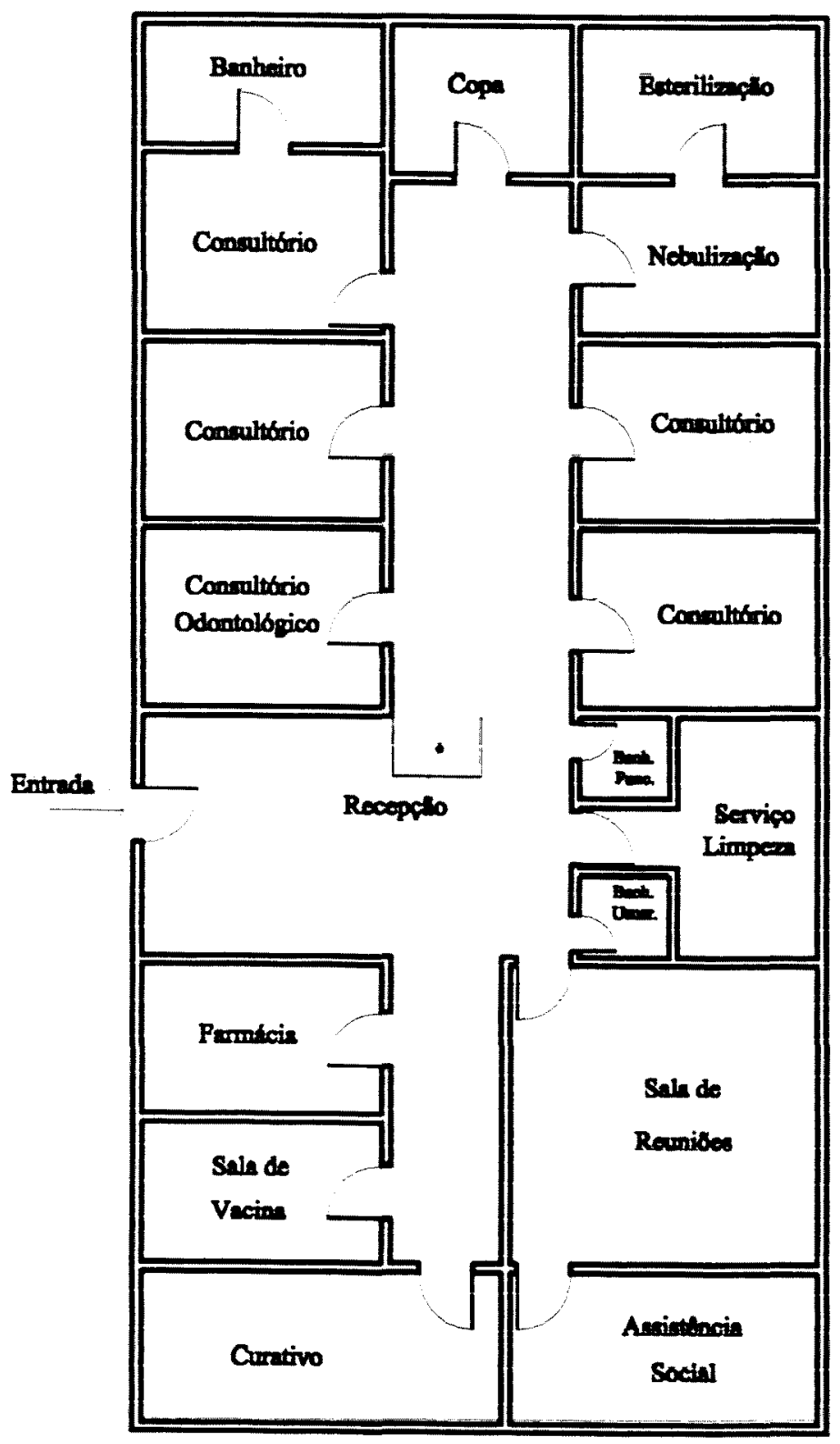

UBS Santa Efigtain 


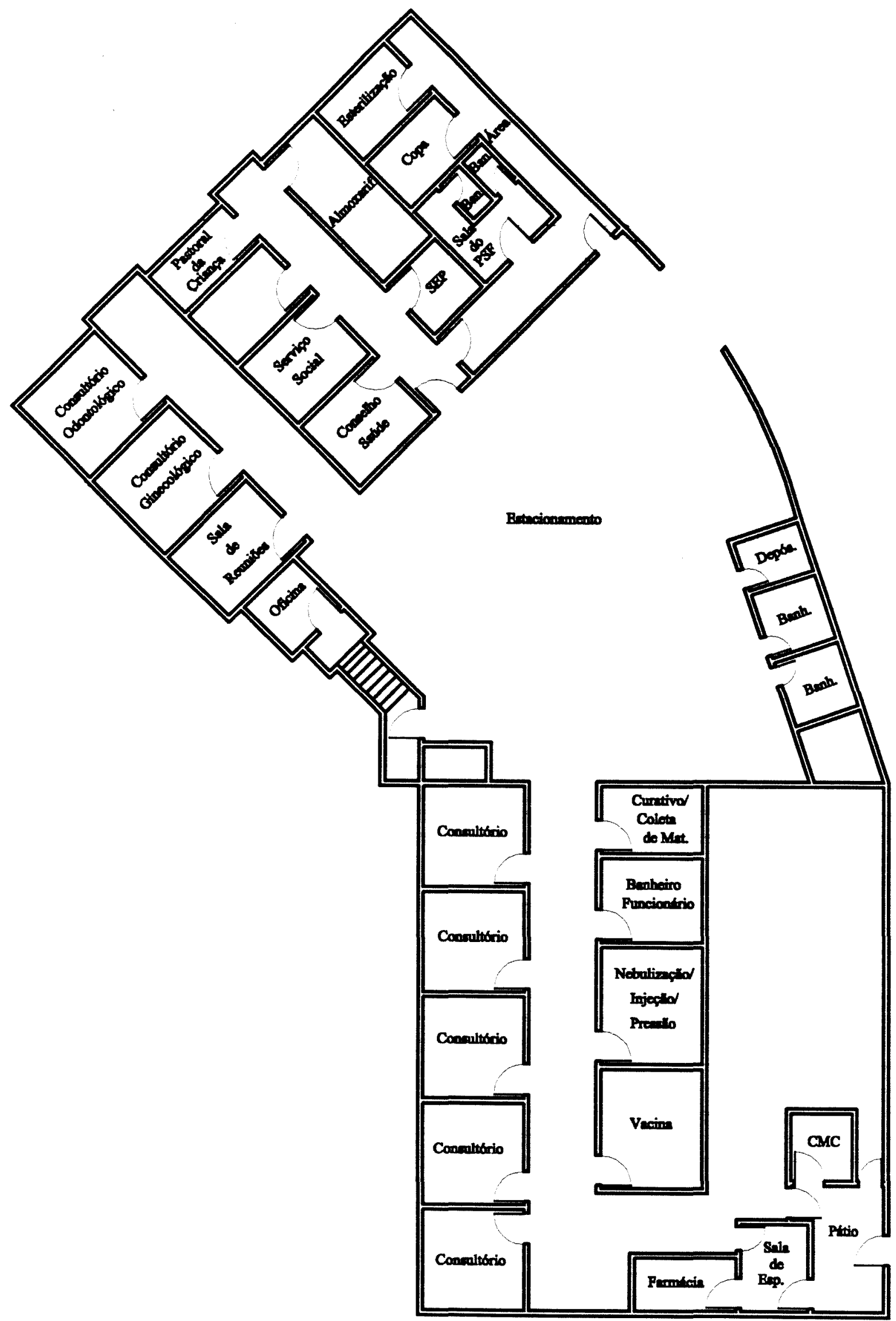

UBS Furtado do Menerese 


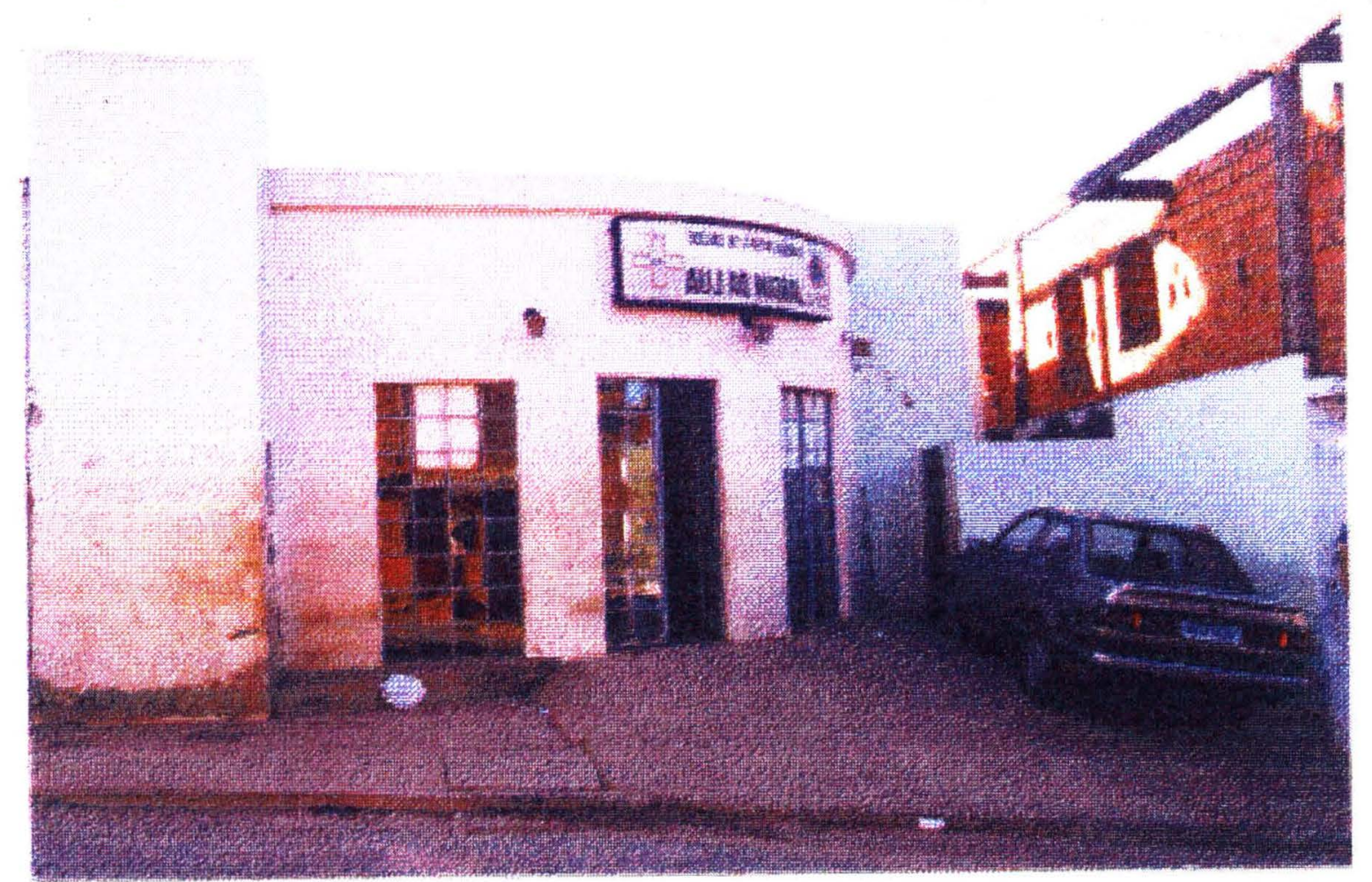

Unidade Básica de Saúde Jardim da Lua

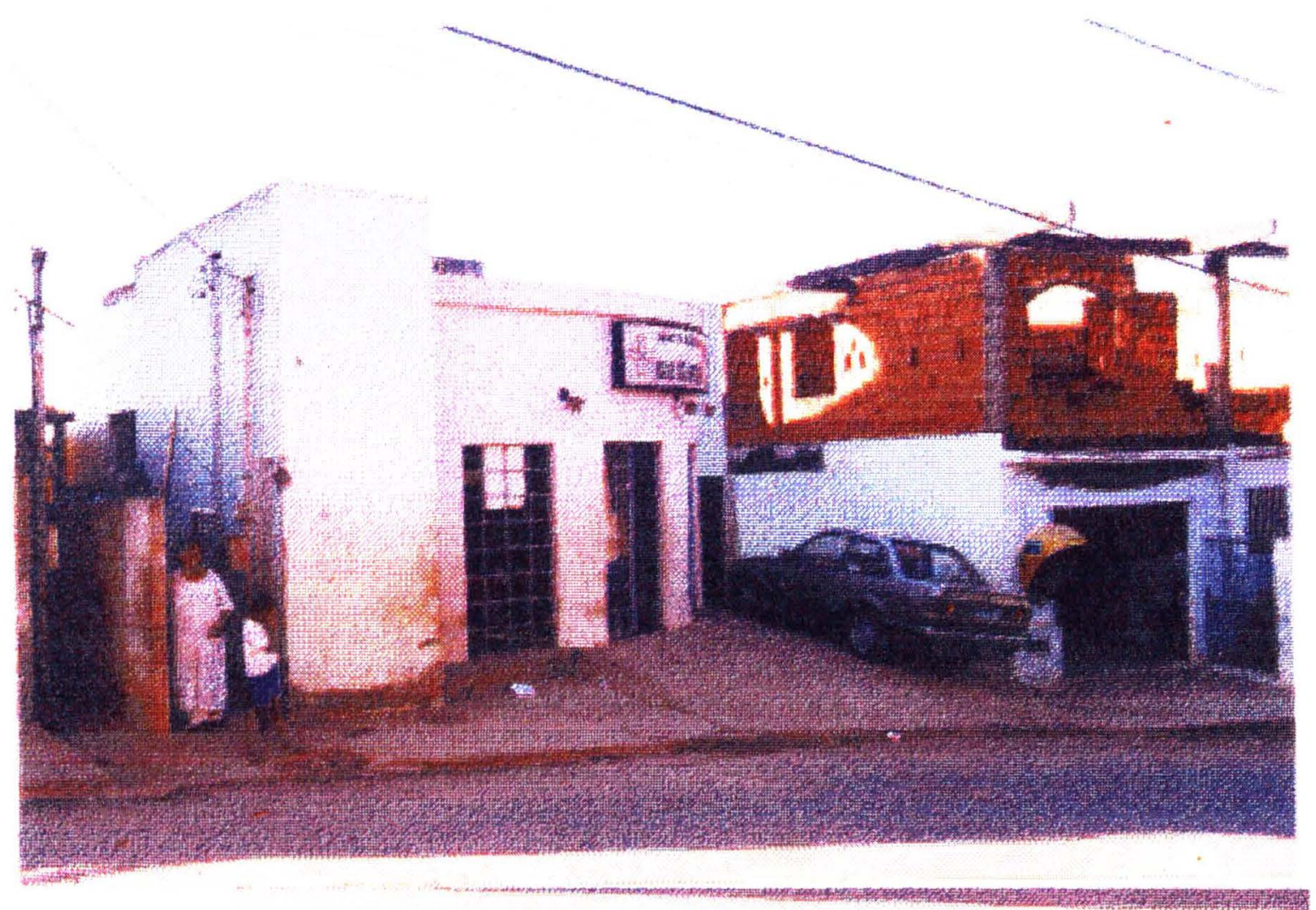




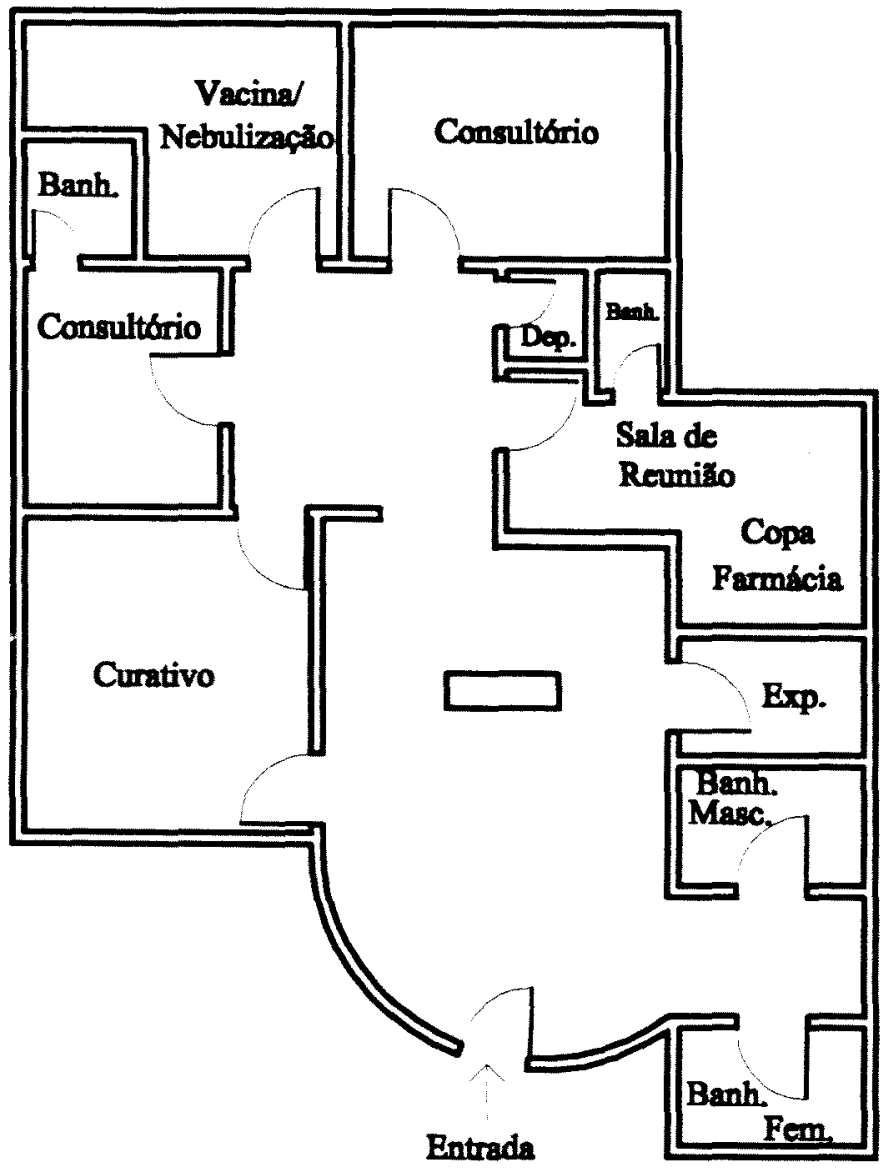

UBS Jandim da Lua 

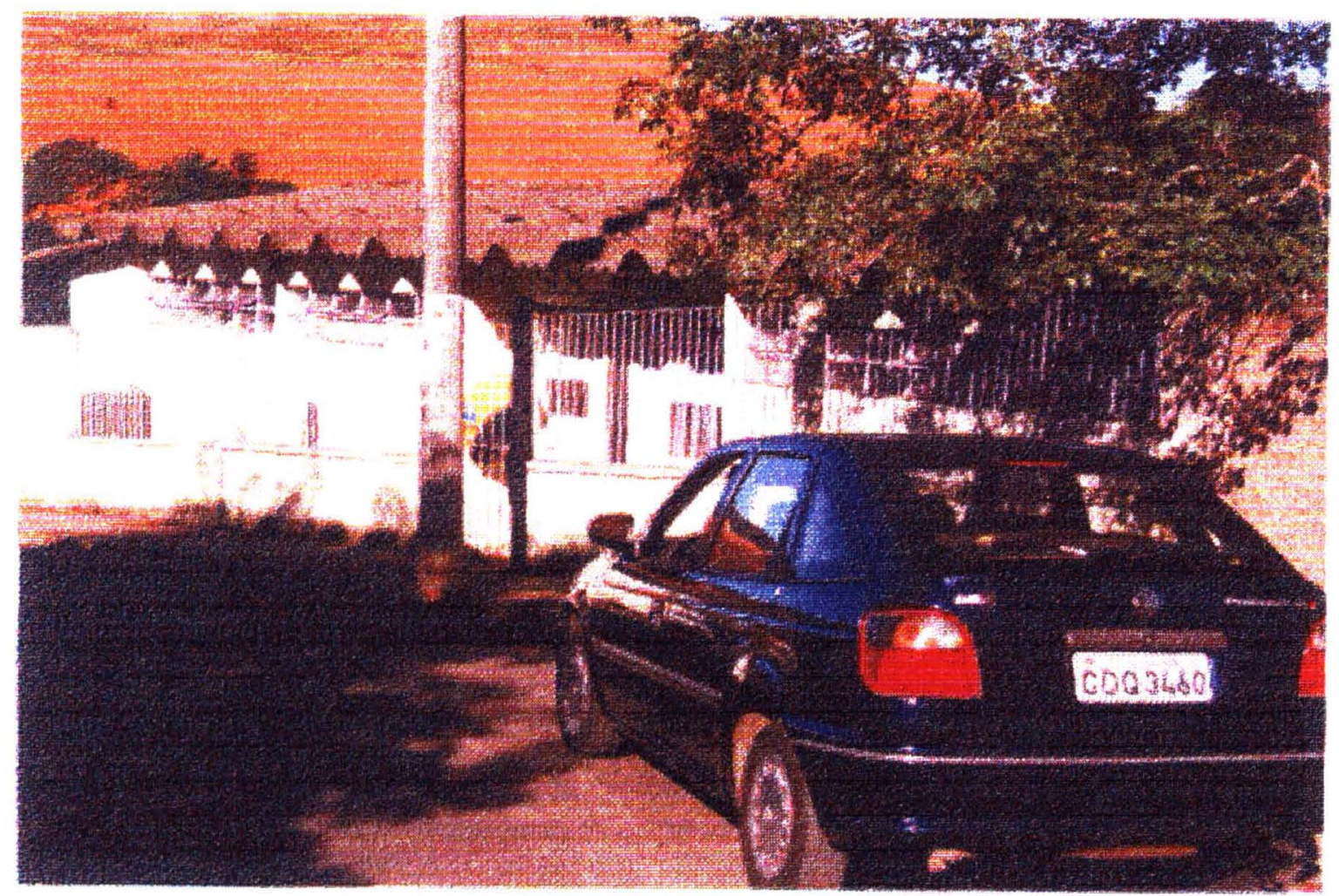

\section{Unidade Básica de Saúde Jardim Esperança}

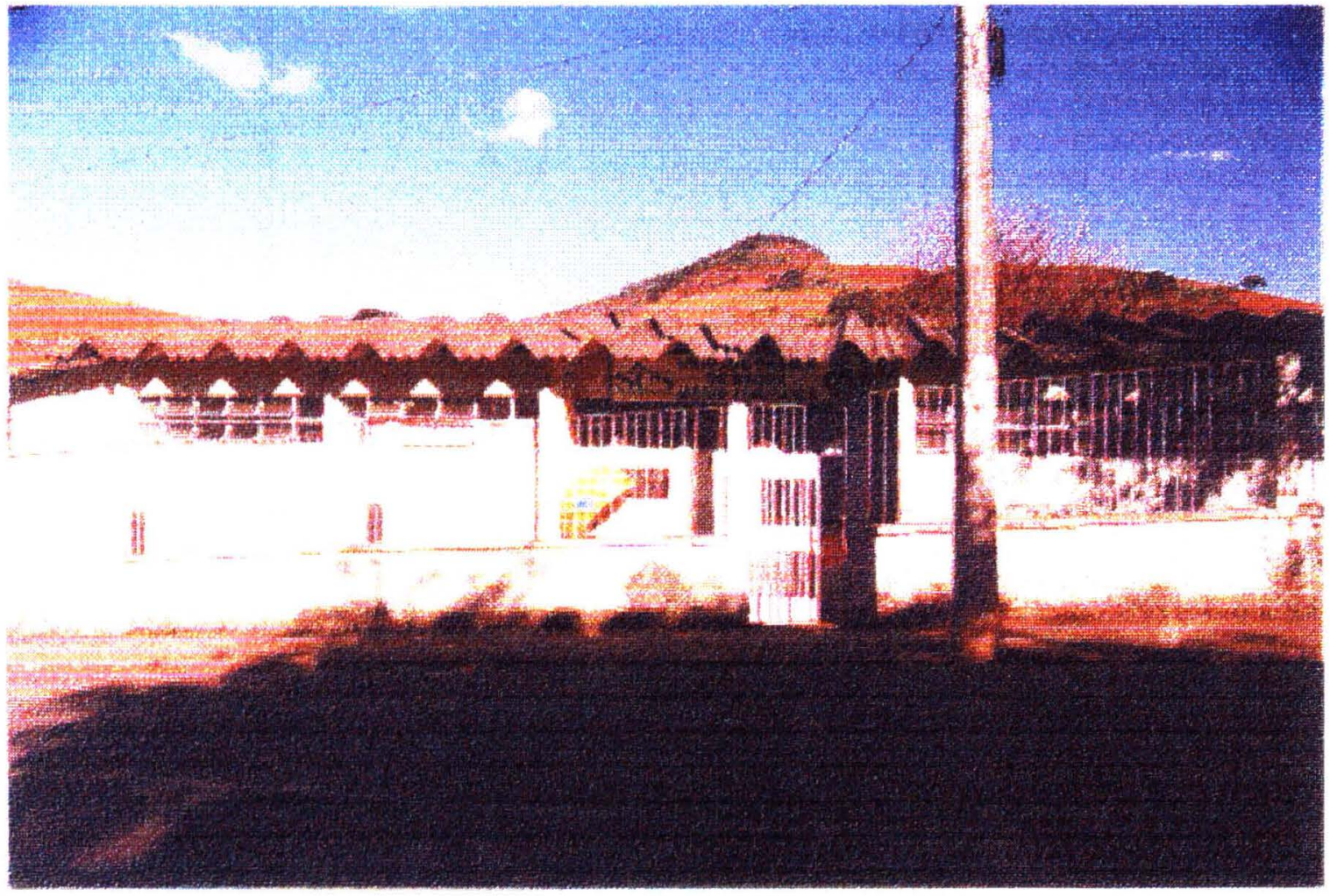




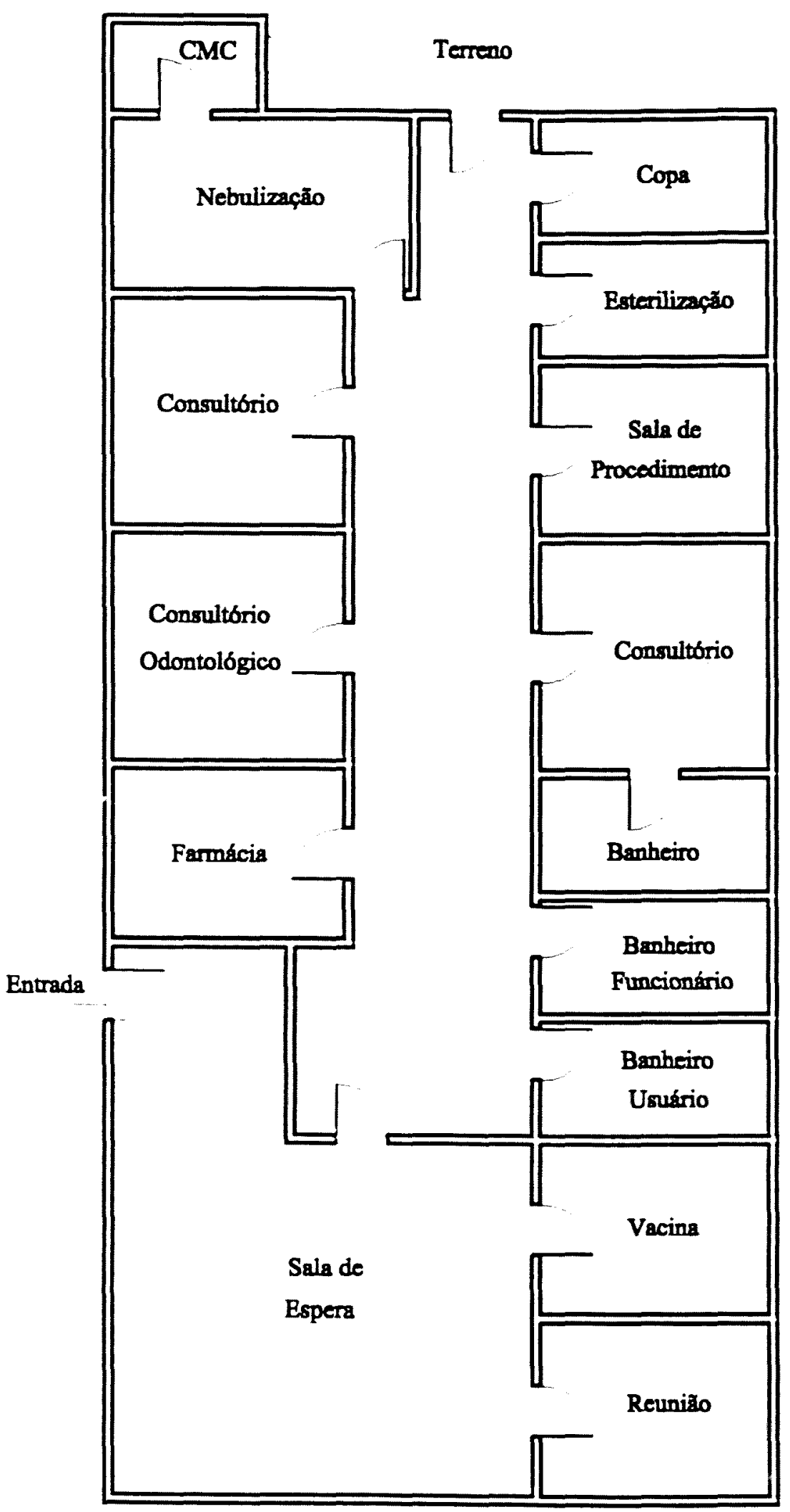

UBS Jardim Esperança 


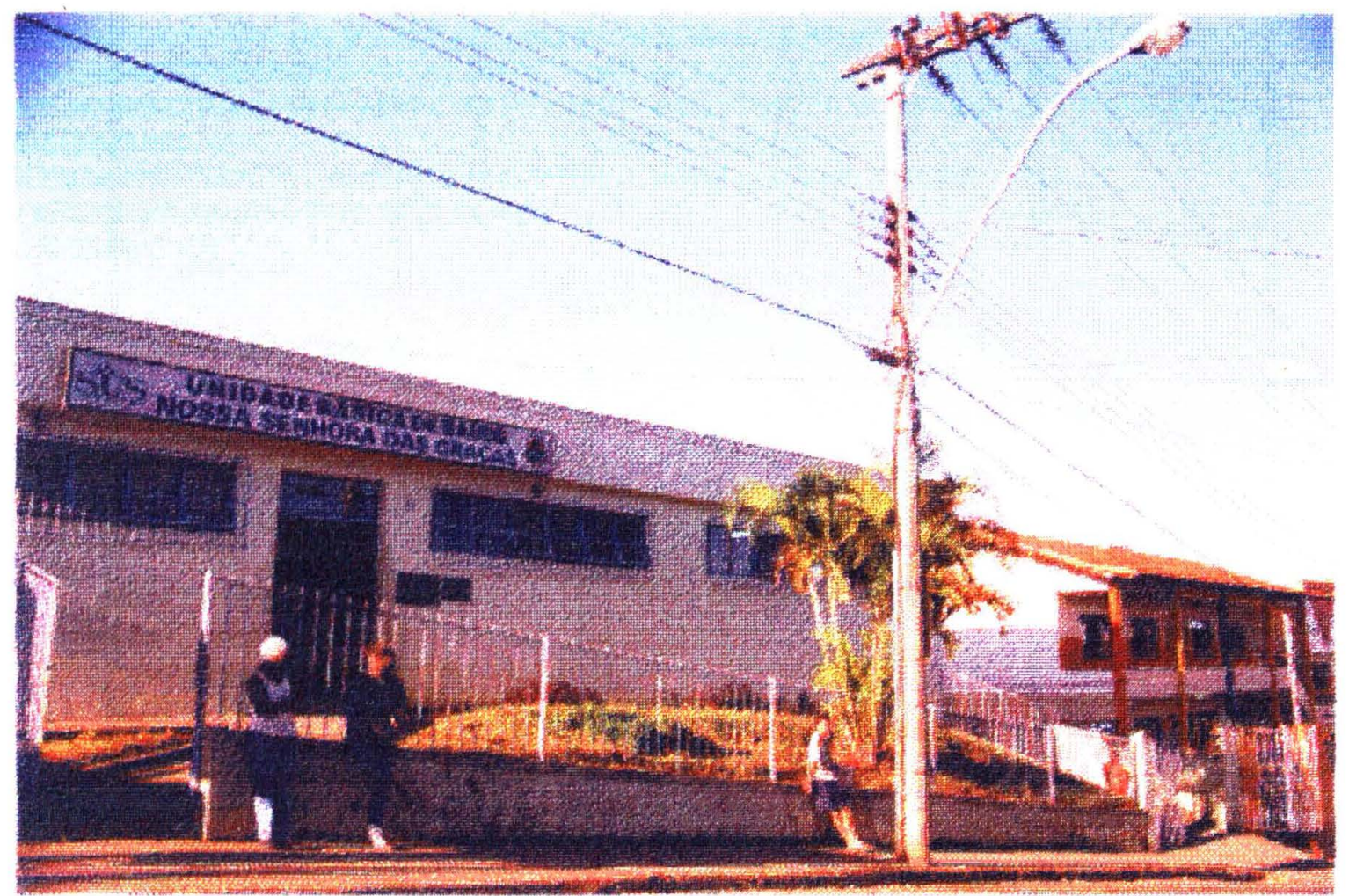

\section{Unidade Básica de Saúde Nossa Senhora das Graças}

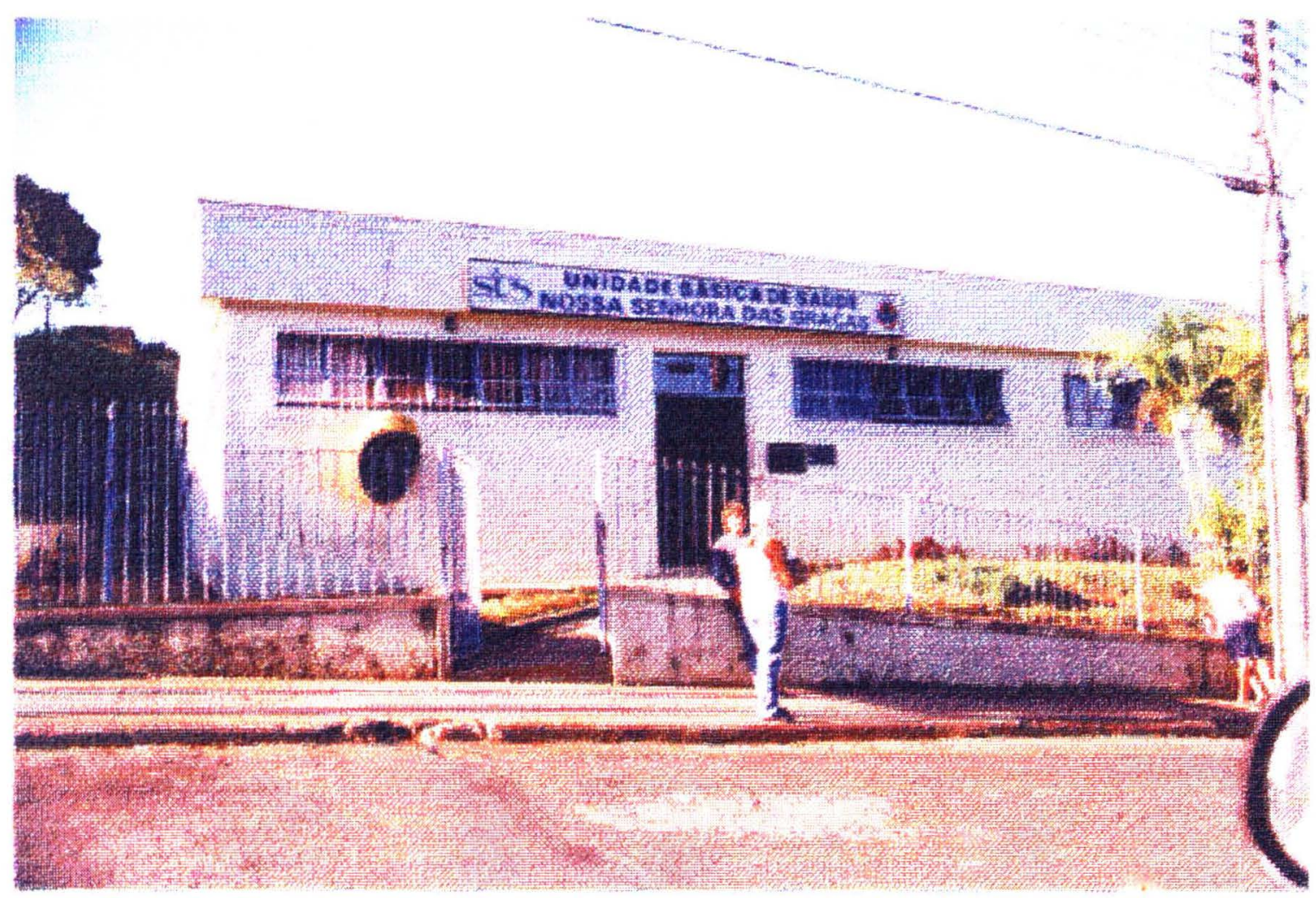




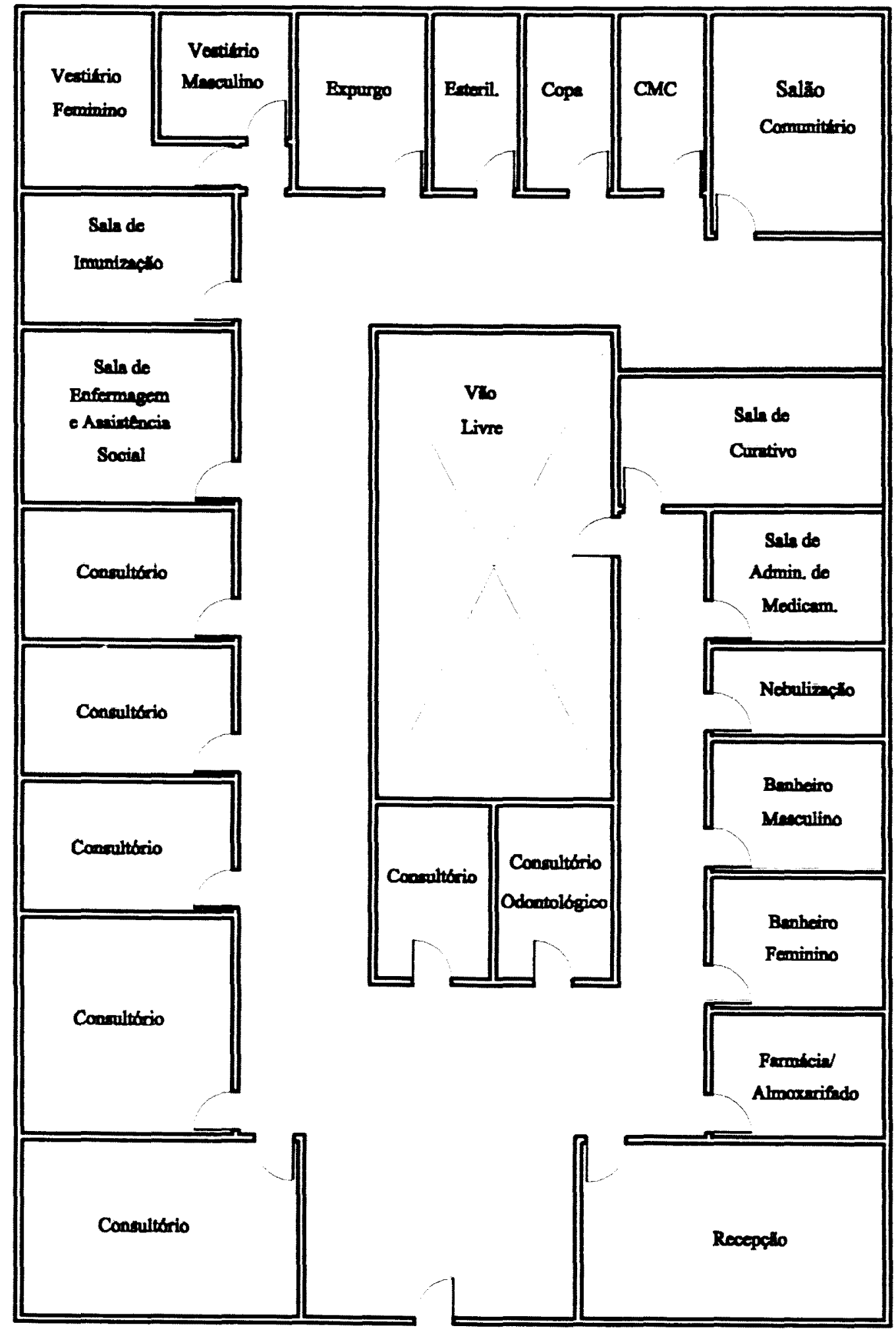

Entradn

UBS Nome Senhora des Graces 


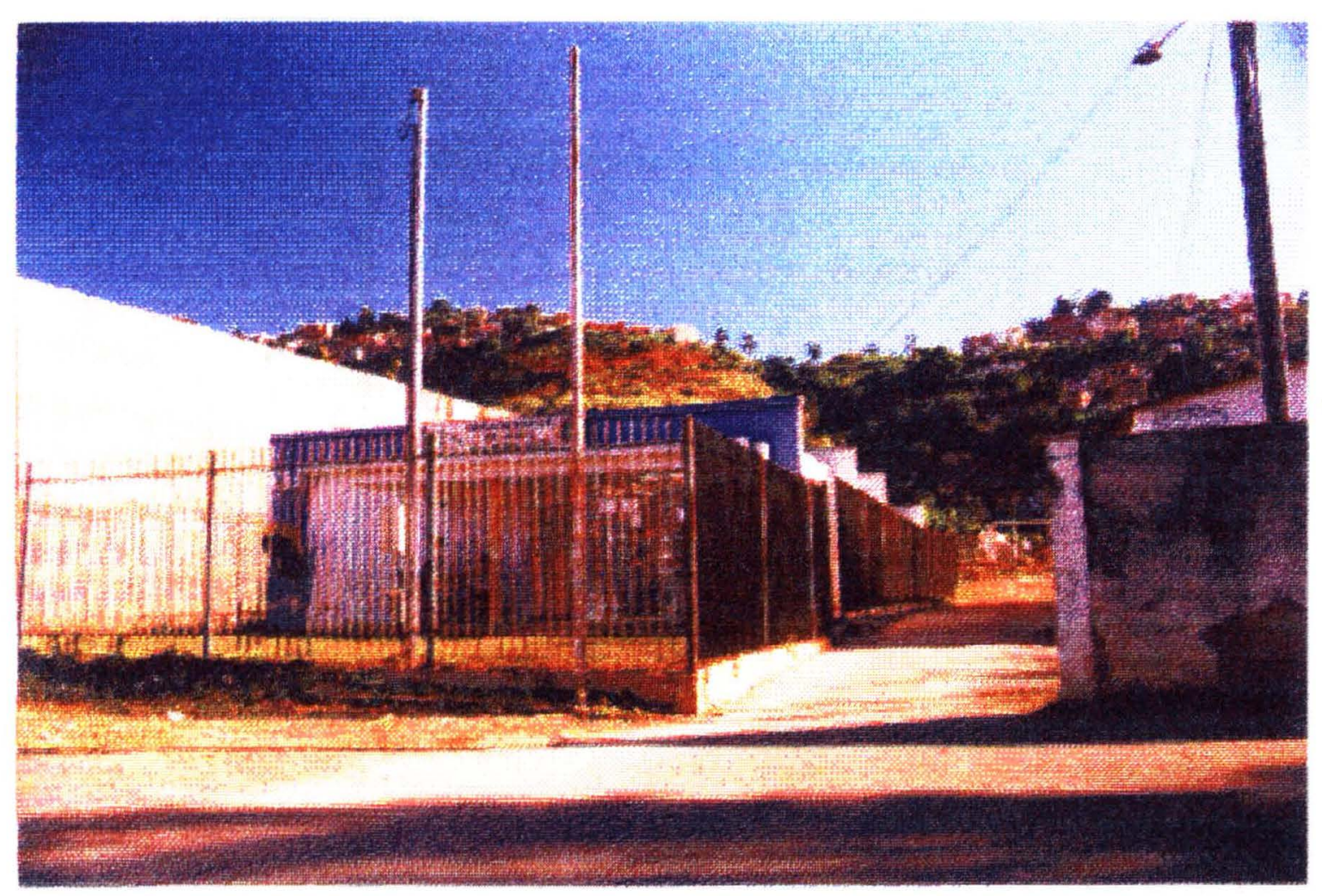

\section{Unidade Básica de Saúde Olavo Costa}

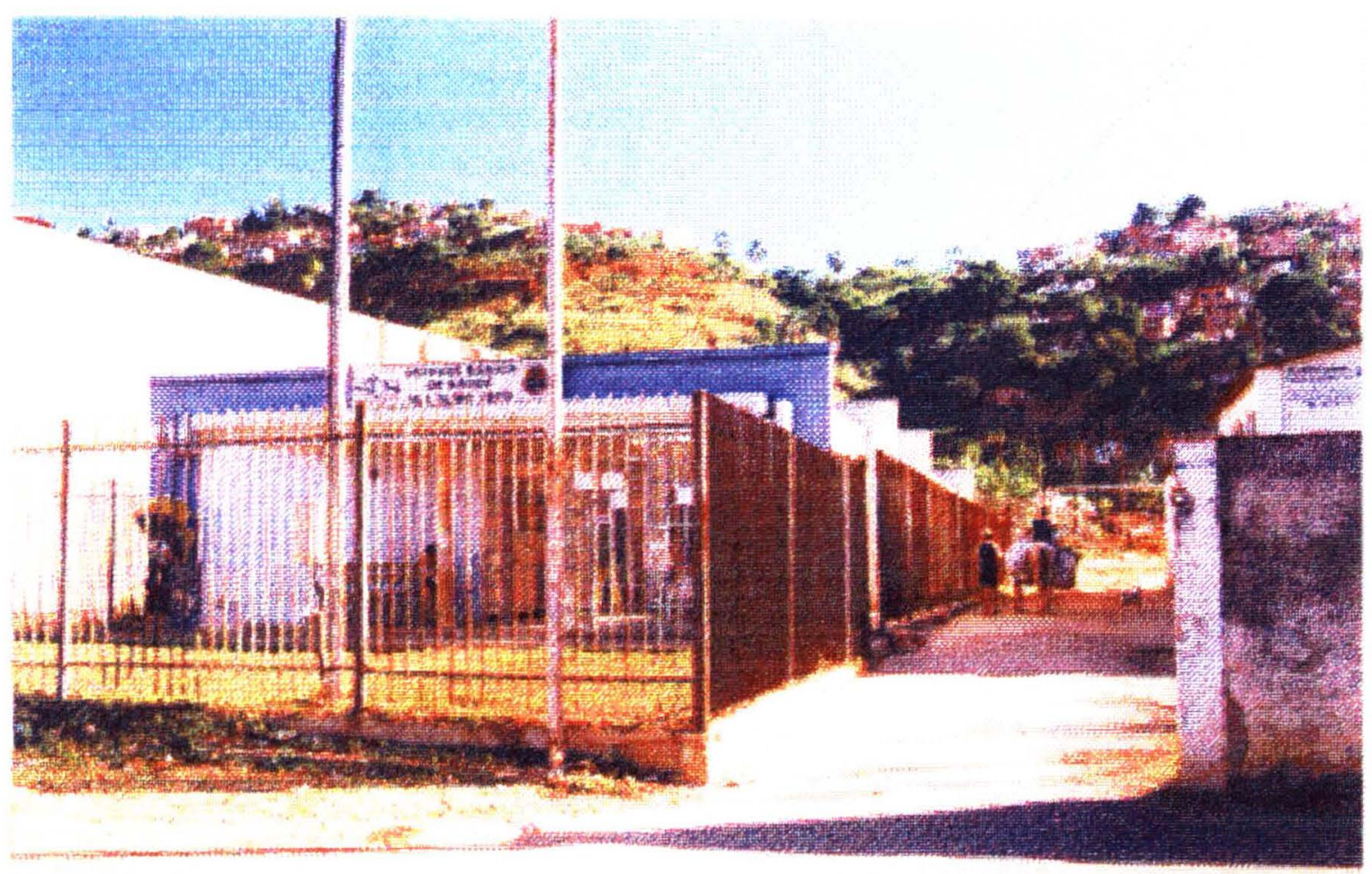




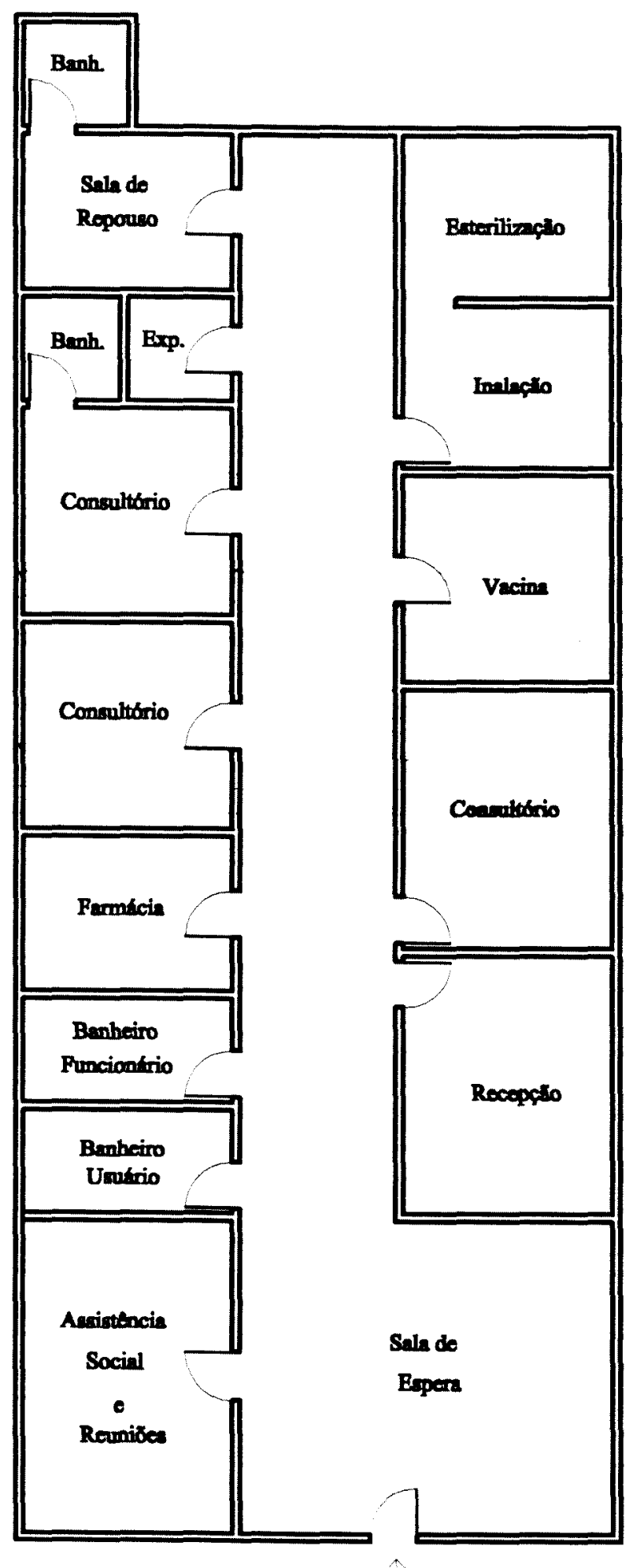

Entrada

UBS Olevo Coste 


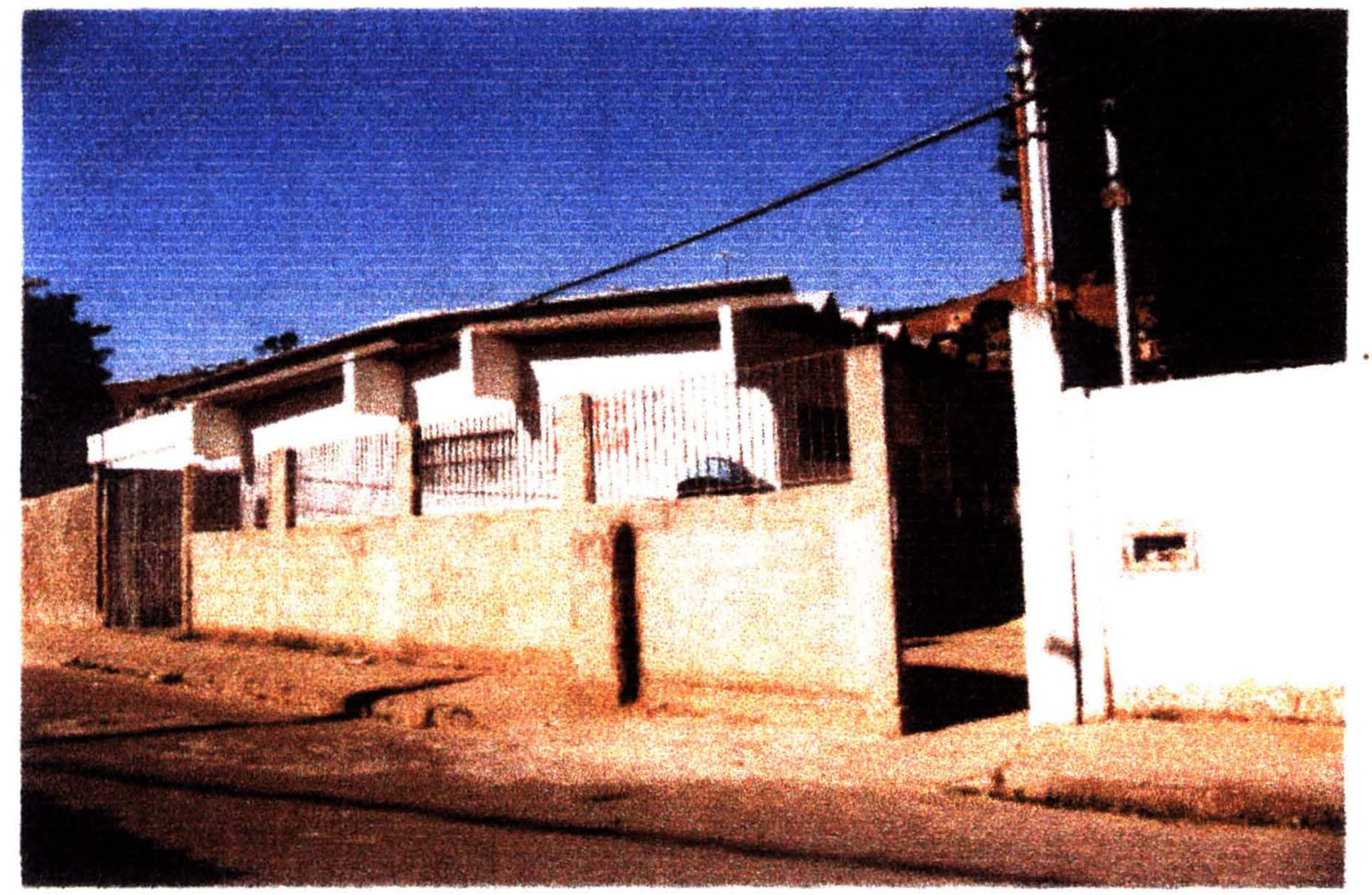

\section{Unidade Básica de Saúde Retiro}




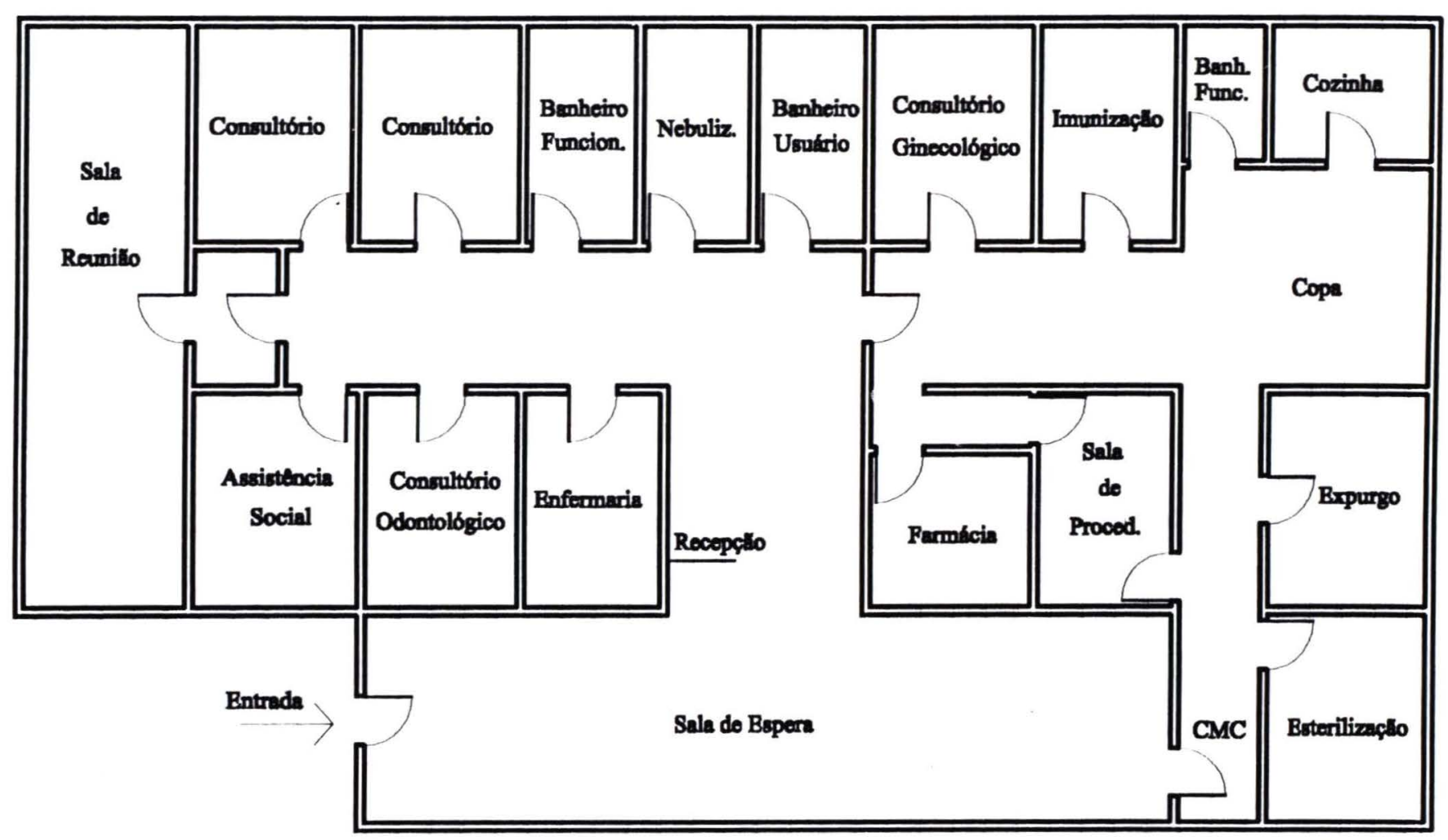

UBS Retiro 


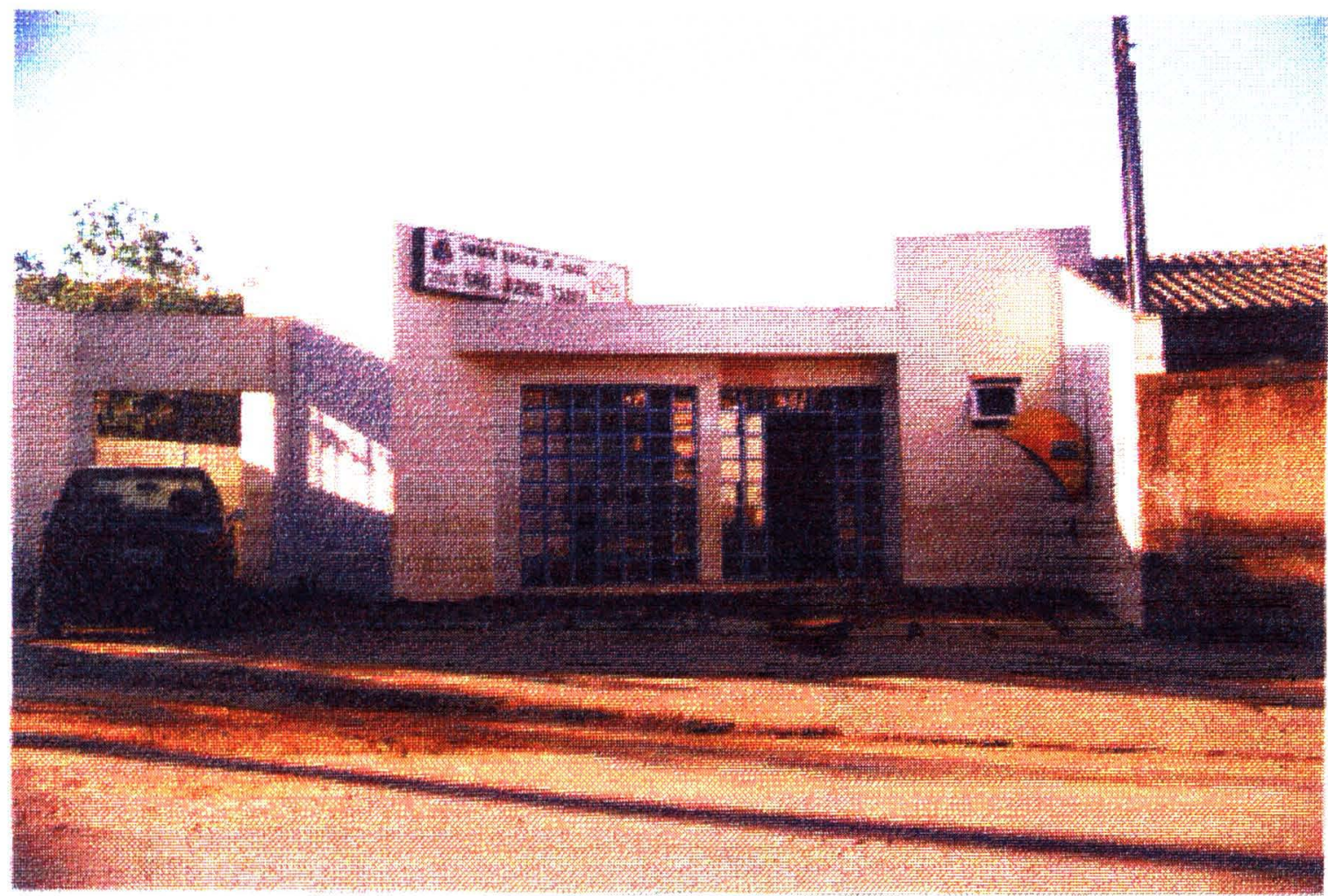

\section{Unidade Básica de Saúde São Judas Tadeu}

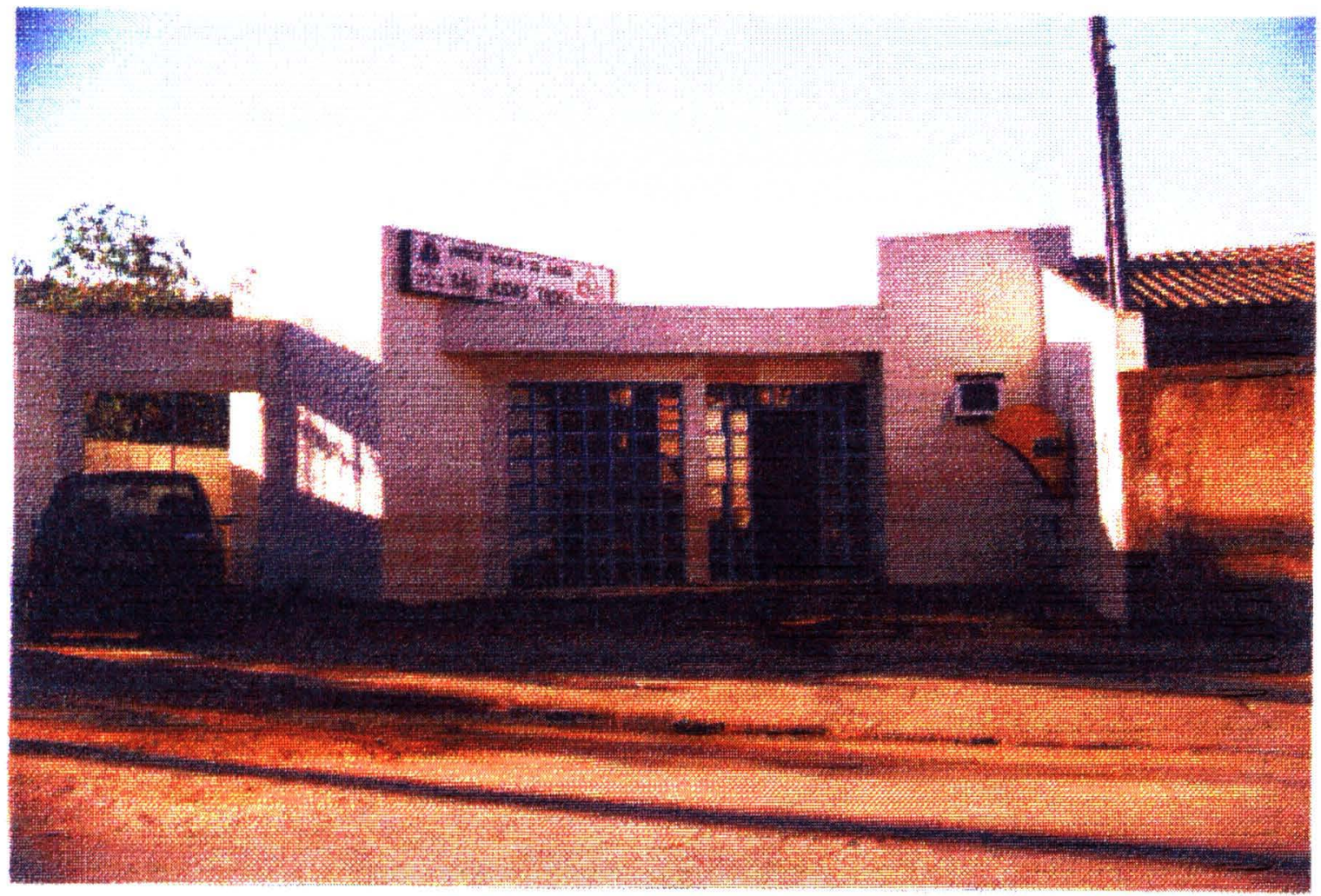

Biblioteca/CIR

FACULDADE DE SAÚDE PÚBLICA UNIVERSIDADE DE SÄO PAULO 


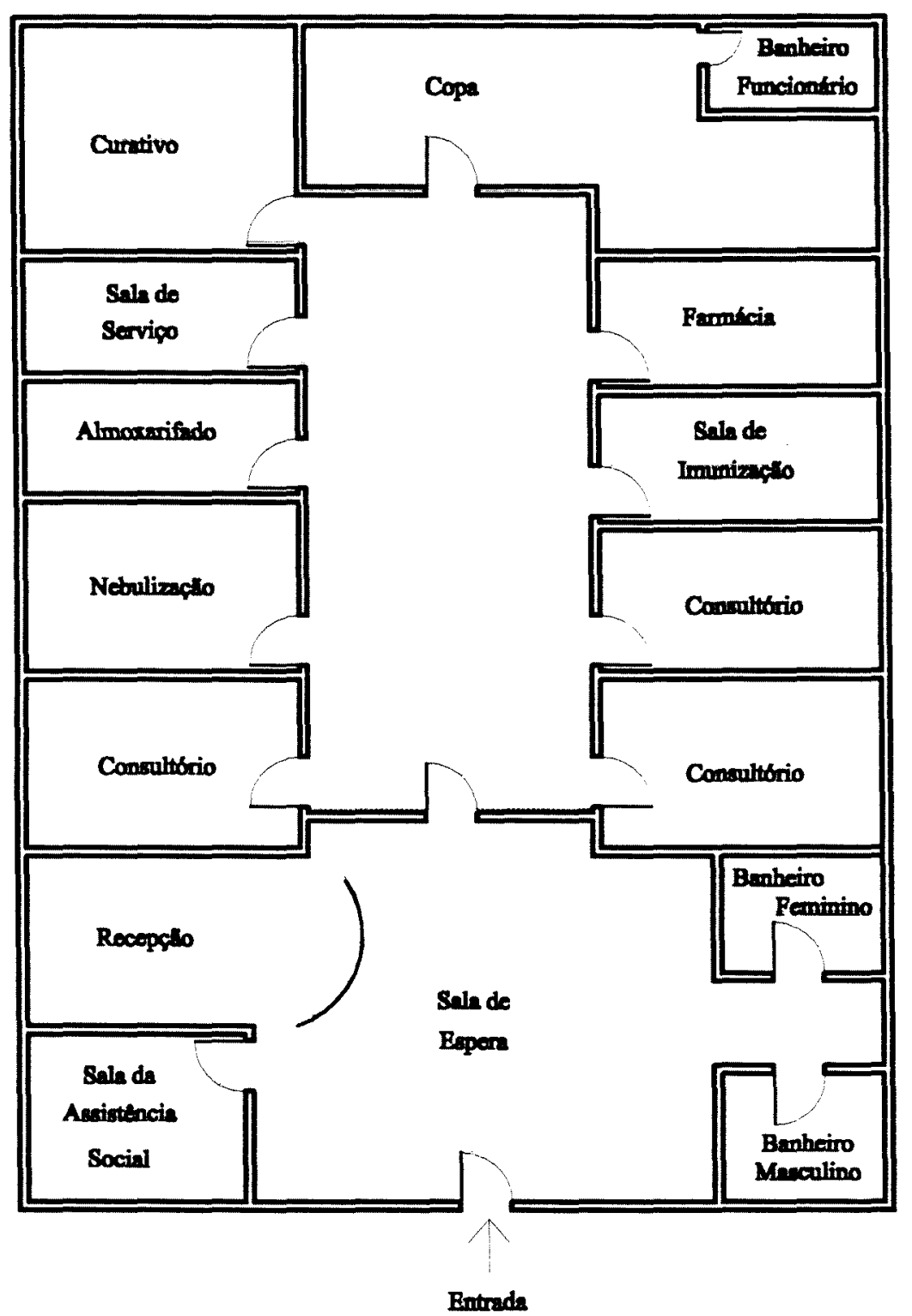

UBS S*o Judas Tadea 


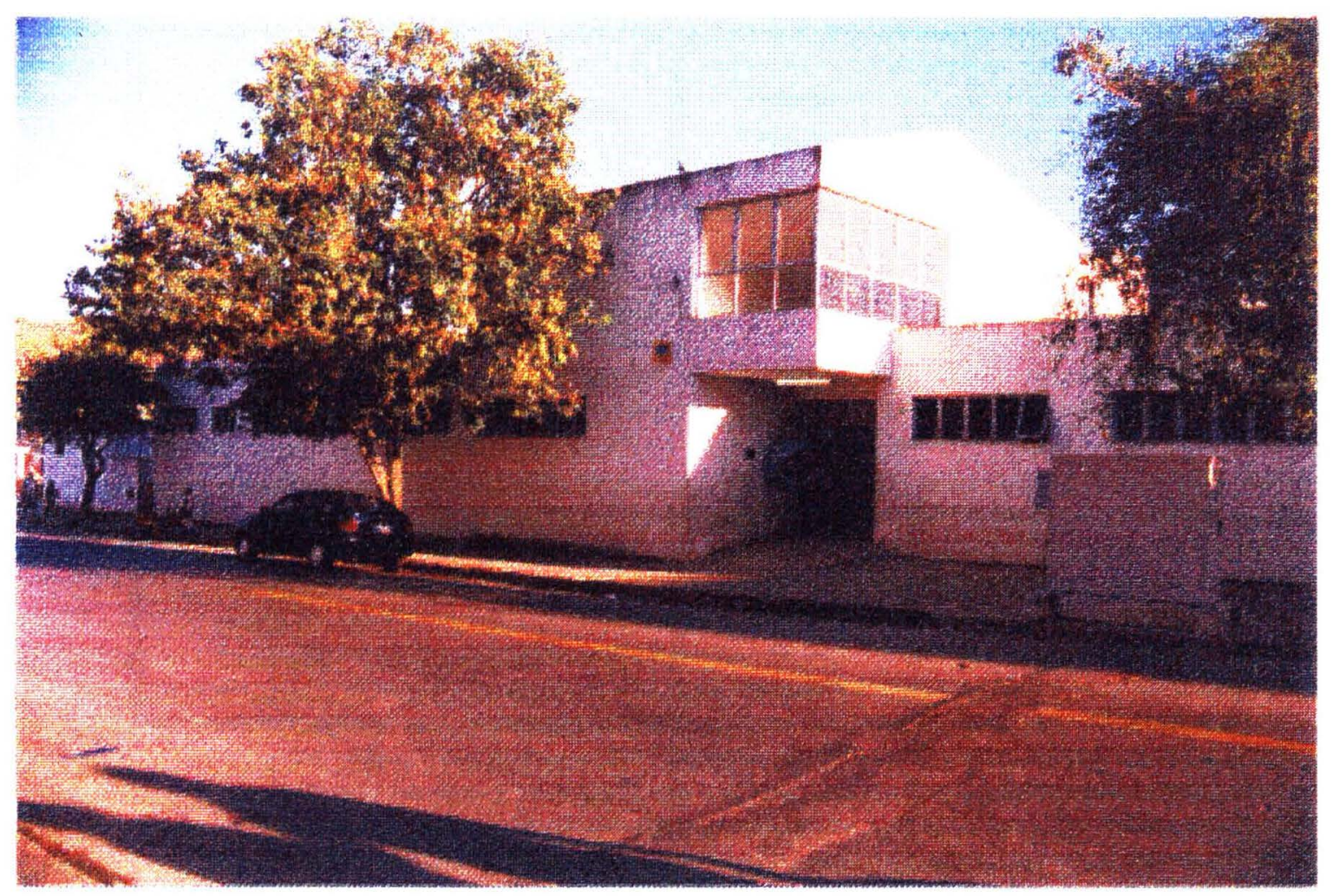

\section{Unidade Básica de Saúde Santa Cruz}

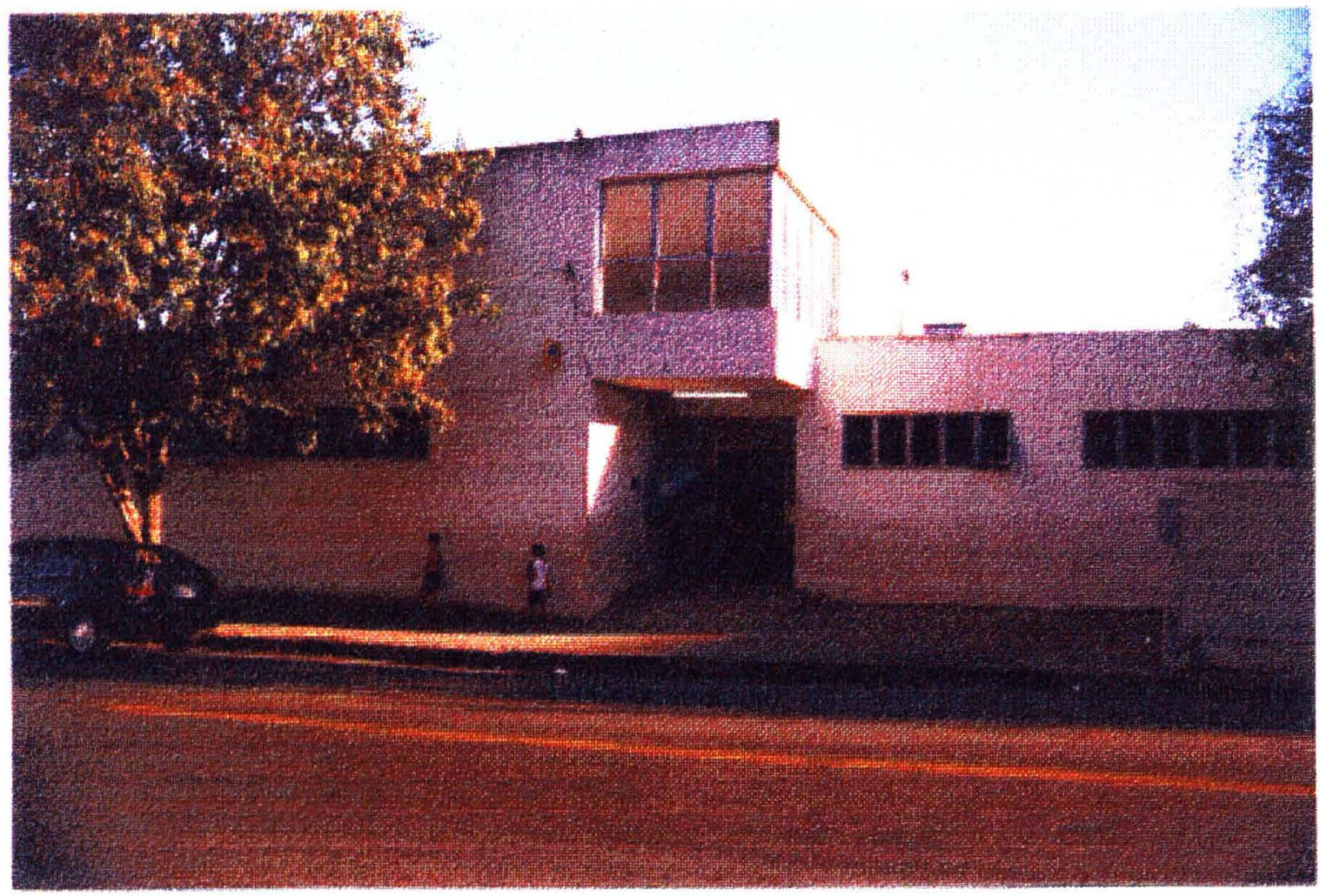




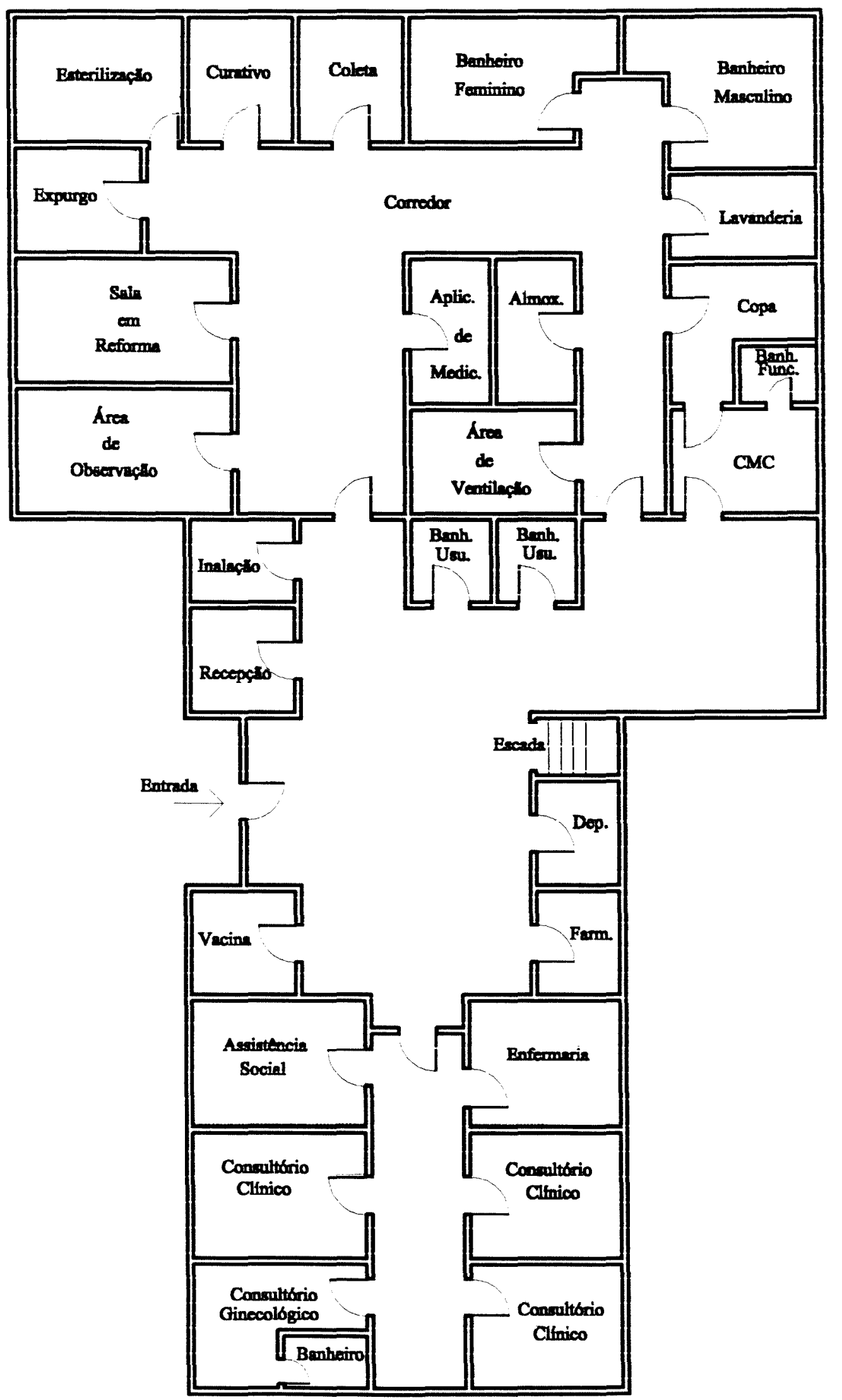

IJRS Senta Crox

$1 \circ$ Pisec 


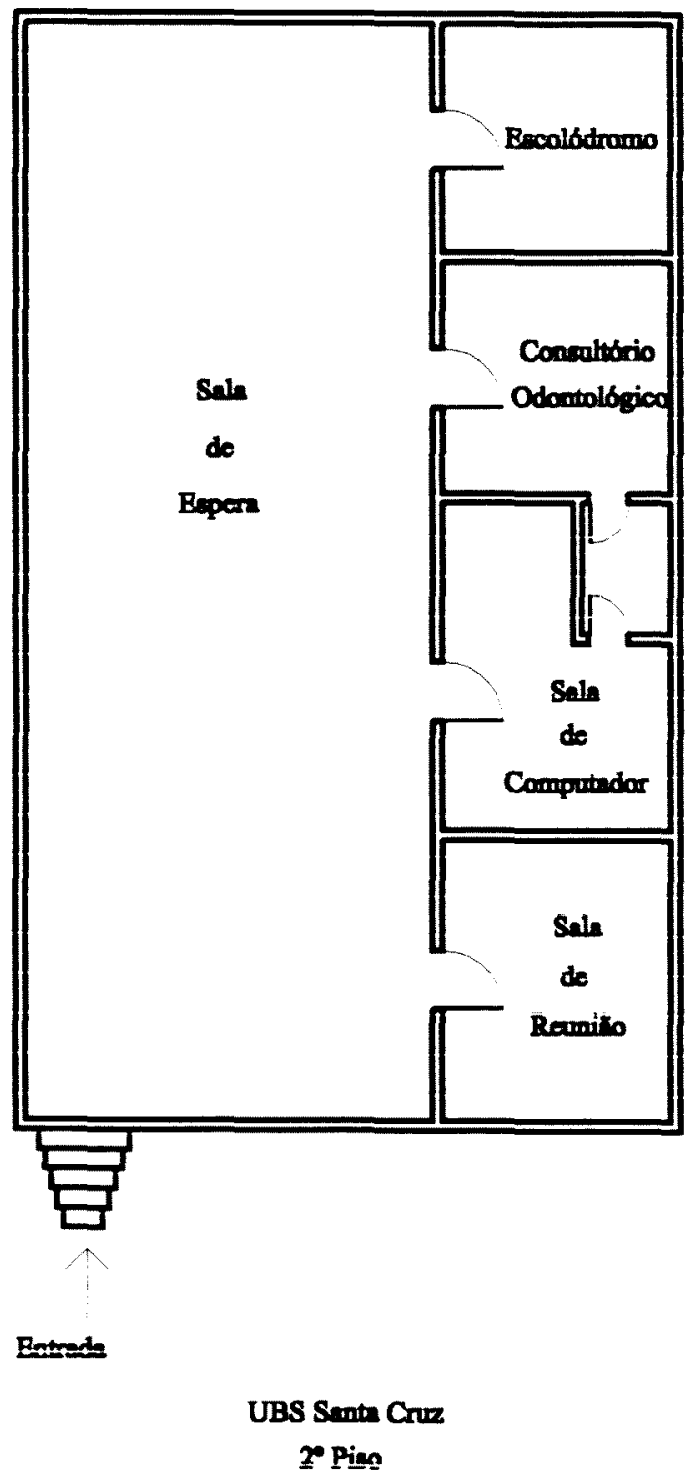


ANEXO 5 


\section{SÃO BENEDITO}

Participaram do levantamento: 1 Enfermeira e 1 Auxiliar (Técnica)

\begin{tabular}{|c|c|c|c|}
\hline LOCAL & CONDIÇÃO FAVORÁVEL & CONDIÇÃO DESFAVORÁVEL/CARGA & PROPOSTAS DE SOLUÇÃO \\
\hline \begin{tabular}{|l|} 
Sala de Espera/ \\
Recepção
\end{tabular} & $\begin{array}{l}\text { É um local bem iluminado e o piso não é } \\
\text { escorregadio }\end{array}$ & $\begin{array}{l}\text { Espaço pouco arejado e muito quente no } \\
\text { periodo da tarde; concentra muitas } \\
\text { pessoas, gerando tumulto e muito barulho; } \\
\text { a frente de vidro é um risco para crianças; } \\
\text { as portas entre a sala e a UBS são de mola, } \\
\text { fazem muito barulho e podem prender as } \\
\text { mãos de crianças (o que já aconteceu). } \\
\text { Na recepção os funcionários ficam muito } \\
\text { expostos, sujeitos a agressões, sentindo } \\
\text { dificuldade em lidar com a população que } \\
\text { chega muito nervosa, agressiva, faltando } \\
\text { com o respeito com os funcionários. Não } \\
\text { há lugar para todos os que esperam, } \\
\text { ficando muitos debruçados no balcão. }\end{array}$ & $\begin{array}{l}\text { Mudar o balcão da recepção para } \\
\text { não ficar muito exposto, proteger a } \\
\text { entrada do Sol com uma cobertura, } \\
\text { educar as pessoas solicitando que na } \\
\text { medida do possível falem mais baixo. }\end{array}$ \\
\hline $\begin{array}{l}\text { Banheiro Fem. } \\
\text { e Masc dos } \\
\text { usuários } \\
\end{array}$ & Individualidade & $\begin{array}{l}\text { Existência de um bebedouro na porta do } \\
\text { banheiro. }\end{array}$ & $\begin{array}{l}\text { Retirar o bebedouro da porta do } \\
\text { banheiro }\end{array}$ \\
\hline Consultório (1) & Nenhuma & $\begin{array}{l}\text { Recebe o barulho da sala de espera e não } \\
\text { tem pia }\end{array}$ & $\begin{array}{l}\text { Utilizar a sala para outra atividade e } \\
\text { construir outra sala para consultório }\end{array}$ \\
\hline $\begin{array}{l}\text { Sala da } \\
\text { odontotologia }\end{array}$ & Boa localização e é de fácil acesso & $\begin{array}{l}\text { Sala pequena, com muitc barulho devido } \\
\text { ao compressor. } \\
\text { Insuficiência e falta de qualidade do } \\
\text { material }\end{array}$ & $\begin{array}{l}\text { Fechar o compressor do lado de fora } \\
\text { da sala, construir um escovódromo e } \\
\text { ampliar o espaço da sala. }\end{array}$ \\
\hline
\end{tabular}




\begin{tabular}{|c|c|c|c|}
\hline Consultório (2) & Bem iluminado e ventilado & $\begin{array}{l}\text { Recebe muito barulho do compressor e } \\
\text { nebulizador }\end{array}$ & $\begin{array}{l}\text { Retirar o compressor da sala da } \\
\text { odonto }\end{array}$ \\
\hline $\begin{array}{l}\text { Sala de } \\
\text { vacinação }\end{array}$ & $\begin{array}{l}\text { É utilizada apenas para vacina, tem pia, } \\
\text { bancada, colchonete, local de vacinação } \\
\text { de crianças deitadas, arquivo, geladeira, } \\
\text { é uma sala ótima }\end{array}$ & Não tem dificuldades & Não tem nada para melhorar \\
\hline $\begin{array}{l}\text { Sala de } \\
\text { nebulização }\end{array}$ & Bom tamanho e tem pia & Sala com muito barulho e pouco ventilada & Retirar o nebulizador da sala. \\
\hline Copa & $\begin{array}{l}\text { Bem iluminada e ventilada, tem um } \\
\text { fogão, permite que se visualize o balcão } \\
\text { de recepção. É um espaço que pode ser } \\
\text { usado para descanso }\end{array}$ & $\begin{array}{l}\text { Não tem conforto. É utilizada também } \\
\text { como Central de Marcação de Consultas } \\
\text { (CMC). A cozinha é inadequada (tem um } \\
\text { tanque dentro) }\end{array}$ & $\begin{array}{l}\text { Retirar o tanque da cozinha, fazer } \\
\text { um lavanderia com área para secar } \\
\text { roupa e separar a CMC }\end{array}$ \\
\hline $\begin{array}{l}\text { Banheiro dos } \\
\text { funcionários }\end{array}$ & & $\begin{array}{l}\text { Tem cheiro de esgoto, o ralo é lacrado } \\
\text { para melhorar o cheiro; ouve-se tudo o } \\
\text { que acontece no banheiro na cozinha, não } \\
\text { oferece privacidade }\end{array}$ & \\
\hline $\begin{array}{l}\text { Sala de } \\
\text { procedimentos }\end{array}$ & $\begin{array}{l}\text { É utilizada apenas para procedimentos, } \\
\text { oferece privacidade }\end{array}$ & Não é muito ventilada & Melhorar a ventilação \\
\hline $\begin{array}{l}\text { Sala de } \\
\text { curativo e } \\
\text { esterilização }\end{array}$ & Não tem nada de bom & $\begin{array}{l}\text { Não é adequada, é abafada, não tem lugar } \\
\text { para preparar e lavar o material, é pequena } \\
\text { por ser utilizada para curativo e } \\
\text { esterilização }\end{array}$ & Separar as atividades em duas salas \\
\hline Expurgo & Existe um espaço destinado ao expurgo & $\begin{array}{l}\text { Pouco ventilado e iluminado, pequeno, } \\
\text { utilizado também para lavar roupa, pano } \\
\text { de chão e material de modo geral }\end{array}$ & $\begin{array}{l}\text { Ter uma lavanderia, e um lugar } \\
\text { especifico para lavar material }\end{array}$ \\
\hline $\begin{array}{l}\text { Consultório } \\
\text { ginecológico }\end{array}$ & $\begin{array}{l}\text { Tem um banheiro na sala, é bem } \\
\text { iluminado e ventilado }\end{array}$ & $\begin{array}{l}\text { É um consultório muito bom, não tem } \\
\text { nada de ruim }\end{array}$ & Nada para melhorar \\
\hline
\end{tabular}




\begin{tabular}{|l|l|l|l|}
\hline Consultório (2) & $\begin{array}{l}\text { Tem uma pia na sala, é bem iluminado e } \\
\text { ventilado }\end{array}$ & Muito barulho da sala de espera & Eliminar o barulho \\
\hline Farmácia & Bem localizada e ventilada & $\begin{array}{l}\text { A iluminação é artificial, é pequena para a } \\
\text { quantidade de medicamentos }\end{array}$ & $\begin{array}{l}\text { Ampliar para a recepção, fazendo } \\
\text { um único ambiente fechado e maior }\end{array}$ \\
\hline Corredores & São bons & Não têm nada de ruim & Nada para melhorar \\
\hline
\end{tabular}

Além das cargas acima foram mencionadas as seguintes cargas:

Dificuldades na relação com a equipe e com a população por falta de respeito, e de entendimento, gerando estresse.

As decisões tomadas nas reuniões não são seguidas

Falta de recursos humanos 


\section{SANTA CECÍLIA}

Participaram do levantamento: 1 Enfermeira e 1 Auxiliar

\begin{tabular}{|c|c|c|c|}
\hline LOCAL & CONDIÇÃO FAVORÁVEL & CONDIÇÃO DESFAVORÁVEL/CARGA & PROPOSTA DE SOLUÇÃO \\
\hline $\begin{array}{l}\text { Sala de } \\
\text { vacinação }\end{array}$ & $\begin{array}{l}\text { É clara e arejada, tem uma aparência } \\
\text { agradável, a cor da parede é suave e } \\
\text { contribui para um ambiente tranqüilo }\end{array}$ & $\begin{array}{l}\text { Sai um odor de esgoto da pia, e tem inseto } \\
\text { (baratas), a iluminação não é boa } \\
\text { (lâmpadas piscando), falta uma maca ou } \\
\text { colchonete para apoiar as crianças durante } \\
\text { a vacinação }\end{array}$ & $\begin{array}{l}\text { Dedetizar, colocar uma maca ou } \\
\text { colchonete, investigar o porquê do } \\
\text { odor }\end{array}$ \\
\hline $\begin{array}{l}\text { Sala de } \\
\text { procedimentos }\end{array}$ & $\begin{array}{l}\text { Bem iluminada e ventilada, recebe a luz } \\
\text { solar, tem uma bancada grande com } \\
\text { armário que ajuda a organizar o espaço }\end{array}$ & $\begin{array}{l}\text { Falta material do tipo luvas, ou quando } \\
\text { tem são muito grandes, tem pouco espaço, } \\
\text { o apoiador de braços é baixo, não tem um } \\
\text { lugar confortável para o paciente, são } \\
\text { muitas atividades para serem realizadas } \\
\text { por uma única funcionária, muitas } \\
\text { atividades burocráticas, os potes de } \\
\text { exames e pedidos costumam vir sujos da } \\
\text { população, não fecham direito, são em } \\
\text { quantidade insuficiente e muito pequenos, } \\
\text { lida-se com material perfuro-cortante o } \\
\text { tempo todo }\end{array}$ & $\begin{array}{l}\text { Ter mais cuidado ao manipular os } \\
\text { materiais, pensar antes de usar os } \\
\text { materiais; utilizar equipamento de } \\
\text { proteção, manter sempre limpa a } \\
\text { sala. }\end{array}$ \\
\hline Expurgo & $\begin{array}{l}\text { O fato de existir um espaço para o } \\
\text { expurgo, é claro }\end{array}$ & $\begin{array}{l}\text { E pequeno, desorganizado, é utilizado } \\
\text { para limpeza de pano de chão e materiais, } \\
\text { não tem uma bancada para apoiar o } \\
\text { material a ser lavado e o que foi lavado, a } \\
\text { torneira espirra água. }\end{array}$ & $\begin{array}{l}\text { Ter outro espaço, separar a limpeza } \\
\text { de materiais da limpeza de roupas e } \\
\text { pano de chão }\end{array}$ \\
\hline
\end{tabular}




\begin{tabular}{|c|c|c|c|}
\hline \begin{tabular}{|l|} 
Consultório do \\
Clínico Geral \\
\end{tabular} & $\begin{array}{l}\text { É uma sala grande, espaçosa e tranqüila } \\
\text { (fica afastada da entrada e recepção) }\end{array}$ & $\begin{array}{l}\text { A pia é pequena, não tem um suporte para } \\
\text { toalha de papel, falta uma balança }\end{array}$ & Instalar um suporte de toalha \\
\hline $\begin{array}{l}\text { Consultório de } \\
\text { pediatria }\end{array}$ & $\begin{array}{l}\text { É organizado e tem um aspecto } \\
\text { agradável }\end{array}$ & $\begin{array}{l}\text { É pequeno e menos espaçoso pelo } \\
\text { acúmulo de material; não tem pia e suporte } \\
\text { para toalha }\end{array}$ & $\begin{array}{l}\text { Trocar os consultórios, solicitar e } \\
\text { instalar um suporte de toalha }\end{array}$ \\
\hline Recepção & $\begin{array}{l}\text { Aparentemente é bonita, clara e arejada, } \\
\text { tem banheiros para os usuários, o balcão } \\
\text { auxilia por isolar e impor limite }\end{array}$ & $\begin{array}{l}\text { Tumultuada por acúmulo de som, muito } \\
\text { ruido, as vezes não comporta a } \\
\text { quantidade de pacientes, principalmente na } \\
\text { parte da manhã, a porta de entrada é única } \\
\text { para CMC e para a Unidade, é o pára-raios } \\
\text { da unidade, o centro nervoso, existe muita } \\
\text { pressão, pela demanda reprimida, por } \\
\text { paciente que não tem educação, exames } \\
\text { que demoram para chegar. }\end{array}$ & $\begin{array}{l}\text { Educar a população, organizar a fila } \\
\text { de espera com senhas, restringir o } \\
\text { acesso ao corredor e às salas, } \\
\text { permitindo a entrada apenas no } \\
\text { momento do atendimento }\end{array}$ \\
\hline Copa & $\begin{array}{l}\text { Existe espaço, oferece certa privacidade } \\
\text { para os funcionários na hora de tomar um } \\
\text { café, é clara e possui uma pia boa }\end{array}$ & $\begin{array}{l}\text { Pequena, o fogão esta necessitando de } \\
\text { uma revisão (solta fuligem), é utilizado } \\
\text { para esterilizar material através da panela } \\
\text { de pressão, falta um cesto de lixo, uma } \\
\text { geladeira, presença de insetos (baratas) }\end{array}$ & $\begin{array}{l}\text { Adquirir um cesto de lixo, uma } \\
\text { geladeira, trocar o fogão e dedetizar }\end{array}$ \\
\hline $\begin{array}{l}\text { Sala de } \\
\text { esterilização }\end{array}$ & Possui uma pia boa, armários e é clara & $\begin{array}{l}\text { Pequena, falta autoclave, presença de } \\
\text { baratas }\end{array}$ & Dedetizar, adquirir autoclave \\
\hline $\begin{array}{l}\text { Sala de } \\
\text { nebulização }\end{array}$ & Nada & $\begin{array}{l}\text { Muito pequena, só cabem } 2 \text { crianças mas } \\
\text { o equipamento tem capacidade para } 4,0 \\
\text { compressor é muito ruidoso, o ruído toma } \\
\text { conta da unidade }\end{array}$ & Isolar o compressor, trocar de sala \\
\hline $\begin{array}{l}\text { Banheiro dos } \\
\text { usuários }\end{array}$ & São grandes e bem localizados & $\begin{array}{l}\text { Há um bebedouro na entrada dos } \\
\text { banheiros }\end{array}$ & Mudar o lugar do bebedouro \\
\hline
\end{tabular}




\begin{tabular}{|l|l|l|l|}
\hline $\begin{array}{l}\text { Sala de } \\
\text { conforto }\end{array}$ & $\begin{array}{l}\text { É utilizada para reuniões por ser bem } \\
\text { isolada, ficar distante da entrada }\end{array}$ & Pequena e quente & Colocar um ventilador \\
\hline $\begin{array}{l}\text { Banheiro dos } \\
\text { funcionários }\end{array}$ & É grande, tem chuveiro, é privativo & A pia é pequena, não tem porta toalha & $\begin{array}{l}\text { Trocar a pia, colocar um porta } \\
\text { toalha }\end{array}$ \\
\hline $\begin{array}{l}\text { Sala da } \\
\text { assistente } \\
\text { social }\end{array}$ & $\begin{array}{l}\text { É bem organizada, individual, tranqüila, } \\
\text { grande }\end{array}$ & É escura & Nada para se fazer \\
\hline Almoxarifado & É grande & $\begin{array}{l}\text { Está localizado no 20andar sendo } \\
\text { cansativo, falta armário e prateleiras }\end{array}$ & Adquirir armários e prateleiras \\
\hline $\begin{array}{l}\text { Sala de } \\
\text { odontologia }\end{array}$ & $\begin{array}{l}\text { É espaçosa, bem iluminada, tem uma } \\
\text { estufa, e aparentemente é bem equipada }\end{array}$ & Tem presença de insetos (baratas) & Dedetizar \\
\hline $\begin{array}{l}\text { Consultório de } \\
\text { ginecologia }\end{array}$ & Tem um banheiro conjugado & $\begin{array}{l}\text { É escura, falta balança de adulto, tem } \\
\text { acúmulo de equipamentos, é pequena, fria } \\
\text { e úmida }\end{array}$ & $\begin{array}{l}\text { Diminuir o banheiro para aumentar a } \\
\text { salquirir uma balança }\end{array}$ \\
\hline $\begin{array}{l}\text { Sala de } \\
\text { atendimento } \\
\text { coletivo }\end{array}$ & $\begin{array}{l}\text { Mal localizada para sua função (fica no } \\
\text { meio da unidade), é escura, quente e } \\
\text { abafada }\end{array}$ & Mudar a função da sala \\
\hline farmácia & Clara e ventilada & $\begin{array}{l}\text { Pequena } \\
\text { demandas se misturam causando tumulto }\end{array}$ & Deveria ser fora da unidade \\
\hline $\begin{array}{l}\text { Sala da Central } \\
\text { de marcação de } \\
\text { Consultas }\end{array}$ & É de bom tamanho & \begin{tabular}{l} 
Grar dentro da unidade as \\
\hline
\end{tabular}
\end{tabular}

Além dessas cargas foram mencionadas também:

Falta de funcionários,

Sobrecarga de trabalho e demanda desorganizada 


\section{UBS SANTA EFIGÊNIA}

Participaram do levantamento: 1 Enfermeira e 1 auxiliar

\begin{tabular}{|c|c|c|c|}
\hline LOCAL & CONDIÇÃO FAVORÁVEL & CONDIÇÃO DESFAVORÁVEL/CARGA & PROPOSTAS DE SOLUÇÃO \\
\hline $\begin{array}{l}\text { Entrada/recep } \\
\text { ção } \\
\end{array}$ & Não tem nada de bom & $\begin{array}{l}\text { Espaço pequeno, pouco ventilado, divide o } \\
\text { posto em duas partes }\end{array}$ & $\begin{array}{l}\text { Melhorar a ventilação, mudar a } \\
\text { recepção de lugar }\end{array}$ \\
\hline \begin{tabular}{|l|}
$\begin{array}{l}\text { Consultório } \\
\text { odontológico }\end{array}$ \\
\end{tabular} & $\begin{array}{l}\hat{E} \text { de bom tamanho, bem iluminado e tem } \\
\text { um escovódromo }\end{array}$ & Falta ventilação e o equipamento é antigo & $\begin{array}{l}\text { Trocar a janela (que é do tipo } \\
\text { basculante e alta) e o equipamento }\end{array}$ \\
\hline Consultórios & $\begin{array}{l}\text { Todos os } 3 \text { são de bom tamanho, bem } \\
\text { localizados de fácil acesso }\end{array}$ & $\begin{array}{l}\text { Para todos falta ventilação e balança } \\
\text { pediátrica }\end{array}$ & $\begin{array}{l}\text { Melhorar a ventilação, colocar } \\
\text { balança pediátrica }\end{array}$ \\
\hline $\begin{array}{l}\text { Consultório } \\
\text { ginecológico }\end{array}$ & $\begin{array}{l}\text { Tem banheiro, é de bom tamanho e bem } \\
\text { localizado }\end{array}$ & $\begin{array}{l}\text { Falta ventilação, a mesa ginecológica é } \\
\text { antiga e está quebrada, falta material } \\
\text { (pinças). }\end{array}$ & Trocar a mesa, melhorar a ventilação \\
\hline Copa & Tem um bom fogão e uma boa pia & Muito pequena, só cabe uma cadeira & $\begin{array}{l}\text { Mudar de local para um espaço } \\
\text { maior }\end{array}$ \\
\hline $\begin{array}{l}\text { Sala de } \\
\text { nebulização }\end{array}$ & Não tem nada de bom & $\begin{array}{l}\text { Pequena, mal ventilada, com muito ruído } \\
\text { do compressor }\end{array}$ & $\begin{array}{l}\text { Aumentar, melhorar a ventilação, } \\
\text { diminuir o barulho do compressor } \\
\text { isolando-o }\end{array}$ \\
\hline $\begin{array}{l}\text { Sala de } \\
\text { esterilização }\end{array}$ & Não tem nada de bom & $\begin{array}{l}\text { Muito pequena, não tem autoclave (só } \\
\text { estufa), a esterilização é feita em panela } \\
\text { de pressão }\end{array}$ & Aumentar o espaço, ter autoclave \\
\hline corredor & Não tem nada de bom & $\begin{array}{l}\text { Nos corredores ficam os arquivos que } \\
\text { atrapalham a passagem, estão em mal } \\
\text { estado de conservação com gavetas } \\
\text { emperradas e são em número insuficiente }\end{array}$ & $\begin{array}{l}\text { Ter mais arquivos em boas } \\
\text { condições e local adequado para } \\
\text { guarda-los }\end{array}$ \\
\hline $\begin{array}{l}\text { Banheiro dos } \\
\text { funcionários }\end{array}$ & Tem um bom tamanho & Falta ventilação e iluminação & Não tem como melhorar \\
\hline
\end{tabular}




\begin{tabular}{|c|c|c|c|}
\hline $\begin{array}{l}\text { Banheiro dos } \\
\text { usuários }\end{array}$ & Tem um bom tamanho & Falta ventilação e iluminação & Não tem como melhorar \\
\hline $\begin{array}{l}\text { Serviço de } \\
\text { limpeza }\end{array}$ & Tem um bom tamanho & Falta armários para guarda de material & Colocar armários \\
\hline $\begin{array}{l}\text { Sala de } \\
\text { reuniões }\end{array}$ & $\begin{array}{l}\text { Bom tamanho, número de cadeiras } \\
\text { suficiente, tem um ventilador de teto, e } \\
\text { uma televisão }\end{array}$ & $\begin{array}{l}\text { Falta ventilação natural, é utilizada para } \\
\text { guardar leite e óleo, e para preparo de } \\
\text { material, esta faltando o vídeo }\end{array}$ & $\begin{array}{l}\text { Ter outro local para guarda do leite } \\
\text { e óleo e para o preparo de material. } \\
\text { Ter um vídeo }\end{array}$ \\
\hline $\begin{array}{l}\text { Sala da } \\
\text { assistente } \\
\text { social }\end{array}$ & $\begin{array}{l}\text { É uma ótima sala, tem computador, } \\
\text { armários pia, mesa e cadeira individual }\end{array}$ & Falta ventilação & Melhorar ventilação \\
\hline $\begin{array}{l}\text { Sala de } \\
\text { curativo }\end{array}$ & Tem um bom tamanho & $\begin{array}{l}\text { É utilizada também para a coleta de } \\
\text { material e guarda de outros materiais que } \\
\text { não para curativos, tem poucos armários, é } \\
\text { pouco ventilada }\end{array}$ & $\begin{array}{l}\text { Ter um local só para coleta de } \\
\text { material, ter mais armárius, retirar da } \\
\text { sala todo o material que não é } \\
\text { específico }\end{array}$ \\
\hline $\begin{array}{l}\text { Sala de } \\
\text { vacina }\end{array}$ & $\begin{array}{l}\text { A geladeira funciona, tem uma pia com } \\
\text { bancada }\end{array}$ & $\begin{array}{l}\text { Não tem uma maca, e nem caberia uma, a } \\
\text { sala é pequena, o acesso é ruim, o } \\
\text { corredor é estreito, devido a sua } \\
\text { localização muitas vezes ocorre tumulto } \\
\text { no atendimento, falta um arquivo para } \\
\text { agendamento e é mal ventilada }\end{array}$ & $\begin{array}{l}\text { Deveria ser uma sala maior, com } \\
\text { maca e arquivo }\end{array}$ \\
\hline farmácia & Tem uma comunicação independente & $\begin{array}{l}\text { Muito pequena, não tem um funcionário } \\
\text { que fica responsável por ela, a contagem } \\
\text { de medicamentos nunca bate, fica aberta } \\
\text { porque é nela que fica o telefone }\end{array}$ & $\begin{array}{l}\text { Retirar o telefone, permanecer } \\
\text { fechada, ter uma pessoa responsável }\end{array}$ \\
\hline
\end{tabular}




\begin{tabular}{|l|l|l|l|}
\hline & & & \\
\hline $\begin{array}{l}\text { Sala da } \\
\text { Central de } \\
\text { marcação } \\
\text { consultas }\end{array}$ & É independente do posto & É muito pequena & Ser uma sala maior \\
\hline
\end{tabular}

Além das cargas acima foram mencionadas as seguintes: não se tem noção de tempo dentro do posto, ele fica abaixo do nível da rua, todas as salas são mal ventiladas devido ao tipo de janela, falta um pediatra, um médico de família e um auxiliar, falta material do tipo sabonete líquido, papel toalha, sempre está faltando alguma coisa, nunca se está satisfeito, sabe-se que se está fazendo a coisa errada mas não tem outro modo de se fazer. 


\section{UBS FURTADO DE MENEZES}

Participaram do levantamento: 1 enfermeira e 3 auxiliares (2 técnicos)

\begin{tabular}{|l|l|l|l|}
\hline LOCAL & CONDIÇÃO FAVORÁVEL & CONDIÇÃO DESFAVORÁEL/CARGA & PROPOSTAS DE SOLUÇÃO \\
\hline $\begin{array}{l}\text { Sala de espera/ } \\
\text { recepção }\end{array}$ & É um espaço bem ventilado e amplo & $\begin{array}{l}\text { O piso e os bancos são de dificil limpeza, } \\
\text { tem um aspecto frio por ser toda de } \\
\text { cimento, no verão é muito quente, falta um } \\
\text { bebedouro,o que tem não está } \\
\text { funcionando. }\end{array}$ & $\begin{array}{l}\text { Criar um espaço mais agradável com } \\
\text { revistas, flores, ter cadeiras também } \\
\text { e nãonas bancos, ventilador de } \\
\text { teto, música de fundo (som } \\
\text { ambiente), ter um bebedouro } \\
\text { funcionando, solicitar a troca do que } \\
\text { tem e não está funcionando }\end{array}$ \\
\hline $\begin{array}{l}\text { Farmácia e } \\
\text { arquivo }\end{array}$ & $\begin{array}{l}\text { Foi feita uma reforma (era bem pior), tem } \\
\text { um balcão que fica próximo do arquivo }\end{array}$ & $\begin{array}{l}\text { Falta espaço, as paredes estão mofadas } \\
\text { devido a infiltração, presença de muito pó } \\
\text { devido a guarda de papéis, o arquivo é } \\
\text { muito pesado e de dificil manuseio, } \\
\text { quando aberto impede a passagem das } \\
\text { pessoas, não tem uma pia para se lavar as } \\
\text { mãos }\end{array}$ & $\begin{array}{l}\text { Manutenção periódica, separar a } \\
\text { farmácia do arquivo, arrumando um } \\
\text { outro local para se guardarem os } \\
\text { apenas para a dispensa semanal, } \\
\text { informatizar, trocar o arquivo }\end{array}$ \\
\hline $\begin{array}{l}\text { Consultório (1) } \\
\text { Consultório (2) }\end{array}$ & $\begin{array}{l}\text { Tem balança pediátrica e de adulto, mesa } \\
\text { clínica e uma pia }\end{array}$ & Pouco ventilado é muito quente e pequeno & Aumentar a janela \\
\hline $\begin{array}{l}\text { Consultório } \\
\text { (3)/ sala de } \\
\text { eletrocardiogra } \\
\text { ma e repouso }\end{array}$ & $\begin{array}{l}\text { Tem um negatoscópio, uma mesa e um } \\
\text { aparelho de eletro que estão } \\
\text { funcionando/ é utilizada muito pouco e } \\
\text { rapidamente }\end{array}$ & Nada de ruim & $\begin{array}{l}\text { Aumentar a janela, e o espaço do } \\
\text { consultório }\end{array}$ \\
\hline $\begin{array}{l}\text { Consultório (4) } \\
\text { Consultório (5) }\end{array}$ & $\begin{array}{l}\text { Tem um bom tamanho } \\
\text { Tem bom tamanho }\end{array}$ & Pouco ventilado e quente & Nada a fazer \\
\hline
\end{tabular}




\begin{tabular}{|c|c|c|c|}
\hline & & & \\
\hline Sala de vacinas & $\begin{array}{l}\text { Tem uma sala e um arquivo especifico } \\
\text { apenas para vacinas }\end{array}$ & $\begin{array}{l}\text { Pouco ventilada, falta iluminação natural, } \\
\text { deveria ter mais espaço para se colocar um } \\
\text { maca, para se entrar na sala tem que se } \\
\text { subir um degrau }\end{array}$ & Reestruturar o espaço \\
\hline $\begin{array}{l}\text { Sala de } \\
\text { reuniões }\end{array}$ & Ampla, iluminada e ventilada & Nada de ruim & Ser um pouco maior \\
\hline $\begin{array}{l}\text { Consultório } \\
\text { ginecológico }\end{array}$ & $\begin{array}{l}\text { Tem um bom espaço, bem iluminada e } \\
\text { ventilada }\end{array}$ & $\begin{array}{l}\text { Não tem um banheiro específico, no verão } \\
\text { é muito quente por receber a luz solar } \\
\text { diretamente, tem um ventilador de teto que } \\
\text { não pode ser usado pois é muito antigo e } \\
\text { não tem manutenção }\end{array}$ & $\begin{array}{l}\text { Colocar cortinas, fazer manutenção } \\
\text { do ventilador }\end{array}$ \\
\hline $\begin{array}{l}\text { Consultório } \\
\text { odontológico }\end{array}$ & Tem um bom espaço & $\begin{array}{l}\text { Muito quente por receber a luz solar } \\
\text { diretamente }\end{array}$ & Colocar cortinas \\
\hline Pastoral da criança & É uma sala grande & Pouco ventilada e escura & Não tem como melhorar \\
\hline \begin{tabular}{|l} 
Sala da \\
Enfermeira
\end{tabular} & $\bar{E}$ bem espaçosa & $\begin{array}{l}\text { Muito escura, não oferece privacidade do } \\
\text { corredor se ouve tudo o que se fala dentro } \\
\text { da sala }\end{array}$ & Não tem como melhorar \\
\hline $\begin{array}{l}\text { Sala do } \\
\text { Serviço social }\end{array}$ & É bem espaçosa & $\begin{array}{l}\text { Muito escura, não oferece privacidade do } \\
\text { corredor se ouve tudo o que se fala dentro } \\
\text { da sala }\end{array}$ & Não tem como melhorar \\
\hline Sala do & É bem espaçosa & Muito escura, não oferece privacidade do & Não tem como melhorar \\
\hline
\end{tabular}




\begin{tabular}{|c|c|c|c|}
\hline Conselho & & $\begin{array}{l}\text { corredor se ouve tudo o que se fala dentro } \\
\text { da sala }\end{array}$ & \\
\hline $\begin{array}{l}\text { Sala de } \\
\text { procedimentos } \\
\text { e de } \\
\text { nebulização }\end{array}$ & $\begin{array}{l}\text { O nebulizador é de fácil desinfecção, tem } \\
\text { uma divisória que separa o espaço de } \\
\text { nebulização do de procedimentos }\end{array}$ & $\begin{array}{l}\text { Pouco ventilada e iluminada, não oferece } \\
\text { privacidade, quando da realização de um } \\
\text { procedimento que exponha o usuário por } \\
\text { não ter uma porta separando os espaços, o } \\
\text { banco da sala de nebulização é de dificil } \\
\text { limpeza, o motor do nebulizador faz muito } \\
\text { ruído, para se entrar na sala tem que se } \\
\text { subir um degrau }\end{array}$ & $\begin{array}{l}\text { Colocar um porta para separar os } \\
\text { espaços, trocar o banco por cadeiras, } \\
\text { isolar o motor do nebulizador } \\
\text { externamente }\end{array}$ \\
\hline $\begin{array}{l}\text { Banheiro dos } \\
\text { funcionários }\end{array}$ & $\begin{array}{l}\text { Tem um banheiro exclusivo dos } \\
\text { funcionários }\end{array}$ & Degrau para entrar no banheiro & Não tem como melhorar \\
\hline Sala da CMC & É uma sala grande e espaçosa & $\begin{array}{l}\text { Fica muito isolada do posto, falta } \\
\text { segurança, é escura, úmida, com aspecto } \\
\text { sujo. }\end{array}$ & $\begin{array}{l}\text { Trazer a CMC para dentro ou mais } \\
\text { próxima do posto }\end{array}$ \\
\hline $\begin{array}{l}\text { Banheiros dos } \\
\text { usuários }\end{array}$ & Ter banheiro exclusivo dos usuários & $\begin{array}{l}\text { Está mal localizado, para se ter acesso aos } \\
\text { banheiros tem que se atravessar toda a } \\
\text { Unidade }\end{array}$ & $\begin{array}{l}\text { Passar a entrada do banheiro para a } \\
\text { parte externa do posto }\end{array}$ \\
\hline Depósito & Grande & Está com acúmulo de cadeiras velhas & $\begin{array}{l}\text { Doar os materiais que não são mais } \\
\text { utilizados }\end{array}$ \\
\hline Almoxarifado & Grande & Escuro, sem ventilação e iluminação & Colocar uma janela \\
\hline SEP & Grande/espaçoso & Escuro & Não tem como melhorar \\
\hline PSF & É uma sala muito boa & Não tem nada de ruim & Não tem nada para melhorar \\
\hline Copa & Grande/espaçosa & $\begin{array}{l}\text { Não tem janela, o piso é de cimento } \\
\text { rústico e de dificil limpeza e manutenção } \\
\end{array}$ & Colocar uma janela, arrumar o piso \\
\hline Área & Tem um espaço destinado a área & Pouco iluminada & Não tem como melhorar \\
\hline $\begin{array}{l}\text { S la de } \\
\text { curativos }\end{array}$ & É espaçosa, tem uma boa pia & $\begin{array}{l}\text { Não é ventilada e iluminada, falta uma } \\
\text { lixeira de pedal, o armário é de vidro e está }\end{array}$ & $\begin{array}{l}\text { Colocar um janela, uma lixeira de } \\
\text { pedal, trocar ou consertar o armário, }\end{array}$ \\
\hline
\end{tabular}




\begin{tabular}{|l|l|l|l|}
\hline & & $\begin{array}{l}\text { com vidro quebrado, não tem a porta da } \\
\text { frente, a sala é utilizada também para } \\
\text { coleta de sangue }\end{array}$ & \\
\hline $\begin{array}{l}\text { Sala de } \\
\text { Esterilização }\end{array}$ & Grande/espaçosa & $\begin{array}{l}\text { Faltam armários, os azulejos da bancada } \\
\text { estão soltando, cai terra do teto e dos } \\
\text { cantos }\end{array}$ & $\begin{array}{l}\text { Colocar mais armários, arrumar os } \\
\text { azulejos e o telhado }\end{array}$ \\
\hline
\end{tabular}

Além das cargas acima forma mencionadas também: falta de insumos, e descontinuidade do trabalho devido a falta de material 


\section{UBS JARDIM DA LUA}

Participaram do levantamento: 1 Enfermeira e 1 Auxiliar

\begin{tabular}{|c|c|c|c|}
\hline LOCAL & CONDIÇÃO FAVORÁVEL & CONDIÇÃO DESFAVORÁVEL/CARGA & PROPOSTA DE SOLUÇÃO \\
\hline $\begin{array}{l}\text { Recepção/ } \\
\text { sala de } \\
\text { espera }\end{array}$ & Espaço bem iluminado e ventilado & $\begin{array}{l}\text { É utilizada tanto como sala de espera } \\
\text { como recepção e sala de atividades } \\
\text { educativas, o banheiro dos usuários é } \\
\text { muito próximo deixando um odor } \\
\text { desagradável no ambiente, o espaço é } \\
\text { pequeno para o número de pessoas que se } \\
\text { atende, às vezes a parede de vidro da } \\
\text { entrada atrapalha o atendimento pois não } \\
\text { oferece privacidade, gerando insegurança } \\
\text { (não se pode deixar uma TV no espaço), } \\
\text { dificulta a realização de atividades } \\
\text { educativas }\end{array}$ & $\begin{array}{l}\text { Separar a recepção da sala de } \\
\text { espera, com uma sala de espera } \\
\text { maior e mais reservada }\end{array}$ \\
\hline \begin{tabular}{|l|} 
Banheiro \\
dos usuários
\end{tabular} & Tem um bom tamanho & $\begin{array}{l}\text { Não tem ventilação, não tem janela é um } \\
\text { pouco escuro }\end{array}$ & Colocar uma janela, um respiro \\
\hline $\begin{array}{l}\text { Sala de } \\
\text { curativos }\end{array}$ & É um sala grande de bom tamanho, & $\begin{array}{l}\text { Falta armário sob a pia, uma lâmpada } \\
\text { fluorescente, um carrinho de curativo, uma } \\
\text { persiana na janela para oferecer mais } \\
\text { privacidade e mais espaço para organizar } \\
\text { os materiais pois o armário da sala está } \\
\text { com a prateleira quebrada, dificultando seu } \\
\text { uso. A sala é utilizada também para coleta } \\
\text { e preparo de material }\end{array}$ & $\begin{array}{l}\text { Colocar a lâmpada que está faltando, } \\
\text { e o armário sob a pia que faz parte } \\
\text { do projeto original da UBS, } \\
\text { consertar a prateleira do armário, } \\
\text { separar as atividades, e fazer uma } \\
\text { desinfeção após a coleta de material }\end{array}$ \\
\hline
\end{tabular}




\begin{tabular}{|c|c|c|c|}
\hline $\begin{array}{l}\text { Consultório } \\
\text { com } \\
\text { banheiro/gin } \\
\text { ecológico }\end{array}$ & $\begin{array}{l}\text { Espaçoso, tem uma pia com balcão, é bem } \\
\text { ventilado, tem um banheiro, e a cama de } \\
\text { exames é boa }\end{array}$ & $\begin{array}{l}\text { Não tem ventilação no banheiro, o piso é } \\
\text { do tipo vulcapiso e a tinta das paredes não } \\
\text { é lavável dificultando a limpeza e } \\
\text { desinfecção, tem pouca iluminação natural, } \\
\text { falta armário sob a pia, na janela tem uma } \\
\text { cortina de tecido }\end{array}$ & $\begin{array}{l}\text { Melhorar a ventilação do banheiro, } \\
\text { trocar o piso e a tinta das paredes, } \\
\text { colocar um armário sob a pia e } \\
\text { trocar a cortina por persianas }\end{array}$ \\
\hline $\begin{array}{l}\text { Sala de } \\
\text { vacina/nebul } \\
\text { ização/proc } \\
\text { edimentos/ } \\
\text { esterilização }\end{array}$ & Grande, ventilada e iluminada & $\begin{array}{l}\text { O espaço não ser utilizado apenas para } \\
\text { vacina e muito ruido do compressor }\end{array}$ & $\begin{array}{l}\text { Ter uma sala só para vacina, uma } \\
\text { para nebulização, com o compressor } \\
\text { externo, uma para procedimentos e } \\
\text { uma para esterilização }\end{array}$ \\
\hline Consultório & $\begin{array}{l}\text { É grande, espaçoso, iluminado, ventilado, } \\
\text { tem uma boa pia }\end{array}$ & $\begin{array}{l}\text { A televisão fica dentro da sala, falta uma } \\
\text { balança de criança, a balança de adulto fica } \\
\text { muito próxima da janela }\end{array}$ & $\begin{array}{l}\text { Tirar a televisão da sala, colocar uma } \\
\text { mesa com a balança de criança }\end{array}$ \\
\hline Depósito & É de fácil acesso & $\begin{array}{l}\text { E improvisado, as prateleiras são altas e } \\
\text { dificultam a manipulação do material, o } \\
\text { espaço é pequeno, para a guarda de } \\
\text { medicamentos não é ventilado }\end{array}$ & Ser maior \\
\hline $\begin{array}{l}\text { Sala de } \\
\text { reuniões/co } \\
\mathrm{pa} / \\
\text { farmácia/C } \\
\mathrm{MC} \\
\end{array}$ & Não tem nada & $\begin{array}{l}\text { A mesma sala é utilizada para várias } \\
\text { atividades, a sala é pouco iluminada, as } \\
\text { lâmpadas queimam muito (talvez má } \\
\text { instalação elétrica) }\end{array}$ & $\begin{array}{l}\text { Ter uma sala só para a farmácia } \\
\text { (dispensação de medicamentos), com } \\
\text { uma pessoa responsável, e deveria } \\
\text { ser perto da recepção, ter uma sala } \\
\text { para a equipe, e uma para a CMC }\end{array}$ \\
\hline Expurgo & Não tem nada & $\begin{array}{l}\text { E um espaço adaptado, mal localizado (no } \\
\text { centro do posto perto da recepção) }\end{array}$ & Ser em outro lugar \\
\hline
\end{tabular}

Além das cargas acima forma citadas também: deveria ter grades nas janelas, e no relógio de energia que fica fora do posto, o posto é muito pequeno , deveria ter 1 . dis salas, falta privacidade

Por outro lado o posto é funcional, prático, o contato com a equipe é facilitado, no geral é iluminado e ventilado, passa uma boa impressão. 
UBS JARDIM ESPERANÇA

Participaram do levantamento: 1 enfermeira e 2 auxiliares

\begin{tabular}{|c|c|c|c|}
\hline LOCAL & CONDIÇÃO FAVORÁVEL & $\begin{array}{l}\text { CONDIÇÃO } \\
\text { DESFAVORÁVEL/CARGAS }\end{array}$ & PROPOSTA DE SOLUÇÃO \\
\hline $\begin{array}{l}\text { Sala de } \\
\text { reuniões }\end{array}$ & $\begin{array}{l}\text { É uma sala melhor que muitas outras do } \\
\text { posto, tem mesa e cadeiras, tem recursos }\end{array}$ & $\begin{array}{l}\text { É pequena, pouco ventilada, mal localizada } \\
\text { recebe todo o ruído da entrada e as } \\
\text { atividades são interrompidas pelos } \\
\text { usuários que têm fácil acesso à sala, é } \\
\text { utilizada também pela Assistente Social, e } \\
\text { para guarda de material, a parede está com } \\
\text { infiltração. }\end{array}$ & $\begin{array}{l}\text { Colocar em prática o projeto de } \\
\text { reforma do posto, ter outro espaço } \\
\text { para a Assistente Social }\end{array}$ \\
\hline Sala de vacina & Tem uma mesa com balança & $\begin{array}{l}\text { É pequena, utilizada também para controle } \\
\text { de exames preventivos e consultas de } \\
\text { enfermagem, pouco ventilada, as paredes } \\
\text { são de dificil limpeza e desinfecção, não } \\
\text { são azulejadas e não são laváveis, estão } \\
\text { com infiltração, a sala não oferece } \\
\text { privacidade, ouve-se o que está } \\
\text { acontecendo (sala de reuniões e da } \\
\text { Assistente Social) }\end{array}$ & Ser uma sala apenas para vacina \\
\hline $\begin{array}{l}\text { Banheiro dos } \\
\text { usuários }\end{array}$ & Grande, bem iluminado & $\begin{array}{l}\text { Localização (de frente para a entrada), não } \\
\text { possui separação entre masculino e } \\
\text { feminino, pouco ventilado }\end{array}$ & $\begin{array}{l}\text { Mudar a localização, e ser separado } \\
\text { o masculino do feminino }\end{array}$ \\
\hline $\begin{array}{l}\text { Banheiro dos } \\
\text { funcionários/ } \\
\text { d pósito }\end{array}$ & Como depósito é um bom espaço & $\begin{array}{l}\text { Está sendo utilizado apenas como depósito } \\
\text { de material de limpeza, a descarga não } \\
\text { funciona, não tem chuveiro }\end{array}$ & $\begin{array}{l}\text { Instalar um chuveiro e consertar a } \\
\text { descarga para ser utilizado como } \\
\text { banheiro, separar para masculino e } \\
\text { feminino; construir um almoxarifado }\end{array}$ \\
\hline
\end{tabular}




\begin{tabular}{|c|c|c|c|}
\hline $\begin{array}{l}\text { Banheiro dos } \\
\text { funcionários }\end{array}$ & $\begin{array}{l}\text { Não tem nada de bom por estar sendo } \\
\text { utilizado como banheiro de funcionários }\end{array}$ & $\begin{array}{l}\text { Fica dentro do consultório, é pequeno, } \\
\text { pouco ventilado, utilizado também para } \\
\text { guarda de materiais, e de medicamentos }\end{array}$ & $\begin{array}{l}\text { Retirar a guarda de material e de } \\
\text { medicamentos, ser utilizado apenas } \\
\text { pelos usuários do consultório }\end{array}$ \\
\hline $\begin{array}{l}\text { Consultório } \\
\text { ginecológico/ } \\
\text { clínico }\end{array}$ & $\begin{array}{l}\text { Tem um banheiro e uma mesa } \\
\text { ginecológica boa }\end{array}$ & $\begin{array}{l}\text { Pequena para ser utilizado como } \\
\text { consultório ginecológico, não é ventilado, } \\
\text { é utilizado para duas funções }\end{array}$ & $\begin{array}{l}\text { Ser utilizado apenas como } \\
\text { consultório de clínica }\end{array}$ \\
\hline $\begin{array}{l}\text { Sala de } \\
\text { procedimentos }\end{array}$ & $\begin{array}{l}\text { Ventilado, tem uma boa pia e armários } \\
\text { para guarda de material }\end{array}$ & $\begin{array}{l}\text { É utilizado tambémi para preparo de } \\
\text { material, é pequeno, não tem bancada }\end{array}$ & $\begin{array}{l}\text { Colocar uma bancada para preparo } \\
\text { de materiais e ser utilizado apenas } \\
\text { para essa atividade }\end{array}$ \\
\hline $\begin{array}{l}\text { Sala de } \\
\text { esterilização }\end{array}$ & $\begin{array}{l}\text { Ventilada, iluminada, recebe a luz solar } \\
\text { diretamente }\end{array}$ & $\begin{array}{l}\text { Pequena, utilizada para guarda de } \\
\text { pertences dos funcionários, falta uma } \\
\text { bancada e prateleiras }\end{array}$ & $\begin{array}{l}\text { Ter um espaço para guarda de } \\
\text { pertences dos funcionários, colocar } \\
\text { uma bancada e prateleiras }\end{array}$ \\
\hline Copa & Não tem nada de bom & É muito pequena & $\begin{array}{l}\text { Ser um espaço maior, ter uma } \\
\text { geladeira }\end{array}$ \\
\hline Sala da CMC & $\begin{array}{l}\text { Bem localizado, se comunicando com o } \\
\text { exterior da unidade, é grande, arejado, } \\
\text { recebe luz solar }\end{array}$ & $\begin{array}{l}\text { Falta um armário, para guarda dos } \\
\text { pertences da mirim }\end{array}$ & Ter um armário \\
\hline $\begin{array}{l}\text { Sala de } \\
\text { nebulização }\end{array}$ & Bem ventilada & $\begin{array}{l}\text { É pequena, muito ruidosa, no compressor } \\
\text { está faltando uma chave para desliga-lo } \\
\text { tendo-se que utilizar a tomada } \\
\text { diretamente, quando se liga a tomada solta } \\
\text { faísca }\end{array}$ & $\begin{array}{l}\text { A sala ser mais afastada do posto } \\
\text { para o ruído não incomodar }\end{array}$ \\
\hline Consultório & É de bom tamanho & $\begin{array}{l}\text { Tem infiltração nas paredes, é utilizado } \\
\text { para pediatria, pré-natal e eletro, ficando } \\
\text { tumultuado }\end{array}$ & Não se utilizado para eletro \\
\hline $\begin{array}{l}\text { Consultório } \\
\text { dentário }\end{array}$ & Tem uma estufa própria, e bem ventilado & $\begin{array}{l}\text { As paredes tem iniiltração, o equipamento } \\
\text { é antigo, falta armário, a pia é pequena, o }\end{array}$ & $\begin{array}{l}\text { Colocar um armário, uma bancada, } \\
\text { trocar a pia, isolar o compressor, }\end{array}$ \\
\hline
\end{tabular}




\begin{tabular}{|l|l|l|l|}
\hline & & $\begin{array}{l}\text { compressor fica dentro da sala gerando } \\
\text { muito ruido }\end{array}$ & azulejar as paredes \\
\hline Farmácia & Bem localizada, é próxima da recepção & $\begin{array}{l}\text { Pequena, não tem ventilação, não recebe a } \\
\text { luz solar, tem umidade, utilizada para } \\
\text { guarda do arquivo }\end{array}$ & $\begin{array}{l}\text { Ser utilizada apenas para guarda de } \\
\text { medicamentos, ter uma janela para } \\
\text { se dar a medicação }\end{array}$ \\
\hline $\begin{array}{l}\text { Recepção/sala } \\
\text { de espera }\end{array}$ & $\begin{array}{l}\text { É muito bom, possibilita privacidade, a } \\
\text { sala de espera é utilizada também para } \\
\text { reunião }\end{array}$ & Não tem nada & Não tem nada \\
\hline
\end{tabular}

Além das cargas acima foram mencionada também: bom relacionamento com a comunidade, falta de recursos (medicamentos, material de curativo, material permanente para se fazer o exame preventivo), tem muita cobrança da população que pensa que são os funcionários que não solicitam os materiais que estão faltando, falta recursos humanos, a equipe tem um bom relacionamento 


\section{UBS NOSSA SENHORA DAS GRAÇAS}

Participaram do levantamento: 1 Enfermeira e 4 Auxiliares

\begin{tabular}{|c|c|c|c|}
\hline LOCAL & CONDIÇÃO FAVORÁVEL & CONDIÇÃO DESFAVORÁVEL/CARGA & PROPOSTAS DE SOLUÇÃO \\
\hline Sala de espera & Tamanho e ventilação & $\begin{array}{l}\text { Falta um flanelógrafo e quadro de avisos o } \\
\text { som da TV atrapalha os consultórios e o } \\
\text { atendimento }\end{array}$ & $\begin{array}{l}\text { Mudar a TV de lugar, colocar mais } \\
\text { quadros }\end{array}$ \\
\hline Recepção & $\begin{array}{l}\text { É um lugar espaçoso, tem telefone, o } \\
\text { ambiente de trabalho e o pessoal são } \\
\text { muito bons }\end{array}$ & $\begin{array}{l}\text { Os arquivos são antigos e alguns estão } \\
\text { quebrados, muito quente no verão, recebe } \\
\text { sol direto, é pouco ventilado, falta material } \\
\text { e não oferece segurança devido a } \\
\text { proximidade com os usuários }\end{array}$ & $\begin{array}{l}\text { Trocar todos os arquivos, colocar } \\
\text { um ventilador de teto, ter mais } \\
\text { material do tipo envelopes e papel }\end{array}$ \\
\hline Farmácia & $\begin{array}{l}\text { É grande e espaçosa, bem localizada e a } \\
\text { disposição da prateleiras favorece o } \\
\text { trabalho }\end{array}$ & $\begin{array}{l}\text { Falta remédios, a quantidade é insuficiente, } \\
\text { o que é básico deveria ter em quantidade } \\
\text { maior, falta organização, dificuldade em } \\
\text { se fazer o controle dos medicamentos por } \\
\text { ter que ficar mais de um funcionário } \\
\text { responsável pela dispensação de } \\
\text { medicamentos, exigência de cópia de } \\
\text { receita dos usuários que nem sempre } \\
\text { trazem, a sala é muito quente por receber } \\
\text { sol diretamente }\end{array}$ & $\begin{array}{l}\text { Suprir com quantidade e qualidade, } \\
\text { retirar a exigência de cópia da } \\
\text { receita, melhorar o controle, ter } \\
\text { apenas um funcionário responsável }\end{array}$ \\
\hline $\begin{array}{l}\text { Sanitários } \\
\text { masculino e } \\
\text { feminino }\end{array}$ & $\begin{array}{l}\text { Quantidade de vasos sanitários, e } \\
\text { caimento da água }\end{array}$ & $\begin{array}{l}\text { Estão constantemente com defeito nos } \\
\text { registros e no lavabo, falta conservação, o } \\
\text { tipo de descarga não é funcional }\end{array}$ & $\begin{array}{l}\text { Trabalhar a educação do usuário e } \\
\text { fazer manutenção constante dos } \\
\text { sanitários }\end{array}$ \\
\hline $\begin{array}{l}\text { Sala de } \\
\text { nebulização }\end{array}$ & Espaçosa e tem boas cadeiras & $\begin{array}{l}\text { Falta uma pia com bancada, e o número de } \\
\text { bicos de oxigênio são insuficientes }\end{array}$ & $\begin{array}{l}\text { Aumentar o número de bicos e } \\
\text { instalar uma pia }\end{array}$ \\
\hline
\end{tabular}




\begin{tabular}{|c|c|c|c|}
\hline $\begin{array}{l}\text { Sala de coleta } \\
\text { de exames e } \\
\text { administração } \\
\text { de } \\
\text { medicamentos }\end{array}$ & $\begin{array}{l}\text { Espaçosa, é bem localizada e tem uma } \\
\text { pia muito boa com toalheiro }\end{array}$ & $\begin{array}{l}\text { Falta material do tipo seringas, tem uma } \\
\text { mesa de exames que talvez devesse ser } \\
\text { trocada por uma maca/cama para } \\
\text { hidratação }\end{array}$ & $\begin{array}{l}\text { Suprir de material, trocar a mesa } \\
\text { pela maca/cama }\end{array}$ \\
\hline $\begin{array}{l}\text { Sala de } \\
\text { curativos }\end{array}$ & $\begin{array}{l}\text { Espaçosa, tem uma pia muito boa e uma } \\
\text { ducha para limpeza dos curativos e é } \\
\text { ventilada }\end{array}$ & $\begin{array}{l}\text { Falta uma mesa móvel, ou um carrinho de } \\
\text { curativo, torneira e sabão adequado, para } \\
\text { se ter acesso ao outro lado do posto tem } \\
\text { que se atravessar todo o posto }\end{array}$ & $\begin{array}{l}\text { Instalar uma torneira de pedal ou de } \\
\text { manivela, saboneteira para sabão } \\
\text { líquido e colocar um carrinho de } \\
\text { curativo, abrir a porta do corredor } \\
\text { que comunica um lado com o outro } \\
\text { do posto }\end{array}$ \\
\hline $\begin{array}{l}\text { Salão } \\
\text { comunitário }\end{array}$ & $\begin{array}{l}\text { Espaçoso, bem ventilado tem um } \\
\text { sanitário dentro da sala }\end{array}$ & $\begin{array}{l}\text { É muito claro para uso de retroprojetor ou } \\
\text { televisão, falta limpeza mais constante é } \\
\text { utilizado também para secagem de roupas }\end{array}$ & $\begin{array}{l}\text { Colocar uma cortina ou persianas, } \\
\text { realizar limpeza constante, não ser } \\
\text { utilizado para secagem de roupas }\end{array}$ \\
\hline Sala da CMC & $\begin{array}{l}\text { A sala é utilizada rapidamente, o acesso é } \\
\text { bom }\end{array}$ & $\begin{array}{l}\text { Não tem ventilação e tem pouca } \\
\text { iluminação }\end{array}$ & Não tem como melhorar \\
\hline $\begin{array}{l}\text { Sala de } \\
\text { esterilização }\end{array}$ & $\begin{array}{l}\text { Espaçosa, tem uma boa bancada, estufa, } \\
\text { e autoclave }\end{array}$ & $\begin{array}{l}\text { A torneira da pia não está funcionando, } \\
\text { falta material do tipo campo e tambor para } \\
\text { algodão }\end{array}$ & Suprir de material \\
\hline Expurgo & Tem um bom tanque, pia e prateleiras & $\begin{array}{l}\text { E utilizado também para acondicionar o } \\
\text { lixo do posto }\end{array}$ & $\begin{array}{l}\text { Construir na área externa ao posto } \\
\text { uma cobertura para } \\
\text { acondicionamento do lixo }\end{array}$ \\
\hline $\begin{array}{l}\text { Sanitários } \\
\text { feminino e } \\
\text { masculino dos } \\
\text { funcionário } \\
\end{array}$ & $\begin{array}{l}\text { Tem chuveiro, é espaçoso, tem armários } \\
\text { individuais }\end{array}$ & $\begin{array}{l}\text { Precisa de conservação, os azulejos estão } \\
\text { caindo, a descarga não é funcional demora } \\
\text { para poder ser reutilizada, o espelho é } \\
\text { pequeno e falta uma porta no chuveiro }\end{array}$ & $\begin{array}{l}\text { Trocar a descarga, colocar um } \\
\text { espelho maior e melhor e uma porta } \\
\text { no chuveiro }\end{array}$ \\
\hline
\end{tabular}




\begin{tabular}{|l|l|l|l|}
\hline S & & & \\
\hline Sala de vacinas & $\begin{array}{l}\text { Tem uma boa geladeira e pia, um arquivo } \\
\text { e armários }\end{array}$ & É pequena, está mal localizada & Mudar de local \\
\hline $\begin{array}{l}\text { Sala da } \\
\begin{array}{l}\text { Asfermeira e } \\
\text { Social }\end{array}\end{array}$ & Tem armários, arquivo e telefone & $\begin{array}{l}\text { Deveria ser um espaço para cada } \\
\text { profissional pois dificulta o atendimento }\end{array}$ & Ser uma sala para cada especialidade \\
\hline $\begin{array}{l}\text { A, B, C, D, E ensultórios } \\
\text { F }\end{array}$ & $\begin{array}{l}\text { Espaçosos, tem cadeiras, pias e } \\
\text { toalheiros }\end{array}$ & $\begin{array}{l}\text { Falta negatoscópio, otoscópio, aparelho de } \\
\text { PA e ventilador de teto. No consultório C } \\
\text { há um odor que vem do ralo e no } \\
\text { consultório E (ginecológico) falta um } \\
\text { banheiro, a mesa é pequena e não é firme e } \\
\text { falta uma mesa auxiliar ou um carrinho de } \\
\text { curativo }\end{array}$ & $\begin{array}{l}\text { Fanutenção e conserto do } \\
\text { ralonstrução de um banheiro e } \\
\text { suprir os recursos que estão faltando }\end{array}$ \\
\hline $\begin{array}{l}\text { Consultório } \\
\text { odontológico }\end{array}$ & Espaçoso & $\begin{array}{l}\text { Falta uma pia com bancada, autoclave, os } \\
\text { materiais estão em péssimo estado, os } \\
\text { equipamentos e o compressor estão } \\
\text { constantemente com defeito, falta um } \\
\text { escovódromo }\end{array}$ & $\begin{array}{l}\text { Trocar o equipamento, colocar uma } \\
\text { pia com bancada, e instalar um } \\
\text { escovódromo }\end{array}$ \\
\hline Copa & Tem pia, geladeira e fogão & $\begin{array}{l}\text { Falta um porta copos descartáveis e a talha } \\
\text { de água está muito velha }\end{array}$ & $\begin{array}{l}\text { Trocar a talha, colocar um porta } \\
\text { copos }\end{array}$ \\
\hline
\end{tabular}

Além das cargas acima foram mencionadas também: dificuldade de transporte, pois os ônibus possuem horários dificeis, o bebedouro está com problemas, falta um filtro na entrada da água, o corredor deveria ser fechado para não permitir a entrada de usuários fora do momento de atendimento, ao redor da unidade deveria ser cercado e ter iluminação para diminuir a vulnerabilidade, ter serviço de capina constante e um pouco mais de embelezamento, serviço de jardinagem. 


\section{UBS OLAVO COSTA}

Participaram do levantamento: 1 enfermeira e 1 auxiliar

\begin{tabular}{|l|l|l|l|}
\hline LOCAL & CONDIÇÃO FAVORÁVEL & $\begin{array}{l}\text { CONDIÇÃO } \\
\text { DESFAVORÁVEL/CARGA }\end{array}$ & PROPOSTAS DE SOLUÇÃO \\
\hline $\begin{array}{l}\text { Sala de } \\
\text { espera/recep } \\
\text { ção }\end{array}$ & $\begin{array}{l}\text { É de bom tamanho, favorece o diálogo pela } \\
\text { proximidade com as pessoas }\end{array}$ & $\begin{array}{l}\text { Ocorre muita confusão, pois chegam } \\
\text { todos os usuários ao mesmo tempo, e } \\
\text { muitos gritam e discutem com o } \\
\text { funcionário da recepção. O local é muito } \\
\text { aberto, exposto, barulhento e estressante. } \\
\text { Falta funcionário, ocorre desvio de } \\
\text { função, a população é muito ansiosa }\end{array}$ & $\begin{array}{l}\text { Deveria ter uma sala mais fechada } \\
\text { para a recepção e a sala de espera } \\
\text { deveria ser mais reservada e } \\
\text { atento }\end{array}$ \\
\hline $\begin{array}{l}\text { Consultório } \\
\text { de clinica }\end{array}$ & $\begin{array}{l}\text { Tem balança adulto e infantil, pia, mesa, o a área de } \\
\text { atendimento neste consultório é mais } \\
\text { tranqüilo pela postura da médica }\end{array}$ & $\begin{array}{l}\text { Os usuários ficam aglomerados na frente } \\
\text { do consultório devido à planta fisica }\end{array}$ & $\begin{array}{l}\text { Colocar uma porta entre a recepção e } \\
\text { o corredor para impedir a entrada de } \\
\text { quem não esta sendo atendido }\end{array}$ \\
\hline $\begin{array}{l}\text { Sala de } \\
\text { vacina }\end{array}$ & $\begin{array}{l}\text { Tem um tamanho adequado, boa iluminação } \\
\text { e uma bancada }\end{array}$ & $\begin{array}{l}\text { Ficam muitas pessoas na porta, causando } \\
\text { tumulto, a limpeza é deficiente por falta } \\
\text { de material adequado e pelo movimento } \\
\text { de pessoas que é muito grande, a } \\
\text { geladeira já foi encontrada desligada e } \\
\text { aberta por ter um acesso fácil aos } \\
\text { pacientes }\end{array}$ & $\begin{array}{l}\text { Limitar a entrada das pessoas na } \\
\text { sendo atendidos no momento, colocar } \\
\text { outra porta externa, para se ter a } \\
\text { entrada por uma porta, saída por } \\
\text { outra. }\end{array}$ \\
\hline $\begin{array}{l}\text { Sala de } \\
\text { nebulização }\end{array}$ & Tem uma boa iluminação & $\begin{array}{l}\text { Espaço é insuficiente, é pequena, muito } \\
\text { ruidosa, é utilizada também para coleta } \\
\text { de material e curativo, o mobiliário é } \\
\text { insuficiente, a pia é pequena e não tem } \\
\text { uma bancada }\end{array}$ & $\begin{array}{l}\text { Realizar apenas a nebulização na sala, } \\
\text { separando sala limpa de contaminada }\end{array}$ \\
\hline
\end{tabular}




\begin{tabular}{|c|c|c|c|}
\hline Esterilização & $\begin{array}{l}\text { E iluminada, ventilada, tem autoclave e } \\
\text { estufa }\end{array}$ & $\begin{array}{l}\text { É pequena, com pouco espaço, existe } \\
\text { cruzamento de material limpo com } \\
\text { contaminado, ocorre acúmulo de material } \\
\text { esterilizado na sala }\end{array}$ & $\begin{array}{l}\text { Separar as atividades, ter uma sala } \\
\text { para esterilização, outra para } \\
\text { armazenamento e outra para preparo }\end{array}$ \\
\hline $\begin{array}{l}\text { Sala de } \\
\text { repouso }\end{array}$ & $\begin{array}{l}\text { Tem um banheiro que é utilizado } \\
\text { exclusivamente pelos funcionários }\end{array}$ & $\begin{array}{l}\text { É pequena, utilizada para guardar leite, } \\
\text { para observação de pacientes quando } \\
\text { necessário, pela CMC, raramente se tem } \\
\text { tempo para chegar e ficar nela } \\
\text { descansando, quando chove o posto é } \\
\text { inundado pela água que vem do esgoto, } \\
\text { sendo esta a primeira sala a ser inundada, } \\
\text { está com janelas e estante quebradas }\end{array}$ & $\begin{array}{l}\text { Mais armários, estantes e arquivos em } \\
\text { boas condições para acondicionar e } \\
\text { organizar melhor o material, conserto } \\
\text { do esgoto, ter uma sala para guarda } \\
\text { de leite, uma para observação de } \\
\text { pacientes e uma para a CMC }\end{array}$ \\
\hline Expurgo & Existe um espaço destinado ao expurgo & $\begin{array}{l}\text { É pequeno, utilizado também como área } \\
\text { de serviço, não tem lugar para } \\
\text { acondicionar o material, o mesmo tanque } \\
\text { que é utilizado para limpeza do pano de } \\
\text { chão é utilizado para limpeza de material }\end{array}$ & $\begin{array}{l}\text { Colocar outro tanque para separar a } \\
\text { limpeza de pano de chão de material }\end{array}$ \\
\hline Consultório & Tem um banheiro dentro & $\begin{array}{l}\text { É pequeno, tem pouco espaço, a médica } \\
\text { atende os pacientes fora do agendamento } \\
\text { gerando tumulto e acúmulo de pessoas } \\
\text { na frente do consultório }\end{array}$ & $\begin{array}{l}\text { Limitar a entrada de pacientes no } \\
\text { posto para apenas os que estão sendo } \\
\text { atendidos, melhorar a organização } \\
\text { administrativa do posto }\end{array}$ \\
\hline Consultório & Mais organizado, com menos tumulto & $\begin{array}{l}\text { A balança de adulto não está calibrada e } \\
\text { o aparelho de PA não está funcionando, } \\
\text { ocorre aglomeração de pessoas na porta }\end{array}$ & $\begin{array}{l}\text { Limitar a entrada de pacientes no } \\
\text { posto para apenas os que estão sendo } \\
\text { atendidos, }\end{array}$ \\
\hline I armácia & Não tem nada de bom & $\begin{array}{l}\text { E pequena, a iluminação e a ventilação } \\
\text { são insuficientes, há um odor forte de }\end{array}$ & $\begin{array}{l}\text { Construir uma rede de esgoto, } \\
\text { aumentar o espaço melhorar a }\end{array}$ \\
\hline
\end{tabular}




\begin{tabular}{|l|l|l|l|}
\hline & & $\begin{array}{l}\text { esgoto, localização é muito próxima da } \\
\text { entrada }\end{array}$ & $\begin{array}{l}\text { iluminação e ventilação, mudar de } \\
\text { lugar }\end{array}$ \\
\hline $\begin{array}{l}\text { Sanitário dos } \\
\text { usuários }\end{array}$ & $\begin{array}{l}\text { É de fácil acesso, o vaso sanitário e a pia } \\
\text { funcionam é azulejado }\end{array}$ & $\begin{array}{l}\text { A limpeza é deficiente, estão sempre } \\
\text { sujos, as torneiras ficam abertas }\end{array}$ & $\begin{array}{l}\text { Educar/orientar os usuários sobre o } \\
\text { uso dos banheiros }\end{array}$ \\
\hline $\begin{array}{l}\text { Sala da } \\
\text { Assistente } \\
\text { Social }\end{array}$ & Bom tamanho é espaçosa & $\begin{array}{l}\text { Quando chove alaga, é um espaço pouco } \\
\text { utilizado }\end{array}$ & $\begin{array}{l}\text { Aproveitar melhor o espaço, por } \\
\text { exemplo para guarda de leite em } \\
\text { armário fechado }\end{array}$ \\
\hline
\end{tabular}

Além das cargas acima foram mencionadas também: falta de recursos humanos, desvio de função, a equipe é bem entrosada, existe proximidade com a comunidade, respeito entre a equipe e a comunidade. 


\section{UBS RETIRO}

Participaram do levantamento: 1 enfermeira e 2 auxiliares

\begin{tabular}{|c|c|c|c|}
\hline LOCAL & CONDIÇÕES FAVORÁVEIS & $\begin{array}{l}\text { CONDIÇÕES } \\
\text { DESFAVORÁVEIS/CARGAS }\end{array}$ & PROPOSTAS DE SOLUÇÃO \\
\hline Recepção & Existência do balcão & $\begin{array}{l}\text { A demanda é maior do que a capacidade } \\
\text { de atendimento ( }{ }^{\circ}{ }^{\circ} \text { de vagas) e a } \\
\text { possibilidade de resolução dos problemas } \\
\text { da comunidade também é limitada } \\
\text { acarretando insatisfação da população e da } \\
\text { equipe que fica sobrecarregada, os } \\
\text { pacientes trazem animais que muitas vezes } \\
\text { querem entrar no posto }\end{array}$ & $\begin{array}{l}\text { Fazer um rodízio de funcionários na } \\
\text { recepção para marcação de } \\
\text { consultas, fazer um sistema de } \\
\text { agendamento de consultas }\end{array}$ \\
\hline $\begin{array}{l}\text { Sala da } \\
\text { enfermeira }\end{array}$ & É próxima da entrada & $\begin{array}{l}\text { Pequena, iluminação e ventilação } \\
\text { deficientes, é utilizada apenas para se } \\
\text { verificar a PA, a enfermagem não fica } \\
\text { apenas em uma sala }\end{array}$ & Colocar uma janela maior \\
\hline $\begin{array}{l}\text { Consultório } \\
\text { odontoló } \\
\text { gico }\end{array}$ & & $\begin{array}{l}\text { Ventilação e iluminação deficientes, muito } \\
\text { ruído devido ao compressor }\end{array}$ & $\begin{array}{l}\text { Isolar o compressor do lado de fora } \\
\text { do posto, aumentar a janela }\end{array}$ \\
\hline $\begin{array}{l}\text { Sala da } \\
\text { assistente } \\
\text { social }\end{array}$ & & $\begin{array}{l}\text { É utilizada também como consultório } \\
\text { médico, ventilação e iluminação são } \\
\text { deficientes }\end{array}$ & Aumentar a janela \\
\hline $\begin{array}{l}\text { Sala de } \\
\text { reuniões }\end{array}$ & $\begin{array}{l}\text { E grande, espaçosa, bem iluminada, tem } \\
\text { entrada independente, tem vídeo e TV }\end{array}$ & É muito quente & Colocar ventiladores de teto \\
\hline $\begin{array}{l}\text { Consultório } \\
\text { médicos }\end{array}$ & $\begin{array}{l}\text { Cada médico tem o seu consultório } \\
\text { privativo com exceção do que utiliza a sala } \\
\text { da assistente nos horários em que ela não }\end{array}$ & $\begin{array}{l}\text { Muito ruído do corredor, iluminação e } \\
\text { ventilação deficientes }\end{array}$ & $\begin{array}{l}\text { Colocar uma porta no corredor para } \\
\text { limitar a entrada dos usuários }\end{array}$ \\
\hline
\end{tabular}




\begin{tabular}{|c|c|c|c|}
\hline & está & & \\
\hline $\begin{array}{l}\text { Sanitário } \\
\text { dos } \\
\text { funcionários }\end{array}$ & Não tem nada de bom & $\begin{array}{l}\text { Tem odor de esgoto, está sendo utilizado } \\
\text { para guarda de material de limpeza, por ser } \\
\text { de frente para entrada não oferece } \\
\text { privacidade }\end{array}$ & $\begin{array}{l}\text { Não tem como resolver o problema } \\
\text { do odor, pois o posto está abaixo do } \\
\text { nível da rua, o que permite a entrada } \\
\text { do esgoto, para solucionar teria que } \\
\text { se construir outro banheiro }\end{array}$ \\
\hline \begin{tabular}{|l|} 
Sala de \\
nebulização
\end{tabular} & Existe a sala, antes não existia, era pior & $\begin{array}{l}\text { Pequena, iluminação e ventilação } \\
\text { deficientes, muito ruído do inalador }\end{array}$ & \\
\hline \begin{tabular}{|l|}
$\begin{array}{l}\text { Sanitário de } \\
\text { usuários }\end{array}$ \\
\end{tabular} & Não tem nada de bom & $\begin{array}{l}\text { Pequeno, ventilação e iluminação } \\
\text { deficientes, odor de esgoto }\end{array}$ & Construir outro banheiro \\
\hline \begin{tabular}{|l|l|} 
Consultório \\
ginccológico
\end{tabular} & & $\begin{array}{l}\text { Ventilação deficiente, falta um banheiro, } \\
\text { muito ruído da parte externa }\end{array}$ & Construir um banheiro \\
\hline $\begin{array}{l}\text { Sala de } \\
\text { vacina }\end{array}$ & Tem descartex. & $\begin{array}{l}\text { Pequena, falta uma maca para vacinação } \\
\text { de crianças deitada, iluminação e } \\
\text { ventilação deficiente, a mesa é pequena, e } \\
\text { os descartex são insuficientes em tamanho } \\
\text { quantidade. }\end{array}$ & $\begin{array}{l}\text { Colocar uma maca, ter mais } \\
\text { descartex }\end{array}$ \\
\hline \begin{tabular}{|l|} 
Sanitário de \\
funcionários
\end{tabular} & Grande, espaçoso & $\begin{array}{l}\text { Falta chuveiro, iluminação e ventilação são } \\
\text { deficientes }\end{array}$ & Colocar um chuveiro \\
\hline Cozinha & $\begin{array}{l}\text { Tem um espaço para cozinha, antes não } \\
\text { tinha }\end{array}$ & $\begin{array}{l}\text { É utilizada também como área de serviço } \\
\text { (o tanque fica dentro da cozinha), não tem } \\
\text { armário e fogão, o filtro de água (talha) } \\
\text { fica sobre uma cadeira }\end{array}$ & $\begin{array}{l}\text { Utilizar o espaço apenas como } \\
\text { cozinha, construir outro espaço para } \\
\text { área de serviço, colocar um armário, } \\
\text { fogão e uma mesa para apoiar o } \\
\text { filtro de água }\end{array}$ \\
\hline Copa & $\begin{array}{l}\text { Tem um espaço para cozinha, antes não } \\
\text { tinha }\end{array}$ & $\begin{array}{l}\text { Pequena, a janela dá de frente para um } \\
\text { muro, ventilação e iluminação deficientes }\end{array}$ & Não tem como melhorar \\
\hline Expurgo & Nunca falta desincrostante & $\begin{array}{l}\text { Pequeno, ventilação e iluminação } \\
\text { deficientes }\end{array}$ & $\begin{array}{l}\text { Não tem como solucionar os } \\
\text { problemas }\end{array}$ \\
\hline
\end{tabular}




\begin{tabular}{|l|l|l|l|}
\hline $\begin{array}{l}\text { Sala de } \\
\text { esterilização }\end{array}$ & $\begin{array}{l}\text { Tem autoclave, estufa, luvas e uma } \\
\text { comunicação com o expurgo por uma janela }\end{array}$ & $\begin{array}{l}\text { Ventilação é deficiente o espaço é } \\
\text { utilizado também pela CMC }\end{array}$ & $\begin{array}{l}\text { Colocar uma divisória para separar o } \\
\text { espaço da CMC (já está sendo feito) }\end{array}$ \\
\hline Farmácia & $\begin{array}{l}\text { Utilizada apenas para guarda de } \\
\text { medicamentos }\end{array}$ & Ventilação deficiente, falta medicamentos & Ter mais medicamentos \\
\hline $\begin{array}{l}\text { Sala de } \\
\text { procediment } \\
\text { os }\end{array}$ & $\begin{array}{l}\text { Tem uma comunicação com o expurgo por } \\
\text { uma janela }\end{array}$ & $\begin{array}{l}\text { Iluminação e ventilação deficientes, a maca } \\
\text { é pequena, falta uma escada de dois } \\
\text { degraus e uma mesa }\end{array}$ & $\begin{array}{l}\text { Colocar um escada de dois degraus e } \\
\text { uma mesa, trocar a maca }\end{array}$ \\
\hline $\begin{array}{l}\text { Sala da } \\
\text { CMC }\end{array}$ & Tem comunicação externa ao posto & $\begin{array}{l}\hat{E} \text { muito quente e falta uma cobertura para } \\
\text { abrigar os usuários }\end{array}$ & Colocar um cobertura externa \\
\hline Corredores & $\begin{array}{l}\text { Iluminação e ventilação deficiente, piso } \\
\text { escorregadio }\end{array}$ & \\
\hline
\end{tabular}

Além das cargas acima foram mencionadas também: falta de material de curativos, estresse no relacionamento com a comunidade e com a equipe, dificuldade de compreensão por parte dos médicos do trabalho de equipe, apesar de tudo todos gostam do que fazem 


\section{UBS SÃO JUDAS}

Participaram do levantamento: 1 enfermeira e 1 auxiliar

\begin{tabular}{|c|c|c|c|}
\hline LOCAL & CONDIÇÕES FAVORÁVEIS & $\begin{array}{l}\text { CONDIÇÕES } \\
\text { DESFAVORÁVEIS/CARGAS }\end{array}$ & PROPOSTAS DE SOLUÇÃO \\
\hline $\begin{array}{l}\text { Sala de } \\
\text { espera }\end{array}$ & $\begin{array}{l}\text { É ampla, bem iluminada, possibilita a } \\
\text { visualização de todos e a proximidade com } \\
\text { os usuários, possui uma boa disposição das } \\
\text { cadeiras }\end{array}$ & $\begin{array}{l}\text { Falta conforto e recursos como vídeo e } \\
\text { TV, a frente é toda de vidro deixando sem } \\
\text { proteção a unidade e as pessoas, não } \\
\text { oferece segurança, os vidros são de dificil } \\
\text { limpeza acumulando sujeira e favorecendo } \\
\text { a proliferação de insetos }\end{array}$ & $\begin{array}{l}\text { Colocar mais cadeiras anatômicas e } \\
\text { fixas, e vídeo e TV, colocar grades } \\
\text { na frente }\end{array}$ \\
\hline $\begin{array}{l}\text { Sala da } \\
\text { assistente } \\
\text { social }\end{array}$ & Não tem nada & $\begin{array}{l}\text { E pequena, a ventilação insuficiente, está } \\
\text { mal localizada, possibilita o acesso dos } \\
\text { usuários que interrompem o trabalho, falta } \\
\text { privacidade }\end{array}$ & $\begin{array}{l}\text { Mudar a sala para a CMC e } \\
\text { construir outra sala para a Assistente } \\
\text { social }\end{array}$ \\
\hline Recepção & O balcão é bonito dá um aspecto agradável & $\begin{array}{l}\text { O Sol incide diretamente nas costas de } \\
\text { quem está no balcão, o piso é de ardósia e } \\
\text { possui muitas frestas, está inacabado e não } \\
\text { tem caimento de água }\end{array}$ & $\begin{array}{l}\text { Colocar um toldo ou uma árvore na } \\
\text { frente do posto, dar um acabamento } \\
\text { no piso }\end{array}$ \\
\hline $\begin{array}{l}\text { Sala de } \\
\text { curativo }\end{array}$ & $\begin{array}{l}\text { É grande, bem iluminada, possui bancada } \\
\text { de inox, pia, gavetas, armários }\end{array}$ & $\begin{array}{l}\text { Recebe a luz solar direta no periodo da } \\
\text { tarde, a ventilação é deficiente }\end{array}$ & $\begin{array}{l}\text { Fazer uma proteção contra o Sol na } \\
\text { parte externa, e aproveitar parte da } \\
\text { sala para nebulização }\end{array}$ \\
\hline Copa & É bem ventilada & $\begin{array}{l}\text { Dá acesso para o banheiro dos } \\
\text { funcionários, é utilizada também pela } \\
\text { CMC, e para a guarda da estufa }\end{array}$ & $\begin{array}{l}\text { Retirar a CMC e a estufa do espaço, } \\
\text { utilizar apenas como copa }\end{array}$ \\
\hline Farmácia & $\begin{array}{l}\text { O controle dos medicamentos é bem feito, } \\
\text { quando falta no posto é porque está }\end{array}$ & $\begin{array}{l}\text { É pequena, tem apenas uma estante, falta } \\
\text { medicação }\end{array}$ & Ter mais medicação \\
\hline
\end{tabular}




\begin{tabular}{|c|c|c|c|}
\hline & faltando na rede & & \\
\hline $\begin{array}{l}\text { Sala de } \\
\text { vacina }\end{array}$ & É ótima, possui bancada de inox, gavetas & Tem mofo devido a uma infiltração & $\begin{array}{l}\text { Consertar a infiltração e pintar as } \\
\text { paredes }\end{array}$ \\
\hline $\begin{array}{l}\text { Banheiros } \\
\text { dos usuários }\end{array}$ & São bons & Nada de ruim & Nada para melhorar \\
\hline $\begin{array}{l}\text { Consultórios } \\
\text { de clínica e } \\
\text { pediátrico }\end{array}$ & & $\begin{array}{l}\text { A ventilação não é suficiente e o piso não } \\
\text { tem escoamento de água dificultando a } \\
\text { limpeza. }\end{array}$ & Não tem como melhorar \\
\hline $\begin{array}{l}\text { Consultório } \\
\text { ginecológico }\end{array}$ & $\begin{array}{l}\text { Tem pia, iluminação suficiente, tem duas } \\
\text { portas uma para entrada do usuário outra } \\
\text { para a saida o que não permite o } \\
\text { cruzamento do usuário dentro do posto }\end{array}$ & $\begin{array}{l}\text { O banheiro esta com infiltração, e o teto } \\
\text { tem risco de cair, a sala esta sendo } \\
\text { utilizada como sala de nebulização }\end{array}$ & Manutenção do banheiro \\
\hline Almoxarifado & Não tem nada de bom & $\begin{array}{l}\text { É pequeno, iluminação e ventilação } \\
\text { insuficiente, está sendo utilizado para } \\
\text { guarda de material provisoriamente será } \\
\text { utilizado como sala de nebulização }\end{array}$ & $\begin{array}{l}\text { Ser utilizado apenas para guarda de } \\
\text { material de limpeza }\end{array}$ \\
\hline $\begin{array}{l}\text { Sala de } \\
\text { serviço }\end{array}$ & $\begin{array}{l}\text { Tem um bom tanque, ventilação é } \\
\text { suficiente e tem comunicação com uma } \\
\text { área externa }\end{array}$ & $\begin{array}{l}\text { Todo o material de limpeza e guardado } \\
\text { nela }\end{array}$ & $\begin{array}{l}\text { Guardar o material de limpeza em } \\
\text { outro local }\end{array}$ \\
\hline $\begin{array}{l}\text { A parte } \\
\text { externa do } \\
\text { posto }\end{array}$ & É boa & $\begin{array}{l}\text { Necessita de capina, deveria haver uma } \\
\text { cobertura e grade ao redor do posto para } \\
\text { proteger o usuário do Sol e da chuva }\end{array}$ & $\begin{array}{l}\text { Providenciar capina, colocar grade e } \\
\text { cobertura. }\end{array}$ \\
\hline
\end{tabular}

Além das cargas acima foram mencionadas também: mal planejamento do posto que foi construído sem consulta aos trabalhadores, e o que foi solicitado não foi providenciado, falta uma sala para esterilização, o posto é mal localizado dentro do bairro, falta recursos humanos e material, falta autoclave, o gerente não tem força, falta reconhecimento de todos os profissionais como membros da equipe do PSF, hoje apenas o médico está recebendo remuneração diferenciada, a comunidade é tranquiila, educada, há um bom relacionamento com a equipe 


\section{UBS SANTA CRUZ}

Participaram do levantamento: 1 enfermeira e 1 auxiliar (técnica)

\begin{tabular}{|c|c|c|c|}
\hline LOCAL & CONDIÇÃO FAVORÁVEL & CONDIÇÃO DESFAVORÁVEL/CARGA & PROPOSTAS DE SOLUÇÃO \\
\hline Recepção & $\begin{array}{l}\text { Espaço e iluminação suficientes, condição } \\
\text { fisica adequada }\end{array}$ & $\begin{array}{l}\text { Muito quente no verão, falta de recursos } \\
\text { humanos, telefone sempre com defeito, } \\
\text { número de funcionários é insuficiente para } \\
\text { o atendimento da demanda, os arquivos } \\
\text { são pesados, mal conservados e em } \\
\text { número insuficiente ficando com as } \\
\text { gavetas abarrotados de envelopes e } \\
\text { prontuários que ficam mal conservados, } \\
\text { dificultando a manipulação dos mesmos. } \\
\text { Funcionários sobrecarregados de trabalho, } \\
\text { com problemas de saúde. Já iniciaram a } \\
\text { reforma do arquivo mas tiveram que parar } \\
\text { por falta de funcionário }\end{array}$ & $\begin{array}{l}\text { Receber mais envelopes, arquivos e } \\
\text { fichas (já tem um projeto por escrito } \\
\text { solicitando isso à Prefeitura, mas até } \\
\text { o momento não obtiveram resposta, } \\
\text { receberam doação da comunidade) } \\
\text { Dar continuidade à reforma do } \\
\text { arquivo, receber mais recursos } \\
\text { humanos }\end{array}$ \\
\hline $\begin{array}{l}\text { Sala de } \\
\text { nebulização }\end{array}$ & $\begin{array}{l}\text { A pia foi reformada, foram retirados os } \\
\text { azulejos que estavam soltos }\end{array}$ & $\begin{array}{l}\text { Espaço pequeno, local húmido com } \\
\text { infiltração, não recebe luz solar direta, } \\
\text { ventilação deficiente, muito ruído do } \\
\text { compressor }\end{array}$ & $\begin{array}{l}\text { Retirar o compressor da sala (já tem } \\
\text { o local para colocar, mas ainda não } \\
\text { foi retirado), aumentar o número de } \\
\text { bicos, mudar de sala, mudar o } \\
\text { compressor de lugar na sala }\end{array}$ \\
\hline $\begin{array}{l}\text { Sala de } \\
\text { observação }\end{array}$ & Tamanho é bom & $\begin{array}{l}\text { Camas com as manivelas quebradas, } \\
\text { ventilação deficiente, falta uma mesa } \\
\text { auxiliar para fazer medicação }\end{array}$ & $\begin{array}{l}\text { Manutenção das camas, adquirir uma } \\
\text { mesa auxiliar }\end{array}$ \\
\hline $\begin{array}{l}\text { Sala em } \\
\text { reforma }\end{array}$ & Pia excelente & $\begin{array}{l}\text { Piso do tipo paviflex gastou de tanto lavar } \\
\text { e soltou }\end{array}$ & Já esta em reforma \\
\hline
\end{tabular}




\begin{tabular}{|c|c|c|c|}
\hline $\begin{array}{l}\text { Sala de } \\
\text { curativos }\end{array}$ & Não tem nada de bom & $\begin{array}{l}\text { É pequena, ventilação insuficiente, é muito } \\
\text { quente, a cuba da pia é muito rasa, a maca } \\
\text { esta bamba }\end{array}$ & Mudar de sala \\
\hline Expurgo & $\begin{array}{l}\text { Espaço bom, bem localizada em relação a } \\
\text { sala de esterilização }\end{array}$ & Nada de desfavorável & Não tem nada para melhorar \\
\hline $\begin{array}{l}\text { Sala de } \\
\text { esterilização }\end{array}$ & $\begin{array}{l}\text { A pia é boa, tem um bom espaço e armário } \\
\text { para guarda de material }\end{array}$ & $\begin{array}{l}\text { Falta autoclave, falta instalação hidráulica } \\
\text { para saída da água e do vapor, que é solto } \\
\text { todo dentro da sala, não tem local para } \\
\text { colocar a estufa que fica sobre o balcão e } \\
\text { atrapalha o preparo de material }\end{array}$ & $\begin{array}{l}\text { Fazer a instalação hidráulica para } \\
\text { entrada e saida de água, colocar uma } \\
\text { mesa para preparo de material ou } \\
\text { para apoiar a estufa. }\end{array}$ \\
\hline $\begin{array}{l}\text { Sala de coleta } \\
\text { de material }\end{array}$ & Não tem nada & $\begin{array}{l}\text { E pequena, quente, a pia está quebrada, } \\
\text { originalmente era uma sala para pequena } \\
\text { cirurgia }\end{array}$ & $\begin{array}{l}\text { Reforma da pia e melhorar a } \\
\text { ventilação }\end{array}$ \\
\hline $\begin{array}{l}\text { Sala para } \\
\text { aplicação de } \\
\text { medicamento } \\
\text { S }\end{array}$ & É uma sala boa & O piso é inadequado, esta gasto e falho & Reformar o piso \\
\hline $\begin{array}{l}\text { Sanitário } \\
\text { feminino e } \\
\text { masculino }\end{array}$ & $\begin{array}{l}\text { É grande, espaçoso, tem duas pias grandes } \\
\text { boas }\end{array}$ & $\begin{array}{l}\text { Não está sendo utilizado como banheiro, } \\
\text { as descargas não funcionam, não tem } \\
\text { chuveiro (foi roubado), é utilizado como } \\
\text { área de serviço para secagem de roupa, } \\
\text { falta um espelho e armário para guarda dos } \\
\text { pertences dos funcionários }\end{array}$ & $\begin{array}{l}\text { Consertar as descargas, fechar as } \\
\text { prateleiras para servirem como } \\
\text { armário, colocar um espelho }\end{array}$ \\
\hline Lavanderia & Tem um tanque bom, é bem ventilada & $\begin{array}{l}\text { Quase não é utilizada, não tem espaço para } \\
\text { secagem de roupa, é utilizada para limpeza } \\
\text { de panos de chão as pias dos banheiros é } \\
\text { que são utilizadas para limpeza das roupas } \\
\text { pois só tem um tanque }\end{array}$ & $\begin{array}{l}\text { Utilizar a área externa para secagem } \\
\text { de roupas, colocar outro tanque na } \\
\text { área de serviço para limpeza de } \\
\text { lençóis, campos, etc }\end{array}$ \\
\hline
\end{tabular}




\begin{tabular}{|c|c|c|c|}
\hline Almoxarifado & Não tem nada de bom & $\begin{array}{l}\text { É pequeno, abafado e quente, pois a } \\
\text { ventilação é deficiente }\end{array}$ & Mudar de sala ou aumentar \\
\hline Copa & $\begin{array}{l}\text { E grande, espaçosa, tem fogão, geladeira } \\
\text { (doada pela comunidade) }\end{array}$ & Falta armário & Colocar armários \\
\hline Sala da CMC & $\begin{array}{l}\text { Tem comunicação com a copa e um } \\
\text { banheiro que esta sendo usado pelos } \\
\text { funcionários }\end{array}$ & É um espaço adaptado & Não tem como melhorar \\
\hline $\begin{array}{l}\text { Sanitário dos } \\
\text { funcionários } \\
\text { (que fica na } \\
\text { sala da } \mathrm{CMC} \text { ) } \\
\end{array}$ & A descarga funciona & $\begin{array}{l}\text { É pequeno, não tem pia, está sendo usado } \\
\text { provisoriamente }\end{array}$ & $\begin{array}{l}\text { Consertar os banheiros feminino e } \\
\text { masculino }\end{array}$ \\
\hline \begin{tabular}{|l|}
$\begin{array}{l}\text { Sanitários de } \\
\text { usuários }\end{array}$ \\
\end{tabular} & $\begin{array}{l}\text { São de bom tamanho, um tem apoio para } \\
\text { deficiente }\end{array}$ & $\begin{array}{l}\text { As descargas não funcionam, o piso está } \\
\text { quebrado e solto }\end{array}$ & Consertar as descargas e o piso \\
\hline Depósito & Não tem nada de bom & $\begin{array}{l}\text { Serve para guardar material de limpeza e o } \\
\text { lixo, a ventilação e insuficiente, o pé } \\
\text { direito é baixo }\end{array}$ & $\begin{array}{l}\text { Construir um depósito para o lixo } \\
\text { fora da unidade }\end{array}$ \\
\hline Farmácia & $\begin{array}{l}\text { A localização, próxima da entrada e da } \\
\text { recepção favorece o trabalho }\end{array}$ & $\begin{array}{l}\text { Pequena e insegura por ser aberta com } \\
\text { comunicação direta com a sala de espera, } \\
\text { já ocorreu uma invasão no posto quando } \\
\text { forma roubados todos os preservativos. }\end{array}$ & $\begin{array}{l}\text { Colocar grades, que já foram } \\
\text { conseguidas, mas falta serem } \\
\text { instaladas }\end{array}$ \\
\hline $\begin{array}{l}\text { Sala da } \\
\text { enfermeira }\end{array}$ & $\begin{array}{l}\hat{E} \text { bem ventilada, da acesso para a sala de } \\
\text { espera }\end{array}$ & $\begin{array}{l}\text { As vezes os usuários entiam sem serem } \\
\text { convidados, as cubas das pias são rasas. }\end{array}$ & $\begin{array}{l}\text { Orientar e educar a comunidade, } \\
\text { trocar as cubas das pias } \\
\end{array}$ \\
\hline $\begin{array}{l}\text { Consultório } \\
\text { clínico }\end{array}$ & $\begin{array}{l}\text { E de bom tamanho, ventilado e tem uma } \\
\text { pia boa }\end{array}$ & Não tem nada de ruim & Nada para melhorar \\
\hline $\begin{array}{l}\text { onsultório } \\
\text { ginecológico }\end{array}$ & Tem um banheiro na sala & $\begin{array}{l}\text { É pequeno, a ventilação é insuficiente, a } \\
\text { pia é pequena, o banheiro teve infiltração, } \\
\text { os azulejos tiveram que ser retirados }\end{array}$ & Não tem como melhorar \\
\hline
\end{tabular}




\begin{tabular}{|c|c|c|c|}
\hline $\begin{array}{l}\text { Sala da } \\
\text { assistente } \\
\text { social }\end{array}$ & $\begin{array}{l}\text { Tem um bom tamanho e número de } \\
\text { cadeiras suficientes }\end{array}$ & $\begin{array}{l}\text { É utilizada para reuniões da equipe e do } \\
\text { conselho, a mesa fica encostada na parede } \\
\text { para não cair, falta quadro de avisos, e } \\
\text { arquivo para guarda de material educativo }\end{array}$ & Consertar a mesa \\
\hline $\begin{array}{l}\text { Sala de } \\
\text { vacinas }\end{array}$ & É utilizada exclusivamente para vacina & $\begin{array}{l}\text { É pequena, a ventilação é insuficiente, os } \\
\text { azulejos foram retirados pois começaram a } \\
\text { cair, o piso é de dificil limpeza e } \\
\text { desinfecção, falta um local para preparo } \\
\text { da vacina, a pia é rasa e pequena }\end{array}$ & $\begin{array}{l}\text { Trocar o piso a pia, colocar um } \\
\text { bancada para preparo de vacina. }\end{array}$ \\
\hline $\begin{array}{l}\text { Sala de } \\
\text { espera }\end{array}$ & $\begin{array}{l}\text { E ampla, a escada que dá para o andar } \\
\text { superior tem degraus grandes, e corrimão }\end{array}$ & $\begin{array}{l}\text { Falta bancos para acomodar os usuários, } \\
\text { quadro de avisos, a escada está com o piso } \\
\text { soltando }\end{array}$ & $\begin{array}{l}\text { Consertar o piso da escada, adquirir } \\
\text { mais bancos }\end{array}$ \\
\hline $\begin{array}{l}\text { Sala de } \\
\text { reuniões }\end{array}$ & É reservada & $\begin{array}{l}\text { Esta sendo utilizada apenas para fazer } \\
\text { reunião de direitos reprodutivos, é quente } \\
\text { a ventilação é insuficiente, não tem } \\
\text { cadeiras para ela, o quadro não está } \\
\text { afixado }\end{array}$ & Afixar o quadro, colocar cadeiras \\
\hline $\begin{array}{l}\text { Sala do } \\
\text { computador }\end{array}$ & É grande & Mal utilizada & $\begin{array}{l}\text { Deveria ter sido instalado o } \\
\text { consultório do dentista nela }\end{array}$ \\
\hline $\begin{array}{l}\text { Consultório } \\
\text { odontológico }\end{array}$ & Há consultório & $\begin{array}{l}\text { É pequena, a pia é pequena e rasa, o } \\
\text { compressor fica dentro da sala e gera }\end{array}$ & $\begin{array}{l}\text { Isolar o compressor, trocar a pia, } \\
\text { colocar uma escrivaninha }\end{array}$ \\
\hline
\end{tabular}




\begin{tabular}{|l|l|l|l|}
\hline & & $\begin{array}{l}\text { muito ruído, falta uma escrivaninha, a } \\
\text { mesa é improvisada }\end{array}$ & \\
\hline Escovódromo & Há espaço & $\begin{array}{l}\text { É pequeno, ainda não está sendo utilizado, } \\
\text { faltam as pias individuais }\end{array}$ & Instalar as pias \\
\hline
\end{tabular}

Além das cargas acima forma mencionadas também: falta de recursos humanos, impossibilitando o trabalho extra-muros, apesar de a construção do posto ser recente ele foi mal construído e às pressas, os azulejos cairam e apenas após insistentes reclamações é que foi feita uma reforma que não atendeu a todas as necessidades, existência de muita burocracia para a solicitação de reparos, falta material, remédios, seringas, o número de atendimento é insuficiente para atender a demanda, ocorre um distanciamento do nível central com a unidade, e uma insatisfação da comunidade com os funcionários dos posto, pela proximidade, o nível central cobra mas não dá retorno. 